Portland State University

PDXScholar

$1-1-2011$

\title{
Opening Black Boxes and Following Traces: An Exploration of the Coalition for a Livable Future's Regional Equity Atlas Actor-World, 2003-2007
}

Meg Merrick

Portland State University

Follow this and additional works at: https://pdxscholar.library.pdx.edu/open_access_etds Let us know how access to this document benefits you.

Recommended Citation

Merrick, Meg, "Opening Black Boxes and Following Traces: An Exploration of the Coalition for a Livable Future's Regional Equity Atlas Actor-World, 2003-2007" (2011). Dissertations and Theses. Paper 298. https://doi.org/10.15760/etd.298

This Dissertation is brought to you for free and open access. It has been accepted for inclusion in Dissertations and Theses by an authorized administrator of PDXScholar. Please contact us if we can make this document more accessible: pdxscholar@pdx.edu. 
Opening Black Boxes and Following Traces: An Exploration of the Coalition for a Livable Future's Regional Equity Atlas Actor-World, 2003-2007

by

Margrete Bernard Merrick

A dissertation submitted in partial fulfillment of the requirements for the degree of

\author{
Doctor of Philosophy \\ in \\ Urban Studies
}

\author{
Dissertation Committee: \\ Seymour Adler, Chair \\ Carl Abbott \\ Ethan Seltzer \\ Vivek Shandas \\ Michael Flower
}

Portland State University (C)2011 


\begin{abstract}
Maps have longed been recognized as instruments of power and persuasion. With the recent proliferation of maps in the media and on the Internet has come an increasing desire among groups advocating for environmental and social change to have access to maps (the product) and mapping (the process) to more effectively promote their agendas. However, this is not as simple as it seems. Far from being neutral conduits of "truth," maps are constructed by a myriad of social interactions among heterogeneous actors (human and technical) that left unacknowledged can lead to an untapped potential of the power of maps. Adopting actor-network theory's (ANT) theoretical framework that accepts nonhuman entities as actors in the social, and its methodological protocols, this study contributes to the needed empirical evidence relating to the ways in which maps and mapping behave and function in society, particularly in the grassroots advocacy context and neighborhood scale, through a case study of the products, and thereby the process, of the Coalition for a Livable Future?s (CLF) Regional Equity Atlas four-year endeavor. The purpose of this study is to account for and expose the complexity of relations among data, technology, people, and organizations that underlie it and the ways in which these relations affected the atlas itself. Four interrelated themes emerge from this study. The first relates to CLF's contribution to equity mapping discourse including its participatory approach to equity mapping, its definition of equity, and the subsequent impacts of both of these things on the mapping process. The second relates more specifically to the contributions of the embedded ideologies that are integral to the GIS software that was
\end{abstract}


used and the roles that they played. The third theme is the importance of process in community-based mapping projects and the recognition that they are social processes in the comprehensive sense that ANT theorists advocate. The fourth theme relates to how maps work, specifically, maps as maps versus the idea of maps. 


\section{Dedication}

This dissertation is dedicated to my family, particularly my husband, Rod, who supported me throughout this long journey.

I would also like to dedicate this study to the memory of Craig Wollner whose neverwavering faith in my work gave me the confidence to pursue this study. 


\section{Acknowledgements}

This study would not have been possible without the guidance and support of my dissertation committee, particularly, my dissertation chair, Sy Adler. Clearly, such a detailed case study would not have been possible without the willingness of the key players to share their observations and documents with me. I would to thank Jill Fuglister and Ron Carley from CLF for their generosity in time and documents. Aside from CLF staff, Ken Radin was the only participant to stay with the project from start to finish. He deserves special thanks for not only sharing his thoughts about the process with me but also sharing all of his documents related to the project. This proved to be a treasure-trove that greatly enriched the study. In addition, I would like to thank Tasha Harmon for her openness and frank reflections about the workings of the project that provided me with an insider's experience of the inner workings of Equity Atlas project from a non-technical point of view. Irina Sharkova provided me with insights from an expert-academic perspective that proved invaluable. In addition, I would like to give special thanks to Ethan Seltzer, Zack Semske, Alex Campbell, Jim Labbe, Ryan Sullivan, Kris Smock, Steve Johnson, and Suzanne Briggs for their time, documents, and the perspectives they brought to this study, as well as the many others who provided advice, information, assistance, and support in large and small ways along this journey. 


\section{Table of Contents}

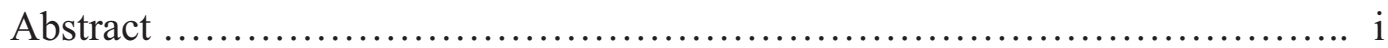

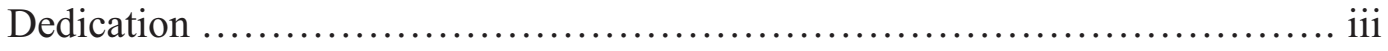

Acknowledgements ................................................. iv

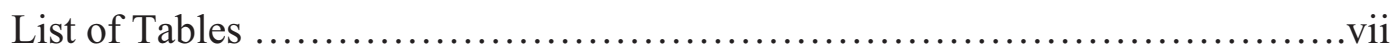

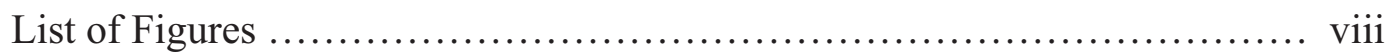

Chapter 1

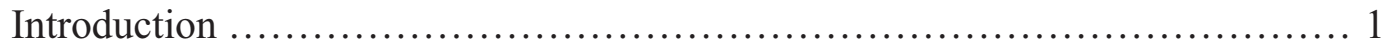

Chapter 2

Literature Review .................................................... 16

Chapter 3

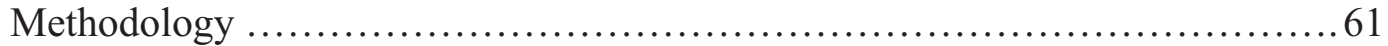

Chapter 4

A Coalition for a Livable Future: the Pre-Atlas Years

Chapter 5

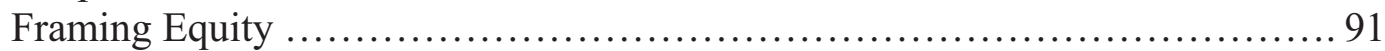

Chapter 6

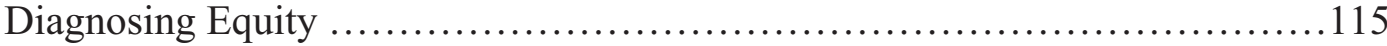

Chapter 7

From Vector to Raster: The Post-Summit Phase ........................... 154

Chapter 8

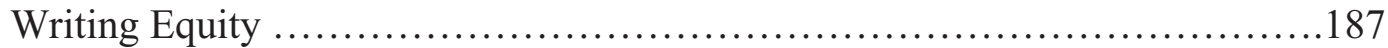

Chapter 9

Making Maps Work: Building an Equity Agenda ...........................2219

Chapter 10

The Atlas: An Analysis .................................................244 


\section{Chapter 11}

Black Boxes and Traces:

Findings, Recommendations, and Future Research

Epilogue

Regional Equity Atlas 2.0 Considerations

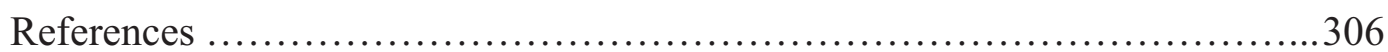

Appendices

A. Regional Equity Atlas Project Contributors and Tax Filings........ 321

B. Regional Equity Atlas Project Timeline.......................... 323

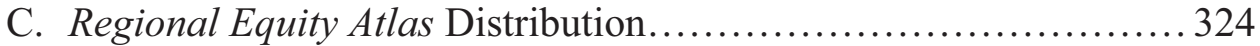

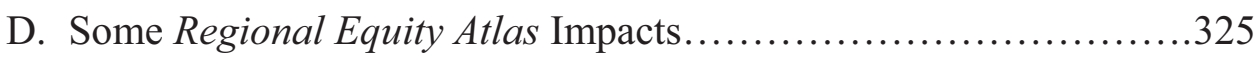




\section{List of Tables}

Table 4.1. CLF Self-Assessment ................................... 85

Table 6.1. Focus Group Census Maps ................................ 132

Table 6.2. Focus Group Access Variable Maps ............................ 132

Table 8.1. Neighborhood Summary Maps ............................ 204

Table 10.1. Summary Variables and Components by Neighborhood .......... 260

Table 10.2. Access to Housing Chapter: Maps, Tables, Graphs ...............262

Table 10.3. Access to Schools Chapter: Maps and Tables ................... 265

Table 10.4. Access to Transportation Chapter: Maps .......................269

Table 10.5. Health and Design Chapter: Maps ........................... 271

Table 10.6. Access to Parks and Nature Chapter: Maps ......................274 


\section{List of Figures}

Figure 6.1. Choropleth map: Population Per Acre............................119

Figure 6.2. Percent Population Non-White, 2000, by Census Tract..............122

Figure 6.3. 2000: Percent Hispanic Origin................................. 140

Figure 6.4. Percent African American non-Hispanic by Census Tract.......... 146

Figure 6.5. Change 1990-2000: Percent African American non-Hispanic....... 147

Figure 7.1. Map by Radin from the “Atlas Brochure Draft,” August 16, 2004..169

Figure 7.2. Draft Raster Map and Legend.................................. 174

Figure 7.3. Draft Raster Map and Legend................................... 176

Figure 8.1. Transportation Access Map.................................... 192

Figure 8.2. Transit Access Summary Score................................. 194

Figure 9.1. 2000: Distribution of Native Americans......................... 229

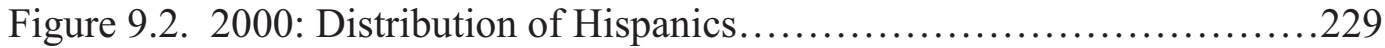

Figure 9.3. Change in Distribution of Children in Poverty, 1990-2000....... 230

Figure 9.4. Change in Distribution of Upper Income Households, 1990-2000..231

Figure 9.5. Change in Distribution of African Americans, 1990-2000_........ 232

Figure 10.1. Merrick's Conceptual Model of CLF's Equity Framework.........246

Figure 10.2. The Four Map Stages included in the Regional Equity Atlas.......248

Figure 10.3. 1989: Median Household Income by Census Block Group.........257

Figure 10.4. Change 1990-2000: Distribution of Upper-Income Households...257

Figure 10.5. Access to Public Parkland and Nature ..........................2276 


\section{Chapter 1. Introduction}

\section{Statement of the Problem}

Maps have longed been recognized as instruments of power and persuasion. With the recent proliferation of maps in the media and on the Internet has come an increasing desire among groups advocating for environmental and social change to have access to maps and mapping to more effectively promote their agendas. However, this is not as simple as it might seem.

Historically, the delineation and naming of nation states, natural resources, and navigation depicted in maps have provided information to power (utilitarian) and projected images of power (ideological) to others (Wood et al., 2010). While much of cartographic history has been driven by political conquest and control over territory, people, and resources where linkages can clearly be drawn between the text of the map and structures of power, whether or not a map appears to be overtly political there is always a complexity of power relations that underlie every map that has real consequences (Harley, 1989).

Harley (1989 and 2001) has shown, for example, that the interplay between social and technological "rules" (the "subliminal geometry" of mapmaking or the inherent distortions of map projections, the central foci of maps with the construction of "hemispheres" so that America could have its own, for example, and the design and choice of symbology) have helped "to codify, to legitimate, and to promote world views" (Harley, 1989, p. 6). Some claim that the process of mapmaking should be characterized more as a process of knowledge creation than revelation (Kitchin and 
Dodge, 2007), and that these linkages and processes must be understood by map patrons, mapmakers, and consumers in order for maps to be both ethically and effectively employed (Harley, 1989; Wood, 2002).

Critical cartography theorists have examined not only the power relations that underlie every map but the ontology of maps themselves. From this critical perspective, maps are active; they actively construct knowledge, they exercise power and, importantly to advocacy and community development, can be a powerful means of promoting social change (Crampton and Krygier, 2006, p. 15) (Craib, 2000; Sparke, 1998). Put another way, they "work" (Wood et al., 2010). And as a cartographic historian, it was Harley, who, in his investigation of historic maps, saw the relevance of Foucault's theorizations of power and knowledge and Derrida's notions of deconstruction to uncovering the meanings and workings of maps.

The addition of semiotics to the analysis of geographic visualization by Wood and Fels (1986) and how maps "work" by MacEachren (2004) have provided vehicles by which to explore the ways in which maps are also "constructed" by map users through their own experiences. In this way, each map works as many as each map user uniquely interprets its image and signs - begging the question as to every map's authorship and purpose (Del Casino Jr. and Hanna, 2006). Furthermore, Kitchen and Dodge (2007) argue that maps are ontogenic in nature: "Maps are of-the-moment, brought into being through practices (embodied, social, technical), always remade every time they are engaged with" (Kitchen and Dodge, 2007, p. 335). Wood (1992) suggests that this reality of map construction turns the positivist communication model 
of map creation, where the "objective" cartographer constructs a "neutral"

communication "channel" (the map) that is designed to precisely communicate "truth" to the user, on its head. The binary notions of good maps and bad maps, expert mapmakers and amateurs, "useful" maps and "useless" maps are seen as falsehoods or illusions (Del Casino Jr. and Hanna, 2006).

Recognizing the power of maps to promote social and political change, the authority of computer generated maps, and the increasing availability of geographic information systems (GIS) technology, participatory GIS (PGIS) advocates have sought to democratize mapping by conflating the map patron, mapmaker, and consumer into one interest at the grassroots level. In this way, PGIS proponents hope to unleash the power of mapping, specifically GIS mapping, through the democratization of sign, symbol, spatial abstraction, and analysis for those who have been previously excluded (Pickles, 1995; Talen, 2000; Weiner et al., 2002; Ghose and Elwood, 2003; Merrick, 2003).

While a great deal of attention has been paid in academic circles to the promise of participatory GIS, the reality of putting fully functional mapping technology in the hands of previously untrained grassroots' interests has been fraught with difficulty. Hardware, software, data, technical and analytical knowhow, and sometimes Internet access, are out of reach for most grassroots organizations.

Because of the still complex interface of fully functional GIS software, community and advocacy organizations that understand the potential of maps to 
promote their agendas, opt, if they can, to hire, or enlist in a volunteer capacity, experts to tell their stories for them. This requires resources or connections that many organizations do not have. However, Merrick and Dorwart (2002) have argued that sometimes extraordinarily simple GIS applications, requiring relatively inexpensive or free software and little expertise, can be relatively easily used by community groups to create maps that have meaning for them as well as others. Most recently, the rise of cybercartography offers new opportunities for the nonexpert to create maps - as can been seen in the "mashup" phenomenon most closely associated with Google Earth and Google Maps on the Internet. Unfortunately, most GIS experts and policymakers have discounted such nonexpert applications as overly simple, lacking in sophistication and analytical power, and therefore, not useful in the policy-making arena.

Some have questioned whether or not a truly participatory GIS is even possible given the top-down nature of the technology (Abbot et al., 1998). Indeed, most of what is considered to be "bottom-up GIS" (Talen, 2000) is accomplished through a kind of triple translation process whereby community members' observations, concerns, and desires are conveyed to a GIS technician who then operationalizes the information in a GIS which in turn, with the assistance of the technician, translates and abstracts the information into a map. Whether or not this particular kind of filtering of grassroots' interests can be called a bottom-up process is a real question.

It can be and is, indeed, argued by cartographic/GIScience elites that the use of "well-crafted" maps, such as government generated census or environmental hazard 
maps, by community and advocacy groups should be encouraged. However, any use of maps made by others for their own purposes, from a critical perspective, makes it imperative that the nature of maps and the mapping process be understood by those who seek to utilize them for empowerment or advocacy. This is because the selection processes that are integral to mapmaking, by technicians, software designers, and technology, that choose one method or procedure over another, can't help but emphasize some things at the expense of others (Black, 1997). Empowerment through mapping, as in everything else, is linked to choices and who is making them.

The power of maps to persuade and the facility of GIS technology to analyze are seductive. And, the potential for an unquestioned acceptance and reliance on the technology's processes to analyze and its products to suggest solutions have grown as the adoption of GIS by a wide array of enterprises has exploded. For example, arguing that GIS technology has "captured" planning practice "to an unprecedented degree” (Lejano, 2008, p. 653), and accepting that GIS “mappings” are social constructs as well as "social actors" (in the sense that actor-network theorists see technology as a social actor), Lejano (2008) suggests that GIS has affected planners and their practice in ways, unbeknownst to them, that are not always positive. This is what he calls, GIS's "most subtle impact"- the invisible or unconsidered workings of the technology on the users themselves (Lejano, 2008, p. 654). Specifically, Lejano (2008) points to GIS's analytical power that has extended its reach far beyond traditional mapping and has resulted in an overreliance by planners on "artifice" for problem-solving rather than on-the-ground engagement. 
Related to this is the unprecedented ability of GIS technology to reduce complex data to simple abstractions. These abstractions, or representations, are affected by the "deceivingly rational logic," (exemplified by overlay analysis) that underlies GIS's use when, in fact, its underlying logic is normative (Lejano, 2008, p. 654). This, Lejano (2008) contends, can lead to spurious propositions. Overlay analysis, which appears to be integrative in its operation, is not a substitute, Lejano argues, for the integrative knowledge that comes out of actual experience. An unquestioned reliance on GIS alienates the planner because he or she tends to "lose the habitus of place" (Lejano, 2008, p. 673); ultimately, GIS “transforms mappers themselves, keeping them from authenticity in their identity and practice" (Lejano, 2008, p. 673). This has real-world ramifications in terms of the solutions that planners propose and plans that they make.

Similarly, in their study of the adoption of GIS for district-level administration in India, Walsham and Sahay (1999) found that interests are inscribed into GIS (including the hardware, software, and data) that require users to "adopt attitudes and interests congruent with those of the interests inscribed in the technology" (p. 49) in order to make it useful. This "subtle" effect on users of GIS, especially in different cultural settings and the maps they make, have consequences - in this case, an unsuccessful adoption of the technology.

The effects that Lejano (2008) and Walsham and Sahay (1999) were able to identify, by adopting the actor-network theoretical (ANT) perspective, are an important recognition of the active role that the GIS enterprise (including software 
programmers with their biases, the resulting software and its design, data and their forms and availability, the attitudes and worldviews of the technicians, map patrons, and map users) plays in the process of mapmaking and map use that are poorly understood and rarely get acknowledged.

We know that maps work: they are active; they "practice" (Kitchin and Dodge, 2007); they construct knowledge; they persuade; they conceal and reveal; they exercise power in ways that are obvious and not so obvious; and, particularly if they are created by acknowledged experts or are computer-generated, they have authority. They also attract and delight. Aberley (1993) states that, in his experience, whenever people are brought together to explore maps, as he has done in his mapping-forempowerment projects with First Nations people and others in Canada, there is always a lively reaction suggesting that "maps hold some primal attraction for the human animal" (p. 1). Like the undeniable attraction of the treasure map offering the chance to find what is hidden, "maps unravel the mysteries of the present and future of place through the depiction of fixed and flowing energy layered in patterns of opportunity" (Aberley, 1993, p. 1). For these reasons, in addition to the prominence of mapping in society generally, during this second cartographic revolution (Buisseret, 1992), it is easy to see the attractiveness of maps and mapping to organizations (largely ignorant of the underlying complexities) not only advocating for environmental and social change but for those wishing to engage community members at the grassroots level. In their introduction to the special 2006 issue on "Critical Cartographies and GIScience" of the ACME E-Journal, Harris and Harrower (2006) worry about the 
continued gulf between critical theory, mapping technology, and practice. They acknowledge the argument that critical cartography/GIScience is little more than academic debate with little relevance to the cartographer, GIS software designer or GIS professional, and map patrons, let alone consumers, but suggest that theoretical advances have been made (such as the application of ANT) that do, indeed, have direct application to the ways in which maps behave and function in society. What is needed, these authors contend, is a body of empirical evidence, informed by the theory, to better understand cartographic interactions (with all of their subtlety and ambiguity), applications, and influences on society (Harris and Harrower, 2006, p. 8). This is important because in this second cartographic revolution, with its proliferation of map images and exchanges (in the media and on the Internet) and the persisting unchallenged authority that such images hold, people will be hurt or empowered by "the power of maps."

\section{Purpose of the Study, Its Significance, and Research Questions}

Adopting ANT's theoretical framework that accepts nonhuman entities as actors in the "social," and its methodological protocols, this study seeks to contribute to the needed empirical evidence relating to the ways in which maps and mapping behave and function in society through a case study of the products, and thereby the process, of the Coalition for a Livable Future's (CLF) Regional Equity Atlas four-year endeavor. In so doing, this study seeks to "interrogate maps as representational practices" or "map spaces" (according to Del Casino Jr. and Hanna, 2006, maps are spaces where maps and mappings are both representations and practices). In opening 
the "black box" or "simplification" (Doolin and Lowe, 2002) that is the atlas document and its maps and by "tracing" the translations (Latour, 2005), transformations, and interactions among the "actants" (human and non-human actors), the purpose of this study is to expose the complexity of relations among the data, technology, people, and organizations that underlie it.

Given the expectations that were built around The Regional Equity Atlas (2007) over its four years of development, and the importance that CLF gave to the power of maps, the published atlas is something of a puzzlement. The idea of an atlas generally brings to mind a book of maps with charts, tables and text playing a secondary role. The maps are the primary storytellers. But The Regional Equity Atlas turned out to be something quite different, more of a report than an atlas, where the maps retreat and rely on text to supply their meaning. This study asks why and how this happened and seeks to uncover its significance.

Further, this study asks why a community-based advocacy organization, such as CLF, would take on such a daunting task for itself - to map equity and make an atlas out of it. It is clear from the four years of work and the resources that CLF and its partners put into the Equity Atlas project that it believed that equity (a rather complex and amorphous notion) could be mapped, that the implications of inequity would be more easily understood if mapped, and that solutions would present themselves through the maps. This study explores these questions and assumptions to reveal the complexity of social relations that underlie the atlas document and their impacts on CLF, the academic partners, and the document itself. 


\section{Significance of the Study}

In addition to contributing to the literature related to how maps and mapping work in society in general terms, this case study specifically explores the effects of maps and mapping on a community organization enmeshed in participatory processes and advocacy. CLF's Regional Equity Atlas provides an unusual opportunity for such a study on several fronts. First is the importance of CLF as an organization. Since its inception, the Coalition has been enormously influential in shaping regional policy in the Portland metropolitan area - most noteworthy, the incorporation of many of its positions into Metro's 2040 Regional Framework Plan and the election of several of its members to public office. It did this, in part, through the utilization of maps: Myron Orfield's Portland Metropolitics (1998) maps, that were commissioned by CLF, were used by CLF to both better understand the regional issues and to advocate for their positions during Metro's 2040 planning process prior to the publication of the Portland Metropolitics report.

Second, it could be argued that CLF was born of maps. It was a presentation of maps by Orfield in 1994 to an audience of housing, environmental, and land use advocates that inspired many who were there to move out of their silos to work together to form a coalition of organizations that would work collaboratively to influence Metro's long-term regional planning goals.

Third, CLF, because of its history, believed in the power of maps to reveal and to persuade. And, because of its advocacy role, it was willing to put all the resources it could muster behind the Equity Atlas process. This was not a trivial pursuit as far as 
CLF was concerned; it was central to its mission and, as this study reveals, was central to bolstering its identity.

Fourth, CLF took on, without understanding the full implications of what it was doing, the exceedingly difficult task of trying to translate "equity" into a GIS mapping environment. CLF had been remarkably successful, during its relatively short life, in developing a highly participatory and collaborative culture, utilizing its own members' expertise whenever possible. And, this approach had gotten results. Two things are important here: the first is that CLF wanted to actively participate in the Equity Atlas process - it would frame equity, identify the indicators, and determine the acceptability of the maps; and second, having expertise in equity through its membership, it believed that it could take on the task of translating equity into GIS, with its university partner and GIS professional volunteers, that had baffled experts for some time. This characteristic of CLF offers an opportunity for delving into the affects of assumed participatory processes in this technical realm.

Finally, because of the extenuated timeline of the Equity Atlas process, that produced literally hundreds of maps and historical documentation, opportunities were provided to delve into the thought processes, actions, and reactions by the various actors that might have been more difficult to identify in a more compressed timeframe with less output.

\section{Scope of the Study}

As ANT requires, there is no a priori assumption as to the scale or hierarchy of the actor-networks involved - the world, in fact, is flat according to ANT (Latour, 
2005). Because of its exploratory nature and because the research begins with the atlas document that was published in 2007 by an organization that began in 1994, it was understood at the outset that temporal parameters would be set around that timeframe, beginning with the 2007 document and going as far back in the organization's history as the traces would lead.

Furthermore, although the Equity Atlas actor-world (Callon, 1986), made up of actor-networks, could theoretically exist in enormous breadth and detail (all of CLF's members over time, the participants of various focus groups, the participants of the roll-out sessions, the public at large), the focus of this study is on the detailed relations among the most immediate actants in relationship to maps and CLF during the specified timeframe. These include the Coalition as an organization, the human actors including CLF's former and present directors, key members and contractors, Portland State University-based partners and consultants, data forms, and cartographic and GIS procedures. Although the construction of a chronology is essential, this is not a comprehensive history of CLF.

\section{Definition of Terms}

ANT has its own terminology; some key terms are defined here.

Actor-Network. Originating in the investigation of scientific practices, actornetwork theory sees the social as being comprised of networks of heterogeneous actors (human and nonhuman) each of which is the effect of its own heterogeneous actornetwork. Given the parity (generalized symmetry) between human and nonhuman actors, the term "actant" is often used to identify them. According to Latour (2005), 
"a network is not made of nylon thread, words or any durable substance but is the trace left behind by some moving agent" (p. 132). Actors take shape in relationship to each other. Actor-networks describe the internal workings of an actor-world. Latour (2005) has also referred to ANT as a "sociology of associations" (p. 108). But it is important to understand that there should be no a priori assumptions as to scale or hierarchy of actor-networks: the world is flat (Latour, 2005).

Actor-World. An actor-world associates heterogeneous entities. It defines their identity, the roles they should play, the nature of the bonds that unite them, their respective sizes and the history in which they participate (Callon, 1986, p. 24).

Translation. A connection that transports transformations is called a "translation." A network is "traced" by these translations in scholars accounts: ". . . there is no society, no social realm, and no social ties, but there exist translations between mediators that may generate traceable associations" (Latour, 2005, p. 108). A translation "thus maps out a geography of necessary points of passage for those elements who wish to continue to exist and develop" (Callon, 1986, p. 27).

Black Box. A black box is any setting that, no matter how complex it is or how contested its history has been, is now so stable and certain that it can be treated as a fact where only the input and output counts. Black boxes may always be reopened. "The aim is to open up these black boxes, these simplifications that we take for granted all too often and expose the way that translations occur and associations are generated" (Doolin and Lowe, 2002, p. 73). 
In addition to the previously defined terms associated with ANT, this study refers to the notion of participation and what that means in the context of the Equity Atlas mapping process. The term PGIS (participatory GIS) and the notion of participation, more generally, are referred to at various points in this study. Some clarification is required. First, a distinction needs to be drawn between PGIS and the better known and earlier coined term, PPGIS or public participation GIS, which is discussed more fully in Chapter 2 of this study. As Schlossberg and Shuford (2005) point out, both "public" and "participation" are very broad terms that when paired, as they are in PPGIS, have resulted in an imprecise definition and inconsistent applications. Even in the planning literature, from which the term "public participation" was borrowed, this is the case (Tulloch and Shapiro, 2003; Schlossberg and Shuford, 2005). Assuming that the democratization of GIS is important as a vehicle of empowerment for everyone, some have advocated for dropping the first "P" in favor of an emphasis on the second, or participation in the GIS process. It is this assumption that this study adopts with an emphasis on what participatory GIS means in the context of CLF's Equity Atlas endeavor.

\section{Study Limitations}

This is a case study that is both exploratory and qualitative. The nature of the ANT approach requires both. Other than the assumption of the heterogeneity of social actors and the theoretical abstractions of relationship, it is up the researcher to expose the existence and quality of relationships in a particular actor-world, in this case the 
Equity Atlas actor-world. This means that the study's findings, while suggestive as they build on theory and previous research, may not be generalizable. 


\section{Chapter 2. Literature Review}

Several key themes emerge from this study that warrant an exploration of the literature. First, the amorphous nature of equity as a concept, its operationalization in various analytical settings, and the incorporation of equity into the GIS environment have puzzled analysts for some time. Since the 1960s, numerous attempts have been made to incorporate notions of equity into public facility siting decisions, environmental justice analyses, and urban planning, but none have been, according to the literature, entirely satisfactory. By the time CLF was ready to move ahead with the Atlas, there was no consensus about how to do it.

Second, the mapping of complex notions such as equity using GIS technology requires knowledge not only of the models that are the underpinnings of the technology itself and how to accommodate various data types within the constraints of those models but an understanding of the impacts of the resulting abstractions. Long before there was GIS technology, demographers and cartographers grappled with and debated about the inadequacies of the choropleth technique, often used with aggregated census data, to display distributions of phenomena where they actually occur in geographic space. According to the literature, these, too, are debates that have not yet been resolved but the advantages and disadvantages of various cartographic approaches were well known, at the time the Atlas process began, among cartographic elites. Both the impact of the inner-workings of GIS and the cartographic output that was controlled by the constraints of the technology and the GIS analysts 
for the Equity Atlas played a critical role in the legibility and acceptability of the maps as well as the time that the overall project took.

An additional theme relates to participatory processes generally, the idea of participatory GIS, and competing notions of expertise. CLF hired one of its founding members, who was an affordable housing expert and advocate, to be the project lead. The university partner, beginning with the Institute of Portland Metropolitan Studies (IMS) and later the Population Research Center (PRC), both at Portland State University (PSU), provided the services of a graduate student with GIS experience to produce the mapping for the Atlas. The project was never formally articulated as participatory research or conceived of as being a participatory GIS process, however, the extent to which CLF was involved in framing the issue, the identification of variables, and questioning the mapping processes themselves crossed the boundaries of a typical expert/client relationship. The literature indicates that the breakdown between the clear lines of authority relating to experts and clients in society, generally, has been occurring for some time. And, clearly, CLF felt that it could challenge, as experts in grassroots issues (including equity and communication), the authority of the academics and their maps.

\section{Mapping Equity and Mapping Opportunity}

\section{Accounting for Equity}

A clear antecedent of equity mapping comes out of facility location modeling literature. Although emphasis in this field, until the 1970s, was largely placed on the criteria of efficiency and effectiveness, notions of equity and fairness, particularly 
related to the siting of public facilities, began to be incorporated into facility location models during this time. A review of the literature by Marsh and Schilling (1994) found, however, that not only was there a lack of agreement about equity's meaning and how to measure it among contributing researchers from a variety of fields including transportation (Berman and Kaplan, 1990; Gopalan et al., 1990; ), public policy (Coulter, 1980), economics (Campbell, 1990; Champernowne, 1974; Kolm, 1976), planning (Mayhew and Leonardi, 1982), health (Kinman, 1999), and geography (McAllister, 1976; Morrill and Symons, 1977) but even within the facility locational modeling discipline itself.

For their analysis of twenty statistical measures of equity designed to be incorporated into facility location decision-making, Marsh and Schilling (1994) employed a definition of equity specifically related to facility location decisionmaking. Here, "equity" exists when "each group receives its fair share of the effect of the facility siting decision" (Marsh and Schilling, 1994, p. 3). An "effect," in the context of this definition of equity, is a "change in the status quo of a value of interest caused by influences from the location and size of facilities being sited" (Marsh and Schilling, 1994, p. 3). A "group" is an aggregation of individuals on which effects are measured. The aggregation of individuals may be based on spatial proximity or some attribute (such as income, race, ethnicity, or age) that is associated with the individuals.

In general, effects are dependent on distance but not always. Determinants of an effect on a group might be a straight-line distance to a hazardous facility, the 
response time for emergency services, or a non-linear function such as noise or risk. A non-distance effect, for example, could be the level of traffic congestion at a facility based on its use (Marsh and Schilling, 1994). Public facilities, such as a park, may have positive effects but they can also have negative effects, as in the case of a sewage treatment plant. In other words, proximity may be beneficial or harmful depending on the nature of the facility.

Weighting and scaling of attributes are considerations and were used in some of the models the authors reviewed. Examples of attributes that could be considered for weighting or scaling include degrees of social need (the poor or mentally ill, for example); desire (public referendum, vote); value (dollars, worth); demand (usage, complaints); social merit (education, employment); population size; geographic extent; and what the "burden-benefit accord" (those who receive the most benefit also receive the most cost) (Marsh and Schilling, 1994).

While March and Schilling (1994) found all of the measures they reviewed to be wanting in one respect or another, the exercise allowed them to identify seven characteristics of equity measures about which there was some degree of consensus although no single author agreed with all seven. They are: (1) analytic tractability or the convenience of computation; (2) appropriateness (the measure should reflect the decision-makers' or stakeholders' background, values, and knowledge; (3) impartiality (the measure should be not be biased toward any group being measured); (4) the principle of transfers that essentially justifies a transfer of some benefit from one group to another without negatively impacting either group; (5) scale of invariance 
(here, a measure exhibits no change in the level of equity if the effects on all groups are multiplied by a constant - typically, measures are normalized to meet this criterion); (6) Pareto optimality (Vilfredo Pareto's efficiency principle implies that as the solution improves conditions, none of the individuals or groups being affected will be worse off) (Marsh and Schilling, 1994, p. 15); and (7) normalization (normalizing measures allows for the comparison among distributions of effects that use different units of measure).

Marsh and Schilling (1994) concluded that in spite of the fact that it could be impossible for any single, universal measure of equity to be developed, that did not mean that any of the measures reviewed was sufficient. Specifically, they suggested that more work was necessary to identify possible missing criteria for equity as well as a set of measures that would satisfy them. In addition, the apparent conflict between efficiency, so fundamental to traditional approaches to facility siting decision-making, and equity needed further investigation.

In 1998, Emily Talen published two papers geared toward the urban planning community, one with Luc Anselin in Environment and Planning A, and another in the Journal of the American Planning Association, that argue for importance of spatial equity in terms of the accessibility of urban services and propose a scheme for using GIS to explore the question of "whether or not, or to what degree the distribution of urban services is equitable" (Talen and Anselin, 1998, p. 596).

Stressing the importance of measurement and how it is done, Talen and Anselin (1998) take what they call a "spatial analytical" approach to assessing several 
different ways of determining the degree to which the distribution of urban services is equitable. Through a case study that examines the distribution of playgrounds in relationship to children and minorities, in Tulsa, Oklahoma, Talen and Anselin (1998) compared measures, in addition to the method that they identify as the traditional approach that simply counts services within some "geographic container" and does not consider spatial externalities - conditions outside of the container, using GIS technology, based on the gravity model, average distance, and distance to the nearest playground as indicators of accessibility. The results of this comparison indicated that the different ways in which the spatial externalities are incorporated into the various indices (the gravity index, the average distance index, and the nearest distance index) resulted in different geographic patterns and, therefore, make it difficult to come to agreement "on the characterization of spatial equity" (Talen and Anselin, 1998, p. 609).

Further, for the census tracts with significant Moran statistics for spatial equity, Talen and Anselin (1998) incorporated population age and proxies for race and income in an exploratory investigation of any association between these populations and the spatial inequity identified in the previous procedures. This two step process, they suggest, has the potential to identify "mismatches" between access to services and minority populations with the caveat that each of these approaches result in different findings and that the least successful approach is the traditional one, largely because it cannot take into account conditions outside of the geographic containers selected for analysis (Talen and Anselin, 1998). 
In "Visualizing Fairness: Equity Maps for Planners" (1998), Talen argued that the status quo for urban service allocation, at the time, tended to occur according to some pre-defined per capita allocation without regard to fairness. Building a case based on the analyses of urban planner Norman Krumholz $(1975,1982)$, Krumholz and Forrester (1990), Marsh and Schilling (1994), and others, for the incorporation of equity and fairness into decision-making processes centered on public resource allocation, Talen contended that it would be a complicated business made up of not only a myriad of methodological decisions but also a host of "value judgments about who should benefit, the nature of social justice, and the definition of political consensus" (Talen, 1998, p. 22).

The question that Talen (1998) was attempting to address was how the spatial equity of public resource distribution could be effectively analyzed and incorporated into decision-making processes. The solution she suggested was what she called "equity mapping," an interactive method using GIS and built on the assessment of methods that she and Anselin (1998) described in their article previously cited. However, she did not prescribe one set method or set of variables. Instead, she laid out the choices that analysts and decision-makers would need to be prepared to make in the equity mapping process. These include the type of facility or set of facilities to be analyzed; the attributes of the population to be included (race, income, age, etc.), the type of accessibility measure or measures to use (if comparisons are desired); the type of distance measure to use (straight-line, or network, for example); and the parameters of the access measures (Talen, 1998). Once these decisions are made the 
locations of facilities and the demographic data could be entered into a GIS for analysis. Talen (1998) saw this process as iterative and exploratory: "[r]elationships are discovered and assessed, and data inputs are reformulated to investigate, in an interactive way, existing and/or planned equity patterns" (p. 36).

On a related track, concern about the association between the locations of hazardous facilities in particular and communities of color and the poor that arose in the 1960s spawned the environmental justice movement and a body of literature that has sought to use spatial analysis specifically to identify inequity. The 1987 report, Toxic Wastes and Race in the United States: A National Report on the Racial and Economic Characteristics of Communities with Hazardous Waste Sites, published by the United Church of Christ's Commission on Racial Justice, used mapping and statistical analysis to reveal a hard-to-refute correlation between the locations of nation's hazardous facilities the locations of communities of color. Although it was not the first study to suggest such a finding, its breadth and use of maps and statistics to argue its case made it groundbreaking in terms of influence; its publication is marked as a seminal event in the environmental justice movement's history on envirojustice.org's "Environmental Justice Timeline.”

In her review and critique of a variety of approaches to mapping environmental injustice that proliferated in the aftermath of the "Toxic Wastes and Race" report, Maantay (2002) suggests that the mapping and analyzing of such phenomena are not as straightforward as they might appear to be - that simply plotting hazardous facilities or land uses in relationship to communities of color, while producing 
"dramatic maps" (Maantay, 2002, p. 161), as "social constructions," (Maantay, 2002, p. 161) such maps can be challenged for bias. Furthermore, Maantay (2002) contends that these types of maps, that illustrate more than analyze, are not able to yield definitive findings about differential exposure levels or health outcomes for populations living close to environmental hazards. This, she states, makes these types of studies not particularly useful in conclusively demonstrating the unequal burden that these populations endure.

Suggesting that this problem could be addressed through the utilization of new methods made possible with GIS technology - a technology that had rapidly developed during the decade of the 1990s - Maantay (2002) reviewed thirteen GISbased environmental equity studies that took place between 1993 and 2000, focusing specifically on what was being mapped and how it was measured. Like Marsh and Schilling (1994), Maantay found that there were, especially in the earlier studies, definitional, conceptual, methodogolical, and data problems that limited their usefulness. These problems also raised questions about GIS's capability for investigating either environmental health or equity.

An additional issue revealed through the analysis of these studies was causality and what the various researchers found related to it. Some studies indicated that race should be used as a predictor of environmental injustice while others suggested that income was the more reliable predictor. Still others found that race and income were so closely tied to each other that they could not be effectively untangled; they would have to be taken together to be a reliable predictor of inequity. Furthermore, in terms 
of causality, the studies indicated that there was something of a chicken and egg question related to intentionality, in other words, which came first the people or the environmental hazard (Maantay, 2002). This quandary, Maantay (2002) argues, is a "fool's errand" and that what really matters, once an environmental injustice is revealed, is how policymakers address it.

Like Marsh and Schilling (1994), Maantay suggests that race and income should not be the only indicators of disadvantaged populations and that other vulnerable populations such as children, pregnant women, the elderly, the sick, and future generations be considered for analysis.

Other issues, related to both definitions and measurement, include the question of what should be counted as a hazard as well as the type and degree of impact of each hazard. According to Maantay (2002), too many of the studies she reviewed focused on only one set of hazards leading to incomplete assessments of environmental inequity and therefore misleading results. Insufficient data related to emissions generated from facilities and the lack of valid measurement also have contributed to the lack of modeling exhibited in these studies of the proximity of a population to an environmental hazard and the likelihood of exposure.

Another concern identified in at least one of the studies reviewed is what is known as the "modifiable area unit" (MAU) problem where the results of research differ depending on the geographic scale of analysis. As data are aggregated up to larger geographic units, for example, from census tract to city to county, they become less reliable. However, the unit of analysis is typically driven by the availability of the 
data. Recognizing the importance of high resolution data to the accuracy of environmental justice analysis, Maantay (2002) points out that community members should be encouraged to collect their own information about the locations and conditions of hazardous facilities in their communities to ground-truth the information in national databases.

As recently as 2005 , Tsou et al., suggested that researchers still had not come up with a way to evaluate spatial equity comprehensively, that models for analysis still focused on single types of public facilities not taking into account the effects of different kinds of facilities or the desires of community members for or against them. While most researchers have agreed that spatial equity should be measured by the physical distance to such things as schools, health facilities, or even cultural events, Tsou et al. (2005) argue that a more ambitious approach should consider not just physical access to facilities and resources: not just jobs, for example, but a choice of jobs; and, not just access to cultural events, but a choice of cultural events, etc.

What they put forward is a method of micro analysis that utilizes a new "integrated equity index" to consider relative spatial equity in terms of the spatial allocation of each type of public facility for each resident of the city - in this case, Ren-De, Taiwan. The index is comprised of characteristics that are important for planners: service range/impact area and spatial separation; preference of residents for different types of facilities (determined by a survey); and the different sizes of public facilities of the same type that have varying effects on the residents (Tsou et al., 2005). The range of a facility is set as a function of its size. The preference of residents for 
each type of facility is determined by an attitude scale survey. GIS is then used to measure the spatial separation in terms of street networks or minimum distance. While the authors admit that their approach falls short of fully interpreting the "real" relationships among public facilities, they claim that the implementation of their index provides an intuitive summary of the data in 3-D GIS and a spatial equity analysis based on spatial auto-correlation techniques (Tsou et al., 2005).

\section{Mapping Opportunity}

In 1993, john a. powell founded the Institute on Race and Poverty at the University of Minnesota Law School to investigate, build coalitions, and affect policy related to racialized poverty and changing policies and practices that affect lowincome communities of color (Institute on Race and Poverty, 2002 and 2011). Powell was an expert witness for the plaintiffs in the 1996, U.S. District Court case Thompson v. $H U D$ filed by the American Civil Liberties Union on behalf of 16,000 public housing residents in Baltimore (Reece and Schultheis, 2009). The result of the case was that U.S. District Court Judge Marvin Garbis ruled that the U.S. Department of Housing and Urban Development (HUD) had violated the Fair Housing Act by failing to provide subsidized housing throughout the region and that HUD could not consider the city of Baltimore to be a "container" to house the region's poor (Reece and Schultheis, 2009).

In 2003, about the same time that CLF was ramping up its Equity Atlas effort, powell was invited to be the first executive director of the Kirwan Institute for the Study of Race and Ethnicity and the Gregory H. Williams Chair in Civil Rights and 
Civil Liberties, in the Moritz College of Law at Ohio State University. It was there that powell began to extensively use GIS mapping to execute his "opportunity-based" housing model as the basis for his recommended remedy to Baltimore's fair housing violation and that was later applied to cities and regions across the country (Reece and Schultheis, 2009).

The "opportunity map" for Baltimore was a neighborhood analysis of indicators of neighborhood health, educational opportunity, and economic opportunity and mobility in the Baltimore region (Reece and Schultheis, 2009). To do this, an "opportunity index" was built based on the assumption that "where you live is more important than what you live in ..." (Gambhir, 2007), and that the location of one's residence is "the primary mechanism for accessing opportunity in our society" (Gambhir, 2007). According to the Kirwan Institute, the location of housing determines the quality of schools one's children can attend, the quality of public services available, access to transportation and employment, exposure to health risks, and access to health care among other things (Gambhir, 2007). Most importantly, for people living in high poverty areas, these factors can "significantly" affect life's outcomes (Gambhir, 2007).

Kirwan's "Communities of Opportunity” framework is a model of fair housing and community development based on two premises: (1) everyone should have fair access to "critical opportunity structures" needed to succeed in life; and (2) “affirmatively connecting people to opportunity creates positive, transformative change in communities" (Gambhir, 2007). The opportunity mapping methodology is 
built on the identification and selection of indicators of high and low opportunity that have been, through research and experience, established by the Kirwan Institute with the direction of local steering committees so that concerns specific to a particular region may be incorporated if possible. But the central requirement is the establishment of a clear connection between an indicator and Kirwan's definition of opportunity (Gambhir, 2007).

The data that Kirwan uses for opportunity mapping come from federal sources (such as the Census Bureau, HUD, the Environmental Protection Agency), state and local governmental organizations (transportation agencies, school districts, regional and city planning agencies), and other sources such as Schoolmatters.org, ESRI, DataPlace.org, and Claritas. It is important to note that although some of Kirwan's early work aggregated the data by neighborhood boundaries, in more recent years, Kirwan has generally moved away from neighborhood geographies to census tracts for its unit of analysis primarily because census tracts are easier to use in litigious settings. When the data aren't available in the desired geography, either census tracts or neighborhoods, analysts reallocate the data through a vector to raster, proportional, conversion process using GIS.

These data are then placed into indicator categories: education; economic/employment; neighborhood quality; transportation/mobility; and health and environment (Gambhir, 2007). A matrix of all of the variables in their categories is developed that includes an indication of its positive or negative effect on opportunity. For example, under the education category, Kirwan includes the educational 
attainment for the total population (defined as the percentage of the population with a college degree), school poverty for neighborhood schools (defined as the percentage of economically disadvantaged students), and teacher qualifications (defined as the percentage of Highly Qualified Teachers). Each of these is then identified as having a positive or negative effect on opportunity - for the previously described indicators the effects would be positive, negative, and positive.

A z-score is then calculated for each of the indicators based on the regional mean. The scores are then adjusted for the direction effect (positive or negative). An "opportunity index" is developed for each census tract based on the average of the zscores for all of the indicators by category. The opportunity mapping methodology applies no weighting to any of the indicators because there is no consensus in the literature to rely upon. Finally, the census tracts are ranked by z-score into five categories with nominal rather than numeric labels from very low to very high, with very low being the bottom 20 percent and very high in the top 20 percent (Gambhir, 2007). These scores are then mapped by census tract or neighborhood to create easyto-interpret maps of opportunity or the lack thereof.

Kirwan claims that the strength of its approach is that it is a statistical measure, it is grounded in social science literature, and it is intuitive (Gambhir, 2007). And its strength has been demonstrated by the fact that since 2004, according to the Kirwan Institute's website, it has been engaged in 39 opportunity mapping projects for regions around the nation directly and has assisted numerous others in using the Kirwan metholodogy to create their own opportunity maps. 
This notion of "opportunity" mapping provides a different slant on efforts to map equity, or inequity, to which it is related. Because of its origin in the Baltimore court case where the mapping exercise was intended to inform solutions to the ghettoization of subsidized housing (a problem that was acknowledged by the court) by identifying places where opportunity already exists and where subsidized housing should go, it has a very different feel from the other approaches described here. This is in part because its agenda is clear and its focus is relatively narrow: the provision of subsidized housing where it can make the most constructive difference in people's lives.

The literature related to equity mapping prior to CLF's effort assumes that whatever analytical approach is taken, it will be accomplished by experts: academics, nonprofit groups with technical expertise, or the technical experts within planning agencies. And, while it is true that advocates for various causes including environmental justice and affordable housing have always used data and reports to support their claims, the use of GIS generated maps for these purposes was relatively new. In the 1990s, Myron Orfield (2002), with his metropoltics work, and CLF, in their use of Orfield's maps, were unusual in this respect. There was little concern expressed in the literature during this time about either the public consumption of the maps that would result from these analyses, except to say that maps can make a substantial visual impact (Maantay, 2002), or what a participatory process might look like in terms of the mapping of equity. 


\section{Spatial Models, Data, and the Problem of Cartography}

It goes without saying that maps are an abstraction of geographic reality. Mapmaking involves a process of selection and simplification, of exaggeration and diminution that combine fact and fiction, consciously and unconsciously on the part of the mapmaker to communicate intentional and inevitably unintentional messages. The introduction of computing technology, particularly GIS software, to the enterprise of map production, while hugely advantageous in many respects, required the abstraction process to be translated through the parameters of computers - the " 0 ' $\mathrm{s}$ " and " 1 's" that are at the core of their operation. As Longley et al. (2001) have said, "geographic reality is infinitely complex but computers are finite" (p. 84). Because of requirements unique to computers, decisions have to be made in determining how spatial phenomena are modeled using GIS technology that are often different from those that were made in earlier times. These choices have developed over time into two conceptual modeling paradigms: the field-based (Worboys, 1995) or raster data model (Aronoff, 1995; Longley et al, 2001) and the object-based (Worboys, 1995) or vector data model (Aronoff, 1995; Longley et al, 2001).

A data model, in the GIS context, is "a set of constructs for describing and representing selected aspects of the real world in a computer" (Longley et al., 2001, p. 184). The usefulness of any data model in this context is determined by how closely it can simulate aspects of the actual geographic world (Worboys, 1995). Worboys (1995) gives the example of cartography and way-finding where the geographic world (what he calls the "source domain") is modeled by a map (the 
"target domain"). A user needing to travel from one city to another by road consults and analyzes the map and then translates the results of the analysis to navigate through the real road network to get to the desired destination. If, Worboys (1995) suggests, the map is a good model of the real road system, the journey will be successful. The existence of two dominant data models, instead of one, used in GIS today reflects the imperfections in their simulation capabilities that are largely a product of the requirements of the digital realm. As models, each has strengths and weaknesses that can be mitigated to some extent by the appropriateness of their application.

\section{The Raster Data Model}

In the raster data model, the earth is overlaid by a regular grid of cells or pixels. These are most often square but can be rectangular, triangular, or some other regular interlocking shape. Each cell or pixel is "filled" with a single measured attribute based on one of several encoding systems (Chrisman, 1997; Longely et al., 2001). According to Chrisman (1997), the raster model has close links to the physical design of computer graphics hardware or the cathode ray tube (CRT) that renders images in pixels. The first generation of GISs that went beyond simple visual overlay (performed by computer aided drafting (CAD) and digital image overlay programs) used the raster data model precisely because the cells or pixels that are the basis of the model were easily handled as a numerical array by the programming languages of the

time and because of the visual output provided by CRTs (Aronoff, 1995; Chrisman, 1997). 
Geographic features, such as roads, forests, and lakes, are rendered as a single, string, or grouping of cells or pixels that are defined by their row and column positions and contain the same attribute value. The area that each cell renders of the "real" world determines the spatial resolution available to the mapmaker. And because the locations of geographic phenomena can only be identified by the cell row and cell column in the grid, the precision of their locations is dependent on the size or resolution of the grid's cells. Thus, the precision required to render XY coordinates isn't possible using the raster data model.

The raster data model has many strengths, however. It is a relatively simple data structure in that the cell location "addresses" are binary. Overlay analysis, which is achieved through cell arithmetic from layer to layer, is efficient and easily implemented. Because geographic space is modeled as individual cells, the raster model is well suited to rendering and analyzing phenomena that are highly variable over space such as natural features - soil composition, vegetation, air quality, or water quality, for example. Furthermore, it is essential to the efficient manipulation and enhancement of digital images such as areal photography and satellite imagery (Aronoff, 1995). As a result, the raster data model is widely used in environmental applications.

The raster model, as previously mentioned, does have drawbacks. Again, locational precision is dependent on the cell size used. The smaller the cells, the higher the locational precision but also the larger the data structure. This was especially a problem when computer processing power and data storage were more 
costly; it is less a detriment today. Another drawback of the raster approach is its output that produces jagged boundaries for all geographic features. This can be mediated some with the use of a high resolution grid but at a cost of what could be considered unacceptably large data files. The raster data model is not a good choice where locational precision is required such as political or legal boundaries. It is also not an efficient way of producing and modeling geographic information with little or no variability (Aronoff, 1995; Chrisman, 1997).

\section{The Vector Data Model}

The vector data model can provide for the precise positioning of features in geographic space (Aronoff, 1995). In the vector data model, geographic features are represented as points (XY coordinates), lines (a string of two or more XY coordinates connected to each other indicating distance), and polygons (an ordered and closed set of XY coordinates indicating area). Chrisman (1997) points out that cartographic data structures using the vector model do not usually provide more complicated options other than a straight line between XY coordinates or points. Thus, curves, rendered in this model are constructed with a series of closely spaced XY coordinates connected by straight-line segments. This, Chrisman (1997) points out, is different from graphics and illustration software where paths between points may be Bezier curves or splines. GIS software, unlike graphics or illustration software, is required to model spatial phenomena for analysis where the regularity (integral to Bezier curves) of spatial forms is seen only in man-made structures such as highways. Therefore, the features that are modeled using the vector approach are dependent on XY coordinates that are 
connected to each other by straight lines only (Aronoff, 1995). And while the possible number of XY coordinates may be continuous, in reality, the smoothness of a curve or accurateness of any feature for that matter, is dependent on the number of XY coordinates available at a given scale. Spatial relationships (or topology) among geographic features using this model are encoded in the data structure by a digitizing method, for translating geographic features into the computer, that identifies adjacent features.

Some of the advantages of the vector data model include the compactness of the data structure, relative to the raster model, that produces much smaller data files; an efficient method for encoding topology (or spatial relationships) that among other things allows for network analysis capability; relative to the raster model, a higher level of location precision for certain feature types, particularly points; and a graphic output that produces clean boundary edges that more closely resemble hand-drawn or CAD produced maps (Aronoff, 1995).

Disadvantages relative to the raster data model include a more complicated data structure than the raster model; the more complicated data structure requires relatively complex software coding to achieve overlay analysis as opposed to the simple cell-to-cell arithmetic required for overlays in the raster model; high spatial variability, such as attributes of vegetation or water quality, is inefficient; and manipulation and enhancement of digital images is extremely difficult (Aronoff, 1995). 
Because of the efficiencies related to the creation of the types of spatial data (streets, municipal boundaries, census boundaries, and property ownership) most desired by government (early identified by the GIS software industry as the principle market for their product), file size, processing power, and the familiarity of its output, the vector data model has become the basis for most GIS software packages with raster tools provided as an add-on. The vector approach is the default model for ESRI's GIS software and the lines or arcs that connect the XY coordinates used in the vector approach are the basis for the naming of ESRI's suite of GIS products, ArcInfo and ArcGIS. It was in the vector realm that Radin made his pre-Summit iterations of the Equity Atlas maps - a logical choice given the nature of the software available to him and the Census geographies that he was working with.

\section{Vector and Raster: the Challenge of Census Geographies}

At about the time that the U.S. Census Bureau began to implement the systematic small area aggregation of its data into Census tracts, geographers began to suggest that the division of geographic space into smaller areas alone was not sufficient to accurately display the population density within them. As early as 1936, in an article published in the Geographic Review, Wright challenged the "realism" of such maps. Commenting on maps of population density in Cape Cod, Massachusetts by township, Wright wrote:

Anyone who has visited the region knows that large parts are uninhabited. ... Fringing Nantucket Sound is a string of villages, but elsewhere the sandy outwash plains that intervene between the moraines and the sound are thinly peopled ...[the map] gives no idea 
whatever of these local differences. (Wright, 1936, p. 103)

Although Wright was referring to a much larger geographic subdivision (townships) than a Census tract, the problem that he identified related to the generalization of aggregated data over map space, particularly population density, inherent in the choropleth mapping technique and its apparent lack of association with what was actually occurring on the ground, is just as relevant at the Census tract level. Geographers and cartographers have struggled with this issue ever since.

Early attempts to create more realistic population density maps have included simply removing areas within a given geographic data container or zone (in this case, townships) that were known to have little or no population such as "wastelands not in farms" or areas occupied only part of the year (Wright, 1936, p. 103). In pre-GIS days and before the availability of remotely sensed data, these areas were determined in a "rough and ready" manner through the visual inspection of U.S. Geologic Survey maps and personal recollections (Wright, 1936). The removal of areas with little or no population from consideration produces more realistic maps, however, Wright (1936) states that such methods are crude, little more than "controlled guesswork" with highly generalized boundaries.

Another possible method for displaying population density is the dot-density technique where each dot represents one or more people. Although the total number of dots for a given geographical data aggregation unit may be statistically correct, the actual placement of the dots are not (Wright, 1936). And, although, theoretically, one could count each and every dot to calculate a density for a given area in actuality, 
where dots are placed closely together, this is impossible to do without a computer. GIS software does permit the user to create dot-density maps of aggregated data, however, the dots are place randomly within the area of aggregation and not necessarily where people are actually located.

Wright's own, he believed insufficient, solution to the problem rested on a system that combined the combination of inspecting additional geographic information such as topography and other known factors (land ownership for example) with a simple statistical analysis to identify homogeneous geographic areas instead of essentially arbitrary enumeration areas or political boundaries. Wright's 1936 article that advocated a dasymetric approach (where the underlying statistics drive spatial delineation) to mapping population density laid the foundation for future discussions among cartographers and geographers related to the inadequacies of choropleth mapping of population or social data and the search for alternatives - discussions that gained increased interest with the introduction of GIS technology to analysis and cartography. Wright's proposed solution to the lack of realism in choropleth maps of population density also spoke to issue of data allocation and reallocation to more meaningful geographic areas.

Openshaw and Taylor (1981), in fact, criticize their quantitative colleagues (active in the 1960s and 70s) for largely discounting the issue's importance by treating the weaknesses of the choropleth approach as largely an issue of scale - that with the aggregation of enumeration zones comes increased scale. The problem, Openshaw and Taylor (1981) suggest is the assumption that unit of aggregation, or zonal unit, is $a$ 
priori given. This assumption may be a tolerable statistical assumption for "people who do not know any better" (p. 60) but it is not an acceptable geographical assumption on which to base applications of quantitative techniques in geography. Zonal systems are not "divinely given;" their constituent zones are not uniquely meaningful fixed entities. If that were the case, there would be, they suggest, no problem. Instead, the same individual data points can be aggregated to provide different areal "representations" that yield data with little resemblance to the "real" data that existed before the geographic aggregations occurred (Openshaw and Taylor, 1981, p. 60). Moreover, misrepresentations of data are exacerbated when one set of arbitrarily assigned zones are aggregated to another system of zones. Such nested systems have the potential to create a "combinatorial explosion" of misrepresentation (Openshaw and Taylor, 1981). The uncertainties related to the choices of zoning systems and their modifiability have, Openshaw and Taylor (1981) suggest, real impacts on geographic analysis.

Recognizing that there would be no easy solutions to this "modifiable areal unit" problem, Openshaw and Taylor (1981) insist that, at the very least, the problem should be acknowledged and attempts made to address it. Stating that it is unlikely that there can be a purely statistical or mathematical solution to the modifiable areal unit problem, they argue for the necessity of a "geographic solution" to what is inherently geographic problem.

Additional concerns related to the choropleth mapping technique, over and above those already discussed, relate not only to the over-representation of population 
density in large geographic units and under-representation of population density in small geographic units but also to the classification schemes of data inherent to the choropleth approach. Not only do classification schemes produce different cartographic outcomes for the same data that introduce varying levels of error (although as Langford and Unwin (1994) point out, classification techniques, such as Jenk's Optimal, have been developed to minimize error), the number of classes into which the data are divided also make a perceptual difference (Langford and Unwin, 1994). Furthermore, the abrupt changes that occur across boundaries in such maps do not exist in reality causing additional interpretation difficulties (Langford and Unwin, 1994).

Just as important is the variability in the size and shape of the areal units themselves making comparisons between them virtually impossible (Langfor and Uniwn, 1994). Langfor and Unwin (1994) suggest that one solution would be to use a standardized areal unit such as the grid squares put forward by Browne and Millington (1983). However, data are rarely available in this form. Most demographic data come from the Census Bureau or private sources that are aggregated using Census geographies, zip codes, or transportation area zones.

The combination of the emergence of GIS technology and the availability of digital Census and other demographic data has inspired a related discussion focused on the issue of data aggregation, spatial incongruity, and data reallocation (Goodchild et al., 1992; Mennis, 2003; Langford and Unwin, 1994; Voss et al., 1999). Census geographies and zip codes don't necessarily conform to geographies that consumers or 
analysts are most interested in such as neighborhood or watershed boundaries; this is what as referred to as "spatial incongruity." The reallocation of one set of generalized data from one zonal system to another is ripe for error without the introduction of ancillary information, or areal interpolation, to produce a clearer picture of the geographic distributions of the original data (Goodchild et al. 1992; Voss et al., 1999). Hence, the flurry of a revival of interest in dasymetric mapping and the use of cells or rasters for analysis and display of demographic data as a first step to data reallocation (Eicher and Brewer, 2001; Goodchild et al., 1992; Mennis, 2003; Langford and Unwin, 1994; Voss et al., 1999).

\section{Dasymetric Mapping and Areal Interpolation: Some Approaches}

According to Eicher and Brewer (2001) a dasymetric map "depicts quantitative areal data using boundaries that divide the mapping area into zones of the relative homogeneity with the purpose of best portraying the underlying statistical surface" (Eicher and Brewer, 2001, p. 125). It is this "best portrayal" of the underlying statistics in the spatial context that is its strength. Eicher and Brewer (2001) suggest that dasymetric mapping and the dasymetric method have, however, become "ambiguous" terms with the emergence of areal interpolation research. The dasymetric method for these researchers is a particular form of areal interpolation that the authors" refer to as the "grid-binary" method. However, cartographers understand dasymetric mapping as a general class of thematic maps that are produced by several methods and go so far as to say that most forms of "intelligent" areal interpolation, 
including Wright's 1936 approach, could be considered dasymetric mapping (Eicher and Brewer, 2001).

Related to the mapping and analysis of Census data in particular, Goodchild et al. (1992) describe a number of approaches to areal interpolation utilizing GIS that have been put forward for consideration. Since Goodchild et al.'s overview, others have been added. Most include the addition of ancillary information to inform the data assignment and all, reviewed here, require the conversion to grid cells. The dominance of the raster approach is due at least in part to its ability to accommodate remotely sensed imagery so important to the inclusion of environmental data as well as the wide variety of cartographic modeling operations (such as grid cell arithmetic, Boolean, and neighborhood functions) available using GIS software (Martin, 1989). Moreover, population density is a continuous function (Langford and Unwin, 1994) for which the raster data model is much better equipped to handle. The approaches that follow are included to provide some context for the decisions that Radin would make for the Equity Atlas project as he moved from the choropleth, vector approach to a raster modeling environment.

Raster modeling without ancillary data: centroids and radial kernal functions. This approach outlined by Goodchild et al. (1992) and proposed by Martin (1989; Martin and Bracken, 1991) uses the centroids of enumeration zones and a gravitydecay function to create a raster surface from the original data. Martin's approach assumes that: (1) a centroid defines a location with above average population density for the local area or enumeration zone for which it acts as the summary point; (2) a 
centroid's population is geographically distributed based on some distance decay function with a finite geographic extent; (3) "regions" may exist in the "population plane" in which there is no population (Martin, 1989). Clearly, the weakness in this approach that lacks ancillary information rests in the assumption that the population is higher than the average population density for the local area at the centroid's location.

Raster modeling with ancillary data: remotely sensed data. Langford and Unwin (1994) argue for the strengths of dasymetric mapping, as opposed to the approach just described, and propose the use of remotely sensed data which is available and can be relatively easily integrated into a GIS because of their raster data structure. The advantage of remotely sensed data, such as Landsat Thematic Mapper multi-spectral imagery, is that they can be classified into land use categories that can then be translated into a simple binary class structure such as "occupied" and "unoccupied" (Langford and Unwin, 1994). Even with the inevitable resolution and interpretation errors unavoidable with imagery of this type, Langford and Unwin (1994) argue that the output is still preferable to the choropleth approach.

Dasymetric mapping and vector-based ancillary data: Eicher and Brewer (2001) are strong proponents of what they consider "underutilized" dasymetric mapping technique for population data. In their examination of five different dasymetric methods, they employ vector land use data from the U.S. Geological Survey which they convert to a grid or raster for the purpose of areal interpolation in a GIS. Using Eicher and Brewer's technique, any reliable land use vector file can be considered viable ancillary data for areal interpolation for this purpose. 
Dasymetric mapping using road networks. Recognizing the drawbacks of vector polygon allocation or "areal weighting" techniques (that allow for the reallocation of data from one polygon to another based on the proportional size of polygon overlap from one system of zonal unit to another) as well as errors associated with the incorporation of remotely sensed imagery using the dasymetric mapping approach suggested by Langford and Unwin (1994), Voss et al. (1999) agree that the dasymetric approach is sound but that a more straightforward and better proxy for population location may be found in the density of road segments and nodes. This approach is based on the assumption that "arcs" or roads located inside of an enumeration zone are an indication of the location of housing units and, therefore, the resident population. The greater the number of arcs or roads (and corresponding nodes or intersections) the higher the population density. Voss et al. tested their basic method for error using arcs and nodes separately, against the two most common approaches at the time, centroid assignment and areal weighting, in rural Census blocks in Crawford County, Wisconsin. Their results suggest that this general approach (particularly that using nodes) does improve spatial interpolation over the other methods tested with some caveats. Because the number of Census blocks chosen for the study was small and predominantly rural, they may not be representative of rural Census blocks elsewhere. However, these authors argue that this approach has an intuitive appeal and ease of use that make it attractive. One major limitation of this approach that the authors do not discuss that is relevant in more urbanized areas is that road density doesn't always indicate residential uses. 
Refinements. Building on the work of Langford and Unwin (1999) as well as that of Eicher and Brewer (2001), Mennis (2003) proposes the addition of empirical sampling to determine the appropriate percentage of source population assignment and an approach similar to Wright's (1936) area-based weighting to address differences in area among ancillary data classes within a given areal unit. Mennis's study incorporates remotely sensed imagery and Census block group population data across a large swath of urban and rural land in southeast Pennsylvania allowing him to assess the reliability of his technique across the urban/rural continuum. Mennis (2003) suggests that although empirical sampling cannot provide a predictive model of the relationship between categorical ancillary data (the classification outcomes of remotely sensed imagery in this case), it is helpful in removing some of the subjectivity involved in population assignments based entirely on the subjective judgment of the analyst (Mennis, 2003). In addition, Mennis's technique of areal weighting to improve the accuracy of the redistribution of population according to ancillary data proved to be effective.

It has been observed that you can't get milk any more detail from an image than it offers in the first place; the information simply isn't there. The resolution or cell sizes of aggregated Census data are the Census geographies themselves. Cartographers and geographers, recognizing the value of incorporating socioeconomic data into their work have been frustrated by the lack of locational specificity of aggregated population data (acknowledging the requirement for confidentiality in the collection of these data). The introduction of GIS technology has made some of 
these techniques, such as Wright's areal weighting method, easier and has made others, such as the incorporation of remotely sensed imagery to areal interpolation possible. All of them offer trade-offs and none can recreate the conditions "on the ground."

The geo-analytical and cartographic complexities outlined above wove themselves into CLF's equity atlas process in ways that were entirely unanticipated. This was largely due to the lack of cartographic experience on the part of the primary PSU GIS analyst and CLF's assumptions about the process that developed out of its highly educated, and in many cases, professionalized membership, a history of selfreliance, and its participatory culture. These assumptions drove CLF to involve itself not only in the problem of defining equity and identifying the variables that would measure equity but to repeatedly question decisions related to the mapmaking itself. And, because this behavior was assumed rather than negotiated up front, it created ambiguous lines of authority and expertise between the Coalition and the technical experts.

\section{Experts, Clients, Mapping, and the Democratization of Knowledge Production}

CLF saw itself as both a partner with PSU and a client - roles that may not be entirely compatible. Initially, under IMS, PSU's role appeared to be more of a partnership in the sense that Ethan Seltzer, then director of IMS, participated with CLF in the early discussions that resulted in the atlas idea and its framing, and also in the sense that the technical work that IMS provided, utilizing a work-study graduate student, was accomplished through a close working relationship with CLF's own 
project lead. The shift of the project from IMS to PRC, however, because of the expert-consultant role that PRC played and continues to play with school districts, municipalities, and other clients, brought the consultant/client nature of the relationship to the forefront. In exploring the complexity of this relationship, one that profoundly impacted the Equity Atlas process and products, it is important to view it both from CLF's point of view as client and partner as well as that of the academic or "expert" consultants. These views were shaped by the evolving nature of expertise and the role that experts play in politics and society as a whole.

In reviewing the historical relationship between liberalism and expertise, Rose (1993) puts forward four features of liberalism that are intrinsically tied to expertise. First, he suggests that although all governments are dependent on "knowledge of that which is to be governed" and have some degree of knowledge about the art of government, liberalism associates government with "positive knowledges" of human conduct that have been developed within the social and human sciences. Activities of government are tied to theories (philosophies of progress, for example), techniques (such as the compulsory medical inspection of school children), and persons with knowledge (accountants, architects, social workers) (Rose, 1993).

Second, Rose (1993) states that liberalism depends on the "subjects of rule" to be active in their own government. As a result, liberal government is dependent on "devices" (such as schools, the domesticated family, the reformatory prison) that have the potential to create individuals who will govern, master, and care for themselves. 
Third, liberal government is inherently bound to the authority of expertise (Rose, 1993). Rose (1993) suggests that from the mid- $19^{\text {th }}$ century, liberal governments in trying to mitigate events (especially those reinterpreted as "social problems") also sought to utilize expertise (to govern at a distance) without compromising its independence. Unlike Larson (1984) who identifies experts themselves as the primary actors in these activities, Rose (1993) argues that liberal governments for their own interests granted authority to experts while simultaneously securing their autonomy through licensure, professionalization, and bureaucratization.

Fourth, liberalism requires a continual questioning of the activity of rule (Rose, 1993). If, according to the tenants of liberalism, "objects of rule" are governed by their own laws (the "laws of the natural"), under what conditions can they be ruled by the "laws of the political"? What provides the legitimacy of authority? Liberalism, through its perpetual self-questioning, asks not whether to govern more, but how to govern better. This question, Rose (1993) argues, must be answered through various technical means; democracy and expertise are two such means.

Moving to the present, Rose (1993) characterizes the new relationship between expertise and politics in advanced liberal government as one of distrust. As a result, advanced liberal government has adopted devices intended to "recreate" the distance between it and other social actors. Whereas expertise had been permitted to establish "enclosures" within which its authority and autonomy could not be challenged, advanced liberal modes of government have replaced the "calculative regimes of knowledge" with the calculative regimes of accounting and financial management 
(Rose, 1993). The audit, Rose suggests, has been one response to the plurality of expertise and "the inherent controversality and undecidability of its truth claims" (Rose, 1993, p. 295), a claim that oddly resonates with the proponents of "Mode 2" knowledge production (Gibbons, 2000; Nowotny et al., 2001; Nowotny et al., 2003), which is socially distributed, application-oriented, transdisciplinary, and subject to multiple "accountabilities" such as the audit - not just the traditional peer review.

With the social upheaval of the 1960 s, experts began to be challenged by various publics who questioned expert claims to special knowledge, their humanitarian ethos, and institutional delivery systems (Haug and Sussman, 1969). These challenges, Haug and Sussman (1969) argue, represented a new stage in the interaction between professionals/experts, and society and one that had the potential to seriously undermine expert views of professional autonomy. This stage they identify as "the revolt of the client" (Haug and Sussman, 1969). Haug and Sussman (1969) focus on the professional/client relationship because unlike the general public that typically stereotypes professions and experts, clients are in the position to recognize the skills of the professional and expert consultant and to grant the required autonomy. Moreover, the power of the professional or expert consultant to determine the best action for any particular case and the autonomy required to do so depend on the consent of the client.

Acknowledging that the composition of the client-publics vary from profession to profession or discipline to discipline, Haug and Sussman (1969) considered for their analysis four cases: the physician/chronic hospital patient relationship; social workers 
and welfare clients; college professors and students; and school teachers and ghetto parents. Their findings revealed significant challenges to authority of these professionals on several grounds. These include: the perceived inadequacy of the expertise; professional claims to altruism were unfounded; delivery systems intended to support professional authority were defective or inadequate; delivery systems were understood to be too efficient and exceeded what clients considered appropriate bounds of authority (Haug and Sussman, 1969). All of these findings challenge the occupational and institutional claims of the professional or expert and go to the heart of professional identity as the "wise expert." Not surprisingly, professional response has tended to be heated resistance ranging from outright repression to subtle cooptation (Haug and Sussman, 1969).

This revolt of the client has coincided with an explosion and dissemination of knowledge (Lopata, 1976). Society has also experienced an expansive growth of occupational experts. However, Lopata (1976) suggests that knowledge monopolization is much less possible with the impacts of mass communication and an increasingly educated public [note: this article was written in the 1970s; the impact of the Internet has undoubtedly accentuated the situation]. Increasingly, Americans refuse to take a passive, unquestioning role in their interactions with professionals. The characteristic demeanor of traditional experts, that of the impersonal, objective, but concerned professional, as well as its asymmetry of self-disclosure in relationship to clients have all been called into question. Strained relations between experts and clients isn't new, Lopata argues, what is new is the changed demeanor and knowledge 
base of many clients who demand a greater level of control over their interactions with experts. Expert-client relations will, Lopata (1976) predicted, become more varied depending on the level of sophistication of both parties in the knowledge for which the relationship is formed. Where applicable, the future of expert-client, expert-expert, and even client-client relations will require a re-thinking of the rules of engagement and, where applicable, a complete overhaul of codes of ethics for new or modified expert roles (Lopata, 1976).

In addressing possible impacts on professionals and experts of the rising educational level of the population as a whole, and therefore potential clients, Wilensky (1964) suggests that the condition presents a paradox: with greater educational attainment comes greater sophistication about professional matters, more skepticism related to the certainties of practice, and the potential for some sharing of professional and expert knowledge, with the possibility that "the mysteries [associated with professionalism and expertise] lose their enchantment" (Wilensky, 1969:150); on the other hand, Wilensky believed that a more educated populace would be more willing to use expert and professional services, an assumption reiterated by Stich and Nibett (1984) in their reflection on the role of experts and authorities in society but with a level of concern:

The role of experts and authorities in our cognitive lives has been all but ignored by modern epistemologists. Yet it is the hallmark of an educated and reflective person that he recognizes, consults, and defers to authority on a wide range of topics.... Indeed, it is our suspicion that one of the principle effects of education is to socialize people to defer to cognitive authorities. (Stich and Nibett, 1984, p. 236-237) 
According to Stich and Nibett (1984), public education systems have promoted the deference to experts and the widespread belief in expertise during the last century. Because of, and in spite of this, Larson (1984), like the anti-liberal arguments of Habermas and Foucault (Turner, 2001, p. 145), suggests that an increasing dependence on scientific and technical expertise promoted in the educational context has, in fact, reduced legitimate citizen participation in decision-making (Larson, 1984, p. 39). In the relationships between experts and their clients all of these things may be true: an educated public while more likely to seek and rely on expertise has also breached the barriers constructed by experts and professionals to protect their own interests. The "client-public" now sees through "the aura of mystery" that surrounds professionalism as a "mysteriousness" that can also be "deliberately used as a tactical device, a means of building prestige and power" (Wilensky, 1964, p. 149). The resulting murkiness of roles of expert-professionals and clients is ripe for both conflict and opportunity.

Put back into the context of liberal political theory, Turner (2001) suggests that the acceptance of expertise, under modern conditions, is the result of genuine public discourse. Liberalism, itself, creates the conditions in which this public discourse takes place. And, these conditions "live in the political decisions we make to regard assertions as open to public discussion or not" (Turner, 2001, p. 145).

In creating its Regional Equity Atlas, what CLF didn't have was reliable (not volunteer) GIS expertise or the cloak of objectivity that a university could provide. CLF hired one of its own founding members and affordable housing expert to head up the Atlas project and enlisted its membership to identify the indicators and variables 
by which equity would be measured. Furthermore, it was always assumed by CLF that it would be its staff and membership that would assess, through focus groups and other means, the effectiveness of the technical experts' work. In doing this, CLF encroached on territory that typically belonged to the community of technical experts exemplifying the trends described in the literature.

\section{Academic Experts and Choices of Engagement}

In his discussion of science in society, Pielke, Jr. (2007) argues that scientists have choices in terms of how they engage with society and describes four "idealized" roles for scientists in public decision-making: the pure scientist; the issue advocate; the science arbitrator; and what he calls the "honest broker."

The "pure scientist" does his or her work without regard to its utility. Scientific findings go "into a reserve of knowledge" where they will be available to everyone, leaving the pure scientist isolated and protected from the business of policymaking. Pielke (2007) suggests, however, that the pure scientist is more a myth than reality.

The "science arbiter" while seeking the neutrality of the pure scientist, recognizes that scientific experts have a role to play in informing policy and, as a result, often engage in questions they consider appropriate to the "scientific" enterprise that come from policy-makers. By focusing on "positive" questions that can be examined through the scientific method, they believe that they can stay above the political fray (Pielke Jr., 2007). 
The "honest broker of policy alternatives" believes in the importance of science informing policy and engages with policy-makers by "clarifying" and "expanding" the choices available to them. Honest brokers often sit on advisory panels recognizing that no single scientist can represent all areas of expertise. The honest broker seeks "to place scientific understandings in the context of a smorgasbord of policy options" (Pielke, Jr., 2007: 17).

The "issue advocate" believes that science must engage in politics and, therefore, aligns him or herself with particular interest groups to actively participate in the decision-making process. Issue advocates can be seen everywhere and represent any number of political perspectives. While sympathetic to the issue advocacy role, Pielke (2007) finds this role concerning, calling it a threat to the others, particularly the honest broker of policy alternatives. This is because the issue advocate often operates in a stealth fashion, masquerading as a pure scientist or science arbiter, to promote a particular agenda. The consequence of this, according to Pielke (2007), is the "reinforcement of the twin trends of scientization of political debate and the pathological politicization of science" (Pielke, Jr., 2007, p. 136) and a potential threat to the credibility of science generally. In arguing that scientists and other experts have choices in terms of if, how, and when they engage in society and policy and politics in particular, Pielke (2007) suggests that they also need to be conscious of the potential impacts of these choices both on science and society.

It is possible to see Pielke's archtypes as a continuum of involvement or engagement with the public from isolation (the pure scientist) to a clear alignment and 
association with at particular interest (the issue advocate). In the context of this study, the academics, rather than adopting a single role for the duration of their relationship with CLF, appeared to have, unconsciously, placed themselves at different times and circumstances at various points along this continuum contributing to a sense of confusion and conflict that plagued the process and challenged the notion of partnership that the parties had adopted without articulating what that would mean.

Even when the idea of partnership between communities and academic institutions is highly valued and seen as a requirement, as in the cases of participatory action research (PAR) and community-based participatory research (CBPR), such partnerships have been found to be difficult. Issues of trust and mistrust, equity and inequity of resources, who benefits, and ownership of data are just a few of the challenges that present themselves in these contexts (Israel et al., 1998; Schoultz et al., 2006). Conflicts can also arise over differences in perspective, priorities, assumptions, values, beliefs, language, funding, the relative importance of tasks and processes, and the time commitment involved (Israel et al., 1998).

In addition, there can be confusion among researchers and community partners about what it means to participate versus what it means to be involved. McTaggart (1991) argues that to participate is to share in the ways in which the research is conceptualized and practiced while mere involvement requires neither. Tandon, according to McTaggart (1991) suggests that determinants of true participation must include agenda setting, data collection and analysis, and control over the use of the outcomes of the process. 
It has been recommended that procedures can be put in place at the outset of research partnerships to mitigate potential conflicts. These include the establishment of operating norms that foster listening, openness, democratic leadership, agreement to disagree, identifying and addressing conflicts, negotiation, compromise, and equality (Israel et al., 1998). But, in order to do this, the research process must first be understood by all of the parties to be a participatory partnership.

\section{Participatory GIS}

The notion of participatory GIS (PGIS), also referred to as public participation GIS (PPGIS), which comes out of concerns about the power of the technology to control as well as its ability to create, store, analyze, manipulate and visualize information, and the power differentials related to all of these capabilities (Pickles, 1995; Sheppard, 1995; Harris and Weiner, 1996; and a host of others) seeks to shift the balance of power relations through the integration of indigenous or local spatial knowledge with "expert" data for indigenous peoples and grassroots communities. And while there is now agreement among scholars as to the relevancy of the concern and the response, debates continue as to the meanings of "public" and "participation" as well as the goals to be achieved and how to achieve them (Dunn, 2007; Schlossberg and Shuford, 2005). By embracing the social, PGIS/PPGIS must accept the "messiness" and "fuzziness" of indigenous or grassroots spatial knowledge (Dunn, 2007), which are antithetical to GIS's underlying conceptual models; despite traditional definitions of GIS that include people as components, PGIS/PPGIS is far more than this conception (Tolluch, 2002 and 2003). 
In 2002, Aberley and Sieber (2002) developed fourteen principles for PPGIS that include associations with community development and environmental stewardship, capacity building, inclusionary and participatory practices (particularly PAR and grounded research), multi-disciplinary approaches, the inclusion of a variety of manual and digital tools and data types (such as oral data and imagery), accessible software, interactive web approaches, life-long learning, and transparency of practice (Aberley and Sieber, 2002). Recognizing that social geographies are in fact "fuzzy, ambiguous and incomplete" (Dunn, 2007, p. 631), Sieber (2004) has suggested that GIS software code be written to accommodate these characteristics. However, conventional GIS software remains dominant in these efforts. And, even though PGIS/PPGIS advocates affirm the importance of community control and ownership of information, the representation of local and indigenous spatial knowledge, the accommodation of fuzzy space, and the democratization of GIS (Dunn, 2007), in spite of attempts to provide participants with multiple ways of interacting with the information (Shiffer, 2002), once information is incorporated into a GIS (such as Talen's, 2000, "bottom-up GIS") it is shaped and filtered by values and points of view rarely apparent to nonexperts. In discussing the "ironic" effects of spatial information technology (SIT) in the developing world, Fox et al. (2006) observe that these "technologies [including GIS] consist of widespread patterns of material and conceptual practices that embody and deploy particular strategic values and meanings" (p. 100). In light of this reality, what participation really means in the typical PGIS/PPGIS context (participation or involvement?) is a very good question. 
A widespread concern has developed among PGIS/PPGIS practitioners about the effectiveness of PGIS/PPGIS projects to promote community agendas or the sustainability of their effects and any skills that are developed - even to the point of questioning the future role of GIS in PGIS/PPGIS in some circles (Dunn, 2007). This is not surprising given the dependency on expert technical capabilities as well as the use of high cost GIS technology (including hardware and software) that are prevalent in PGIS/PPGIS activities as well as the concerns relating to the realities of participatory practices just outlined.

It is worth noting that although PGIS and PPGIS are often used interchangeably, as they are above, they have different emphases. The adoption of the term "PGIS" by some researchers and practitioners, is largely in response to the fact that both "public" and "participation" have broad meanings which, when paired as they are in PPGIS, have led to imprecise definitions as to what is meant by PPGIS activities, inconsistent applications, and incomparable results (Schlossberg and Shuford, 2005). PPGIS activities have been considered everything from extensive grassroots engagement to the display of public records, in a spatial context, on the Internet by public agencies with little or no citizen involvement (Schlossberg and Shuford (2005). As a result, numerous researchers including Jankowski and Nyerges (2003), Tulloch and Shapiro (2003), and Schlossberg and Shuford (2005) have suggested ways in which to come to terms with the multiple meanings of "public" and "publics" coupled with the continua of "participation," - manipulation to citizen control (Arnstein, 1969), informing to ongoing involvement (Dorcey et al., 1994), and 
educating to joint decision-making (Wiedemann and Femers, 1993) - that exist under the PPGIS banner.

To simplify the matter, and assuming that the democratization of GIS is important as a vehicle of empowerment for everyone, some have advocated for dropping the first "P" in favor of an emphasis on the second, participation. It is this assumption that this study adopts with an emphasis on what participatory GIS means in the context of CLF, as an advocacy coalition, and CLF's Equity Atlas endeavor. As previously stated, CLF's Regional Equity Atlas was never articulated as a PGIS project per se, but, as will be shown by this investigation, there were assumptions and expectations on CLF's part that the process would function in a participatory fashion perhaps even to a greater extent than is the case in most explicitly PGIS/PPGIS processes. 


\section{Chapter 3. Methodology}

\section{The Theoretical Framework}

Born out of ongoing efforts within the social studies of science and technology, actor-network theory (Latour, 2005; Callon, 1999; Law, 1992) allows the researcher to see and understand the social as being comprised of interactions among heterogeneous actors that include nonhuman actors. Latour (2005) has called it a "sociology of associations." Actor-network theory can be seen as a systematic way to reveal the infrastructure that is usually left out of the "heroic" accounts of scientific and technological achievements. Actors take shape in relationship to each other and are themselves the result of an actor-network of heterogeneous actors.

Most studies employing actor-network theory as a theoretical frame are case studies focused on opening black boxes that are the products of technology. For example, Law (2002) in a study focused on industrial design, begins with a brochure for a 1958 design for a British military aircraft to uncover the hidden heterogeneities, complexities, absences and presences inherent in technological design. He "magnifies" the mathematical formula for the wing design to see the various relations and factors behind it; the history of the technical terms that are used to label its functionality; the memoranda of its manufacturer describing its effects on the pilots, of wind and speed, and the fear of Russian pilots. In identifying the complexity of relations behind the design, Law was able to describe and better understand the "oscillations" involved in the industrial design process. Like Law's exploration, this study begins with a document. It looks to this document, the Regional Equity Atlas, 
its contents (text, tables, graphs, and maps) to identify the hidden heterogeneities, complexities, absences and presences inherent in the creative endeavor. Specifically, it focuses on the exchanges, the nature of the exchanges and what was exchanged to understand what was left out.

One important concept of ANT, and key to this study, is the notion of the "black box" that "contains that which no longer needs to be reconsidered, those things whose contents have become a matter of indifference" (Callon and Latour, 1981, p. 285). The more science and technology succeed, the more opaque and "blackboxed" they become (Latour, 1999). Black boxes may appear to be sealed but can always be reopened. Maps, particularly computer-generated maps, can be black boxes - as can an atlas. In the case of the GIS-generated maps included in this study, what we see, what they permit us to see, and what we respond to is the result of a myriad of human and technical relationships and negotiations that include not only the map patrons (CLF as an institution and a coalition of community-based organizations, CLF board members, and CLF staff), the authors of the Atlas text, and the analysts, but also the requirements of computers, the GIS software and its makers, and the analytical and display options embedded in it by software designers, the debates of cartographers, the available data, focus group participants, sponsors, the graphic designer and publication constraints, and available funding. Therefore, the maps that are included in the Atlas, and the Atlas document itself, are simplifications of a complexity of relationships. The purpose this study is to reveal the full complement of actors and to "expose the way that translations occur[red] and associations [were] generated" (Doolin and Lowe, 
2002 , p. 73), in other words, the complexity of relationships that formed not only the Atlas document but possible effects of mapping projects on nonexpert advocacy organizations and their expert partners.

The Regional Equity Atlas project could be studied in a number of ways. What ANT allows the researcher to do is to fully take into account the socio-technical nature of this mapmaking and map use endeavor. A full accounting of this process isn't possible without the acknowledgment of the roles played by GIS technology and data forms in what the software permits and doesn't permit and what the resulting maps allow a user to see and not see independent of the intent of the GIS analyst, CLF, or the authors of the explanatory text.

This case study also embraces Del Casino Jr. and Hanna's (2006) notion of “map space.” For Del Casino Jr. and Hanna (2006), map spaces exist where “[m]aps that people simultaneously make and use mediate their experience of space" and where both map users' physical experiences of place and understandings of landscape and places are guided and informed by the superficial and "innumerable intertextual and experiential references always present in any map" (p. 44). Map spaces are, by definition, "always partial and contested sites" that reveal the inseparability of representation and use (Del Casino Jr. and Hanna, 2006, p. 44). Map space (consisting of maps, people, ideas, and places) is a type of actor-network, and with regard to this study would be considered a "sub" actor-network to the overall actor-network that comprises the "actor-world" (Callon, 1999, p. 20). 
It must be acknowledged at the outset that the author of this study was staff at the Institute of Portland Metropolitan Studies (IMS) at Portland State University for the duration of the Equity Atlas process and was peripherally involved in the early discussions between IMS and CLF about the project and later when the decision was made to move the project from IMS to PRC. The author also conducted a survey of participants for CLF of two Equity Atlas rollout workshops in 2007 in anticipation of the publication of the Atlas document.

\section{Data Collection}

\section{Methods}

As ANT dictates, there is no a priori assumption as to the scale or hierarchy of the actor-networks involved here - the world is flat according to ANT (Latour, 2005). ANT, methodologically, has two major approaches and both are qualitative: one follows human actors through interviews and ethnographic approaches; the other follows "traces" and examines "inscriptions" (images including maps, texts of all kinds, databases, presentations, etc.). In this particular case, the net could have been cast either very broadly or more narrowly. Detail and nuance are essential, thus, the number of actors, human and nonhuman, were limited to those who were immediate to the Equity Atlas endeavor. Some were identified at the outset of the study and others were identified through snowballing as the initial interviews and the examination of artifacts revealed additional critical actors.

The process began with an examination the Atlas document including its maps, text, tables, and graphs to establish authorship including the nonhuman contributors 
such as the data and software components involved. From this list of authors, the initial list of interviewees was established. These included: Ken Radin, the GIS analyst for the Atlas; Tasha Harmon, founding member of CLF, consultant/ initial Atlas author and equity framer; Ethan Seltzer, former IMS director and initial PSU lead; Jill Fuglister, then Co-director of CLF responsible for the Atlas; Irina Sharkova, PRC and later PSU principle investigator; Jim Labbe, Portland Audubon on loan to CLF for the Equity Atlas project; Alex Campbell, consultant to CLF and primary author after Harmon left the project; and Steve Johnson, PSU staff and active CLF member during the early phases of the Atlas project. Based on these interviews additional interviews were conducted with Ron Carley, Co-director and founding member of CLF; Zack Semke, CLF's first coordinator; and Kris Smock, consultant with CLF during the later stages of the Atlas project and designer of the Equity Atlas rollout strategy. With the exception of Sharkova, who relocated to Olympia, Washington, all of these interviews were face-to-face and digitally recorded. In the case of Sharkova, the interview was by telephone and digitally recorded. In addition, an email questionnaire was sent to Ryan Sullivan, who was in 2008 based in Boston and was the graphic designer for the project. Finally, for technical clarification regarding the Kirwan Institute's Opportunity Maps approach, an informal telephone interview was conducted of Jason Reece who developed the Opportunity Maps methodology. He provided the relevant literature cited in this study.

The interviews were in-depth and semi-structured. An interview guide (Rubin and Babbie, 2001) was developed that included the same set of background questions 
for all of the interviewees. Questions included: their professional background and training; when and how they came to know about CLF; when and how they got involved with CLF. The interviewees were also asked a set of open-ended questions regarding their particular roles in and contributions to CLF and/or the Equity Atlas project and their perceptions of the process and product. In the cases of Radin and Sharkova, questions probed the technical aspects of the project including their approaches to GIS, the process of modeling, and data issues. The interviewees were also given the opportunity to explore in detail any issues they believed to be pertinent. In addition, the Atlas document was made available for reference. Each of these interviews lasted as long as either the interviewee had time for or as long as he or she had something to say. They were at a minimum of one hour, most ranged from one to two hours, and in the case of Radin, two, one and one-half hour interviews were conducted on two consecutive days.

In addition, all of the interviewees were asked to make relevant documentation available if possible. Radin, who is a meticulous record keeper, provided literally hundreds of documents electronically including all of his email exchanges for the duration of the project, meeting memoranda, clarification documents, Harmon's equity framing documents, most of his map iterations, and his and Fuglister's PowerPoint presentations. Nearly all of these documents were dated, in the file name, the email stamp, or the in the attachments. His documents proved to be a treasure-trove and the depth of research and analysis in this study would not have been possible without them. Jim Labbe provided documents relating to Metro's Regional Greenspaces Bond 
Measure. Steve Johnson provided academic papers he had written related to CLF.

CLF provided access to their Board minutes and other relevant documents including a copy of its commissioned history by Walljasper that was produced in 2000. And, Kris Smock made available all of her documentation related to the Equity Atlas community rollout sessions including her focus group feedback and the PowerPoint presentations and scripts that she'd developed that were shown in these sessions. Documents relating to ESRI's GIS ArcView 3.x software, that was used for the Atlas, were accessed online.

\section{Data Analysis}

Latour (2005) recommends an approach to ANT research and data analysis that is akin to qualitative data analysis procedures outlined by Creswell (1994) that allows for a high degree of interactivity with the data and is inductive in approach where themes emerge directly from the data (Patton, 1980). Latour (2005) suggests that four notebooks be kept. The first is a log of the inquiry itself. The second is a notebook for gathering information in such a way that it is possible to simultaneously keep all of the items in a chronological order and to categorize them that evolve over time into greater levels of refinement. The third notebook is kept on hand for "ad libitum" writing trials - there should be continuous sketches and drafts (Latour, 2005, p. 134). The fourth notebook, and perhaps particular to the ANT approach and beyond the scope of this study, it is recommended, should be kept to "kept to register the effects of the written account on the actors whose world has been either deployed or unified. This second experiment, added to the fieldwork itself, is essential to check how an 
account plays its role of assembling the social. The study might be finished but the experiment goes on ..." (Latour, 2005, p. 135). The first three of these notebooks were kept although they became hybrids of handwritten and electronic notations.

To assist in the categorization of data from the interview transcripts, these data were entered into the Atlas.ti (v. 6) content analysis software tool and coded. Coding was performed using the constant comparative method advocated by grounded theorists and categories developed from which a theory can be derived (Glazer and Strauss, 1967; Stauss and Corbin, 1990). Specifically, Atlas.ti's open coding options, including vivo codes that use the interviewees exact words, were utilized. Atlas.ti "families" were then created that combined to create broader categories of data. This process also allowed for the identification of several of the direct quotes included in the study narrative. However, this tool could not easily provide either temporal ordering required or the level of detailed pairing of text to map images and other content that were essential to understanding the interactions and translations among the actors. For these tasks, Latour's notebook approach proved more effective. Thus, Atlas.ti proved most useful as an in-depth screening tool for the interview data that pointed to key themes that guided the overall analysis.

It should be pointed out that other documentary evidence was not entered into Atlas.ti. These include email correspondence, meeting memoranda, CLF Board minutes, explanatory documentation, PowerPoint presentations, and the maps. This is due to the fragmentary and incomplete nature of much of the textual evidence, particularly the email correspondence and Board minutes, and the nontextual quality 
of the imagery. Although Atlas.ti developers suggest that the software may also be used for image content analysis as well as for text, given the large number of maps that had to be analyzed for this study, this approach proved to be awkward and timeconsuming. Once an historical chronology was established, a manual visual inspection/comparison approach focused on the motives, means, legibility of paper, PowerPoint, or pdf versions of the maps in the context of and relationship to the other evidence was found to be far more nimble.

While it would have been illuminating to have been able to do ethnographic observations of the ways in which the participants in the Equity Atlas process interacted with the maps throughout the process, these were not possible. Instead, these interactions were reconstructed through the recollections of the interviewees, documented observations, PowerPoint presentations, and the ways in which the maps were transformed over time.

The approach to analyzing the maps that this study takes is worth some additional discussion. This study takes a critical approach to cartographic or map analysis. This means that rather than seeing maps as neutral conduits of objective truth to the map consumer (sometimes referred to as Robinsonian cartography) they are understood as active; that they, according to Crampton and Krygier (2006), "make [emphasis in the original] reality as much as they represent it...instead of focusing on how we can map the subject...[we could] focus on the ways in which mapping and the cartographic gaze have coded subjects and produced identities" (Pickles quoted in Crampton and Krygier, 2006, p. 15). Maps are creatures of political, historical, and 
social contexts in which they themselves participate. As ANT suggests, they are actors and actor-networks. What this means is that they must be examined and interpreted not only in terms of the political, historical, and social contexts broadly speaking but in relationship to the intended purpose and means of their production; the effects of the means of production; their legibility and effectiveness in relation to their original purpose; and the effects that they appear to have had as social actors independent of their intended purpose.

\section{Trustworthiness of the Data}

According to Bowen (2005), Denzin and Lincoln suggest four factors that should be considered in ascertaining the trustworthiness of findings of qualitative research. These are credibility, dependability, confirmability, and transferability. Transferability, or the confidence that other researchers have to apply the findings of the study to their own, is dependent on the other three factors. The primary means of assuring the credibility, dependability, and confirmability of the data was through triangulation or corroboration. When there appeared to be disagreement among the data, follow-up questions were asked of interviewees, and/or further investigation into additional evidence was conducted. Where there was no supporting evidence, the data were eliminated from the study but this was a rare occurrence. Using these criteria, the evidence appeared to be trustworthy. Additionally, all interviewees reviewed their interview transcripts for accuracy and were invited to make corrections or additions if they desired to do so. 


\section{Limitations of the Study}

In terms of design, methods, and findings, this study has limitations. This qualitative case study is entirely dependent on interviews and various types of documentary evidence. Although every effort was made to gather and evaluate as much evidence as possible within the study's scope, the evidence is, admittedly, incomplete. And, although a nearly complete record of the mapping process and the responses of most of the key actors were made possible by Radin's meticulous recordkeeping and his willingness to share them, documents relating to CLF and other actors in the process were less complete, inaccessible, or nonexistent. Moreover, the authorship of some of the documents wasn't always clear even after extensive investigation. Authorship is important to identifying possible bias. However, it was rare when such a document was central to the study and so these were not often included.

Limitations also include possible interview respondent bias resulting from selective or faulty memory, responses to the human subjects notification which all interviewees read and signed, and the presence of a recording device (that was used only if indicated by affirmation on the human subjects form - all agreed to this). In addition, the interviewees had different levels of involvement in the process with different functions at different times. This means that their evidence must be partial. The study was purposely limited in terms of timeframe and actors in order to provide depth and nuance; these limits, along with the large amount of documentary evidence that was provided by the interviewees meant that a great deal of attention could be 
dedicated to triangulation and filling in the holes from multiple sources to create a more complete picture.

The strength of this study is its depth that was made possible by the generosity of the interviewees in terms of their time, interest, and willingness to share their experiences, observations, and the large number of documents that provided real insights into the project's gyrations and social interactions.

\section{Sequence of the Narrative}

It should be noted that although the research itself began with the Equity Atlas document that was published in the summer of 2007 , the narrative is written chronologically to document the social interactions of the actors as they developed over time. 


\section{Chapter 4. A Coalition for a Livable Future: the Pre-Atlas Years The Birth of a Coalition}

It could be said that CLF was born of maps. When Robert Liberty, then executive director of 1000 Friends of Oregon, brought Myron Orfield to Portland to speak in 1994, Orfield captivated his audience by a notion and an argument he called, metropolitics, buttressed by a striking display of maps. Using cluster analysis to group places with "common characteristics of social and political need and locally available tax sources" (Orfield, 2002, p. 9), Orfield created a simple blue to red dichromatic typology to reveal often stark inequities across regions. Central city decay, according to Orfield, was a function of a disjointed, competitive, metropolitical dynamic that was out of sync with the essential functional totality of regions. The economic and social success of places, Orfield suggested, lay in a cohesive, visionary metropolitics built on fiscal equity (between city and suburb), land-use reform (to promote sustainability), and accountable regional government (Orfield, 2002, p. 173).

The argument was ripe for Portland. The Portland metropolitan area had established the only elected regional government in the nation, Metro, in 1979. With jurisdiction over transportation, waste disposal, parks, and water quality for Portland's tri-county area, in 1994, Metro was engaged in its first major long-range planning effort, Region 2040. Many who attended Orfield's talk were inspired to apply its logic to Portland. 
For this event, Liberty had invited friends and associates, mostly activists engaged in land use, urban design, the environment, and affordable housing reform - people who knew and admired each other's work but who, until then, had largely focused on single issues. Orfield's maps provided an epiphany for many attendees that resulted in a reexamination of their advocacy efforts in the context of Metro's Region 2040 planning process that suggested an approach that would promote the integration of represented issues and a collaboration of efforts instead of the inevitable competitive approach to affecting policy. Among those who attended Orfield's presentation was long-time community activist, Steve Johnson, who describes his and other's reaction this way:

It was like, here's a way, visually, with a map, to mobilize the inner city and the outer suburbs. This was the first key issue that political mobilization could be around - the inequalities in the region - there was an unfair distribution of resources. (Johnson, 2008)

Soon after, interested parties came together in a series of meetings sponsored by 1000 Friends to educate each other about their areas of concern, build trust, and to brainstorm strategy. In addition to 1000 Friends of Oregon, represented organizations included the Audubon Society, the American Institute of Architects (AIA), the Bicycle Transportation Alliance (BTA), and the Community Development Network (CDN), organizations that formed the steering committee for what would become the Coalition for a Livable Future (CLF). Johnson (Johnson, 1998b) has described this emerging coalition as a "learning organization" (Kofman and Senge, 2003) because it provided a "space" where people could: 
...talk from their hearts and connect with one another in the spirit of dialogue ... When people talk and listen to each other this way, they create a field of alignment that produces tremendous power to invent new realities in conversation, and to bring these new realities in action.

(Kofman and Senge, 2003, p. 21)

Part of this learning was the realization that powerful interests had instituted, what CDN executive director, Tasha Harmon called a "divide and conquer" strategy to defeat progressive advocacy efforts (Harmon quoted in Walljasper, 1999, p. 5). Working together to support each other's issues could provide a formidable force to defeat that strategy and create a new reality for the future of the region.

Over the next several months, the dialogue continued and the group's membership grew to 25 organizations including 1000 Friends of Oregon, the Audubon Society, the Community Development Network, the Urban League of Portland, the Oregon Food Bank, the Ecumenical Ministries of Oregon and the Willamette Pedestrian Coalition. In late 1994, the group drafted a set of principles that identified their common ecological, economic, and social goals (Walljasper, 1999) to promote livability throughout the region. The Coalition for a Livable Future announced itself on November 28, 1994 when it presented a comprehensive set of amendments to the Metro Region 2040 Growth Concept (Johnson CLF draft paper, 1998a, p. 7).

\section{The Coalition at Work: The Shaping of a Plan}

After this initial burst of activity and in preparation for the next phase of Metro's long-range planning process, the development of the Region 2040 Framework Plan, it became apparent to CLF's steering committee that the Coalition needed someone who, at the very least, would provide some level of administrative support 
(Carley, 2010). The situation was seen as urgent enough that the Coalition managed to put together enough funding to hire a half-time, coordinator position in early 1995. In addition, 1000 Friends offered to provide office space for the new hire and add the position to its payroll (Semke, 2010). With funding and office space in place, CLF hired Zack Semke, a recent Stanford graduate who was doing volunteer work with Pete Bartholemew, 1000 Friend's transportation policy expert, to be the Coalition's first coordinator. Quickly more funds were raised and Semke's position became fulltime (Semke, 2010).

As is required in the very early days of any organization, Semke's initial tasks were primarily administrative: scheduling meetings, record-keeping, accounting. But as Semke's advocacy skills became apparent and the needs of the organization became more pressing (related to the dictates of the 2040 Framework timeline), Semke took on the role of CLF spokesperson (Carley, 2010). Lisa Jackson was then hired in a halftime position to provide administrative support.

Although, during the period CLF was housed by 1000 Friends, and Semske and Jackson were on 1000 Friends' payroll, this arrangement was purely a technicality (Semke, 2010). CLF was not a division or department of 1000 Friends. Instead, funding for CLF's work came from the Coalition members in the form of membership dues and the procurement of grant dollars. What 1000 Friends contributed beyond the other members was the contribution of office space and a pass-through capacity to distribute those funds for the purpose of financing CLF's administrative functions. 
Key to CLF's identity, during its early years, was the decision not to incorporate: the formality that would be imposed by incorporation was seen as a hindrance to the vitality of relationships that had emerged among the members. They didn't need a legal mechanism to keep them together. Semke puts it this way:

One of the things that, from my perspective, was really special about the Coalition was that it really was a coalition....that it didn't exist unless the people, unless the organizations came together.

(Semke, 2010)

The lack of the kind of organizational structure that would have been required under a 501(c)3 incorporation, for example, meant that the membership had to have tremendous trust in each other and was completely dependent on each other's organization's willingness to participate to get things done. And, getting things doneresponding to the 2040 Framework Plan opportunity - required money for research and public outreach, as well as administration.

Lacking nonprofit status meant that CLF could not be a fiscal agent for grants. As a result, CLF created a means by which it would assign fiscal agency to whichever of the member organizations seemed most appropriate (Carley, 2010; Semke, 2010):

There was tremendous trust around the table, so who would be the fiscal agent, I think, came down to funding strategy - who would be the most attractive organization to be seen as the lead by a particular funder. And, so, sometimes that was 1000 Friends of Oregon, sometimes it was Audubon Society. (Semke, 2010)

And so, for example, a major Meyer Memorial Trust grant went through the Audubon Society, and the Ford Foundation and HUD grants that funded much of the 2040 Framework policy work, were funneled through 1000 Friends (Semke, 2010). Using 
this technique, between 1995 and 1998 (when Semke left CLF), the Coalition raised approximately \$2 million (Semke, 2010) some of which paid for a full-blown metropolitics analysis of Portland by Orfield, Portland Metropolitics: A Regional Agenda for Community and Stability, published by CLF in 1998. And, although the publication of this report came after the conclusion of Metro's 2040 planning effort, some of the maps that were included in the report but released prior to its publication were used by CLF to aid in its efforts to influence the plan (Carley, 2010).

As far as the distribution of grant-awarded funds went, a remarkable generosity of spirit developed among the membership through this fundraising process that went far beyond strategy. Founding member, a then Audubon Society staff member and current CLF co-executive director, Ron Carley, describes it this way:

When we received a grant - when we found out who [which of the member organizations] got it - there would be a sit-down, a discussion. There would be just flat out times when we'd say, who needs the money the most? ... There were a couple of times where we said, well, we could always use more money, we always need money but we're doing better right now and I think the housing folks really need it. Clearly, we'll take a smaller share or no share and they should get the money.... That is unheard of. (Carley, 2010)

Carley (2010) believes that this sense of generosity based on a deep level of trust among the members that was developed in the Coalition's formative stage has had a long-lasting impact on the organization's sense of itself and its survival.

Trust was also critical to the extent to which in-kind contributions were made by the member organizations. For example, CLF's Urban Design "working group" recruited twenty-six architects to donate their services to improve the design of 
rowhouse development as an affordable housing strategy in response to neighborhood opposition for aesthetic reasons. The Transportation Reform working group of members created a public education campaign that was funded in part by municipal and state agencies to encourage commuters to use alternative transportation one day a week (Walljasper, 1999).

With a funding strategy and mechanism in place, CLF's process of selfeducation and identification of common values and goals prepared it well for the collaborative approach to advocacy that it would take to influence the direction of Metro's Region 2040 Framework Plan. Housing advocates now understood the importance of riparian protection to the livability of the region, for example, and vice versa. As a result, CLF could turn out large numbers of people across constituencies to advocate for its commonly held positions. Affordable housing advocates filled the Metro Council's hearing room to testify in favor of wetland protection and environmentalists did likewise to promote the adoption of a fair share housing policy for the region. Sometimes, members' enthusiasms got the better of them:

... it was a really heady experience for affordable housing advocates to have environmentalists helping them with their work and vice versa. If anything, they were at loggerheads sometimes at the hearings because they hadn't talked to each other beforehand. (Semke, 2010)

Simultaneously, Coalition members organized training sessions for community members wanting to participate in the 2040 planning process. They sponsored a region-wide public forum on affordable housing. And with the Ecumenical Ministries of Oregon, CLF staged a rally to draw attention to the beneficial effects of the 
metropolitan urban growth boundary (UGB) on the availability of affordable housing (Walljasper, 1999).

The result of CLF's first foray into the policy arena was impressive. Mary Kyle McCurdy, staff attorney at 1000 Friends of Oregon, estimated that out of 15pages of recommendations related to land use, transportation, and housing that CLF presented to the Metro Council, two-thirds were adopted in 1997 into the 2040 Framework Plan (Walljasper, 1999:4).

\section{Early Challenges}

While CLF, by nearly every measure, was enormously successful during its 2040 Framework Plan phase, it faced challenges in two key areas: organizational structure and membership composition. The first relates to the nature of the organization itself: the coalition form of relationship and organizational life-cyle issues. The second relates to the social and political climate in the Portland region, particularly around issues of race and class.

\section{Structural Challenges}

One key challenge that all coalitions encounter is an inherent dual-allegiance that member organizations face between the goals and objectives of their primary organization and those of the broader coalition of organizations (Butterfoss et al., 1993; Mizhari and Morrison, 1993). In spite of the remarkable collegiality that was demonstrated by members in the funding arena, this type of conflict is cited in CLF's own history, Coalition for a Livable Future: Working for a just and sustainable region (Walljasper, 1999). The Association of Oregon Rail and Transit Advocates' (AORTA) 
objected to what it feared would be CLF's support for the proposed South-North light rail line, a proposal that it believed had been compromised by political deal-making. To address this potential breakdown among the members, a special meeting was set up to discuss CLF's public position. Although the CLF membership ultimately decided to endorse the rail line, AORTA members were satisfied that their objections had been aired and despite this disagreement, continued its membership in CLF. The mention of this, perhaps, momentary conflict by CLF in its own history is not only a recognition of the potential damage that such conflicts can inflict on a coalition but also a reassurance that it could, in fact, overcome such challenges if the member organizations' positions on critical issues were adequately vetted and consensus reached before taking a public position of its own.

CLF has also acknowledged that some observers questioned CLF's decision to maintain a highly decentralized organizational structure with no executive director as well as its dependence on autonomous working groups and member organizations to strategically and substantially influence policy across three counties (Walljasper, 1999:11). The suggestion here is that the organization would not be able to sustain such an ambitious agenda without a more formalized structure. But while CLF was focused on the 2040 Framework policy work, that, alone, seemed to provide enough momentum to move the Coalition forward.

As stated earlier, there was a strong belief, especially among the founding members, that there was an extraordinary power in the voluntary nature of the coalition and the mutual dependence and trust that had developed among the 
membership to get things done. It had produced an excitement and energy that was often missing when organizations are consumed with the legal formalities of nonprofit status.

Additionally, Walljasper (1999), in his history of CLF, mentions that the organization struggled with self-promotion. There was mounting concern among some members during the latter part of the 1990s, that the organization had not adequately leveraged the media and educational opportunities to promote its message and itself (Walljasper, 1999, p. 11). Whether or not this concern was related to the lack of structure in the organization is debatable but it is clear that the notion of selfpromotion as opposed to issue or policy promotion was antithetical to the culture that had developed in CLF.

\section{Race and Class}

The second challenge CLF faced during this period was recruiting and successfully engaging organizations representing low-income and racial and ethnic minorities, especially African Americans. According to Semke (2010), from the beginning:

There was a real commitment among the steering committee members to make sure there was representation from the African American community - the community that was, when we were talking about inequity and the faster rate of sprawl, the faster the rate of disinvestment in the urban core, and those issues - the Urban League was a logical organization at the time. (Semke, 2010)

At CLF's invitation, the Urban League agreed to join in the Coalition's efforts to affect Metro's policies related to issues of particular concern to the African American 
community: affordable housing, urban neighborhoods, and urban disinvestment. The partnership was made essentially ineffective by life-threatening struggles internal to the Urban League that would cause its eventual collapse. However, CLF didn't stop with the Urban League. CLF added outreach positions to its staff specifically to engage communities of color. But, ultimately, CLF's desire for inclusivity was challenged by "who" it was as well as "who" Portland was at the time:

I think there's just a natural thing - Portland's a white town; it was more white then than it is now. And, the main players in the Coalition were white, even Mike Pullen, who represented the Urban League, is white. So, there's this natural obstacle to overcome in terms of working with people of color. (Semke, 2010)

The trust that had developed among the membership during CLF's infancy was profound. It was a trust that had been easily built out of a sense of mutual respect and excitement over the realization that together they were going to be able to affect widereaching and long-term change in the region. Most of the participants were white and middle-class. But convincing historically marginalized racial and ethnic minority groups of this and the opportunity that the 2040 Framework Plan represented was much harder:

I think that the policy work and dealing with disinvestment and that kind of stuff, those aren't white issues, but the messengers were. And, so, that's part of the challenge is to overcome that and that takes a lot of work and a lot of outreach and trust-building and relationship-building that takes time. (Semke, 2010)

In addition, the Coalition came to believe that many of the issues that it had focused on, especially environmental protection and the provision of affordable housing in the suburbs, seemed distant to inner city residents just trying to survive (Walljasper, 1999, 
p. 9). The problem was, in Semke's words, "[w]e were so policy wonkish, you know" (2010).

\section{Challenges Revisited: Organizational Identity}

I think that 2040 and the Regional Framework Plan had a really [emphasis is Semke's] important role to play. I mean it was part of the special opportunity that we had - the fact that we were able to find common cause and a common vision to come together as a coalition. But equally important was that we had Metro, a directly elected government with real power that happened to be going through this incredibly important planning process. And, so, the work was responding to those opportunities at Metro to a large degree. ... The secret to the success of the Coalition at the beginning was that we had a clear target for all of our work. (Semke, 2010)

Undoubtedly, the collaborative approach CLF took to influence the 2040

Growth Framework Plan, that emerged out of Orfield's 1994 presentation, achieved a great deal more than would have been the case if each organization had worked independently. But, over time, the challenges that CLF was experiencing within the organization suggested the necessity of self-reflection. A March 1998 [this is the date on the file but Carley thinks it dates from late 1997] document, titled "CLF Self Assessment-External" appears to be the result of a brainstorming activity among members focused on the Coalition's perceived strengths and weaknesses (table 4.1). 
Table 4.1. CLF Self-Assessment

\begin{tabular}{|c|c|}
\hline Strengths & Weaknesses \\
\hline Formed diverse/impressive coalition & Not perceived as a "real" organization \\
\hline $\begin{array}{l}\text { Integration of issues and work across lines and } \\
\text { testimony impressive }\end{array}$ & $\begin{array}{l}\text { Tend to preach to converted, need to reach } \\
\text { businesses, local planners in government and } \\
\text { private sectors }\end{array}$ \\
\hline Communication between members exciting & Insufficient regional presence \\
\hline Attempt to articulate common good, common vision & Lack of racial diversity \\
\hline Public recognition of CLF significant & Lack of suburban representation \\
\hline $\begin{array}{l}\text { Learning to be successful at influencing policy within } \\
\text { existing framework }\end{array}$ & $\begin{array}{l}\text { Lack of representation from low income } \\
\text { neighborhoods }\end{array}$ \\
\hline $\begin{array}{l}\text { Religious conference good step in grassroots } \\
\text { outreach }\end{array}$ & $\begin{array}{l}\text { Confusion between stands of individual } \\
\text { organizations and CLF }\end{array}$ \\
\hline $\begin{array}{l}\text { Developing strong regional vision and agenda } \\
\text { articulating the connections well }\end{array}$ & Lack of interaction with rural organizations \\
\hline Successfully influencing Metro policies & $\begin{array}{l}\text { Tend to work within limits of existing system. } \\
\text { Need to work/think outside system and bring } \\
\text { these ideas to a broad audience }\end{array}$ \\
\hline Accomplished a lot with very limited resources & Not reaching a grassroots base \\
\hline Consistent in tracking/influencing Metro & $\begin{array}{l}\text { Need to engage constituency of member } \\
\text { organizations better }\end{array}$ \\
\hline Diversity lets us cover lots of issues & Very little media coverage \\
\hline $\begin{array}{l}\text { Resource for member organizations on issues they } \\
\text { don't usually understand }\end{array}$ & No real influence on state legislative issues \\
\hline $\begin{array}{l}\text { Provides us an opportunity to support each other's } \\
\text { work }\end{array}$ & Lacks organizational methodology \\
\hline $\begin{array}{l}\text { Opportunity for communication between member } \\
\text { organizations }\end{array}$ & Speakers too limited a pool \\
\hline $\begin{array}{l}\text { Built relations and levels of common knowledge and } \\
\text { trust }\end{array}$ & Lack of a strategic plan \\
\hline Support of each other across issues & $\begin{array}{l}\text { Weak channels of communication from CLF } \\
\text { representatives to members of individual } \\
\text { organizations }\end{array}$ \\
\hline \multirow[t]{6}{*}{ Great resource for involvement in policy issues } & $\begin{array}{l}\text { Lack of consistent report to membership on } \\
\text { activities }\end{array}$ \\
\hline & $\begin{array}{l}\text { Member organization participation is } \\
\text { inconsistent and often limited }\end{array}$ \\
\hline & Lack of coherent outreach strategy \\
\hline & Mission and objectives too general \\
\hline & Need clearly articulated and vivid vision \\
\hline & Need better distribution of information \\
\hline
\end{tabular}

Source: CLF, 1998.

The strengths identified here are not only central attributes of coalitions in general but are central to their survival (Butterfoss et al., 1993). While CLF

acknowledged challenges to the organization in the aftermath of its Region 2040 
successes (Walljasper, 1999), this exercise in self-reflection reveals a profound crisis of organizational identity during this time. Confusion among members about its vision, mission and goals, a lack of a coherent strategy, the inability of the organization to enlist a more diverse membership, insufficient lines of communication (internally and externally), conflict among members and the uneven participation of the member organizations, and the lack of a public identity as an organization are all mentioned here.

The quest for identity is not inconsequential for organizations. It can be difficult to address and is most often avoided until the effective functioning of an organization is at risk (Albert and Whetten, 2004, p. 90). An organization's identity affects its values and mission; it affects the choices an organization makes. The quest for an organizational identity can also be linked to where the organization is in its lifecycle (Albert and Whetten, 2004). Immediately after the Region 2040 period, CLF's members seemed to be adrift - without a well enough articulated rationale and strategy for moving forward.

Albert and Whetten (2004) suggest that organizations must be able to articulate their identities and that an adequate statement of organizational identity should contain three criteria: (1) the criterion of "claimed central character;" (2) the criterion of "claimed distinctiveness;" and (3) the "criterion of claimed temporal continuity" (2004, p. 90).

The criterion of claimed central character is understood as features that are the "essence" of the organization. Key to CLF's early identity is its name: Coalition for a 
Livable Future. It has a subject (the coalition), and implied action ("for"), and an objective (a "livable future"). It says what it is (a coalition of organizations), that it will act, and what it will act to promote (a "livable future").

While it is true that CLF, early on, developed a set of principles that provided more precision to these very ambiguous terms as a response Region 2040, after the incorporation of much of what it had advocated for into the Framework Plan, there appears to have been a need to carve out an identity that could live beyond that process. After Metro's Framework Plan was adopted, the membership did ask the question of whether or not to continue but the assumption had always been that CLF would go on and the answer to that question was affirmative (Carley, 2010).

The criterion of claimed distinctiveness is associated with features that distinguish the organization from similar organizations. In CLF's case, its distinction is the coalition approach to advocacy not its articulated objective. Furthermore, the Coalition had consciously made the decision not to compete with its members by incorporating itself. Thus, it was thought of, by its membership, as a true coalition with a small "c."

The criterion of claimed temporal continuity points to organizational features that endure over time (Albert and Whetten, 2004). Indeed, the loss of identity can threaten the life of organizations just as it does with people. Albert and Whetten (2004) indicate that the question of temporal continuity has particular importance at the formation stage of an organization, at the loss of an identity-sustaining element such as a dynamic leader, the accomplishment of an organization's raison d'être, 
during extremely rapid growth, a change in "collective status," and retrenchment. Two of these life cycle points are of particular interest with regard to CLF: first, the formation stage of the organization and, second, the accomplishment of the organization's raison d'etre.

It is worth noting that the Coalition emerged out of a catalytic event (Orfield's metropolitics presentation) and the resulting process of informal dialogue focused on an opportunity to affect policy, collectively, in the context of Metro's Region 2040 planning effort. CLF's identity in its formative stage was partly proactive - a coalition to affect change - and partly reactive to Metro's government driven planning process and objectives. The founding organizations were already engaged in regional planning policy with staff members who in their own realms understood and spoke the language of planning policy. In fact, they were policy "wonks" (Carley, 2010; Johnson, 2008; Semke, 2010), who once they found Orfield's metropolitics framework, leapt at the chance to learn about each other's issues to affect regional change. But the urgency to coalesce came from the real power Metro had to affect the region for the long term through its planning authority. The 2040 Regional Framework Plan dictated the issues; Metro, itself, was the target (Semke, 2010) around which CLF's identity formed and thrived.

The adoption of Metro's Regional Framework Plan in December 1997 marked a turning point for the organization. Semke, who had led CLF through this remarkable period with all of its successes in affecting policy and fundraising, recognized that it was time to move on. He liked to create things, be there at the beginning, and take 
them to the next level; he had done that for CLF. Semke was offered just such an opportunity at Portland Taiko and he couldn't refuse. Besides, as Semke put it, "I left at the cusp" (2010).

CLF lost its coordinator but it also lost the thing that had shaped everything it had done. The absence of the Regional Framework planning process with its hearings and deadlines left a vacuum that had to be filled if the organization were to continue. The vacuum also created a space where many of the concerns and insecurities that had been there all along came to the surface and challenged the Coalition's sense of self as evidenced in the circa 1998 self-assessment document. Internally, there was plenty of unfinished business.

Soon, however, Coalition members realized that the target (Metro) hadn't gone away, it had only changed its focus as it moved into implementing the approved plan. Just as CLF had "shadowed" (Johnson, 1998c) Metro's planning process, the Coalition would now monitor Metro's implementation of the policies that CLF had worked so hard for inclusion. CLF flirted (Carley, 2010) with what it called the Metro Monitors Program and tried to recruit community members in various jurisdictions throughout the region to see how some of the goals, objectives, and requirements in the 2040 Plan were being implemented at the local level but this was found to be untenable with the capacity that CLF had at the time (Carley, 2010).

CLF became, for awhile, a kind of catchall for a number of different policies and projects that came up (Carley, 2010). It was during this time that the organization began to toy with applying for its own 501(c)3 nonprofit status so that it would be less 
dependent on others to act as the fiscal agent for its work. It had become increasingly difficult to find organizations willing to take on the role of fiscal agent since funders frequently confused CLF with its member organizations (member organizations often applied for two grants from a foundation, one for CLF and the other for its own purposes) when awarding grants (Carley, 2010). And, it was also during this time of transition that CLF began, much more intentionally, to use sustainability, rather than livability, as its goal employing the notion of the 3-Es of sustainability (economy, environment, and equity) to organize its work plans.

A new phase for the Coalition was slowly emerging. Jill Fuglister was hired to replace Semke as CLF's coordinator in late 1998. In 1999, CLF applied for 501(c)3 status and was officially incorporated in February, 2000 - an incorporation that had been resisted and seen as undesirable six years earlier, now seemed to provide an opportunity for fiscal independence and organizational stability.

By 2000, CLF was comprised of nearly 60 organizations advocating for regional livability but many of the organizational "weaknesses" identified by its members in 1998 persisted. Perhaps most important, in terms of the CLF's own values, was the paltry participation of people of color. CLF began to see that equity, one of the three essential pillars of sustainability, could provide an opportunity for the Coalition to explicitly dedicate itself to issues of race and class rather than planning per se. 


\section{Chapter 5. Framing Equity}

\section{3-E's of Sustainability}

Prosperity, fairness, and a healthy environment are interrelated elements of the human dream of a better future. Sustainable development is a way to pursue that dream through choice and policy.

(President's Council on Sustainable Development, 1996)

The publication of Sustainable America: A New Consensus for the Prosperity, Opportunity and a Healthy Environment for the Future in 1996 not only represented the Clinton administration's national action strategy for sustainable development but it helped to popularize a notion of sustainability that is comprised of three essential and interrelated elements: a healthy environment, a vital economy, and social equity more commonly referred to as the three pillars of sustainability or the 3-E's.

A New Consensus (1996) grounded the dream in a set of sustainability goals and indicators to measure progress toward achieving the goals over time. The indicators were also intended to suggest what information should be gathered and examined recognizing that the indicators could change over time as the nation moved toward achieving the goals and the science and policy options underlying them evolved (President's Council on Sustainable Development, 1996, Chapter 1).

Such a framework had instant appeal to a broad, largely progressive constituency because of its comprehensive nature and the tangibility it offered to the otherwise amorphous notion of sustainability. As CLF struggled with a sense of purpose and identity after the adoption of Metro's 2040 Regional Framework Plan in 1997, the importance of sustainability in general but particularly framed as the 3-E's 
began to emerge in discussions among its members. Sustainability had always been fundamental to their notion of regional livability but the 3-E language offered an opportunity to be more explicit about the connections between the various interests represented in the Coalition.

Metro's 2040 Growth Concept and Framework planning process, which had been the catalyst for the creation of CLF, had been largely framed in the language, processes, and procedures of land use planning and economic development. Planning concepts and tools such as mixed-use zoning, the development of multi-modal transportation policies, jobs-housing balance, urban-rural transitions that reduce sprawl, and urban growth boundary management drove the Region 2040 Growth Framework process and largely shaped how the Coalition thought about itself. Founding CLF member and current co-executive director, Ron Carley (2010) put it this way:

...early on in CLF's lifetime, the very explicit focus was on good progressive planning policy around land use, transportation, environmental protection, and housing. Equity was an implicit value that really simmered under the surface around generally what could be presented as smart growth or new urbanism... (Carley, 2010)

It's not that the notion of sustainability and its three pillars were absent from its members' thinking but, at the time, sustainability, particularly social equity, wasn't overtly on the agenda that CLF was responding to. The emergence of the 3-E framework, after the completion of CLF's Regional Framework Plan involvement, allowed CLF to think anew about the issues at hand and to see its agenda through a 3E lens. 
By the time Orfield contacted the Coalition in 2001 about contracting for a possible update to the 1998 Portland Metropolitics report (an idea triggered by the upcoming release of the 2000 Census data at the census tract level) CLF had begun to think about itself differently. While the Coalition could see real value in an update, especially given the speed at which the Portland metropolitan region was changing and the desire to hold Metro's feet to the fire in terms of its implementation of the 2040 Framework Plan, engaging Orfield would require a significant fundraising effort. Given the necessary level of commitment and a changing view of its needs, CLF's Board began to consider the option of engaging local partners to go beyond "metropolitics" to specifically address questions driven by its membership.

By this time, CLF was comprised of approximately 60 member organizations, with various levels of engagement, representing interests in environmental concerns, land use and urban design, affordable housing, transportation, faith communities, environmental justice, and minority groups. As CLF adopted the promotion of sustainability into its worldview, the lack of any real analysis specifically related to social equity in the region became evident. And this was an issue that the Coalition's Board and staff were particularly sensitive to. CLF, since its inception, had struggled first to enlist and then to engage groups representing racial and ethnic minorities in the context of the 50-year regional planning exercise that was the focus of the organization's early efforts.

While equity was always intrinsic to the work, the reality was that the most engaged members had been middle class and white even when advancing the interests 
of communities of color (Carley, 2010; Semke, 2010). It took Orfield's proposal to trigger the Coalition to revisit what had been so successful in Orfield's metropolics analysis (the power of maps and spatial analysis) to engage its membership and the larger community in an explicit exploration of the state of equity in the region.

Once the decision was made by the CLF Board to move forward, Fuglister began an intense fundraising campaign. CLF Board member and Milwaukie City Councilman, Brain Newman, who was a "map geek" (Fuglister, 2008) and wildly enthusiastic about the idea of the project, had his own idea about its use. According to Fuglister (2008):

... he called me the next day and he said, "I think we could make this a fundraiser. We could do something that was sort of, you know, short and with maps. And, I think we could market it to the jurisdictions who would be key users of the data, and they could pony up some money to help make it happen." And so it was, like, great, because we always need fundraising ideas. (Fuglister, 2008)

Newman's idea was that the best way to demonstrate the value of the project would be to generate some maps at the outset believing that the maps would sell themselves. At the suggestion of then Clackamas County commissioner, Michael Jordan, who was also a CLF Board member, Fuglister and Newman began to ask county and city governments to contribute to the project. The rationale for this strategy was the assumption that local governments would quickly recognize the utility of such a project. Clackamas, Clark, and Multnomah counties as well as the City of Portland did sign on, each with a $\$ 5,000$ contribution, during this early phase of the project. In addition, Jordan encouraged Fuglister to approach Ethan Seltzer at 
the Institute of Portland Metropolitan Studies (IMS) at PSU about the possibility of partnering with CLF to provide the GIS services for the project (Fuglister, 2008).

By late 2001, CLF had been able to generate enough financial support for its equity initiative that Fuglister and the CLF Board felt that with the support of Coalition members, partner organizations, such as PSU and PolicyLink, and volunteers, the project could move forward. Fuglister would oversee the project but it was understood that the project would probably be too time consuming for her to take it on by herself given her other responsibilities.

After consultation with the Board, Fuglister decided to enlist Tasha Harmon who had been a founding member of CLF, a CLF Board member, and an affordable housing expert to the effort. It seemed that Harmon would be a good fit since she was known to be a big picture thinker, had helped CLF to frame equity in the past (Harmon, 2008) and was a good writer (Carley, 2008). As executive director of the Community Development Network (CDN) and as an affordable housing advocate, Harmon had also gained experience in developing consensus and mobilizing a variety of players including volunteers, skills that Fuglister knew would be essential to the project. Harmon had left CDN some years earlier, was doing some consulting work, and was always looking for meaningful projects (Harmon, 2008).

\section{An "Equity Atlas"}

CLF wasn't the only organization in Portland, during the late 1990s, to adopt a 3-E's schema to frame its agenda. Ethan Seltzer, long-time friend to CLF and director of the IMS, quickly understood the advantages of its application as an effective 
organizing principle behind the Institute's annual work plans. By 1998, Seltzer had aligned the Institute's projects with the three pillars of sustainability.

To address the economy, Seltzer developed what became the New Economy Observatory to "fundamentally understand the economy from the standpoint of where and how you might make strategic choices or interventions to affect the development of the economy in the region" (Seltzer, 2008).

In terms of the environment, Seltzer determined that there was a tremendous amount work already being done locally by a number of well-organized groups, including 1000 Friends and the Audubon Society, and that the Institute wouldn't need to expend its resources there. Equity, Seltzer believed, was not only poorly understood but wasn't being addressed well in the region (Seltzer, 2008).

Like sustainability, equity means many things to many people. Seltzer felt it was important to look at what others had done and the processes that they had gone through to tackle equity's meaning and application before launching an IMS equity initiative. Former Portland Planning director and Cleveland city planner, Ernie Bonner, immediately came to mind because of his work, under Norman Krumholz, on Cleveland's ground-breaking Comprehensive Plan in the 1970s:

I went out and interviewed Ernie Bonner because I wanted to hear what Ernie had done in Cleveland to raise equity as an issue that would become an organizing principle for the Cleveland Comprehensive Plan. And, that was really, really helpful because what Ernie and the folks in Cleveland had gone through was a process to try to understand what it meant to address equity as a planning issue. What does it really mean? What are we trying to do when we address equity? Is it about everybody gets the same? Well, no, it's not really about that. Is it only about poor people? Not necessarily. (Seltzer, 2008) 
In 1974, Cleveland's Planning Commission came to the conclusion that the urban crisis in Cleveland had little to do with land uses, zoning, or urban design (with their emphasis on efficiency), rather, the core of the crisis lay in the fundamental inequities embedded in the life of the city. Rather than creating a conventional city plan, the Commission developed a "catalog of objectives, policies, and action programs" intended to address the issue of equity head on (http://www.pdx.edu/usp/planpdxorg-cleveland-policy-plan). This process required the Planning Commission to clearly articulate what equity meant in the context of Cleveland and how that could be translated by Cleveland's planners into specific policies and action programs to make a better city. Fundamentally, equity was defined by the Commission by the notion of choice and the availability of choices for those with the least access to it:

Equity requires that locally-responsible government institutions give priority attention to the goal of promoting a wider range of choices for those Cleveland residents who have few, if any, choices.

(Cleveland Policy Plan, 1974)

The primary goal was to design city policy and programs that could provide "as wide a range of alternatives and opportunities as possible, leaving individuals free to define their own needs and priorities" (Cleveland Planning Commission, 1974). In a very real sense this new emphasis turned planning on its head. In Cleveland, city planning was now about developing a policy environment that would create a "more equitable society, not ... a more efficient political or economic system" (Cleveland Planning Commission, 1974). 
The work of the Cleveland Planning Commission resonated powerfully with Seltzer and it was the Commission's argument for equity and its application to urban planning policy that Seltzer would adopt to shape his thinking about the Institute's contribution to planning. Seltzer began to explore how the Institute could engage in this poorly understood and nearly invisible facet of public policy:

So, we started playing around with the notion then of what we could be doing to address equity. We had been working on the idea of the Community Geography Project [CGP] - the idea of neighborhoods being better able to tell their own story. And, so, the idea of beginning to try to figure out how to map equity became the organizing principle for what we were trying to do with equity. (Seltzer, 2008)

This experiment with GIS and mapping by, for, and of community organizations confirmed Seltzer's belief that maps and mapping could, indeed, provide important insights to the workings of neighborhoods and community desires in a regional context and opened up new possibilities in Seltzer's mind. Seltzer was fascinated by the concept of the thematic atlas and he collected them and shared them with the CGP staff to suggest possibilities for future projects. From its inception, the CGP focused much of its work on the production of maps and collections of maps that explored community issues and told community stories.

In late 2002, when Fuglister and Harmon met with Seltzer to explore a possible partnership to provide GIS expertise and fundraising support for CLF's new equity initiative, it was Seltzer who suggested that the result could be in the form of an atlas rather than a report. And it was Seltzer who coined the term, "equity atlas." (Fuglister, 2008; Harmon, 2008; Carley, 2009; Seltzer, 2008). 
It was also during this formative period of the project that CLF enlisted the help of PolicyLink, a relatively young organization, based in Oakland, California that, like CLF, was focused on research and action around issues of regional sustainability and equity but at a national level - in developing the Equity Atlas idea. PolicyLink's publications, to this point, were primarily driven by text and statistics and not maps. And, while CLF wanted to learn from PolicyLink's approach to the analysis of regional equity, it wanted to take a distinctly different approach in terms of output.

\section{Framing an Equity Atlas}

Harmon was intrigued by the challenge of mapping equity but accepted the Equity Atlas project reluctantly. Nobody to her knowledge had attempted anything like it; there would be a lot of uncertainties:

I was fascinated by the concept but I was also really clear that we had no idea what we were getting in to - that there was no way that we could have an idea until we were in it. And that working with a big pool of volunteers is not simple. And, that it was going to take more time and more energy and more money than any of us thought it was going to. (Harmon, 2008)

Immediately, it became clear that there were two tasks at hand. First, Harmon had to determine precisely what CLF wanted in terms of a product. After the meeting with Seltzer the notion of an equity atlas had a nice ring but what would it really mean? Clearly, it would support CLF's advocacy agenda but how? But at a basic level Harmon understood that the document would be map-driven and visual:

... the idea was to do a document that would look specifically at equity and would use maps to tell the story because we wanted it to be really 
visual and we wanted it to both work at the level of "let's look at the region as a whole geographically" and allow people in specific jurisdictions to drill down. (Harmon, 2008)

Second, CLF would have to come to consensus on the meaning of equity and the implications of mapping equity. Seltzer had indicated that, from his point of view, the Equity Atlas would succeed or fail based on the clarity of the equity framework that CLF would articulate and adopt. In addition, being well-acquainted with CLF's collaborative and participatory culture, Harmon understood that the CLF membership would want to weigh in on every substantive aspect of the project, especially how equity would be framed.

For much of the first half 2003, Harmon focused on developing a draft framework for the effort. It was understood that the audience for the Equity Atlas was key to determining what the product would look like. By March 2003, Harmon's framing documents indicate that CLF determined that the audience for the Atlas would be broad with varying levels of sophistication and expertise: CLF members; targeted constituencies particularly schools, economic development organizations, planners, planning commissions, neighborhood associations, social justice and social action organizations; business leaders; Metro Council and the Metropolitan Policy Advisory Committee; and local elected officials and local government staff.

For Harmon, getting the frame right was critically important and she agonized over it (Harmon, 2008). Her early framing documents provide a glimpse into CLF's aspirations for the Atlas project as well as its concerns as it walked into unknown territory. They also reveal how Harmon and the small Atlas team, that surrounded the 
project, used the Atlas framing arguments to persuade the larger Coalition and potential partners and funders of the relevance and importance of equity to the Coalition's mission and to the region as a whole. The documents span from March 2003 to August 2003 after which there was very little change to CLF's equity framework.

In these documents, Harmon approaches the overall frame by addressing three core elements of the work: (1) identifying the purpose of the Atlas; (2) defining equity; and (3) identifying maps and map layers to be included in the Atlas. The first two elements compose the frame that shapes the third of these elements. What follows is a more detailed discussion of each element.

\section{The Purpose of the Atlas}

When Harmon was recruited to work on the project she understood that CLF's vision for the effort was centered on utilizing the power of maps to visually convey regional equity. CLF's Board, particularly the founding members who had been most influenced by Orfield's work, was convinced not only that mapping would reveal the inequities that they knew were present in the region but that, based on their experience utilizing Orfield's work in advocating for their positions in the 2040 Framework Plan, it would be an effective way to engage policymakers and the general public in the issue. Harmon's earliest draft suggests this as it describes what the Atlas will do:

The Regional Equity Atlas will create a visual portrait of equity conditions related to growth and development in the four-county Portland-Vancouver metropolitan area... (Harmon, March 2003a) 
By describing the Atlas as a visual portrait, emphasis is placed on the maps it is the maps that will tell the equity story. And it is an equity story specifically linked to the issues that were central to CLF's identity during its formation: the impact of growth and development on the region.

Harmon goes on to say that this visual portrait will set the stage for “...regular updates to track regional equity trends over time." There are two things that stand out related to this statement. First is the connection between tracking and the monitoring role that CLF adopted for itself after the completion of the 2040 Framework Plan. The statement also suggests a longterm commitment by CLF to an effort that, at the time, it knew very little about. When CLF hired Orfield to produce the Portland Metropolitics report, it bought into Orfield's analytical framework and was essentially engaged in a client/expert relationship where CLF was the client and Orfield, the nationally acknowledged expert. In this new endeavor, however, CLF was striking out on its own and starting from scratch. It did not know what to expect in terms of commitment of time and resources for the baseline study let alone what future updates would entail. Harmon would say, in retrospect, that the level of ambition indicated by striking out on its own and the long-term commitment suggested here was indicative of a kind of naivety and optimism that was characteristic of CLF from the beginning (Harmon, 2008).

Harmon's first draft also suggests that there would be two related documents, not just one, with somewhat different purposes: 
The Atlas and accompanying Report will also propose strategies for addressing the regional disparities between communities sharing a common geography, ethnic/racial background, age or economic situation that are illustrated in the maps. (Harmon, March 2003a)

The Atlas would make plain the issues by illustrating regional disparities through the graphical quality of the maps with the assumption that there would be a primarily textual document or "report" that would provide a response to the findings of the maps by suggesting strategies to address regional disparities in the policy arena. Thus, the Atlas and the accompanying report would explicitly associate the revealed disparities with development tools that promote equity - an approach that specifically ties the impacts of urban growth to the concerns (transportation, land use, parks and natural areas, economic development, affordable housing) that had characterized those of CLF's membership from the beginning - regional livability:

The central goal is to demonstrate clearly that access to resources and opportunities and the ability to have a range of choices in how and where we live, work, learn, travel, and play and what we eat are core elements of regional livability. To this end, we will map equity indicators for transportation, land use, parks, trails and natural areas, economic development, housing affordability and stability, community health and food security to reveal existing inequalities and provide analysis of the maps that links disparities with regional equitable development tools. (Harmon, March 2003a)

This central goal would be achieved by addressing two questions:

1. To what degree is access to the benefits of regional change and the outcomes of regional decisions to manage regional change limited for locations and populations?

2. What can be done to create better conditions for access by all people and a more equitable distribution of costs and benefits across a wide range of communities? (Harmon, March 2003a) 
While it might appear that the first of these questions is diagnostic and explicitly spatial and the second, policy-oriented, both questions have inherent spatial characteristics that could lend themselves to spatial analysis and mapping.

Again, it is worth noting that equity is defined not only in terms of access to benefits generally but specifically to benefits related to regional change and the results of the policies related to regional change. Equity is tied to urban growth and the region's growth agenda - areas that CLF was experienced in. Moreover, as far as the development of the Atlas was concerned, the emphasis on understanding the ramifications of change over time would have major implications, when the data collection and mapping phases began, that were not adequately appreciated when the framing documents were written.

By August, 2003, the primary purpose of the Atlas had been transformed from an illustrative portrait into a quantitative tool that would measure gains and losses related to equity over time. In fact, the illustrative portrait language that described what the Atlas would do, disappears all together in favor of:

The Equity Atlas is designed to measure how far we are from being "an equitable region" and, over time, whether we are moving towards or away from that goal. (Harmon, August 2003b)

The Coalition understood that the strength of its advocacy efforts rested in large part on the credibility of the analysis it was utilizing to make its arguments. Because Orfield was a widely recognized expert in regional economic and political analysis, there was never any question about the strength of his analyses or the validity of his findings. This time, however, even though the communicative power of maps had 
driven the early thinking about the Atlas, the notion of the visual portrait as a guiding principle was seen as not robust enough and/or lacked the clarity that would ensure the level of rigor that CLF hoped for.

\section{Definition of Equity for Mapping}

In Harmon's earliest framing draft, she prefaced the definition with an

argument for the Atlas effort in the context of the 3-E's of sustainability and planning:

Currently, equity, as it relates to the region's dialogue about sustainability and long-range planning, is not well understood. While regional objectives for the physical environment and the economy are top priorities and fairly clearly understood, regional objectives for equity are practically non-existent. (Harmon, March 2003a)

Like Seltzer had before her, Harmon not only was suggesting that of the 3-E's, equity is the least understood but she was implying that the regional government, Metro, had neglected to grapple with it and make it a priority in its long-range planning efforts.

The audience for this argument was the CLF membership as it summons the Coalition's watchdog role in its relationship with Metro.

She went on to put equity, and by extension sustainability, in the context of population growth and development to suggest that we ignore regional equity at our peril:

If we continue to ignore equity, the costs of leaving a significant portion of the population behind will degrade overall quality of life and undermine our region's long-term prosperity and sustainability.

(Harmon, March 2003a)

Seltzer believed strongly that, as in the case of the Cleveland planning process, the Equity Atlas project should not move forward without a well articulated understanding 
of what an equitable region would look like in this region. Harmon attempted to do this by defining equity in terms of three key aspirations: First:

An equitable region is one where all residents have access to the means for identifying and taking advantage of opportunities for advancing well-being of their households. Of particular concern is widening the range of opportunities for those currently having the fewest choices for where to live, advancing skills, achieving economic well-being, accessing nutritious, affordable food, accessing parks, recreational trails and natural areas, and increasing wealth.

(Harmon, March 2003a)

By focusing on access to the means for identifying and taking advantage of opportunities rather than simply access to opportunities, the aspiration appears to support CLF's role, not only as an advocate, but as an educator and facilitator. It seems to suggest that the revelatory power of the Atlas itself would be one of the means by which residents would be able to identify and take advantage of opportunities. This aspiration also begins to articulate the specific indicators related to choice that were being identified by the CLF membership at the time. Second:

An equitable region is one where the costs of growth and/or change borne by a community are commensurate with the benefit the community receives from growth and/or change.

(Harmon, March 2003a)

This aspiration addresses the necessity of the adoption of an equity position, as far as CLF was concerned, by Metro with regard to its regional growth policy agenda. It also articulates the necessity of a temporal approach to analyzing potential impacts on equity. 
Third:

An equitable region is one where all communities are meaningfully involved as full and equal partners in regional planning decisionmaking. (Harmon, March 2003a)

By this time, notions of participatory decision-making and inclusion were deeply embedded in Oregon politics and planning culture but Harmon was acknowledging how difficult meaningful involvement of all communities is to achieve. This particular aspiration was one that CLF had struggled with internally since its inception and was seeking to remedy with the Equity Atlas project. This first draft of an equity definition remained intact throughout Harmon's tenure and its key ingredients are evident in the published Equity Atlas.

\section{Maps and Timeframe}

Once the goals for the Atlas had been articulated and equity defined, indicators, data, and types of analysis could begin to be identified. According to Fuglister (2008) and Harmon (2008), this was a participatory process that included CLF's members and was begun as soon as the project was initiated.

The March 2003 framework draft identifies six maps or mapping tasks that would result in the final Atlas document. Four of these are "synthesis" maps that combine multiple map layers into one. The remaining two are really categories of mapping (demographic and transportation) that would produce multiple maps.

Demographic characteristics maps. The key demographic variable to be mapped was poverty and every subcategory of poverty that the Census and other data 
sources could offer. Also included in this list were educational attainment, tenure and migration, crime, employment, and primary language (Harmon, March 2003a).

Regional accessibility maps. This series of maps were to portray:

...regional transportation access (by mode), parks/recreational trails/natural areas, access to healthy, water-based recreation, distribution of housing by cost and housing cost burden, housing development by type, job creation by industry and types of job, school conditions/quality, current and recent shifts in percentage of students on free or reduced lunch programs, training/life-long learning opportunities, regional food access... (Harmon, March 2003a)

This potpourri of things represents the feedback from CLF members about what they wanted to see in the Atlas. This is a wish-list of what could be.

Synthesis maps. The dominance of this approach is the recognition, early on, that equity is a multifaceted issue that no single variable would be able to explain. It is also a response to some of the early diagnostic census variable mapping that was proceeding in the background during the framing process. Ken Radin (a PSU graduate student who became the GIS analyst for the project) was generating a multitude of census demographic maps at the time that were difficult to make sense of separately. It was determined by Harmon and Radin that the only way to succinctly convey notions of need, capacity, opportunity, and action was through creation of multivariable indices. The March 2003 framing document identifies four "synthesis maps" that were intended to provide a snapshot of three dimensions of regional equity being explored and a grand total composite of the three to create a concluding "Equity Action Map." They are: 
- A Regional Opportunity Map. A synthesis of the accessibility maps "to create a composite view of the opportunity "geography" of the region;"

- A Populations in Need Map. A "synthesis of the demographic maps to identify the locations of populations in need;"

- A Community Capacity Map. Draws from Orfield's work "to portray the tax capacity, fiscal health, service levels, and other characteristics of the capacity of communities to respond to needs of people living there;"

- An Equity Action Map. A synthesis of the populations in need map, the regional opportunity map, and the community capacity map "to yield a comparison of the accessibility to opportunity and distribution of the benefits of growth with the economic and social conditions of communities." (Harmon, 2003a)

This index approach also recognized CLF's assumption that the Equity Atlas would be short in length. All in all, this would be a very ambitious agenda if the Equity Atlas team were to meet the anticipated print date of May 2004.

For the better part of the year, until late December 2003, Harmon, the mapping team (that included Radin, Seltzer, a small group of GIS professional volunteers, with consultation with PolicyLink), and interested members of the Coalition attempted to provide greater clarity to the data collection and mapping process by creating, during a number of work sessions, a series of "an equitable region is ..." statements for the key variables. In a December $27^{\text {th }}$ document for that year, certain census variables were explicitly identified for "base" mapping under a definitive statement of purpose: 
In an equitable region, being low-income, of a certain ethnicity, under 18 or over 65 , or not having access to a car, would not limit your access to basic necessities, or threaten your basic quality of life.

(Harmon, 2003c)

Under a "Quality of Life/Access Indicators" heading:

In an equitable region: the total housing stock would reflect the actual income mix in the region; all jurisdictions would have a diverse mix of housing, reflecting the demographics of the region as a whole.

(Harmon, 2003c)

Under "Access to Quality Education:"

In an equitable region: all children in the region would have access to high-quality public schools; by extension, all public schools in the region would provide a high-quality education; these schools would be succeeding with all different kinds of kids, kids of all income, races, mother tongues, family configurations, etc. (Harmon, 2003c)

Under the "Transportation Access" heading, after consultation with Bruce Watts and

Amber Ontiveros at Trimet's Diversity and Transit Equity Division:

In an equitable region, an equitable transportation system would: equally prioritize efforts to revitalize poor and minority communities in addition to expanding infrastructure; ensure benefits and burdens from transportation projects; provide high quality service to low-income and minority communities... [and other things based on the availability of data]. (Harmon, 2003c)

Under "Access to Greenspace:"

In an equitable region: every household would have similarly easy access to public parks and open spaces, regardless of where they live...

(Harmon, 2003c)

At this point there was some question about how to articulate ecosystem function into the equity statement and it doesn't appear. Under "Access to Food:"

In an equitable region: all neighborhoods would have full service grocery stores of clusters of stores providing all of the foods full 
service grocery stores provide at comparable prices; low income people in need of emergency assistance could access free food without traveling inordinate distances for needing a car.

(Harmon, 2003c)

Feeling less confident about the final key area of interest, health, it was decided to postpone the development of a "framing story" (Harmon, 2003c) for it. Instead, at Fuglister's recommendation, the approach would be to ask healthfocused questions that were related to the issues "in which we have expertise and are mapping [in any case]" (Harmon, 2003c).

There was one important area that nagged at Harmon from the beginning economic opportunity. In the December 2003 document, Harmon questioned whether mapping unemployed people at fine levels of geographic resolution was even possible and suggests that the jobs category was fraught with "definitional and story issues" (Harmon, 2003c). The omission of jobs-related maps was a major criticism when the Atlas was finally published.

An additional problematic area was the proposed "Democratic Participation" section. Here the problem wasn't the development of an equity story, An equitable region is one where all communities are meaningfully involved as full and equal partners in regional planning and decisionmaking. (Harmon, 2003c)

But, as Harmon said, "[t]his is not the sort of information that lends itself to mapping, or even to statistical analysis" (Harmon, 2003c). For nearly a year, Harmon and Radin had struggled together to come to terms in the mapping environment with one of the simpler datasets available, the newly released Census 2000 Summary File 2 
database, and the reality of the challenges of exploring some of the less well defined and less overtly spatial issues was becoming daunting. And, so, rather than attempting to map civic involvement, Harmon suggested that democratic participation would be best dealt with through a qualitative case study approach - the Interstate Corridor Urban Renewal Area decision-making process (Harmon, 2003c).

\section{Process-related Goals}

CLF had additional process related goals that are worth noting that shed light on the organization's stress on the importance of process and belief in the power of the maps to generate enthusiasm and motivate users to act on its agenda.

In a memorandum to CLF's Board and staff dated August 26, 2003, Harmon talks about a goal for the Atlas of creating an "Aha Moment" that would identify or create more people who would be actively committed to CLF's objectives and would engage in advocating for those objectives.

In terms of the Equity Atlas process and the iterations of maps that were being generated during that process, Harmon outlined three goals: (1) to see how see how well the diagnostic maps (that were being created during the framing process) "speak" to people and identify any other maps that might be included; (2) to hear how the maps relate to the notions of equity held by diverse groups - a ground-truthing exercise in effect; and (3) create more people who are "eager to see and use" the final product (Harmon, 2003b). 


\section{Some Observations}

Orfield's invitation to update Portland Metropolitcs (1998) arrived at a critical time in CLF's organizational life-cycle. The Coalition emerged in response to Metro's Regional 2040 Framework planning process and had formed its identity in relationship to it. At the wildly successful completion of that process, at least as far as the adoption of CLF's agenda was concerned, the Coalition had to decide first, whether or not to continue as a coalition, and second, what the work would be and how to stay motivated in the absence of the deadlines and benchmarks that were intrinsic to Metro's 2040 Plan development. The logical place to find the answers to these questions was Metro - CLF would follow Metro’s planning process into implementation and its new role, like 1000 Friends, would be one of watchdog.

The aftermath of the adoption of the Framework Plan was also the time when CLF began to much more explicitly promote the notion of regional sustainability and it used the 3-E framework to do so. That framework suited CFL well not only because two of the three pillars (the environment and the economy) were areas in which the membership was already deeply engaged but the third, equity, was one that it had struggled with, organizationally, from the beginning.

In addition, CLF's deep knowledge of the 2040 Framework Plan made the Coalition more aware than most of the inadequacies of the Plan related to explicitly defining equity for the region and the development of policy that directly spoke to achieving and equitable region. The combination of the watchdog role that CLF had adopted for itself, its new focus on equity, and the possibility of exploring and 
addressing regional equity using the revelatory power of maps that had inspired the creation of Coalition in the first place and had mobilized it to do its work during its heyday was an itch that had to be scratched - in spite of the fact that it had no experience in this realm.

But, this had always been the spirit behind CLF. Semke (2010), Harmon (2008), Carley (2010), and Fuglister (2008) have independently observed that CLF is eternally optimistic and youthful in its enthusiasms - "adolescent" is a word that was used. And, Harmon would add, "naïve." It is with all of these qualities that the organization would dive into a process that would occupy it for four years. 


\section{Chapter 6. Diagnosing Equity}

The Atlas is, essentially, a mapping project - that is, the primary tool we will use to raise awareness about equity issues is a series of maps ...

(Harmon, CLF Equity Atlas Summit Presentation, 4/3/2004)

We thought, it's a map, you know, how hard could it be?... We knew nothing, or just enough to be dangerous, basically.

(Harmon, 6/23/08)

\section{Realities and Abstractions}

For the lay audience, a GIS is often described as a series of geographically referenced and registered map layers. Each of these map layers represents a particular theme or category of data such as rivers, city boundaries, schools, census tracts, and streets. Because of the mathematics that are built into each layer, spatial relationships associated with the distribution of phenomena and their relationships to each other can be analyzed both within the individual layers and across the set of layers, known as overlay analysis. Generally, what we see as a single map that has been produced by GIS technology is, in fact, the compilation of many single-layer thematic maps.

This concept of layering was central to the early thinking about how to make the Atlas usable, fun, and intuitive. Harmon, Seltzer, Radin, and volunteers from the professional GIS community, notably Mark Bosworth from Metro, Glen Bolen from the urban planning firm of Fregonese-Calthorpe, and Rafael Gutierrez, from Fishman Environmental Consulting, toyed with the idea of creating an atlas that would be a literal translation of overlay analysis into physical form:

... we had this idea that the Atlas was going to have a transparency in it that was the poverty map. The poverty map was a placeholder. We weren't quite sure exactly which map it was going to be. It would be 
something like household income or percent of people in poverty or something that told the income side of the story - that could be overlaid on every other map. (Harmon, 2008)

The idea was that by overlaying a poverty-related transparency onto every other map or variable in the Atlas, people would be able to instantly see where the inequities were greatest in the region. The mapping team saw this approach as innovative with the potential of drawing a larger audience to the document than Orfield's Portland Metropolitics (1998) report had done.

When Harmon signed on to the project, she understood, because of the budget constraints, that the GIS expertise would be provided by multiple parties, some paid and some volunteer. The assumption was that Portland State University (PSU) (either through the Geography Department or the School of Urban Studies and Planning) would provide students with graduate-level GIS training, and that volunteers from the local professional GIS community would come forward to work on the Atlas. And, in fact, early on this was the case. Mark Bosworth from Metro's Data Resource Center who had a strong interest in public participation GIS volunteered, as well as Glen Bollen from Fregonese-Calthorpe and Rafael Gutierrez from Fishman Environmental Consulting. Additionally, PolicyLink, in California, agreed to provide consulting support for the project.

It was anticipated that because PSU students, especially during the summer, could potentially dedicate considerably more time to the effort than the professional volunteers, PSU would take on all of the demographic analysis for the project. The professional volunteers would be responsible for the "access" variables including 
transportation and natural resources, areas in which Metro had substantial expertise and data.

Because of Seltzer's commitment to equity in his own work at IMS and his early involvement in the conceptual phase of the Equity Atlas, the Institute of Portland Metropolitan Studies (IMS) was the logical place for CLF to turn for access to students with GIS expertise from PSU. One student, Ken Radin, jumped out not only because he was enrolled in the Masters in Urban and Regional Planning (MURP) degree (associated with the School of Urban Studies and Planning, the school in which IMS was housed) and had GIS training, but he was familiar with CLF having written a paper about the Coalition for a course at PSU and was supportive of both Coalition and the idea of the Atlas. What clinched the deal was that Radin qualified for work/study funding which meant that his work would be essentially free to the Institute. In early 2003 , Radin officially became a work/study student at the Institute specifically dedicated to working with Harmon to provide the demographic mapping for the Atlas using census data and any other demographic data that might come available.

In terms of his GIS expertise, Radin has called himself a "radical" and at the point he began his work on the Atlas, "a young pup, just out of school [undergraduate], I thought I could do whatever I wanted to [in terms of GIS]" (Radin, 2008a); he was superbly confident of his ability to deliver. Before coming to PSU, he received a bachelor's degree in Environmental Science from Evergreen State College. At Evergreen he took introductory and applied GIS coursework related to 
environmental applications. While at PSU, and prior to his work on the Atlas, he took the required GIS course for planning students, Geographic Data Analysis and Display, from Dr. Irina Sharkova, a USP faculty member and analyst with the Population Research Center (PRC) at PSU; this was his introduction to the geographic analysis and display of demographic data, particularly, census data. During the Atlas process, he would also take a "by arrangement" course with Sharkova that focused on the raster modeling of demographic data.

Over the next nine months, Radin worked closely with Harmon as she endeavored to nail down the theoretical framework for the Atlas, struggled to deal with the barrage of requests from the CLF membership, through its participatory process, to add an increasing number of variables to their inquiry, and to understand, with Harmon, what the demographic data would reveal about equity when mapped. Thus began what would evolve into an uneasy, sometimes contentious negotiation between two worldviews, that of the advocate and the scientist, that would last long past Harmon's tenure on the project. Harmon describes the beginnings of this struggle this way:

When Ken came on there was this long, excruciating, iterative process of backing and forthing about what could the maps look like and what kinds of parameters were going to work, you know. And, would we use median and would we use mean and what were the differences, blah, blah, blah - all the technical stuff. All of the... what if we use standard deviation, blah, blah, blah. And, none of us knew what the hell any of that was. I mean, I was close because I'd had enough GIS but I was like, "Okay, I kind of know what you're talking about." But everybody else was like, "whatever." I just want the map to work, right? (Harmon, 2008) 
During this first, what Harmon and Radin called, "diagnostic phase" of the work, Radin created countless choropleth maps (the most widely used technique for mapping census data) of the census variables that were being identified by CLF members for inclusion in the Atlas. Choropleth maps are created by shading enumeration units, in this case census tracts, with an "intensity" proportional to the data values associated with the units (Slocum, 1999, p. 25) (figure 6.1).

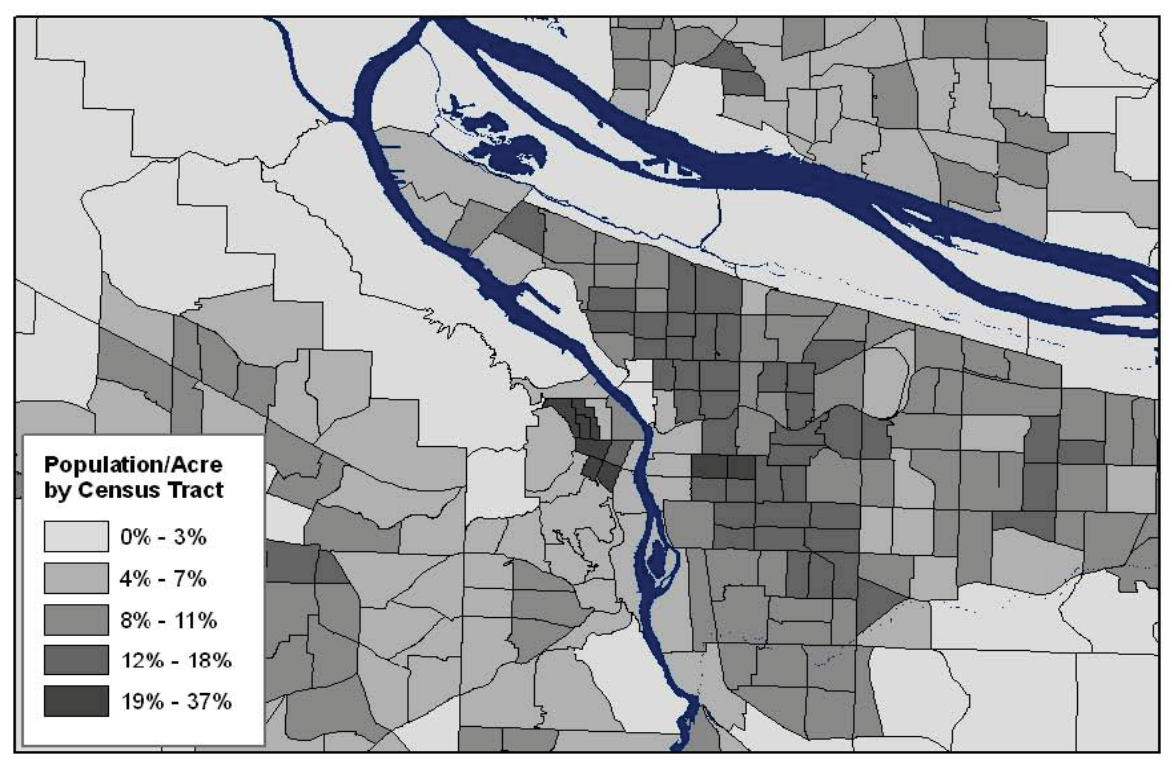

Figure 6.1. Choropleth map: Population Per Acre. Source: Census 2000.

Each variable, where possible, was mapped by the total number per census tract, normalized by the total population (to create percentages of the total) to account for the differing sizes of the census geographies, and the change that occurred between 1990 and 2000.

The pros and cons of each approach (total population, the normalized approach, and change over time) for each variable were discussed and discussed 
again as Harmon struggled with trying to reconcile the stories that each map appeared to be telling with what she knew, from her extensive experience as an affording housing advocate, to be the conditions on the ground (Harmon, 2008; Radin, 2008a). The disconnect between the maps that Radin was creating and what she knew about poverty and housing, in particular, in the Portland region was profoundly troubling to Harmon:

I would go through the maps and I would say, "Wow, you know, something's wrong here, Ken, because, Lake Oswego and Beaverton don't look any different on this map. I know on the ground they are different. So, what's going on? (Harmon, 2008)

And, it wasn't out of total ignorance about GIS that Harmon reacted this way, although she had some level of insecurity about it:

I took one GIS class when I was in planning school so I knew that it was an incredibly powerful technology and that it was incredibly complicated, and I understood how to ask useful questions that people might be able to map. [But], I knew nothing about the technicality ... you know, and my coursework was 15 or 20 years old so the whole technology was different, right? (Harmon, 2008)

But beyond the technology, the Census Bureau geographies used in choropleth mapping were an anathema to Harmon as they are to most people. In reporting census data, they must be spatially aggregated to insure the anonymity of the respondents. A consequence of the decision by the Census Bureau to aggregate its data based on a target population number (that created irregular geographic units in metropolitan areas across the country) as opposed to a uniform spatial grid, for example, is that except in places like Manhattan where population densities were extremely high (at the original delineation of its tracts) with resulting tracts exceedingly small, there is an unknown 
relationship between the data and their actual geographic locations (Martin,1988;

Slocum, 1999). This is not only a problem in rural areas where census enumeration units must be large to accommodate the population numerical target but in urban areas where parks, commercial, or manufacturing activities may consume a significant portion of a tract. In Radin's earliest iterations, he actually extracted parks from the census tract geographies in an attempt to better locate the data.

This disconnect between the data and their actual locations, related to census tracts and census tract size in the context of the choropleth mapping technique, is exacerbated by a disproportionate and, therefore, misleading visual impact of tracts with the most extreme socio-economic characteristics (Dent, 1993; Martin, 1988) a problem that may have contributed to Harmon's discomfort with the maps (figure 6.2).

For someone unfamiliar with the Portland metropolitan area, this map would seem unremarkable, but for someone, like Harmon, who knows the area and issues well, this map would raise red flags because of the misleading impression that it leaves. Several of the most impacted areas depicted in this map (those in the darkest color, adjacent to the Willamette River and rural Clark County) are comprised of the largest, least populated census tracts in the region. The concern that someone in Harmon's position would have is that without a fairly elaborate technical explanation, the Atlas, and CLF, could lose credibility with the broad, and local, audience it hoped to reach. 


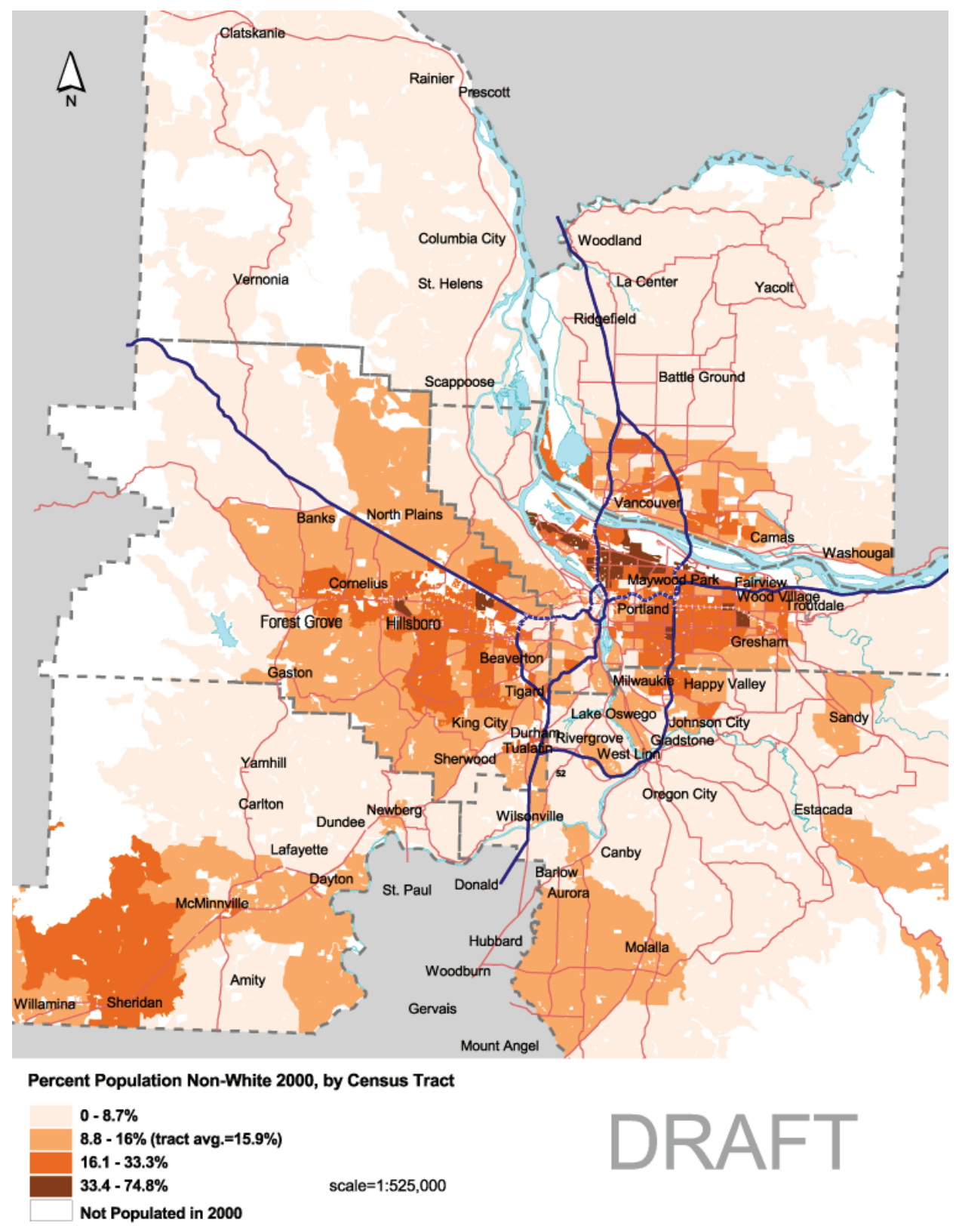

Figure 6.2. Percent Population Non-White, 2000, by Census Tract. Source: "Main Presentation 11-25-03," Ken Radin, cartographer. 


\section{Data Classification and Manipulation}

Data are classified to help us understand them better. In choropleth mapping, typically, shades of a single color are associated with classified values of a single variable from low to high values (or vice versa). There are several well accepted classification methods for accomplishing this (natural breaks, quantiles, equal interval, and standard deviations) each of them with trade-offs. As Harmon began to question some of the maps that Radin was producing during the diagnostic phase, the question about how and why the data were classified they way they were arose. In the beginning, Radin relied on the default method programmed into ESRI's ArcView 3.x GIS software, natural breaks with 5 classes. As the name implies, natural breaks considers the "natural" groupings that emerge when the data are arrayed in a rank-ordered histogram. The goal of this approach is to minimize differences between data values in the same class and maximize values between classes (Slocum, 1999). However, because natural breaks responds to the particular characteristics of a particular dataset, the class breaks and, therefore, the map legends that it produces aren't necessarily intuitive and may be inappropriate when comparing one dataset to another.

Even though this method or class of methods is widely seen as the most reflective of the data array, it wasn't necessarily the most responsive to the story that Harmon was trying to tell. As a result, Harmon and Radin began to "tinker" (Harmon, 2008) not only with the classification schemes included in the software but with the 
idea of custom classifications that could come closest to what Harmon thought was the reality in neighborhoods:

Part of what became clear to me really quickly as Ken and I started working on actual iterations of maps was how - the most blatant way to say this is - how easy it is to manipulate the data, right? Like if you set breaks here then all of a sudden we see the cluster we're expecting to see. If we set the break there, it disappears completely.

(Harmon, 2008)

And so, Harmon and Radin began to play with the class breaks, the number of classes, and classification schemes, including those adopted by partner organization, PolicyLink, in an effort to tease out the story Harmon was trying to tell. They phrased and rephrased their questions, sorting through possible indicators, reconfiguring the data parameters, and playing with color until the story they expected to see was produced.

As they worked through the census variables, struggling to triangulate around the multi-faceted concept of equity, Harmon and Radin began to recognize the importance not only of creating data classes that would make sense in terms of the policy implications of each variable (in mapping median income by census tracts, the income threshold for a family of four, for example, that meets federal poverty or free and reduced price lunch requirements) but of the necessity of normalizing one dataset to another. Harmon saw this as yet another unforeseen complication that she wasn't fully prepared for; Radin saw it as a challenge and an opportunity to use his statistical skills. 
For Radin, this diagnostic phase was both exciting and hugely frustrating. It was exciting because he had some sense of the importance of the project to CLF and the important role that maps and mapping were playing in the process. But the choropleth approach to mapping the census variables wasn't much of a challenge in terms of what he knew he could do with GIS. Aware of his youth and relative lack of experience (especially with cartography: "I am no cartographer" (Radin, 2008a)), but also having real talent in GIS (Sharkova, 2008), Radin felt that the credibility of his work rested on the quality of his analysis - especially the use of statistical approaches. However, because Harmon saw this work as a partnership, rather than being an independent analyst, Radin found that he needed to negotiate everything with her. For example, Radin described his and Harmon's early method at normalization this way:

They [the variables that were being mapped] were standardized by, like, half a standard, you know like not standard deviations but here's the regional value in the middle, and this is half of the regional value, you know what I'm saying, or twice the regional value - that kind of thing. And those were our classes because one of the problems we were having was, what are the classes? Like, what are the significant thresholds for these different variables. So, that was a headache for me, because back then, I was really, like, it's got to be standard deviations it had to be statistical - it had to be normalized. (Radin, 2008a)

Having to deal with these sorts of questions and debates were not what that Harmon expected when she began the process. There was a belief in the authority of "maps" that was fundamentally changed as a result of engaging in the work:

So, I think that the piece of naiveté, when I walked into the process, and I think all of us had - maybe Ken didn't but the rest of us had was this basic naiveté that said, "The maps will answer the question," right? We'll ask the question and the maps will answer it. And, what we discovered is that sometimes the tiniest change in the data 
parameters, like, "Well, are we really asking about people below the poverty line, or, are we asking about people below median income?" would change completely the story we were telling about the region.

(Harmon, 2008)

When a map didn't look quite right to Harmon, Radin would go back to his computer and rework it:

... he would go back and mess with it. And it was like, "well, if I use the mean with standard deviations then it comes out like this." And I'm like, "Oh Jesus, what's the answer? Any of these is the answer!" So, what's the story you want to tell, right? That was a very challenging piece of the work which none of us expected, and we never really talked about. But that piece took an enormous amount of time and energy and created in me, at least, this sense that we weren't, in fact, looking for answers, we were telling a story. (Harmon, 2008)

Harmon had begun the process with the belief that the maps would have an objective authority that would provide the answers to the questions she asked them. But asking questions related to issues about which she had a deep level of knowledge and understanding revealed fallibilities in the practice of mapping at multiple levels, including the foibles of census data aggregation, data classification schemes, and the cartographic representation of data, that while not fully understood by her made her aware of the responsibility of owning of the process of the mapping that she and CLF would have to take on:

Suddenly, there was this set of policy decisions that we had to make about how we were going to represent the answer to the question on the map, rather than what we expected to happen which was, we would ask the question and the map would answer it. (Harmon, 2008) 


\section{Focus Groups}

Between June 2003 and October 2003, Fuglister had taken maternity leave. Upon returning to work, she was anxious to see what progress had been made with the Atlas. The expectation was that the Atlas would be published in summer 2004 and that it would be substantially complete in time for a launch at the spring CLF Summit. Immediately, she was concerned about the number of issues related to the mapping that appeared to be consuming Harmon and Radin's time and wanted to get a better sense of the credibility and relevancy of the maps that had been produced to CLF members and possible consumers of the Atlas:

Ken had created a bunch of maps and we wanted to get feedback from people about what seemed the most compelling, the most relevant: what's singing to you, what's helping tell these stories, or make the points that people wanted to have made. (Fuglister, 2008)

Fuglister proposed that they move ahead as soon as possible with a series of focus groups that had been planned, from the beginning, to test the waters. Fuglister wanted to be sure that the maps would be ready for prime time for CLF's 2004 Summit in April. The focus groups would not only provide a hard deadline before the Summit for Harmon and Radin to work toward but there would be several weeks for any additions, corrections, or adjustments to be made to the maps if necessary. On March $9^{\text {th }}$ and $10^{\text {th }}, 2004$, Harmon conducted three focus groups at PSU.

\section{The Focus Group Presentation: Explaining the Maps}

After introducing Radin as the GIS analyst and mapmaker for the project, Harmon presented the purpose of the Atlas using language directly from the equity 
framework documents that she had been developing simultaneously with the diagnostic mapping process: "The Equity Atlas is designed to measure how far we are from being 'an equitable region' and, over time, whether we are moving towards or away from that goal" (Harmon, Focus Group Pres. Notes, 2004). She further set the stage for the Atlas by describing the definition of an equitable region, related to the Equity Atlas project, as one where "all residents have good access to the means for identifying and taking advantage of opportunities for advancing the well-being of their households" (Harmon, Focus Group Pres. Notes, 2004).

Before introducing the maps, Harmon wanted to prepare the participants of the focus groups for the fact that the maps were not quite where the Coalition had hoped they would be by describing the challenges of the project. The first of these related directly to the framing that she'd struggled with and the difficulty of translating these complex ideas related to equity into maps. Acknowledging poverty as the driving indicator related to equity, the question, Harmon suggested, was how to address it, in the terms that the Atlas required, "as a fundamental determinant of the quality of life" and a determinant of "access to opportunities and community assets" (Harmon, Focus Group Pres. Notes, 2004). The Atlas, according to Harmon, also needed to be able to "make observations about the ways in which local and regional public policy choices make being poor a more severe challenge [emphasis in the original]" and "address the ways in which racial discrimination exacerbates the experience of poverty for people of color [emphasis in the original]" (Harmon, Focus Group Pres. Notes, 2004). Harmon and Radin had spent months exploring population and housing census 
variables and other data sources for ways to triangulate around these issues but there had been no silver bullets.

The second challenge, clearly related to the first, was data limitations, "we can't track much of what we want to track" (Harmon, Focus Group Pres. Notes, 2004). The data limitations included the existence, cost, timeliness, general quality, and availability of data in a uniform and the large geographic scale that was desired for the Atlas.

The third challenge, Harmon stated, was the space limitation of the printed document. The issue was not only cost but the sense that in order for the Atlas to be more widely used than Orfield's Portland Metropolitics (1998) report had been, the Atlas needed to be short. What this meant, according to Harmon, was that it wouldn't be possible to go too deeply into any one subject and that CLF would have to look for "compelling pieces of the story that can be told relatively simply with few words and few maps" (Harmon, Focus Group Pres. Notes, 2004).

Harmon regarded the absence of time and money as a huge challenge for the project. Many things, including additional mapping and writing, could be done with more time and more money. Given the struggles that she and Radin were having developing the kinds of maps that would tell a credible and compelling story about equity in the region, that could also be the kind of measurement tool that the Coalition was hoping for, Harmon felt some level of insecurity about the maps she was about to show to the focus groups. Harmon's presentation notes indicate that she was prepared to tell the participants that the mapping was being done at poverty wages, on Ken's 
part, and by volunteers: "They [the volunteers] are wonderful, and there are limits to how much we can ask of them" (Harmon, Focus Group Pres. Notes, 2004).

Ultimately, Harmon believed that it was important for the focus group participants to understand that what was important wasn't the Atlas itself. Rather, the Atlas should be seen as a "catalyst" for "much other work we hope to get done in the future" (Harmon, Focus Group Pres. Notes, 2004).

Harmon prefaced her map presentation by emphasizing that they were still in the draft or diagnostic mapping stage of the project and needed feedback before she and Radin could move forward. Participants were told that not all of the maps that they would see would be used in the Atlas (to some degree inclusion would be determined by the participants' feedback) and that the classification breaks, "geographic referents," colors, and other "format" factors "will almost certainly change" (Harmon, Focus Group Pres. Notes, 2004).

In addition to the single variable maps that the focus groups would explore, Harmon wanted to emphasize that other types of maps, maps that would reveal relationships between "the 'base map' factors and the 'assets' we are mapping separately right now" would be included in the final Atlas (Harmon, Focus Group Pres. Notes, 2004). In other words, the focus group participants needed to know that they were only seeing a part of what would ultimately be included in the Atlas and that everything could change if need be. 


\section{The Maps}

During the 3-hour sessions, Harmon showed the focus groups 44 maps (29 were of population variables, seven were related to housing, and eight were focused on "access" - primarily transportation and parks and open spaces) (table 6.1) nearly all of which were at a regional, 6-county (Clackamas, Columbia, Multnomah, Washington, and Yamill counties in Oregon, and Clark County in Washington) scale. The vast majority of the data used came from the Census but the access maps relied on data from Trimet (the Portland area's regional transportation agency) and Metro. 
Table 6.1. Focus Group Census Maps (all variables aggregated by census tracts)

\begin{tabular}{|c|c|c|c|}
\hline $\begin{array}{l}\text { The Region (geographic } \\
\text { base map) }\end{array}$ & $\begin{array}{l}\text { \% African American, } \\
1990\end{array}$ & $\begin{array}{l}\text { Number of Linguistically } \\
\text { Isolated Households, } \\
1990\end{array}$ & $\begin{array}{l}\text { Median Housing Value, } \\
2000\end{array}$ \\
\hline $\begin{array}{l}\text { \% Change Median } \\
\text { Income, } \\
1989-1999 \\
\end{array}$ & $\begin{array}{l}\text { \% African American, } \\
2000\end{array}$ & $\begin{array}{l}\text { Number of Linguistically } \\
\text { Isolated Households, } \\
2000\end{array}$ & $\begin{array}{l}\text { \% Change in Median } \\
\text { Housing Value, 1990- } \\
2000\end{array}$ \\
\hline \% People in Poverty, 1990 & $\begin{array}{l}\text { Change in \% African } \\
\text { American, 1990-2000 }\end{array}$ & $\begin{array}{l}\text { Change in Number of } \\
\text { Linguistically Isolated } \\
\text { Households, 1990-2000 }\end{array}$ & $\begin{array}{l}\text { \% Change in Renter } \\
\text { Households' Share of } \\
\text { all HHs, 1990-2000 }\end{array}$ \\
\hline \% People in Poverty, 2000 & \% Hispanic Origin, 1990 & $\begin{array}{l}\text { \% Households } \\
\text { Linguistically Isolated, } \\
1990\end{array}$ & $\begin{array}{l}\% \text { Renter Households } \\
\text { Spending More Than } \\
35 \% \text { of HH income on } \\
\text { Rent }\end{array}$ \\
\hline $\begin{array}{l}\% \text { Change in \% Persons in } \\
\text { Poverty, } 1990-2000\end{array}$ & \% Hispanic Origin, 2000 & $\begin{array}{l}\text { \% Households } \\
\text { Linguistically Isolated, } \\
2000\end{array}$ & $\begin{array}{l}\text { \% Renter Households } \\
\text { Spending More Than } \\
35 \% \text { of HH income on } \\
\text { Rent, } 2000\end{array}$ \\
\hline $\begin{array}{l}\text { Change in Number of } \\
\text { Persons in Poverty, 1990- } \\
2000\end{array}$ & $\begin{array}{l}\text { Change in \% Hispanic } \\
\text { Origin, 1990-2000 }\end{array}$ & $\begin{array}{l}\text { Change in \% } \\
\text { Linguitically } \\
\text { Isolated Households, } \\
1990-2000\end{array}$ & $\begin{array}{l}\% \text { Change in \% Renter } \\
\text { Households Spending } \\
\text { More Than 35\% of HH } \\
\text { income on Rent, } \\
1990-2000\end{array}$ \\
\hline $\begin{array}{l}\text { Portland Close Up of } \\
\text { Change } \\
\text { Map }\end{array}$ & \% Other Race, 1990 & $\begin{array}{l}\text { Average Years of } \\
\text { Education, } 1990\end{array}$ & \\
\hline $\begin{array}{l}\text { \% of White, Non Hispanic } \\
\text { People, } 1990\end{array}$ & $\%$ Other Race, 2000 & $\begin{array}{l}\text { Average Years of } \\
\text { Education, } 2000\end{array}$ & \\
\hline $\begin{array}{l}\% \text { of White, Non Hispanic } \\
\text { People, } 2000\end{array}$ & $\begin{array}{l}\text { Change in \% Other } \\
\text { Race, } \\
1990-2000\end{array}$ & $\begin{array}{l}\text { Change in Average } \\
\text { Years } \\
\text { Education, 1990-2000 }\end{array}$ & \\
\hline $\begin{array}{l}\text { \% Change in \% of White, } \\
\text { Non Hispanic People, } \\
1990-2000\end{array}$ & $\begin{array}{l}\text { \% Two or More Races, } \\
2000 \text { (new category) }\end{array}$ & $\begin{array}{l}\text { Median Housing Value, } \\
1990\end{array}$ & \\
\hline
\end{tabular}

Source: Focus Group Presentation Notes, March 8, 2004, Tasha Harmon, author.

Table 6.2. Focus Group Access Variable Maps

\begin{tabular}{|l|l|l|l|}
\hline $\begin{array}{l}\text { Average Number of } \\
\text { Adults per Vehicle, 1990 }\end{array}$ & $\begin{array}{l}\text { \% Change in Average } \\
\text { Number of Adults per } \\
\text { Vehicle, 1990-2000 }\end{array}$ & $\begin{array}{l}\text { Pouseholds per } \\
\text { Park } \\
\text { Acre }\end{array}$ \\
\hline $\begin{array}{l}\text { Average Number of } \\
\text { Adults per Vehicle, } 2000\end{array}$ & Green Infrastructure & Oregon City Access & \\
\hline
\end{tabular}

Source: Focus Group Presentation Notes, March 8, 2004, Tasha Harmon, author. 
As Harmon projected each map in her PowerPoint presentation, she provided context, specific statistics in some cases, and explanatory comments to aid with map interpretation or to suggest how the maps might be used to investigate further. Regarding the "Percentage of people in poverty by census tract in 2000 " map, for example, Harmon's script stated, that there were "31,323 more people in poverty in the region in 2000 than in 1990, but the population grew faster than poverty, so the percentage of households in poverty fell from $9.7 \%$ to $9.3 \% "$ - things that couldn't be easily seen in the map. In the case of the "Percent change in the percent persons in poverty 1990-2000," Harmon told her audience, “[This map] [s]hows a much more complex picture, but still a decrease in concentration of poverty, at least for now," moving from the data expressed in the map to conjecture, her script indicates that she told them, "any of these orange areas could become new areas of deeply concentrated poverty in the next 10 years - too soon to tell this story yet" (Harmon, Focus Group Presentation Notes, March 8, 2004).

She tried to draw her audience into the maps and the arguments for the variables she was using (or hoped to use) in the housing section of her presentation this way:

...we think carefully about where we are going to live because it makes many things we care about either harder or easier to access or do. I know when I moved to Portland I chose my neighborhood because I could walk to several grocery stores ... I was 10 minutes from downtown by bus ... I could take long walks on pleasant streets anytime day or night without being fearful ... there were lots of street trees and both public and private greenspaces ... there were a variety of 
good public school options for my kids ... there were no major toxin issues ... I could afford decent housing big enough ...

(Harmon, Focus Group Presentation Notes, March 8, 2004)

By personalizing the issue in a way that her audience could related to, the housing maps undoubtedly became more engaging especially after viewing the previous 29 population related maps. But there were no maps of grocery stores, or incidents of crime, or presence of street trees, or air quality - some the key variables to livability and housing that she'd outlined. Harmon had to admit that not as much progress had been made with the "access" variables. This was primarily because to that point, CLF had relegated those to the well-intentioned professional volunteers who could dedicate very limited time to the project. The only maps included in the focus group presentations whose attribution can be verified, other than Radin's, are two choropleth maps ("Parks and Greenspaces Acreage per person by census tract" and "Poverty and Transit Access") created by Bosworth.

Despite Harmon's attempts to engage her audience in the importance of mapping equity, connecting them emotionally through her personal story to the issues at hand as well as the challenges and sometimes subtle differences in interpreting spatially normalized and non-normalized data and statistically standardized and nonstandardized data in the census choropleth mapping context, three hours and 44 maps later, these must of have been mind-numbing sessions. In some respects, by suggesting that nothing was final about the maps, that everything from the variables to the class breaks to the colors could change, that there was still much to explore, and by inviting feedback, Harmon and Fuglister created yet another opening into the 
conceptual, analytical, and technological "can of worms" (Harmon, 2008) that Harmon, Radin, and CLF had created.

\section{The Focus Group Findings}

The focus group participants were CLF members and others who the Coalition had targeted as potential users of the Atlas - in general, a relatively sophisticated audience. Each participant had a broad understanding of the issues that the Coalition was involved in regionally and a deep knowledge related to their own organization's particular issue, geographic focus, or both. As a result, these focus groups were able to provide instructive feedback related to the legibility of the maps before their official debut at the Regional Summit. The feedback fell into five general categories: data; data classification; color; interpreting census geographies; and geographic scale (Radin, “map_comments0304, 2004a).

Data questions. Aside from continuing questions from CLF members related to the desire for additional data, there were questions from the focus group participants about the definitions of the census variables such as: is the prison population included in the "population" variable for the Census? There was a desire for a population basemap based on density and a question about how best to do this: by total population per acre or the number of households per acre? According to Harmon and Radin's written exchange on the data issues after the focus groups had taken place, CLF Board member, Joanne Bauman, apparently understood two of the maps to contradict each other: 
Joanne read the maps as showing an increase in poverty but a decrease in HHs [households] spending too much on rent - check on this and think about how to talk about it. (Harmon quoted in Radin, map_comments0304, 2004a)

To Harmon, this suggested either a problem with the data or a cartographic issue that would need to be dealt with. The focus group experience indicated that she and Radin would need to be prepared to defend everything they had done. Radin believed that the data were correct and responded rather testily that the problem was Joanne's, not his: “Don't worry about the Wilsonville stuff nor Joanne's misconceptions about poverty and housing costs - I've already vetted that." (Radin, map_comments0304, 2004a).

Categorization. The focus group feedback indicated that there was some confusion related to differing legends in some of the maps. As previously discussed, the issues of classification method and classification breaks were an ongoing debate during the diagnostic process. For the focus groups, Radin used at least two different approaches: in most of the maps, he chose natural breaks (which best reflects the distribution of the underlying data therefore different class breaks for each dataset) but in some cases he used standard deviations. Some focus group participants found the use of natural breaks confusing. Harmon and Radin's exchange on the topic based on the results of the focus groups reveals a sense of frustration on Radin's part as he once again tried to address the issues of classification and class breaks:

On the whole classification and breaks discussion (and, yes, that is what I meant on the non-Hispanic White maps, and looking it over now I can't figure out what problem was being referred to), I think we need 
to consider using a consistent methodology for setting breaks (natural or 4 equal) as a way of preventing confusion.

(Radin, map_comments0304, 2004a)

In a document sent to Harmon the same day that specifically addressed

cartographic issues, Radin had clearly rethought the issue and outlined a more detailed approach to classification that argued for applying different approaches to

classification based on the nature of the data and the questions being asked:

The natural breaks method is usually best for showing the clearest differentiation of classes inherent in the underlying data. Sometimes we should probably be choosing culturally or politically important numeric values. For example, PolicyLink chose 0-10, 10-20, 30-40 and 40 and up as their classes for poverty. These were culturally significant to them, maybe just because they were easy breaks to understand. Maybe sometimes, or even overall, we should be focusing on how tract-values compare to regional averages or values. For example, we'd like to know how the people in such and such tract compare to the regional average: on average, are they better or worse off? On the other hand, sometimes comparing to regional averages, or classifying with respect to them, doesn't make a whole lot of sense mostly when we're interested in seeing the geographic pattern of the underlying data, rather than predetermined 'significant' values... In other words, so far we've mostly been interested in discovering patterns that might imply the significant values/breaks/classes [emphasis in the original]...

(Radin, Cartographical_Comments0304, 2004a)

Taking on the role of teacher, Radin was attempting to demonstrate to Harmon the importance and necessity of complexity here. One of the benefits of the natural breaks methods, he suggested, is that it reveals where the significant breaks are when they are unknown. However, he was also arguing that in the policy arena, some significant thresholds have already been established (such as household incomes and household size related to eligibility for federal poverty programs) that everyone recognizes that 
are important milestones that could be used to increase the legibility and meaning of the maps to potential users of the Atlas. Harmon longed for simplicity, an approach that was either easily understood or easily explained but she was also learning that there could be no simple solution because the issues being explored, the data, and mapping process were not simple.

Color. Like many GIS analysts, Radin had no real cartographic training and as a result, relied heavily on the default color schemes designed into the ArcView 3.x GIS software package (Radin, 2008a). While cartography is considered a subdiscipline of geography, it is an enormously complex subject. Formal cartographic training generally rests on tradition, art, and experimental studies where such things as the relationship between human perception and numerical values, data type, and the progression of hue values are tested (Slocum, 1999).

In recent years, the wide-spread use of GIS software by those with no formal training in cartography has meant that more often than not, map design, including color assignment, has been largely dictated by the software itself. The ArcView 3.x program that Radin used for the Atlas maps and had real expertise in, provides a fairly limited selection of predetermined color ramps (predetermined shades of one color that are automatically applied to classes of rank ordered data) for use in singlevariable quantitative mapping. The algorithm used by ESRI in its ArcView 3.x program, utilizes the HSV (hue, saturation, value) color model that the documentation for its newer ArcGIS software (which includes two additional color algorithms) states that although it may be the easiest color model to understand at a theoretical level, the 
HSV color model "may not be the most intuitive for map reading purposes" (ESRI, 2002). The importance of the association between, not only a particular color with a particular variable, but that of the value (in terms of shade) of a particular color to a value range of a variable by map consumers, weren't issues that seemed consequential when the mapping process began but the focus groups suggested that, in fact, these were issues that Harmon and Radin would have to consciously deal with.

For the maps shown to the focus groups, Radin symbolized each census variable with a different color ramp offered by ArcView. Slocum (1999, p. 109) does, in fact, state that mapmakers might want to take advantage of people's associations with color (such as the color green with money and red with heat) when mapping phenomena. However, Radin's selection of the pre-defined beige to brown color scheme for the "Black, non-Hispanic" and "Hispanic Origin" map series (figures 6.2 and 6.3) as well as the selection of ArcView's orange color ramp for "Other" racial minorities drew fire from focus group participants. 


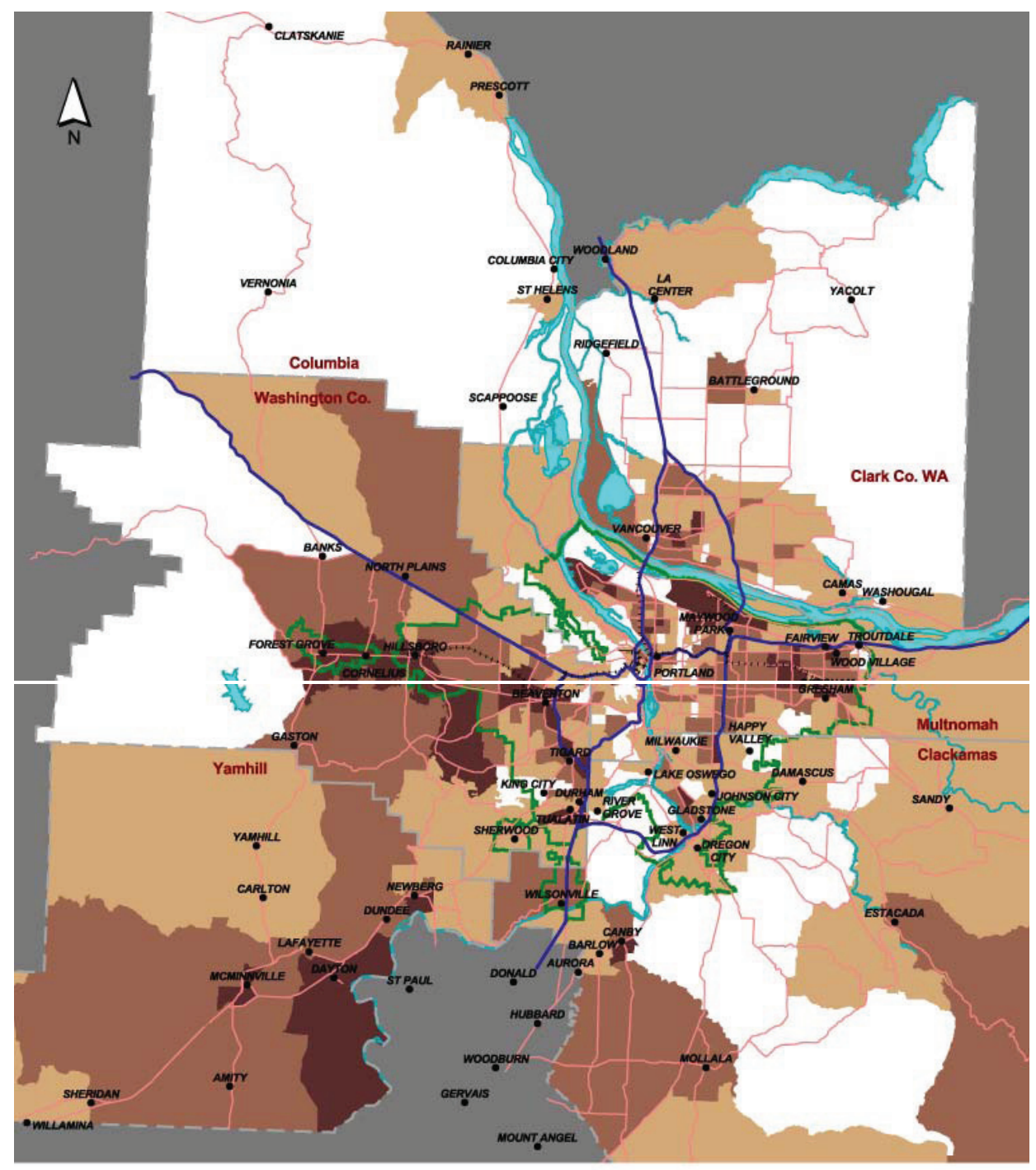

2000: Percent Hispanic Origin
$0-2.6$
$2.7-5.9$
$6-13.4$
$13.5-59.1$
0
10 Miles
scale $=1: 525,000$
same breaks as 1990 map; PMSA=7.4\%

Figure 6.3. 2000: Percent Hispanic Origin. Cartographer, Ken Radin. Source: Radin, "third_iteration_10004" 
In their post-focus group exchange, Harmon actually asked Radin whether or not he believed the reaction to the race-related maps was aesthetic or "due to some connotation about brown and race?" (Radin and Harmon, "Map_Comments3024, 2004). Radin responded unequivocally: "the latter" (Radin and Harmon, "Map_Comments3024, 2004). Harmon believed that the color scheme issue had to be addressed before the Summit and suggested using a single color scheme for all of variables that would be neutral in character such as purple (Radin and Harmon, 2004 Map_Comments0304).

Radin had worked long and hard on the maps thus far and was very concerned about the time that it could take to convert all of the legends into a single color scheme. He suggested, rather, that they first work on the most problematic variables and then later, when there would be more time, consider changing all of the legends for the census variables to one color scheme. Although he didn't document this particular concern, having worked so long with the data and the problems related to classification methods and classification breaks, Radin may also have realized that applying a single color scheme might also require the application of a single classification scheme with a single set of classification breaks - something that he knew was unworkable.

Interpreting census geographies. As previously, discussed, Census Bureau geographies, particularly census tracts, are confusing to people. Because they were originally intended to be permanent and were drawn to encompass a relatively small number of people who had homogeneous demographic characteristics at a particular 
point in time, they can be counter-intuitive in the choropleth mapping context. It had always been confusing to Harmon and feedback from the focus groups confirmed that she was not alone. Harmon pushed Radin once again to come up with some way to deal with the problem:

Need to address issue of large, sparsely populated census tracts showing "big" changes - throws people. Beth Kaye [who was Public Involvement and Legislative Affairs Manager for the City of Portland] suggests creating a grid rather than maps to show comparisons [I don't much like this idea, but perhaps we should talk about it].

(quoting Harmon, Radin and Harmon,"Map_comments0304”)

Radin's solution up to this point had been to add as many natural features to the maps as possible to give the impression of sparsely populated areas - features such as topography, open spaces, and forests (Radin and Harmon, 2004

"Map_comments0304"). And, although he had never really considered the choropleth approach very sophisticated in terms of its spatial analytic power, the Census statistics were, after all, aggregated by enumeration districts (or tracts). He was confused by this first mention of a "grid" approach (choropleth mapping implies the vector model of GIS) and reacted, as Harmon had, negatively to the idea:

I sort of understand the grid idea, but I don't like it. I think we are just going to have to go with the density map and hope for the best. (quoting Radin, Radin and Harmon, 2004, “Map_comments0304”)

Geographic scale. It had been decided by the Coalition early on that Regional Equity Atlas would be just that, regional (encompassing the 6-county Portland metropolitan area including Clark County, Washington). All of the maps that were shown to the focus groups were at the regional scale. While the regional scale 
allowed the participants to see the distributions and patterns across a wide swath of territory, it also meant that the most densely populated areas (generally the smallest census tracts) were difficult see. As a result, there were many requests for large scale, neighborhood-level maps, in geographic areas of particular concern. Harmon suggested to Radin the possibility of creating what she called "closeup's" from the maps that were already completed for CLF's member organizations. Radin's response related to two issues. One was that some of the participants could have the misunderstanding that zooming in to a geographic area would automatically produce more detail in terms of the census geographies: "Oregon City looks pretty clear on the map, so zooming in isn't going to improve this situation. Thus, the problem concerns the level of aggregation of the data (i.e. tracts)" (Radin quoted in Radin and Harmon, 2004, “Map_Comments0324”). The other concern was time and expense in terms of the Atlas project generally. Radin suggested that he could make large scale maps on a map-for-fee basis for interested organizations rather than for inclusion in the Atlas.

\section{Wrapping Things Up and Preparing for the Summit}

We are still in the diagnostic mapping stage - looking at maps to see what they tell us ...

(Harmon, CLF Equity Atlas Summit Presentation, 4/3/2004)

The process of framing equity had led Harmon to believe that an "equity atlas" would be achieved by comparing the Census variable maps, or "basemaps," that generally revealed disparities (pockets of poverty and racial, ethnic, and linguistic isolation) with the access variables, or as Harmon put it, "access to various good things" (Harmon quoted in Radin and Harmon, 2004, "Cartographical_ 
comments0324"). Leading up to the Summit, Harmon was acutely aware of the fastapproaching deadline for the publication of the Atlas document, assumed to be summer of 2004, and all of the work that was still left to be done. In her correspondence with Radin following the focus groups, Harmon outlined a series of steps that she thought could move the project out of the diagnostic phase and into a finalization process. Keeping in mind the budget limitations but also in an effort to promote simplicity, Harmon (2004) stressed the advantages and the economy of overlays and indices and suggested that the mapping team: "(1) overlay access on one or more of the base maps - perhaps percent change in poverty 1990-2000?; and, (2) create indices which are composites of two or more maps" (Harmon quoted in Radin and Harmon, 2004, "Cartographical_comments0324"). However, it is clear that both Harmon and Radin were uncertain about which variables to overlay let alone which variables to index. Moreover, Harmon was still questioning which map to use as a base map and revisited the question of whether or not to create a physical transparency if the base map to enable users to most clearly see the equity issue:

Do we want to have it as a removable transparent overlay tucked in a pocket of the Atlas so people can physically overlay it, or is there another way to help people see clearly the relationship between it and other factors? (quoting Harmon, Radin and Harmon, 2004, "Cartographical_comments0324")

Indexing is complex and opaque and in spite of the advantages that Harmon saw in the technique, she also had reservations about its transparency given CLF's participatory culture and advocacy mission: "They [the indices] need to seem reasonable and logical to people, be understandable, and defensible, and they need to 
help us tell the story well" (Harmon quoted in Radin and Harmon, 2004,

“Cartographical_comments 0324”). To this Radin responded:

We really have to sit down, look at the maps, and choose the best way to tell the stories we want to tell... On the other hand, I still have to make an example of an overlay, which may help us decide which direction to take... (quoting Radin, Radin and Harmon, 2004, "Cartographical_comments0324”)

As the Summit approached, Radin accommodated Harmon's request for a purple color scheme for most of the census variable maps he'd produced for the focus groups. He continued to use the natural breaks classification method for the total population and percent population maps but attempted to provide a way for map consumers to make comparisons across the variables and to the region as a whole by developing an alternate legend that was referenced to the corresponding values for the Portland-Vancouver Primary Metropolitan Statistical Area (PMSA) (figure 6.4). 


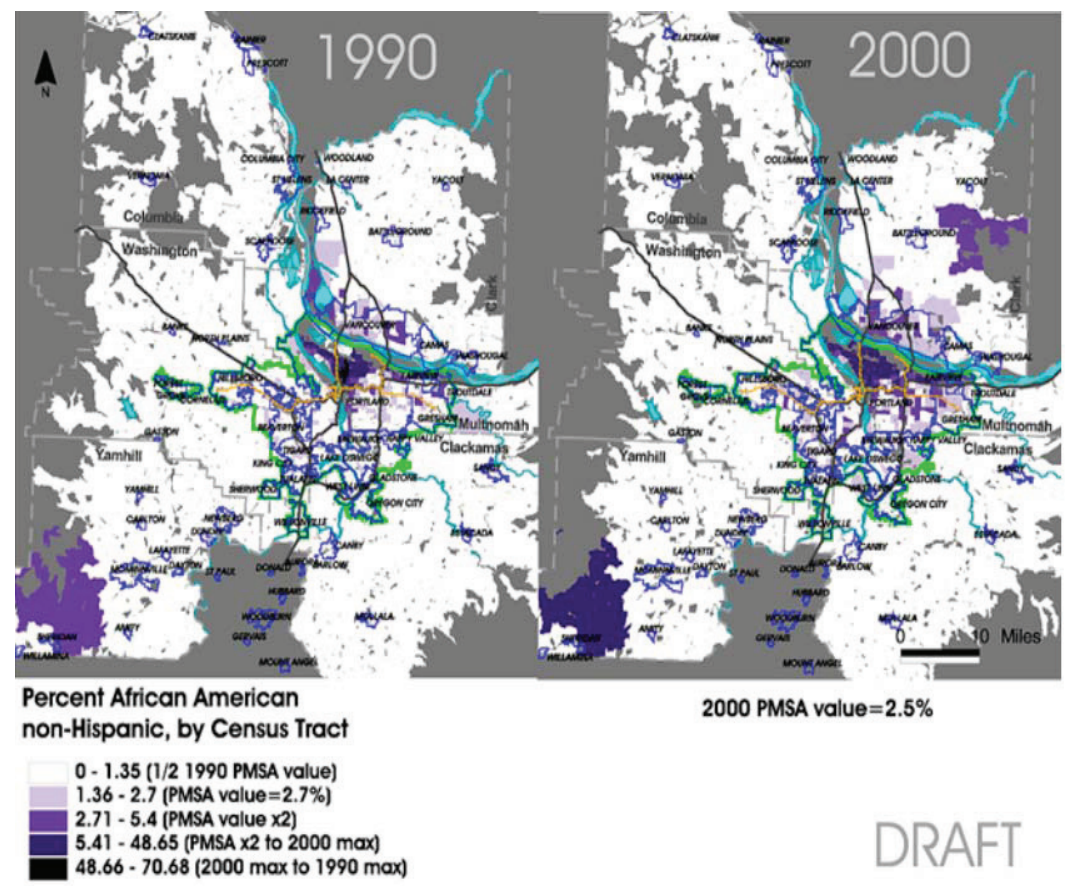

Figure 6.4. Percent African American non-Hispanic by Census Tract. Cartographer, Ken Radin. Source: Radin, "summit_presentation"

For the change over time maps, Radin decided to use standard deviations from the regional mean and employed a dichromatic color scheme (in this case, green to white to purple) a common technique that clearly depicts movement away from the mean (displayed as white) (figure 6.5): 


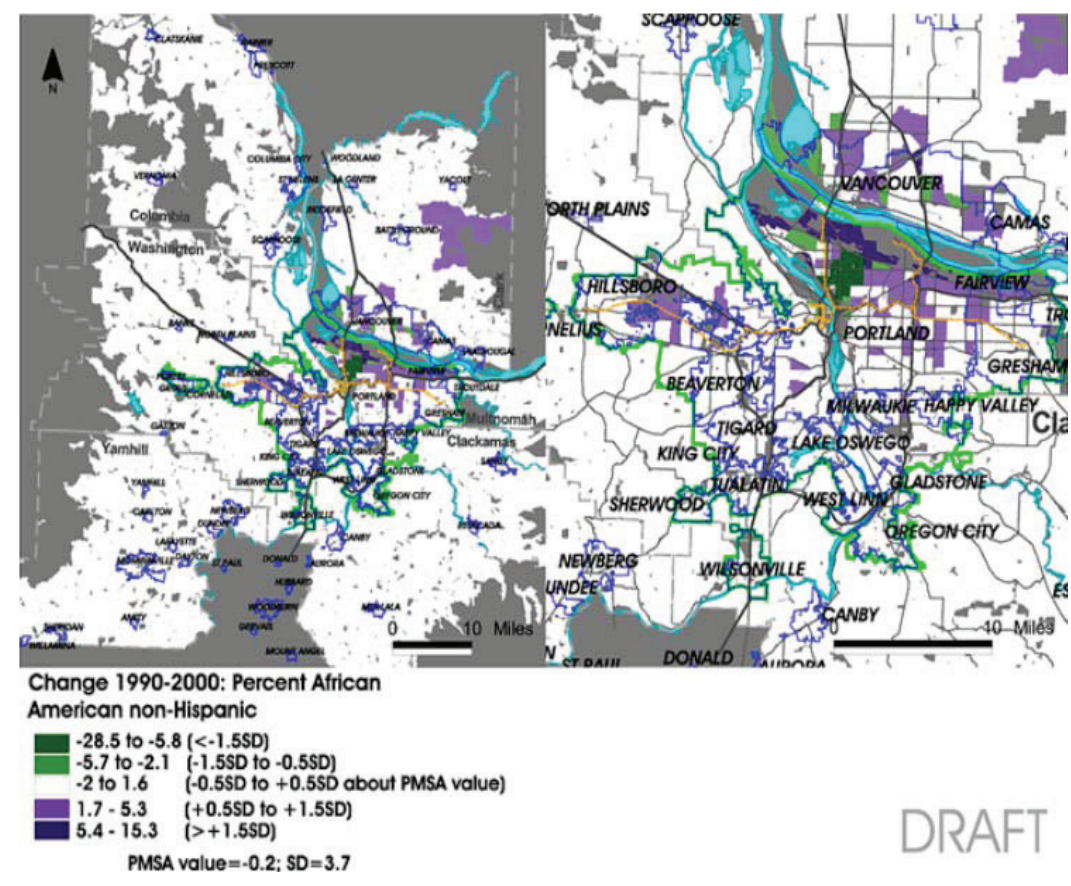

Figure 6.5. Change 1990-2000: Percent African American non-Hispanic. Cartographer, Ken Radin. Source: Radin, 2004, "summit_presentation"

As is evident in figure 6.5, Radin also attempted to address the concerns about scale by including a larger scale version of the map focused on the most urbanized portion of the region.

This process was nitpicking and time-consuming and Radin felt overwhelmed - like everything was falling on his shoulders. He could see what was ahead for the project - the overlays and indices that still hadn't been developed - and the continuing confusion, demonstrated by the focus group feedback, related to map legibility, the choropleth approach, and Census geographies. There was a desire, he knew, on the part of CLF members to see neighborhood level data but the Census tracts didn't line up with the region's neighborhood boundaries. The access variables that the 
professional volunteers were supposedly working on essentially hadn't materialized.

It was this pressure and his own dissatisfaction with the work he'd done so far that drove Radin to revisit the suggestion that Harmon had made about a grid approach. At the time, he hadn't fully understood it in relation to demographic mapping but exploring it to some degree, he began to realize that a grid (raster) approach could offer real and potentially exciting possibilities for tying it all together. The opportunity to use raster analysis resonated with his environmental training in GIS and the challenge of it, he began to realize, appealed his more inventive and "radical" side:

So, this is pushing me to think, what the hell are we going to do? You know, I'm trying to work with things. Sort of moving into new material while trying to tie up the loose ends with the old stuff. All the while, this thing is supposed to be coming out this summer. It's like all these issues are being basically thrust upon me, and it's like I'm the one who's just ... well, I'm the one who was dealing with demographics back in 2004. At that time, I wasn't dealing with access at all. I wasn't dealing with parks. I wasn't dealing with transit. I wasn't dealing with all these different access things. But it was like raster and surfaces are probably going to have to be the answer especially when you're thinking overlay - raster overlay. (Radin, 2008a)

\section{The Summit}

Harmon was keenly aware that things were not as far along as they should have been for the first public unveiling of the Regional Equity Atlas and centerpiece of CLF's 2004 Summit. From her point of view, it had been an agonizing process fraught with conceptual and technical complexity that no one except she and Radin fully comprehended - and she had become increasingly frustrated by the fact that CLF was trying to do it on the cheap. 
As she had done in the focus groups, Harmon felt the need to defend the project's lack of progress and the project's results by explaining its challenges: the conceptual issues; the data limitations; the lack of time and money; and the brevity of the document. Harmon's Summit presentation notes suggest that she may have even stated that Radin was working at "poverty wages for $1 / 3$ of the time he's spending" (Harmon, "summit_presentation_draft", 2004). This was a similar sentiment to one that she'd expressed in her focus group notes. Whether or not this was actually said is not known. And, as she had in the focus groups, Harmon suggested to the Summit's participants that the project was still in the diagnostic stage where "the format (break points, geographic referents, colors, etc.) will almost certainly change" (Harmon, “summit_presentation_draft", 2004).

\section{Observations}

The Summit marked a major turning point in the Regional Equity Atlas process. All of Radin's records relating to the Equity Atlas project are organized in relationship to this event: "Pre-Summit," "Post-Summit," and "Post Post Summit." This is not only because it was where the Atlas was unveiled to the general public, even if only in draft form, for the first time but because it marked a fundamental shift in the way Radin understood the spatial analysis of demographic factors in the GIS environment. Given everything that he and Harmon had struggled with in trying to reconcile the illogic of the census geographies with the actual distributions of demographic phenomena on the ground and the requests for statistics aggregated at 
the neighborhood level, Radin thought that at last he might have a technique that would allow him to move forward.

Once the Summit was over, Harmon focused on trying to come to terms with the steps that would be necessary to finish the Atlas. On the other hand, she had indicated to the Summit participants that nearly everything about the maps could still change - an indication that the mapping team was either still open to additional, undefined input or lacked the confidence to move forward.

Harmon was originally asked to take on the project because of her ability as a thinker and a writer as well as her expertise and advocacy around affordable housing and equity. Harmon was an insider, a founding member of CLF. She had training as a planner and had enough of an introduction to GIS technology that she understood its analytical and communicative power as well as how to ask it questions - but she was not a GIS analyst or cartographer.

In many respects, Radin was seen as a godsend by CLF. Although CLF had had some success in raising funds for the Atlas project (Appendix A), that success was limited by the fact that CLF was treading in uncharted waters: no one had attempted an "equity atlas" before. And while CLF had contracted with Orfield to produce the only other regional mapping project of this general type, Portland Metropolitics (1998), the Coalition had no experience directing and carrying out a project of this type and scale. It is a testament to CLF as an organization and the way in which it had leveraged Orfield's maps during the 2040 Framework process that the Coalition was able to raise the funds that it did given the risks. But everyone recognized that the 
work would have to be done as inexpensively as possible. This meant that although there was considerable enthusiasm from the professional GIS community, their contributions could not be paid for; they would have to volunteer their services - a strategy with inherent risks. PSU's Institute of Metropolitan Studies, because of its relationships with CLF members was the logical place to turn for GIS expertise. Radin was bright, had considerable GIS training and was keenly interested in CLF's work. Because he qualified for work study, his time was essentially free to the Institute.

However, neither Radin nor Harmon had worked extensively with demographic data in a mapping environment. In the beginning, the attitude among CLF members, Harmon, and Radin was, as Harmon said later, "It's a map ... how hard can it be?" (Harmon, 2008). And in the beginning, all, except perhaps Radin, had a belief in the objective authority of maps - that, as Harmon said, "the maps will answer the questions" (Harmon, 2008).

In large part because Harmon and Radin were explicit about their concerns about their ethical responsibility to CLF and the public at large, they sought to find truth in their maps. And because Harmon had substantial knowledge about affordable housing and poverty in the region, the mismatch between what many of the maps were communicating and what she knew to be true on the ground tipped both she and Radin off to the importance and pitfalls related to data aggregation (census geographies), data classification methods and classification breaks, symbology, and scale. 
A related tension that both Harmon and Radin struggled with was the quest for objectivity in their treatment of the data and the need to persuade throughout the mapping process because early on they realized that these two objectives didn't always align. In their interviews and in the documents related to this period, Harmon and Radin, repeatedly refer to "telling stories," that the maps need to tell the story that they (the Coalition) are trying to tell. It was this intense process of struggling and learning that made Harmon realize that she, Radin, and CLF were, in fact, making what amounted to policy decisions in the process of their mapmaking choices - known and unknown (where the software itself is making those choices), consciously and subconsciously (say, for example with color). As far as Harmon was concerned, they would all have to account for their choices in the end.

In a very real sense, Harmon and Radin, found themselves looking under the hood and realized that what was underneath was complicated, much of it foreign and hidden from view. This led to an acute sense of insecurity about their own authority in the process that blurred the line that normally exists between expert and client (expert and consumer) that could have paralyzed the project completely. And, after nearly a year, they were still in the diagnotic stage where everything could still change. Without their knowing it, Harmon, Radin, and the Coalition were practicing a profoundly participatory GIS process with all the messiness that participatory processes entail.

In the aftermath of the Summit, Harmon became intensely aware of the toll that the stress of the project was taking on her health (Harmon, 2008). She would later 
say that they had all been "naïve," that she'd had a premonition about the project at the beginning, but that she suffered from the "eternally optimistic" quality that characterizes CLF:

I had this intuitive hit at that very beginning that we were opening this huge can of worms and that we didn't have the resources to do this. And, essentially said, "As long as they're committed to doing this, I might as well go try to help.” Right? (Harmon, 2008) 


\section{Chapter 7. From Vector to Raster: The Post-Summit Phase}

In the aftermath of CLF's 2004 Regional Summit and all of the frustrations related to the interpretation of the choropleth maps that had been produced, Radin began to seriously explore, with Harmon, Fuglister, and Sharkova, the conversion of the analysis from vector to raster. But it was Harmon's insistence that the maps to date just weren't working that ultimately led to the exploration of other approaches to mapping the census data:

Tasha [Harmon] is probably the central reason why the maps are now surface raster maps because she had such a hell of a time understanding what was going on in the census. She really had this need to know what it was like physically, like what really was on the ground.

(Radin, 2008a)

\section{From Diagnostics to Treatments}

[The] "diagnostic maps," as I see it, are primarily single-variable maps, ... which are being used to help determine both the equity issue to focus on as well as the best way to communicate an equity issue... This is not, or has not been, the best approach. In light of the maps that have been produced, there needs to be more proactive thinking about which variables and mapping strategies will produce an "indicator" of equity or inequity, along the lines of the "issue areas" outlined in the framing document, rather than relying on these diagnostic [single variable] maps to determine what can be told, or telling a story that may be true, but is not supported by the maps...

(Radin, 2004b)

CLF's partnership with IMS was important to the Equity Atlas project in a number of ways. Advocacy was central to CLF's mission but it also knew, based on experience, that the Equity Atlas' credibility would depend on its neutrality something a university could provide. IMS was also able to supply expertise and labor at little cost by utilizing a graduate student for the technical work. Moreover, IMS 
director, Ethan Seltzer, had been instrumental in the early thinking about the project and wanted the Institute to be involved. By spring, 2004, however, concerns related to what was becoming an ambiguous timetable for the project, a dwindling budget, upcoming commitments on IMS's part, and Radin's completion of the Masters in Urban Studies and Planning program at PSU resulted in a search for a new home (that had access to GIS software and data) for Radin (who, no longer eligible for workstudy, would need to be paid) and the Atlas. By April, the decision was largely made to move the Equity Atlas project to the Population Research Center (PRC), also housed in the College of Urban and Public Affairs at PSU.

In many respects, the PRC was a logical choice given the fact that the project was largely demographic in nature and GIS was regularly used by the demographers there. In actuality, however, it would not have been possible without Sharkova's willingness to be engaged in the work. Sharkova had been following the Atlas project through Radin who had taken courses in 2003 from her as an urban planning graduate student. During that time, Radin would discuss technical and data issues related to the Atlas with her which ultimately led to an independent study course in raster modeling in preparation for the conversion to raster for the project. According to Sharkova, "I was really curious and very interested myself in raster modeling and so excited that he was going to look in to that [for the Atlas]." (Sharkova, 2008). Sharkova had been impressed by CLF's policy work and was intrigued by the notion of an equity Atlas. It also helped that CLF Board member and staff at the Center for Urban Studies (CUS) 
at PSU, Steve Johnson, went directly to Sharkova for CLF, seeing her and the PRC as a good fit for the project.

Negotiations between Sharkova and CLF began in earnest in late April, 2004. When the project was housed at IMS, although Radin reported to Seltzer on a regular basis about his general ideas, the progress made, and concerns, the vast majority of his time was spent working independently producing maps or directly with Harmon to sort out, in a give and take fashion, what she wanted.

When the project moved to the PRC, however, the roles and relationships between PSU (with Sharkova acting as the principle investigator and Radin as the GIS analyst) and CLF (represented by Harmon and Fugliser) began to shift. Sharkova didn't have the history with CLF that Seltzer had. Nor had she been involved in the early discussions that shaped CLF's mapping project into an "equity atlas" or the equity framing and indicator discussions.

Unlike Seltzer whose background was planning-focused, Sharkova was a geographer by training, a demographer in practice, and a published GIS expert. Much of her work at the PRC was focused on contracts with public agencies and school districts where expectations, deliverables, and lines of authority were clear. These expert/client relationships could not be characterized as collaborative or participatory in the sense that CLF was accustomed to or in the way in which Harmon and Radin had been working together. But in Sharkova's mind, the Equity Atlas project would not be all that different from her prior experiences: the PRC, which had demographic and GIS expertise and some knowledge of equity mapping through Emily Talen's 
research on the topic, would be engaged by a client (CLF) that was in need of its expertise:

We had a client [CLF]. They wanted us to do some maps... These maps had to do with equity. I was familiar with Emily Talen's equity mapping for planners. At least as far as measurement and GIS, I was informed. (Sharkova, 2008)

From Sharkova's perspective, Harmon and Fuglister seemed to have a clear idea about what they wanted. Radin was already deeply invested in the work and wanted to finish it. Sharkova had tremendous respect for Radin's capabilities and knew that she could rely on him. Moreover, the project seemed interesting; she was "curious" about it (Sharkova, 2008).

In late April, Radin was asked to comment on a draft scope of work that Harmon had put together for the April $15^{\text {th }}$ to October 31, 2004 period anticipating the move to PRC. Radin's April $20^{\text {th }}$ comments to Sharkova about the draft provides several insights into his assessment of the project to date. With Sharkova's involvement in the project he knew he would have someone who could relate to the frustrations he was experiencing because of Harmon's lack of GIS knowledge and, from his perspective, relative lack of analytical sophistication - in other words, he would have an ally. This correspondence between Radin and Sharkova makes it clear that he believed that the project suffered from confusion at the most fundamental levels. Because of this confusion, Radin observed that Harmon kept struggling to utilize the diagnostic maps as if they were the indicators and argued to Sharkova that: 
"The diagnostic maps are not the indicators [emphasis in the original]; they are a tool to use to get us to the indicators..." (Radin, 2004b). Radin added:

Tasha has been trying to formulate "the story' around the "diagnostic maps" (and general ideas) but I don't see how this is possible. It has been, and remains, a core problem, I believe... (Radin, 2004b)

Radin continued his analysis of the progress of the project by suggesting that a key concern was that the links between equity or inequity, the variables, and an effective mapping strategy simply weren't there:

... there needs to be more proactive thinking about which variables and mapping strategies will produce an "indicator" of equity or inequity, along the lines of the "issue areas" outlined in the framing document, rather than relying on these diagnostic maps to determine what can be told, or telling a story that may be true, but is not supported by the maps... (Radin, 2004b)

Given Radin's growing interest in GIS theory, raster modeling, and overlay analysis, it isn't surprising that what intrigued him most in the proposed scope were the aspects of the project related to the development of indexing and overlay methodologies:

This is primarily what I hope to tackle, if not achieve, with our contract [PRC's contract with CLF] (our class [the independent raster modeling course with Sharkova]), that is, working out the appropriate methodology/s, but not producing the full set of composite maps or indicator maps...

(Radin, 2004b)

Paving the way for the transition to raster modeling, Radin concluded that the choropleth maps of census tracts that he had already produced, with the addition of vector overlay analysis, would only be "opening a can of worms: very difficult to produce meaningful, valid, reliable conclusions from an overlay process based on 
census tracts..." (Radin, 2004b). On the other hand, Radin couldn't resist the conceptual challenge of intersecting in the GIS environment, the "vertical" dimension of the socio-economic system with the geo-spatial sphere:

But the overall goal is to get closer to the ideal, I believe, in which case I still think something useful can be produced from some overlaying of tracts, either graphically representing, or discovering, a geographical pattern based on the coincidence or consistency of various socioeconomic variables across space... The objective of this type of analysis seems to be to "map the horizontal dimension of a vertical, hierarchical economic system', i.e. to show the spatial pattern of socioeconomic stratification... (Radin, 2004b)

Aware of CLF's history with Myron Orfield and Portland Metropolitcs (1998), Radin tried to incorporate Orfield's ideas into his objective for the project:

It could also be part of what might be termed an "Orfield" theory, which I'm not too familiar with, but which has to do with gentrifying inner city and increasing poverty in inner-ring suburbs, I believe.

(Radin, 2004b)

Radin (2004b) added: "Tasha is somewhat attached to seeing this in the maps, which isn't entirely helpful..." Harmon's assumptions about what she thought she should be able to see in the maps had plagued Radin throughout the process. In one sense, Harmon, as a widely acknowledged housing expert, was providing ground-truthing for the maps: if the maps didn't look right, something could be wrong with the data, the processing of the data, the classification of the data, or cartographic factors. However, as a GIS analyst and social scientist in-training, Radin knew that care had to be taken to ensure that the maps would not be made as instructed. In spite of these concerns, Radin believed that Harmon's storyline was probably valid based on the maps produced thus far. The problem was that they were simply inadequate to do the job: 
... from what I can tell from the mapping to date, the stories Tasha wants to tell exist; we simply haven't produced the graphics and analysis to support them... This is a major tough spot in the project... (Radin, 2004b)

Radin's frustration with Harmon's use of the single-variable maps as the basis for her storyline had come to a boiling point and was something that he saw as a misuse of the maps. At this point in the process, he had decided that a move to raster was essential to the integrity of the project, but this also meant that a whole new set of maps would need to be made. There had been agreement, indicated in Harmon's early framing documents, that equity or inequity was a multi-dimensional phenomenon that would require either a tremendous number of variables, and therefore a tremendous number pages in the Atlas to convey, or a few composite variables that could be seen as equity indicators; this was still to be done. In his frustration, he wanted to see Harmon focused elsewhere until he and Sharkova had developed an indexing methodology and a new set of maps that Harmon could successfully use to tell the equity story:

If I were the boss, I'd want Tasha to focus her efforts on the "casestudies" portions of the Atlas, or similar, smaller pieces, such as additional research into equity around the nation, for the next two months or so... I simply see no authoring possible in connection with the maps at this time or in the near term... The mapping is in disarray and needs to be seriously focused. The maps to date simply do not tell a story; they can't. (Radin, 2004b)

Harmon and Fuglister had, in fact, begun that May to explore how to move forward with the case studies that they hoped would serve as "Illustrative Vignettes" for the issue of equity in the region and were struggling with how to identify 
"representative" areas or locations to highlight (Harmon, 2004). They had hoped that the maps would be able to inform this decision. However, Radin's admission to Sharkova that the mapping was in "disarray" was remarkable at this point in the project. CLF had expected the Atlas to be ready for publication in late summer of 2004. What is clear from this draft scope of work is that the deadline would have to be extended. With the addition of Sharkova to the team, Radin finally had someone with whom he could confide his analytical and technical concerns and someone who would support the necessity for a redirection.

Radin brought up one additional issue in this document that would significantly affect the forward movement of the project and that was the participation of the volunteers. Because of the lack of resources for the project, it had been assumed from the beginning that the GIS work would be provided by PSU and volunteers who had stepped forward from the professional GIS community. They included Mark Bosworth at Metro, Glen Bolen at Fregonese Calthorpe Associates and Rafael Guiterezz at Fishman Environmental Consulting. The coordination of the volunteers was one of the tasks outlined in the draft scope that Sharkova was supposed to take on. As far as Radin was concerned, this was a "Wild Card" since, thus far, Harmon had been unsuccessful in getting them to adequately respond. From Radin's perspective, however, Bosworth's contribution, in particular, would be essential to the completion of the Atlas because CLF was depending on him, in his capacity at Metro, to provide all the data and maps related to greenspaces (Radin, 2004b). 
On June 16, 2004, Sharkova and PRC officially took over the supervision of the GIS portion of the Equity Atlas project. By the 3-month deadline of September $15^{\text {th }}$, and for just under $\$ 15,000$, specified in the contract between PRC and CLF, the diagnostic maps would be complete, the final maps prepared, and a methodology and protocol document would be developed. In addition, Sharkova would oversee the production of the diagnostic and final maps produced by the mapping team that included Radin and the volunteers. Sharkova would also work with Harmon to determine what overlay and indexing methodologies would be used as well as determine which maps would serve as the best indicators for the "story of regional equity" and which map should serve as the basic overlay map (harkening back to Harmon's framework that envisioned a poverty map as a basic, "transparent" overlay for the Atlas) (Sharkova, 2004a).

Although this scope of work points to overlay and indexing, both procedures that had been anticipated from the start, there is no specific reference to the conversion to raster analysis and no apparent concern about any additional time that it might require. By the time that the contract between CLF and PRC was enacted, Radin had already produced and circulated his first "surface," or raster map to Sharkova, Harmon, and Fuglister for comment and ultimately, approval.

Given the history of the project to this point, this was an overly ambitious timeline. In commenting on the list of maps and possible changes that were identified in the April draft scope of work, Radin noted, "As you may notice, we have a long way to go..." (Radin, 2004b). The difference now was that Sharkova, who was very 
experienced both with the analytical/technical aspects of the project and the professional contracting environment was onboard.

\section{Of Indices, Rasters, and Blackboxes}

In early June 2004, Radin circulated his first "surface" or raster map to Sharkova, Harmon, and Fuglister. He needed their approval to move forward. And, although there were some technical issues related to the conversion of the census data to raster, overall, the reception was positive. Fuglister stated that she thought that, what they all referred to as the "surface" maps, were "much more readable without all of the tract boundaries" and that she thought that this approach would be "very helpful for vignette analysis;" all in all, she gave it "a big thumbs up" (Fuglister, 2004).

Sharkova commented:

This is a very good map: it displays clear and meaningful patterns unobstructed by divisions normally imposed by Census statistical area boundaries (yet it's based on the most detailed data available from the Census). It is a major improvement over Census tract-level maps prepared for the presentation [CLF's Regional Summit] in April.

(Sharkova, 2004b)

Sharkova's support for this approach based on the resolution of the data was something of an exaggeration. Both Radin and Sharkova knew and acknowledged that the most detailed data (those available at the census block level that Radin had used for his "test" map) were only available for a few variables and, therefore, he would be forced to use census block group data for the conversion process instead. Furthermore, choropleth maps using census blocks or block groups would also have been preferable to the census tract maps in terms of spatial resolution. Any question 
that the mapping would move to the raster model, however, was erased by Sharkova's next statement:

I believe that all maps, i.e., the ones to portray trends for the entire region, shall be completed using the method you have used for this map (adjusting the method as it makes sense). (Sharkova, 2004b)

This approach appeared to address the major problems that Harmon and others had identified related to the choropleth maps: confusion about "big" tracts with "big" color and "the general lack of correspondence between the reality on the ground and what the maps were showing" (Radin, 2005). Over the summer of 2004, Radin, in consultation with Sharkova, began to work in earnest, converting various census variables to raster.

In the meantime, work was proceeding on other fronts. One was the issue of indexing and another was coming to terms with how the access to parks and greenspaces maps would move forward.

With Radin focused on mapping, Sharkova took it upon herself to begin a conversation about the desirability of developing a "composite" indicator that would summarize the data already mapped as well as those yet to be mapped (Sharkova, 2004c). Radin and Sharkova believed that this task was essential to moving the project from a focus on variables to the notion of indicators. Moreover, this was a topic about which Sharkova had great interest and expertise. With David L. Cleveland she had, in 2002, co-authored a paper, "Developing Community Quality-of-Life Indicators for Alcohol and Drug Prevention in San Diego County, CA" that was published in Advances in Community Quality of Life Research (Sharkova, 2004c). 
After meeting with Fuglister, Sharkova decided that it would be important to educate her clients about what social indicators are, what a composite index is, and their pluses and minuses according to the academic literature. In an email message dated July $30^{\text {th }}$, that she apologetically described as a "manuscript" that would need some time to "digest," Sharkova essentially modeled for her clients how an academic would approach the problem by reviewing the literature, identifying the pros and cons identified in the literature, and then, objectively assessing the options.

Harmon and Fuglister did not have to be convinced of the desirability of utilizing indices or composite variables into the Atlas but Sharkova wanted to be sure that they understood the opacity of an index - that behind each index lies a multitude of decisions about which there was considerable debate in the literature. Learning about the participatory nature of CLF, Sharkova felt that they, Harmon and Fuglister and, by extension CLF, should share in the decision-making related to an Equity Atlas index and that it was her job to guide them. "What does this all mean for the Regional Equity Atlas?" she asks, rhetorically. In her email, she breaks down her answer into two procedural options: (1) objective; and (2) subjective with caveats.

The objective approach. Using a statistical procedure called factor analysis, Sharkova, suggested that the number of variables could be narrowed to a few "supervariables" those "underlying factors, dimensions or components that cannot be measured directly but express themselves via simple variables" (Sharkova, 2004c). Assuming that the input variables, the diagnostic variables to date, were comprehensive enough, Sharkova anticipated that three major factors would be 
identified based on the statistical procedure: socioeconomic status (high to low), family status (large to small households), and ethnic status ("whiteness," high to low). And, she suggested, that there could be one or two others. Sharkova explained that these would be objective in that they are statistically sound. However, she noted, that the naming of such factors (such as "underclass," "highland elites," or "black poverty," is not objective in that the researcher makes a judgment based on which variables are the strongest in each factor. And, she warned, "factors, although selected for us by statistical software, are similar to composite indexes in that they somewhat hide [the] contributions of their components (Sharkova, 2004c).

The subjective option. Here, Sharkova stated that she could condone some subjective approaches to analysis as long as "we are very clear to ourselves and to future audiences of the Atlas that this is what we have chosen to do and why" (Sharkova, 2004c). Sharkova outlineed three possible approaches, all using poverty as a key variable.

The first option focuses on poverty "regardless of its correlates" and identifies three to four types of geographic areas of high to low poverty. The geographic boundaries of these areas would then be used to summarize relevant census and other data in tabular or graph form. This would organize the collected data into different poverty types defined subjectively and it would not indicate which maps to include in the final atlas. Sharkova also stated that a statistical test would need to be performed to test for statistical significance among the area types. 
The second proposed subjective approach was a modification of the first. This option would utilize two indicators of poverty: that of magnitude (current poverty status as a percent of poverty), and that of direction (change in poverty over ten years). In this approach Sharkova suggested that they would be able to identify geographic areas that: (1) were poor in 1990 and got worse; (2) were poor in 1990 and got better; (3) were affluent in 1990 and got more affluent; (4) were affluent in 1990 and became poor; (5) and two or three other categories such as stable rich and stable poor (Sharkova, 2004c). Here, again, the data would be summarized in tabular or graph form and a statistical test run to ensure statistical significance among the areas.

In the third subjective approach, Sharkova suggested using several variables to come up with a composite index of community stress/vulnerability (Fuglister's term). This approach is subjective in the sense that rather than having statistical software determine the significant factors, they, CLF with Sharkova, would determine what the variables would be and how to weight them for a composite index. Sharkova argued that they might not want to include variables that aren't strongly correlated with each other - suggesting some initial statistical analysis to inform their decision-making. After the variables are selected they would need to be standardized (converted to zscores), so that they would be comparable, and then added together. The resulting numeric range would then be divided into classes as in the case of the choropleth maps. Sharkova pointed out that the number of classes, the class breaks, as well as their interpretation are all subjective. However, she stated that the classification method that Radin had used in the first "60" maps was the "best," most "objective" 
approach because it used standard deviations from the regional mean. Once the classification was completed, the relevant data would be aggregated by "community distress/vulnerability type," tested for statistical significance of the differences between classes, and put into tabular form (Sharkova, 2004c).

Finally, Sharkova warned that "statistical analysis takes time, and it may not produce the desired results..." (Sharkova, 2004c). Based on the maps that were being produced during this time, it appears that the decision was made to proceed with Sharkova's subjective option \#1.

By early August, Harmon was still scrambling to figure out what was happening with the greenspaces portion of the Atlas. An email to Sharkova, Radin, and copied to Jim Labbe (on loan to CLF from the Portland Audubon Society, a founding member organization of CLF) and Ron Carley (CLF Board member and Audubon Society staff), indicates her concern about the status of the mapping that Bosworth had initiated. At this point, Audubon was focusing its efforts on an upcoming greenspaces bond measure that Metro had put forward and saw the Equity Atlas as a valuable advocacy tool. Audubon had agreed to donate a part of Labbe's time to assist Radin (who agreed to take on this task using Bosworth's data) in the mapping effort for the Equity Atlas. Harmon was acutely aware of the time pressure and saw the September $15^{\text {th }}$ deadline of the PRC/CLF contract fast approaching even though they were still discussing the availability of data and what should be mapped (Harmon, Email correspondence, 2004). 
In anticipation of the publication of the Atlas, in mid-August, Harmon

attempted to draft some text to go along with a few of the new maps related to poverty and housing for a brochure publicizing the Atlas. This would be the first time that the public would see the new maps (figure 7.1) and Radin wanted to be sure that Harmon had interpreted them correctly.

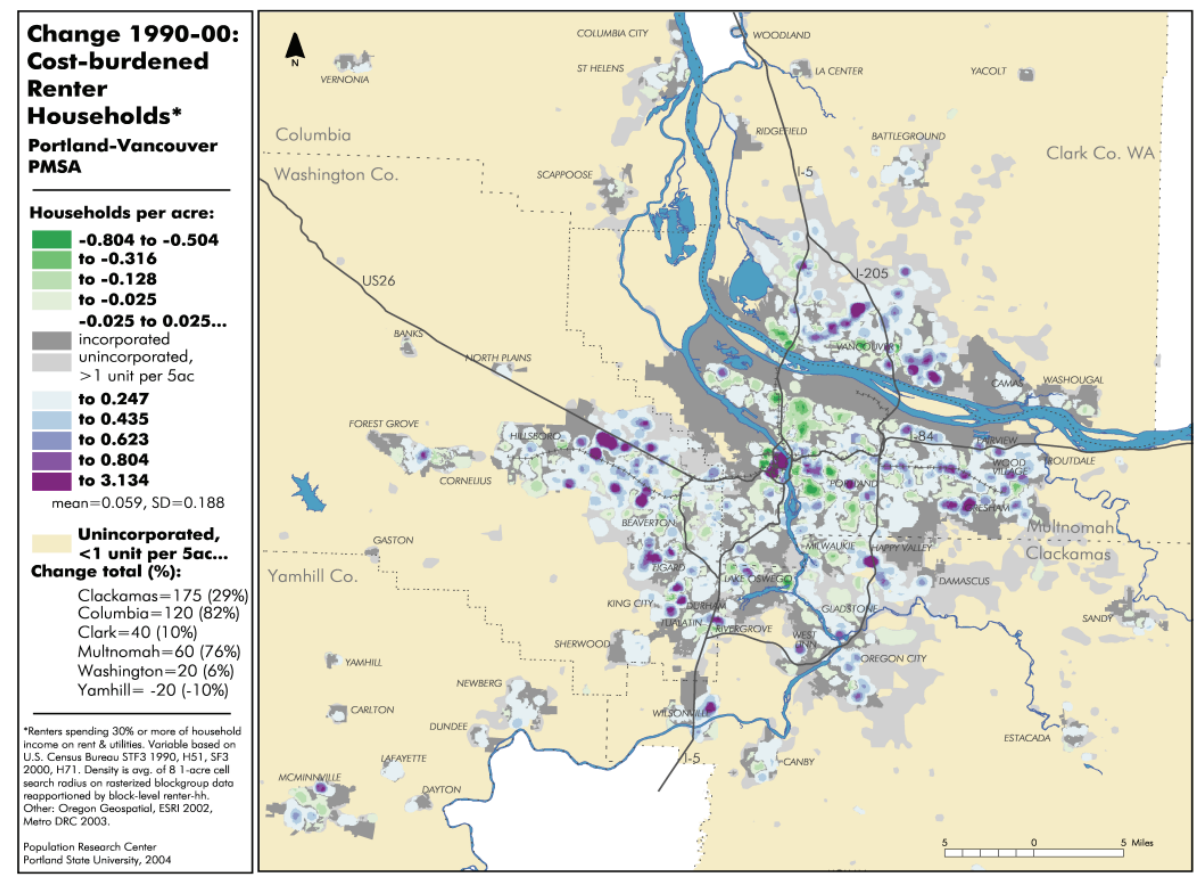

Figure 7.1. Map by Radin from the "Atlas Brochure Draft," August 16, 2004.

The exchange between Harmon and Radin related to these maps makes it clear that the new approach wasn't necessarily more legible than the choropleth maps had been, at least to Harmon. Radin questioned her selection of the particular maps for this purpose, not being sure that they said enough or meant what Harmon thought that they meant: "[I'm] not really sure about these maps" and then relayed to her some 
additional information that a map user would need in order to interpret them correctly

(Harmon and Radin, 2004):

...the most striking feature in my view is the distribution of cost burdened renter hhs - increases happened, it's spotty, nearly all over the place (though note places like Sherwood, Scappoose or Camas where there wasn't much of an increase). Having seen a 2000 multifamily housing map, much of the change in cost burdened renter hhs appears to be the result of areas that got a lot of new multifamily housing, thus an increase in the 'pool' of housing that might contain cost burdened renter hhs [households]...

FYI: I'm told that the increase in 'cost-burdened' owner hhs is probably the result of cheap credit during the 1990s and an influx of new buyers - people who were on the margin earlier but then were able to get into the owner housing market...

(Radin quoted in Harmon and Radin, 2004)

It is interesting that Harmon even attempted any level of interpretation given the legends included in these maps. This would be an issue that would some up later, however.

During the summer, Fuglister engaged graphic designer, Ryan Sullivan, to design the Atlas document. And although the maps for the Atlas were far from complete at this point, Radin prepared a few "design tests" to submit to Sullivan. Based on the list of maps that Radin put together on September 11th, he was still creating maps, some single-variable maps in the raster format and others, also rasters, that utilized the indicator methodology previously discussed (Radin, 2004c).

The September $15^{\text {th }}$ contract deadline came and went as Radin and Sharkova worked more as colleagues than supervisor and supervisee to see their way through the multitude of decisions that had to be made: 
The contract was extended. The first time it was extended to the end of the year. They found a little bit of money to pay for Ken. If you remember how PSU works, I was principal investigator because I was the one responsible for the contract. Ken was a research assistant, however, his role in reality was more of an investigator than an assistant. He was an investigator in his own right... my role was basically a researcher with more experience who oversaw the methodology and who made sure that whatever we were presenting was sound. (Sharkova, 2008)

As Radin drafted each surface or raster map, he would check in with Sharkova to get her reactions, argue his position, and get suggestions. These often lively exchanges were discussions that, as analysts and researchers, they both enjoyed:

Ken would be developing maps. We would talk about every map. And there were many, many drafts of each map. I think maybe we talked about each draft for a couple of hours. We talked a lot - okay, maybe an hour. (Sharkova, 2008)

Somehow CLF managed to put together enough funding to push the project to completion by the end of the year. But, as Sharkova intimated in her indexing "manuscript," the development of indicators and the conversion to raster were only superficially straightforward. Underneath both of these tasks lay any number of questions to be responded to by actors seen and unseen: Radin, Sharkova, Harmon, CLF and its volunteers, and computers via statistical and GIS software. The result, that not even Sharkova and Radin could anticipate, was a tremendously timeconsuming, and often-times frustrating process. In the minutes of CLF's October, 2004 Board Meeting, the following assessment of the Equity Atlas project was recorded:

We are still mapping - it is taking longer than we expected. We think we will be publishing the Atlas in March. We should have mapping 
done by the end of this month. Volunteer mapping didn't work out, which caused delays. (CLF Board Minutes, October, 2004)

\section{Penetrating the Rasters}

In November, 2004, Radin prepared a PowerPoint presentation for the CLF Board of the progress to date. The presentation included forty-six draft maps including maps related to access to parks and greenspaces, education (point maps, not rasters), and grocery stores (very limited). All except for the thirteen education maps, which were largely point location maps, and three others that were not based on census data, were rasters. These thirty raster maps were created by converting census block group data to raster and were entirely focused on poverty and housing-related variables that appear to have employed Sharkova's subjective approach options \#1 and \#2.

The poverty variables (poverty and child poverty) were displayed using the following categories: below average and decrease; below average and increase; above average and decrease; and above average and increase - essentially, the categories suggested in Sharkova's subjective option \#1. For each housing variable, on the other hand, three maps were created: 1990, 2000, and change between 1990 to 2000 units, value, households, or persons per acre (the size of the raster or grid cell) depending on the variable. The housing variables were: owner-occupied new housing; housing value; rented single-family housing; owned single-family housing; multifamily rental housing; households with no vehicle; and persons with a long commute (Radin, 2004d). 
These maps differed from the maps that had been presented in the CLF's April 2004 Summit in a number of significant ways. First, the Census enumeration boundaries were no longer present and the abrupt color changes between the tract boundaries that were so misleading in the choropleth maps were now gone. Second, the census variables appear to be a continuous surface across space. This is because the data were now assigned to acres rather than census tracts. Acres are a uniform areal unit, are relatively small, and have the advantage of being close in size to census blocks - the smallest unit of aggregation used by the Census Bureau.

However, because of the "smoothing" process that Radin used to convert the data to raster surfaces, the population still can appear to be present where there is none but to a much less degree than had been the case with the choropleth approach. The result is that these maps appear to have the look of those created from data available at a very high geographic resolution. Like the earlier maps, these data are categorized in relationship to the regional mean and standard deviations from that mean, however, because the data are now attributed to individual acres rather than census tracts, the legends are often difficult to interpret. For example, as seen in figure 7.2 , what does 0.135 or 0.196 housing units per acre actually mean? 


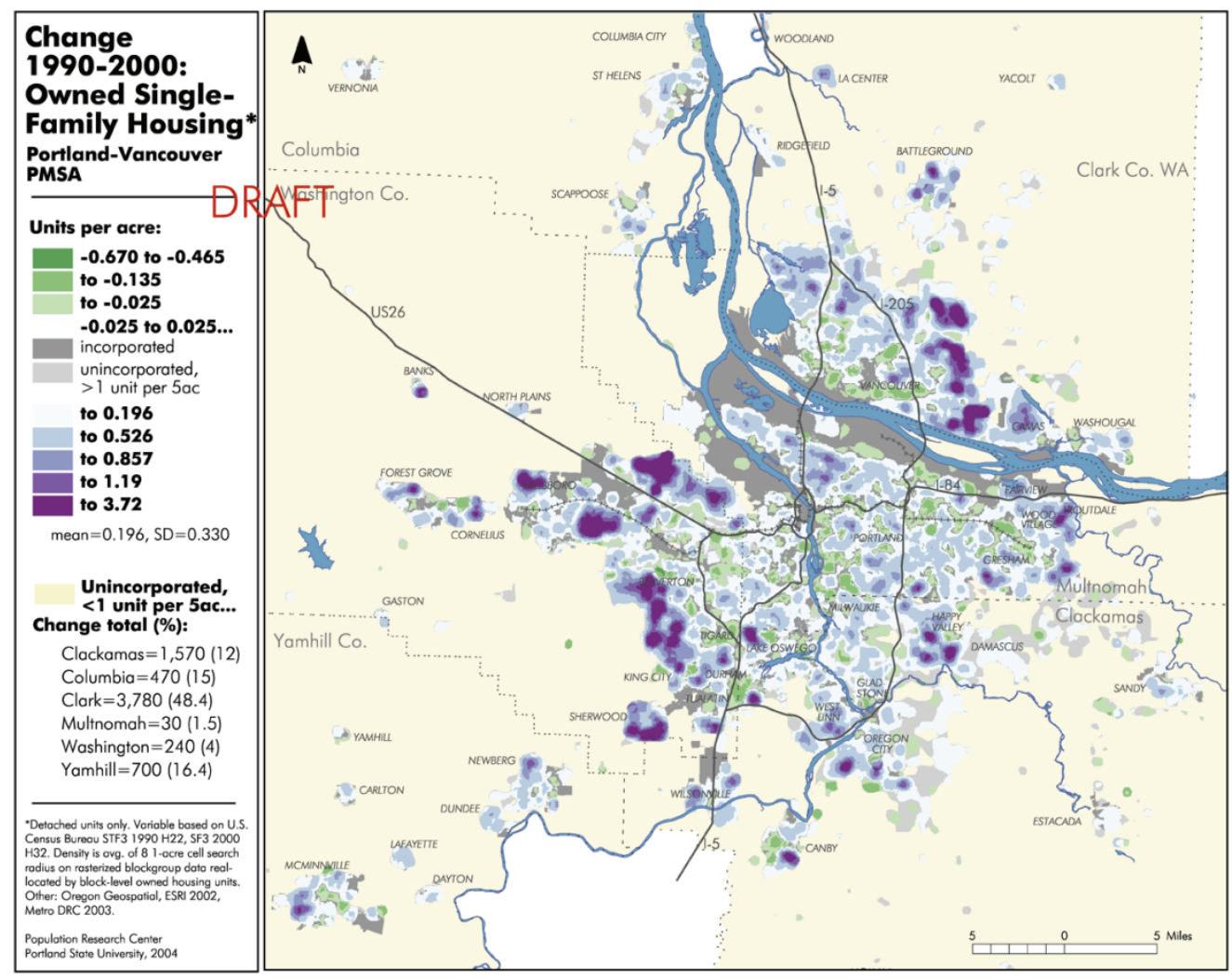

Figure 7.2. Draft Raster Map and Legend. From "CLF Meeting, November 9,2004. Map by Ken Radin. Source: Ken Radin.

There is no evidence in CLF's Board minutes that this presentation was

actually made at the time, or documented reactions to these maps, except for a

December exchange between John Provo, a Ph.D. Candidate and graduate research

assistant at IMS at the time, who was preparing an article that incorporated four of the maps for publication in the Institute's 2005 Briefing Book. Provo loved the look of the maps but was uncertain about his interpretation:

...these are very cool maps! Ken, [Radin] the text below [a short draft of his piece that referred to the maps] is very rough, but I wanted to check in with the artist about my interpretation of his work. The poverty map in particular requires some deft interpretation that I'm not 
capable of at the moment. I also need to be able to place some of these blobs either within or near cities and I hoping you can help me there.

(Provo, 2004)

As the timeline drifted into 2005, and the new March deadline approached, Harmon continued to struggle to draft text to accompany the maps. The challenges related to the interpretation of the new maps were even more cumbersome than those associated with the old choropleth maps. In a February 24, 2005 correspondence with Radin, Harmon expressed her frustration in interpreting the new approach. She complained that the change from median home value to value per acre (figure 7.3), for example, “... is going to make the storytelling much harder - people won't get their brains around it nearly as easily" (Harmon, 2005). Again, based on this example, she asked why he changed the legends from "percentage change" to "change in value per acre:"

The original set of maps I have on housing value shows median house value, not value/acre, and percent change, not change in value per acre as a dollar amount. Again, the old system was much easier for people (including me, clearly) to wrap their brains around. (Harmon, 2005) 


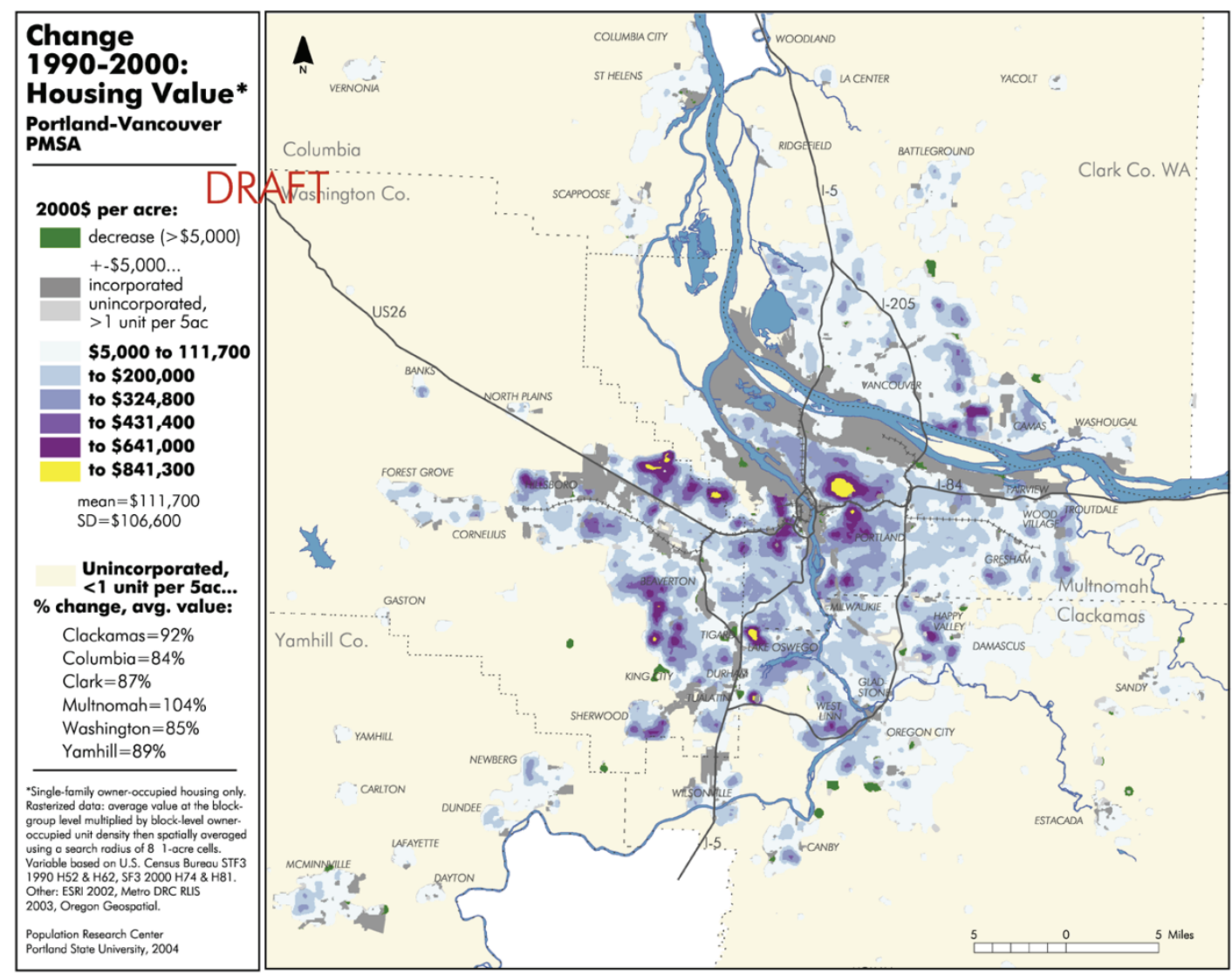

Figure 7.3. Draft Raster Map and Legend. From "CLF Meeting, November 9, 2004. Map by Ken Radin. Source: Ken Radin.

She questioned the change in mapping systems and the allocation of the data to acres as unintuitive and opaque: "Persons per acre seems to hide some of the info that I am used to seeing in these maps - density changes masking other things?" (Harmon, 2005).

While Radin provided short responses to each of her inquires and comments, and there were many not included here, he also decided to prepare a "primer" that he hoped would answer all of her questions in depth. This remarkable document, $A$ Primer on Reading the Surface Demographic Maps dated March 4, 2005, not only 
provides instructions on how to interpret or translate the maps' legends into something more intelligible but offers his thinking as to the rationale for the switch to raster, his critique of the new method, and his methodology. What follows is an overview.

The Rational. Radin recounted that there had been many comments about the earlier choropleth maps that indicated to him that the maps, in his words, "suck" (Radin, 2005). There were several problems that needed to be addressed including: not being able to distinguish cities from unincorporated areas; general confusion related to "big tracts with big color" or the way apparently arbitrary way that the census tracts are delineated; and the "lack of correspondence between the reality on the ground and what the maps were showing" (Radin, 2005). In addition, the kinds of things that people wanted to investigate "happen at a smaller scale than tracts could possibly reveal" (Radin, 2005). He also pointed out that tracts do not fit neatly into the neighborhood scale and thus neighborhood scale changes get lost. This new methodology was an attempt to "get around these problems" (Radin, 2005).

The critique. Radin admitted that his new methods had shortcomings. In the Primer he suggested that while the new maps were good at showing spatial patterns, especially regional spatial patterns, they "defy a more precise, numerical interpretation, at least not without some serious spatial mental work" (Radin, 2005). He continued:

What does a change of " 0.157 " people per acre" mean? [In response to a direct question from Harmon.] What does it look like, for example? Not only is the number unintuitive, there's more to it than that: it's an average change within a certain "search radius" - about $6 \frac{1}{2}$ city blocks - and base on a reworking of aggregated data.... The numbers and 
parameters reflect the best compromise I could come up with, considering the amount of work to be done, the data, the goals, etc. Basically, it's the kind of number ... that makes a standardized approach possible. (Radin, 2005)

In terms of the immediate crisis, which was how Harmon was going to incorporate the maps into her writing, Radin advised her to concentrate on the patterns using "more" and "less," "lighter" and "darker" terms rather than "hard numbers" (Radin, 2005). To correct this problem, Radin suggested that he could create "political units summaries" in tabular form "so that we can have it both ways" in maps and tables (Radin, 2005). The fact was that the conversion to raster had one clear advantage over the old approach, in this respect, it allowed for a relatively easy reallocation of the census data to different geographic boundaries. And, as early as September 2004, Sharkova had discussed this strength of the raster conversion with Fuglister: “... the dataset he has developed allows one to quickly summarize necessary statistics from the layers already created for any custom area" (Sharkova, 2004d). This approach would allow Harmon, for the first time, to be able to utilize statistics at the neighborhood level rather than the tract or block group levels, areas that were readily recognizable not only to Harmon, Fuglister, and CLF members but the public at large. With no neighborhood boundaries on the maps, the visual connection between the raster maps and the aggregated data in the tables, wasn't clear, however.

Wanting Harmon to have some level of appreciation for the challenges he was dealing with, Radin admitted that he was having technical difficulty working with percentages in the surface or raster environment. He confessed that the percentage 
maps that he'd attempted ended up looking like "smoothed block-group boundaries," that were very different in appearance from the other surface maps. Moreover, he simply couldn't make any of the reported "median" values work. Radin's conclusion was that the reported "medians" were derived from the aggregated data by block group and, therefore, couldn't be recreated as surfaces (Radin, 2005).

Legend tutorial. The purpose of any map legend is to help the map reader to interpret the meaning of the map - not hinder it. Because this was so important, and because Radin was beginning to realize the truth of the illegiblity of his legends, he went into depth on this topic, using Harmon's query, "What does a change of 0.157 people per acre mean?" as his example.

First, Radin reiterated that the inclusion of the regional mean and standard deviations in the legends was intended as an aid to interpreting the classification of the data rather than values that can be "readily" used to interpret "hard values' on the ground" (Radin, 2005). The reason, he suggested, for doing this is that these values (the mean and standard deviations) are:

... based on values generated during the GIS statistical method, which itself includes taking an average of values over a certain area ... So, the mean, or average, included in the legend, is an average of values that have already been averaged, or "smoothed." (Radin, 2005)

Furthering the complication, Radin related that the averages in the legends were, in fact, lower than "true" regional values, and the standard deviations were less extreme they would be if he were working with non-averaged, true per acre values (Radin, 2005). Therefore, Radin recommended that these values shouldn't be used to describe 
"the region." That, he suggested, should come from looking at the region as a whole unit and calculating or "looking up" the value - presumably in a summary table that he would create for her (Radin, 2005).

Radin's method, as outlined for Harmon, was much like the centroids and radial kernal functions method outlined by Goodchild et al. (1992) and proposed by Martin (1989) and (Martin and Bracken, 1991). The goal of the process, he explained, was to "move" the block group data around via GIS software to reflect the block level data. The value in doing this was that the population can be distributed where it exists - something that Harmon had long desired:

For example, a block group level variable, such as poverty, would show the whole area of the block group a single color. But from the underlying block data, we know that half the block group has no people at all and, therefore, no poverty. (Radin, 2005)

Radin next provided a simple explanation of the process that ArcView's Spatial Analyst software performs in the conversion to raster and data assignment process:

After we "move" the data, which has been converted to 1-acre cells that cover the region (example, population per acre), we then draw a circle around each of these cells - a circle that's about $6 \frac{1}{2}$ city blocks from the center to edge (radius) - and we take the average of all the cell values that fall within that circle, assigning it to the particular cell around which the circle is drawn. (Radin, 2005)

This procedure is then repeated cell by cell. Why do this? Radin explained that this procedure "smooths" or generalizes the data, "so that it is easier to distinguish regional patterns" and also because since the data came from larger spatial aggregations - block groups - "we have to generalize, or else we create a map that 
implies a level of detail that simply cannot be known from the available data" (Radin, 2005).

To provide enough background for Harmon to decipher his legends Radin

went on to describe, in more real-world terms, his spatial analytical procedures:

A " 1 -acre cell" is just about a city block. In the downtown area, for example, the area occupied by buildings within a given "city block" is about an acre - $208.6 \mathrm{ft}$ x $208.6 \mathrm{ft}$ (Keller Fountain occupies an acre). The "search radius" we used for all the demographic maps was 8 cells, or $8 \times 208.6 \mathrm{ft}$, which equals 1,668.8 ft For reference sake, when we include streets in our conception of the urban landscape, the distance from the center of one intersection to the next is 260 feet ... Hence, the search radius is about $6 \frac{1}{2}$ city blocks. One mile is 5,280 feet. Our search radius expressed in miles is a little less than $1 / 3$ of a mile.... Within the search circle, there are 2001 -acre cells... To really understand the legend values (not necessarily the maps), you need to think about these parameters, dimensions, and methods. (Radin, 2005)

Returning to the question of what a change of 0.157 people per acre means, he suggested "a couple of tricks:"

Picture the $6 \frac{1}{2}$ city block search circle around a single acre cell. First, what kind of change would have to take place in order to change, by a factor of 1 , the population value assigned to the cell, around which the circle has been drawn (change $="+1$ person per acre)? Since the value of that cell will be the average of all the cell values within the search circle, and since there are 200 cells within the search circle, increasing the value of that cell by a factor of 1 would take an increase of 200 people somewhere within the search circle. (Radin, 2005)

And, he went on in an attempt to provide a mathematical and visual method for thinking about his legends:

These 200 people could be in a multifamily complex at the edge of the circle, in a single acre cell, $6 \frac{1}{2}$ blocks away. Or, they could come from several single-family units spread around within the circle. It wouldn't matter: as long as there were 200 more people within the circle drawn 
around the cell for which we are calculating the value, the value in terms of population per acre... (Radin, 2005)

Another way to think about it would be to: “... picture a circle 13 blocks wide and picture 200 people moving into it. That's " 1 person per acre" - change or otherwise.

(Radin, 2005). So, how to calculate an increase of 0.157 persons per acre?

A quick and dirty way to deal with the decimal values is to take their inverse - divide 1 by 0.157 , for example - which produces 6.4. Think of acres per person instead of people per acre. A change of +0.157 is equivalent to a change of 1 person per 6.4 acres. It's like one person moving into an area a little larger than 6 Keller Fountains. ... Alternatively, again, think of what it takes to change a value by a factor of 1 - the 200 people within the circle - and multiply 200 by 0.157 : it equals 31.4. So a change of +0.157 is equivalent to 31.4 people moving into the 13 city-block wide search circle. (Radin, 2005)

Radin ended his primer re-stating his caveat about the reliability of the values associated with each cell. In a sense, the data, through this process, was another degree of separation from those using the Census Bureau's geographies. Furthermore, those geographies at the regional scale were relatively easy to identify unlike individual 1-acre cells. Harmon had gotten used to being able to associate a reliable number with a given census tract. Radin was concerned that she was trying to do the same with individual cells and wanted to discourage that:

We're thinking of calculations and parameters for a single 1-acre cell, which truthfully can't be relied upon so precisely. The value of single cells takes on significance mainly after we're able to see the calculated values for all [emphasis in the original] the cells covering the region.... When all is said and done, we get a map that shows concentrations and dilutions of whatever variable we're looking at; we know that the value of a given cell is more or less genuine - because all the cells around it tend to have similar values (i.e. we see patterns). (Radin, 2005) 
While Radin's primer was intended to make the map interpretation and, by extension, the writing easier for Harmon, the effect was, instead, the opposite. But, she appreciated his tireless efforts in working with her to come up with maps that would work:

Every map, every map took us hours of talking about, "Do we want it here?" and Ken generated ten different kinds. And, then had the color schemes to think about after that. Oh, it was awful! Absolutely, awful! And, Ken should be sainted for the level of patience he showed.

(Harmon, 2008)

\section{Casualties}

As the February 2005 deadline for the Atlas approached, the stress of having to navigate through the interpretive issues of the raster maps and actually put pen to paper had become too much for Harmon. When it had become clear to everyone involved in the project that the deadline wouldn't be met, CLF managed to come up with some additional funds to extend the contract with PRC to June 30th bringing the total of the contracted services from PRC to $\$ 25,000$ (Fuglister, 2005). Harmon, on the other hand, believed that the project could take much longer and her health was suffering. For her, the project was over: "So, at a certain point, I was like, you know, I can't do this anymore. I've been trying and I can't do anymore" (Harmon, 2008).

In Harmon's own assessment of her participation in the Atlas project, she saw as her strengths her ability to be a big picture thinker, her knowledge of many of the underlying issues, particularly the overarching theme of equity, her roots with CLF, and her ability as a writer and storyteller. Her experience in the nonprofit sector also led her to have serious misgivings, when the project was first proposed to her, related 
to the limited budget and the effective utilization of volunteers in such a potentially complicated endeavor. Harmon's limited experience with GIS and its capabilities in combination with her understanding of the complexity of the notion of equity had contributed to a premonition that CLF would be walking into unknown territory and “opening a can of worms” with unforeseen consequences (Harmon, 2008).

Harmon's primary weakness that she identified that had an impact on the project was the fact that she saw herself as an "analyst" and an advocate, not a “marketing guy” who could produce catchy one-liners (Harmon, 2008):

I'm not good at leaving out details. I'm not good at oversimplifying which is exactly what had to happen in order for there to be text in the Atlas that was, you know, that was to be less than a 350-page document. (Harmon, 2008)

The maps were not self-explanatory; they did not speak coherently about equity. Harmon had come to realize in her struggle to come to terms with both sets of maps (the choropleth and the surface/raster maps) that both mapping strategies would require a significant amount of interpretation - even reinterpretation - to tell the equity story that Harmon wanted to tell.

Furthermore, unlike much of the work in which Harmon at been involved in the early days of CLF, she found herself working in a "vacuum" with regard to CLF as a whole. Her perception was that with the exception of Radin, everyone else had come to see the Atlas as "this peripheral, problematic thing" that they "kept dipping back into and then taking off to do other stuff' (Harmon, 2008). Instead of spending her time writing, her time had been consumed with the coordination of the Equity 
Atlas team that included the volunteer GIS professionals (who didn't really have the necessary time to work on the project), the CLF work groups (although with the exception of the greenspaces group, their involvement had been primarily focused on the identification of variables and indicators), and "trying to figure out the frigging maps" (Harmon, 2008). She was running out of money, time, and energy and had very little to show for it. In early spring 2005, Harmon gave notice knowing that aside from her equity framing documents, no usable text had been written: "I finally came to the conclusion that I was doing no one a favor by continuing to pretend that I could finish this - and, so, I left” (Harmon, 2008).

Harmon wasn't the only casualty of the mapping process; the Atlas project itself had to be recalibrated as CLF brought in a new writer, Alex Campbell, to take Harmon's place. He would have to be brought up to speed quickly and the more limited nature of his responsibilities, in comparison to Harmon's, also changed the relationship between the writing and the mapping. Under Harmon's direction, in important ways, the mapping process had been highly participatory (between the “client" - Harmon acted as a proxy for CLF's interests - and consultant; between advocate and scientist) as she and Radin discussed and discussed again the variables and mapping, methods of categorization and class breaks, colors and scale, vector and the possible conversion to raster. Harmon's willingness to discuss and debate, indeed, her need to pry open the lids of the black boxes of the maps, analytical protocols, and GIS technology to understand why the maps didn't' always make sense to her, resulted in an approach to the technical aspects of the mapping that was largely 
exploratory and uncertain in contrast with an approach where the strategy had been set from the outset.

As the project went on, and criticism of the maps (not just from Harmon) continued, Radin came to see the very real advantages of a more traditional, highly structured consultant-expert/client relationship where the boundaries of expertise are more clearly established. In Sharkova, Radin gained a technical ally who understood his frustrations with the analytical process thus far and lent support for the technical and analytical changes and innovations that he wanted to pursue.

Harmon's departure signaled the beginning of a new phase of the Equity Atlas project - one in which the differing notions of expertise (something that was always an undercurrent in the process) would take center stage. Fuglister, who observed the process from beginning to end, described the distinction between what CLF needed and what the technical analysts wanted this way:

The thing I felt was really hard for Ken as a mapmaker, well, two things: the truth about what exactly maps say and don't say, and how you articulate that according to a researcher versus an advocate was a huge fight ... It wasn't that you didn't understand [the maps] if you sat there and thought and thought and thought and talked it through but that is not what your optimal output is when you're trying to make things compelling. (Fuglister, 2008) 


\section{Chapter 8. Writing Equity}

The initial concept was they [Radin and Sharkova] would provide the maps; I would analyze the maps and write about the maps which, you know, is a weird thing to begin with. If the map actually shows you something, shouldn't you just look at the map? (Campbell, 2008)

\section{Writing Equity and the Contested Terrain of Expertise}

In preparation for the writing, through late 2004 and much of 2005, Radin worked at developing and refining his raster methodologies, in consultation with Sharkova, for both the demographic and access maps and dedicated considerable effort to explaining their meaning to Harmon in particular. As early as January 2005, Radin had produced and submitted to CLF a full set of raster demographic maps, a series of schools-related maps that were generally point maps at school locations (a vector rather than raster approach), and a set of access maps related to food, parks, and natural areas (Sharkova and Radin, 2005). The inclusion of the access maps was significant because equity, according to the framing documents, was to be determined by access to, "the means for identifying and taking advantage of opportunities for advancing the well-being of their households" (Harmon, 2003). With this submission, Sharkova and Radin included a memorandum that provided a general description of the variables included in each map as well as an explanation of why some were used and others excluded. In addition, recognizing that this would be the first time that a well-developed set of access maps would be seen by CLF, it is clear that Sharkova and Radin believed that some explanation about their methods would be important. 


\section{The Access Method}

In their January 2005 memorandum, Sharkova and Radin suggested that access should be determined by three primary variables that in addition to distance (which is commonly seen as the chief physical obstacle to access) included the level of service (LOS) and the level of demand (LOD) or level of need. For explanatory purposes, they used the access to food example to describe each variable in more detail.

Regarding distance Sharkova and Radin wrote:

First, the most obvious access measure is distance - preferably and most often network, street distances, but also linear "search radius" distances. A person or population close to, say, a full-service grocery store, has better access to it than someone further away, all else being equal. (Sharkova and Radin, 2005)

By level of service, they suggested:

... a person or population close to more than one grocery store would have better access than a person or population living near only one store - all else being equal. For food access, the number of stores close by is considered the "level of service" variable. Although a true LOS variable would have information about the size of the store or the actual number of people a given store could serve, here we simply assume that more stores can serve more people and, hence, more stores means better access - all things being equal.

(Sharkova and Radin, 2005)

And, by level of demand they meant:

... how many people need to share that one or two stores will effect "access" as well: if in one area, 10,000 people share one store, while in another only 1,000 people share one store, then relatively speaking, the 1,000 people area has better access than the 10,000 one.

(Sharkova and Radin, 2005)

Finally, they put it all together to create a summary measure, or what they called the “distributed need level” (DNL) for access: 
Population by itself is considered the "level of demand" variable, while population divided by level of service produces a summary measure we can call "distributed need level (DNL)." In most cases, a combination of DNL and distance is the summary measure we are looking to map.

(Sharkova and Radin, 2005)

Explaining further they suggested that, "[t]he relationship is easy to conceive:"

... larger population means 'increased demand' or need, smaller or lower level of service means less service to meet need, and larger distances means more 'friction' to overcome in accessing whatever it is you want to access - a grocery store. (Sharkova and Radin, 2005

They provided this concrete example:

Area A has 10,000 people (LOD=10,000), 2 stores $(\mathrm{LOS}=2)$, and an average street-network distance of 1 mile $(\mathrm{d}=1)$ to get to either of the stores.

Area B has 3,000 people, 1 store and an average distance of 2 miles to get to the store. Which area has the best food access?

- divide LOD by LOS to produce DNL (distributed need level)

Area

A DNL $=10,000 / 2=5,000$

Area $\mathrm{B} D N L=3,000 / 1=3,000$

- multiply DNL by distance

Area $\mathrm{A}$ access $=5,000 \times 1 \mathrm{mi}=5,000$

Area $\mathrm{B}$ access $=3,000 \times 2 \mathrm{mi}=6,000$

Area A has better food access than area B: despite having fewer people to serve, the people in Area B have to travel twice as far as those in Area A to get to that food, which increases their access score beyond Area A's score. As distance or population increase, or level of service decreases, a given area's "access" becomes worse. This is the general form that all the access analyses take. (Sharkova and Radin, 2005)

This is generally how access would be operationalized in all of the access

maps, however, Sharkova and Radin added some caveats, suggesting that the spatial characteristics of the entities to which access is being measured, such as grocery stores, where a street network distance can be calculated to a specific point location 
versus irregularly shaped features such as natural habitats or parks that can be accessed at multiple locations, are not the same. In these cases, Sharkova and Radin suggested setting the parameters in the GIS for straight line 1/3 mile search radii for the distance variable and substituting the number of acres of a habitat or park for the number of grocery stores (the LOS variable) in their three-variable formula (Sharkova and Radin, 2005).

Sharkova and Radin evidently felt that they would need to provide more detail about how this procedure could be accomplished within a GIS. Without referring to GIS directly, they essentially described the process that Radin would direct the software perform:

For natural habitat, access is measured at each point in a grid of points evenly spread across the region. At each of these points, we draw a circle around us $-1 / 3$ of a mile to approximate whether something is "nearby" or not - then we measure the two remaining variables: population (LOD) and number of habitat acres (LOS) (distance is built into the search radius $-1 / 3$ of a mile). (Sharkova and Radin, 2005)

Although they did not give a rationale for the 1/3 mile search distance (Radin responded to questions about this later in his Primer on Reading Surface Demographic Maps, in March 2005 and discussed in Chapter 7), they did describe the raster arithmetic that he would direct the software to compute:

"Access" is simply population divided by the number of habitat acres within the 1/3 mile radius search. The higher the value, the worse the access - more people sharing fewer resources. Yet these values are compared to all other values at points covering the region and we can then see access in relative terms; not necessarily that this area is "bad" or "good," but rather, simply, this area is certainly not as good as this one. (Sharkova and Radin, 2005) 
Importantly, they also pointed to issues that their method did not address such as the quality of the produce in a grocery store or the experience consumers might have in each store or place. The pros and cons of various approaches to modeling evidenced in this document were precisely the kinds of issues that Radin and Sharkova found challenging and exciting to examine as they explored the limits of the GIS tool but to a non-technical consumer of the end product, the technical discussion could be mind-numbing.

Finally, Sharkova and Radin described how these procedures and calculations would be translated into the access-related surface maps that they were submitting:

In addition, as we measure, say, the sum of habitat acres within the search radius for each of these points across the region (what's called a "focal sum"), we develop a graduated "surface" that shows which areas have more habitat acres nearby than others. In other words, there is really two distance measures built into this method: one when we set the initial search radius, the other when we are able to see in the map how these "focal sums" vary as the 'search circle' moved from one point to the next, measuring the number of acres at each of the points spread across the region. (Sharkova and Radin, 2005)

This approach to mapping access was markedly different and vastly more complex than the one that Bosworth had proposed for transportation while he was still involved as a volunteer for the project in 2003 (figure 8.1). 


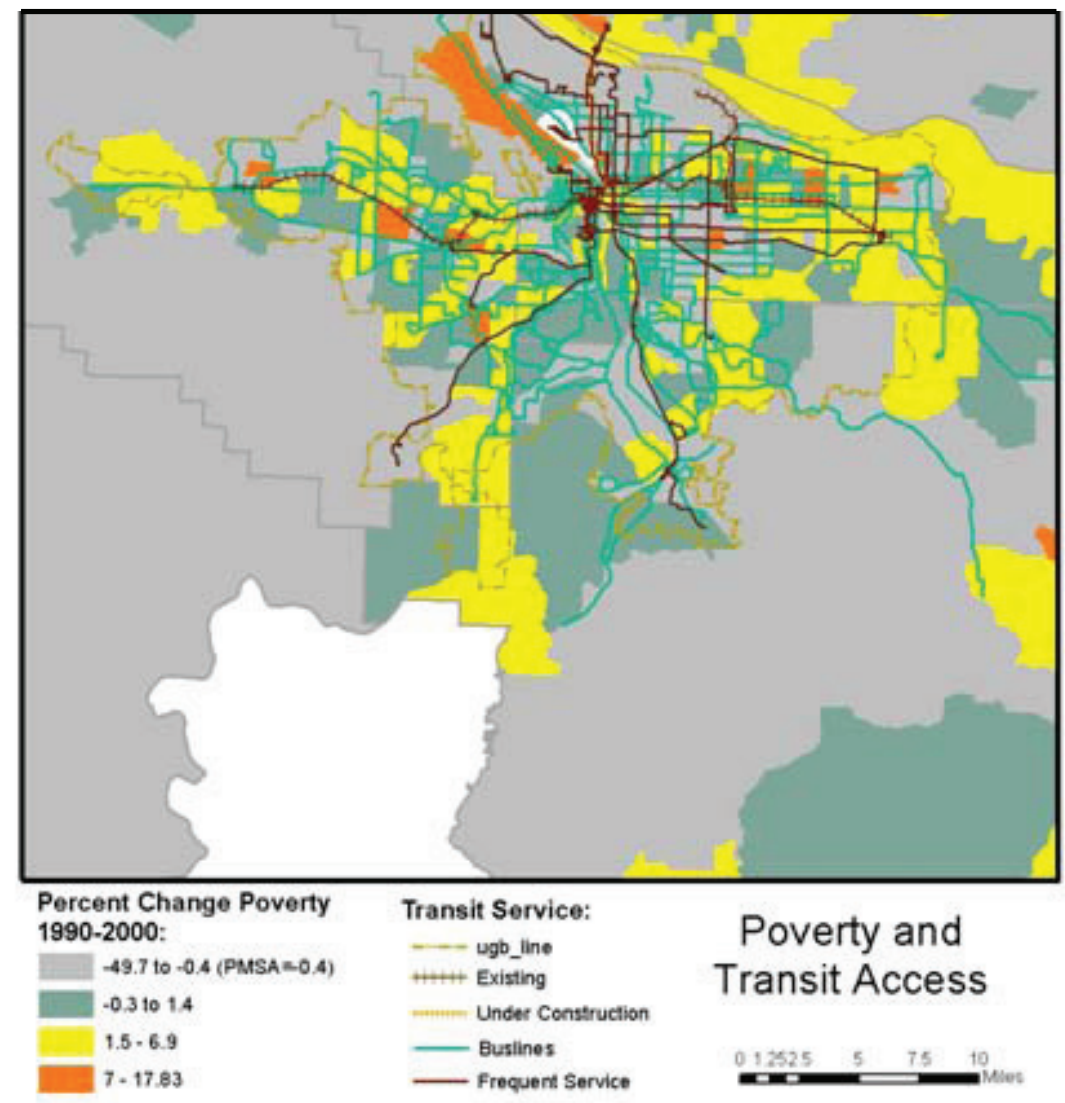

Figure 8.1 Transportation Access Map. Mark Bosworth, cartographer. Source: Radin

Bosworth had been a key player in the early brainstorming for the Atlas that had focused on how to convey the issue of equity via maps. One idea, that had still not been fully resolved until Sharkova and Radin developed their raster methodology, was how to explore equity by viewing all of the variables through the single lens of poverty. The proposal that had sparked everyone's interest was the inclusion of a transparent map of poverty through which all of the other maps could be viewed. It would be a little like putting on a set of 3-D glasses allowing a whole new dimension, the dimension of equity (poverty overlaying each of the access variables) or the lack thereof, to be revealed. Conceptually, poverty was seen as the key driver behind the 
issue of access. This is how Bosworth approached his one surviving access map: the dynamic quality of poverty (change over time) overlaying the location of the transit network.

At the time, Radin had been disappointed in the map's lack of analytical and technical sophistication given the spatial-analytical capabilities of the available GIS software (Radin, 2008a). But, the access maps were not his responsibility then. Once they did become his responsibility, and given the fact that the transition of that responsibility to him corresponded with Radin's own exploration into the power of raster modeling, Radin was anxious to see what he could do. In comparing the two approaches to transit access, aside from the visual simplicity and the lack of spatial analysis in Bosworth's map, the most notable difference is exclusion of the poverty variable in Sharkova and Radin's calculus. Similar to food access and habitat access, Sharkova and Radin approached transit access in terms of distance, supply (LOS) or frequency of service at transit stops, and demand (LOD), the population in a 1/3 mile search radius of each stop to create a statistical surface representing their definition of access (figure 8.2). 


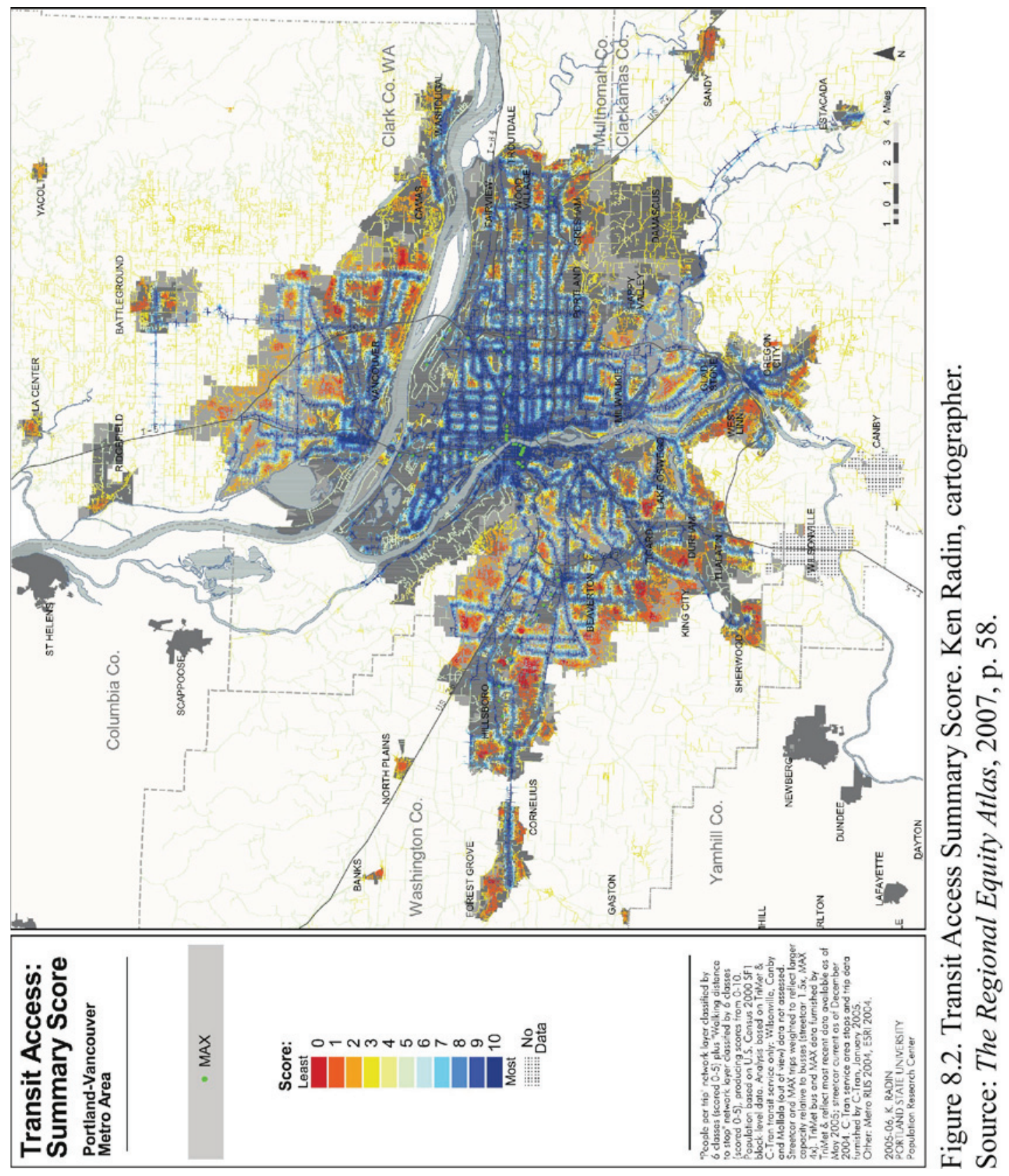


In their January 2005 memorandum, Sharkova and Radin acknowledged that their access maps only tell a part of the story and that there are many other factors that play into the equity question:

... none of the maps are supposed to be 'the final end-all be-all' analysis of access to the various resources or of 'equity.' They should be interpreted based on what they can and do show, and against what one might know about the region in general. Just because an area is red or blue doesn't necessarily mean the area is bad-off or well-off. This needs to be assessed in the context of other factors that are not depicted in the maps, or of the geographic setting in which a phenomenon occurs. (Sharkova and Radin, 2005)

Radin, in consultation with Sharkova, built an access model that was, at least in theory, relatively simple and inherently spatial - one that they believed they could defend. Seeing access determined by distance, supply and demand rather than income (or any other factor such as race) with its complexity of causation, seemed doable in the GIS context in which they were working. But Radin and Sharkova were aware of some of the limitations of their model and suggested that these maps would "need to be assessed in the context of other factors" not included in the maps (Sharkova and Radin, 2005). Furthermore, the cartographic busyness of what they had done made a simple overlay of those other factors, such as poverty, impossible. But the message that they were conveying in the memorandum and the maps made it clear that they believed that they were providing a higher level of spatial and analytical sophistication than had been offered previously.

Explanations of grids, 1/3 mile search radii, and weighted points weren't necessarily helpful, especially to Harmon who by 2005 was feeling enormous 
pressure to get the writing done. As discussed earlier, Harmon found that the mental gymnastics required to utilize the information contained in the maps beyond vague generalities so daunting that the stress of it contributed to her decision to leave the project in spring 2005.

\section{Writing Equity}

Alex Campbell's arrival in Portland in 2005, as far as CLF was concerned, was fortuitous for the Equity Atlas project. Harmon had announced that she was going to have to step down from the project leaving CLF drained of resources and without a primary author. Campbell had come to Portland with a Master's degree in Public Policy from the University of Maryland and eight years of experience doing policy analysis work, that included economic analyses of the Home Mortgage Disclosure Act (HMDA) data, for think tanks in Washington, D.C. Shortly after his arrival, he'd had an informational interview with Seltzer who directed him to CLF. Campbell was anxious to immerse himself in Portland issues and was willing to work as a volunteer if necessary to build his resume (Campbell, 2008). The Equity Atlas needed a writer and Fuglister saw Campbell as smart, experienced, and quick - in other words, a godsend (Fuglister, 2008).

While in essence replacing Harmon, Campbell's role would have to be different. He was a neophyte in terms of the Portland region's issues, he had no history with CLF, and therefore would have to defer to Fuglister more than Harmon had. Additionally, his training and experience were different from Harmon's. Although Harmon was educated as an urban planner and was widely acknowledged as 
an affordable housing expert, she was also an advocate. Campbell's training in public policy and economics provided him with a more positivist outlook and quantitative capabilities that he employed in his previous positions as a policy analyst. He did not see himself as an advocate (Campbell, 2008). Early on, he understood that his task would be to review what Harmon had written and then analyze and write about the maps that Radin and Sharkova had completed. His primary responsibility would be to translate the equity framework to the page and write the housing and transportation chapters and more if he was able to.

In preparation for the writing, Campbell set to work delving into the foundational documents that Harmon had developed, familiarizing himself with the equity discussion at the national and local levels, and studying the maps. However, in spite of being a relatively sophisticated data consumer, Campbell found the maps exceedingly difficult to interpret and the process of working with them cumbersome and unworkable:

I spent, literally, a lot of time with pdfs of maps on my computer switching back and forth between the pdfs. They were not exactly the same size either. I was not working in ArcView [the GIS software program that Radin used] which was to be expected because I don't know it. It really wasn't working. For one thing, it was just so difficult to draw out the comparisons. And, secondly, they're just maps, there's no geography through which to talk about them. (Campbell, 2008)

Campbell remembers receiving approximately 40 mostly single-variable maps that Radin referred to as "diagnostic maps" (Campbell, 2008). Campbell quickly realized that these single-variable maps would be insufficient to the task of analyzing regional equity - an opinion that was shared by Radin and Sharkova. To say anything 
meaningful about equity, Campbell concluded, would require a multivariable analysis (Campbell, 2008). Campbell's impression was that there was agreement among them (Campbell, Radin, and Sharkova) that what was really needed to explore regional equity was a whole new generation of maps that "cross-compared" multiple variables (Campbell, 2008). However, there was no time or money.

Campbell's observation that these were "just maps" that had "no geography through which to talk about them [comparisons between variables]" is telling and relates to the shortcomings of both of the mapping strategies that had been adopted to that point. The choropleth maps using census tract boundaries didn't relate directly to neighborhood geographies that people could more readily recognize and the pixels that made up the raster maps were impossible to extract data from or connect to place as well. Moreover, like Harmon, Campbell found interpreting the legends for the raster maps convoluted. Although one of the rationales that Radin and Sharkova had used in arguing for the raster approach was that it would allow for the reallocation of the data from Census geographies to neighborhood boundaries, the reallocation to neighborhoods had not yet been done.

According to Campbell (2008), he experienced considerable push-back from Sharkova and Radin when he asked for access to the raw data, and not just the maps, in order to manipulate and ultimately understand and report on the data for his chapters. His impression was that they saw themselves as the keepers of the data, the analytical experts, and they believed that the maps provided everything that he would need (Campbell, 2008): 
There was definitely some tension between Ken [Radin] and Irina [Sharkova] on the one hand, and Jill [Fuglister] and I on the other. I felt like Ken and Irina sort of felt like the maps spoke for themselves and really viewed the project as an atlas. (Campbell, 2008)

Based on a memo that Radin wrote sometime in 2005, in response to an inquiry from Campbell, it is clear that Campbell was having trouble deciphering the access maps and wanted details about Radin's methodology and precisely how Radin was planning to develop the access summary statistics (Radin, date unknown). Without full access to the data, in order for Campbell to have confidence in the statistics that he was given, he wanted to know how they were derived. The maps didn't allow him to attach numbers meaningfully to places, such as neighborhoods, or to be able to understand the significance of those numbers relative to each other, let alone understand equity. Campbell (2008) concluded that he simply couldn't write "without some kind of analytic that wasn't just maps." Finally, he was given access to the data for exploratory purposes: "I got the data and I did some initial very rough multi-variable analysis, not because I wanted to include it but to help myself think about what was there" (Campbell (2008). But Campbell felt there was strong resistance from Sharkova and Radin against his doing anything more with the data (Campbell, 2008).

Radin, Sharkova, Fuglister, and Campbell met several times to iron out differences and to try to come to consensus about how to proceed with the data, the analysis, and the writing. And, although Radin had intended to create neighborhood summary statistics, it was Campbell's insistence on having direct access to the data 
and need for some sort of index, that would provide a means of comparison from one neighborhood to another, that forced the issue. As a result, Radin developed a neighborhood summary table that included not only reallocated 1990 and 2000 Census population variables by neighborhood but also change over time and overall rankings, or "tiers" of the neighborhoods developed from z-scores that allow for crossneighborhood comparisons (Campbell, 2008; Radin, 2008b). This table (used by all of the authors) and some additional tabular data, not the maps, became the basis for most of the text in at least Campbell's chapters in the final document.

In the end, Radin came to see the neighborhood summary table, not the maps, as the key to exploring regional equity:

I think the closest we came is the neighborhood summary table with the indexes. That was really the core of what I'd been asked to do all along. And the truth is... I came to some realization that the more complex kind of things we thought we could do or wanted to do were just not going to happen. It was just always about trying to simplify... at some point I realized it had to be all about simplifying, simplifying things - trying to simplify and generalize and all that kind of stuff easy consumption of data and information. (Radin, 2008b)

Radin would ultimately map several of the variables included in the published document by neighborhood boundaries. But, it is curious that there are no “neighborhood by tier" (or rank) maps - which would have been much like Kirwan's Opportunity approach and would have allowed a user, more easily, to compare neighborhoods - included in the final document.

From Campbell's perspective, the neighborhood summary statistics were essential to progressing beyond the theory. Campbell had taken on the challenge of 
moving the equity discussion from a series of single-variable maps to the complexity of equity conditions that had defeated Harmon. And he, as an analyst, had been able to see that the bridge between to two was missing:

There was a theoretical foundation but the translation of that to what we [were] actually trying to study was definitely missing. All of us were aware of that at some level. I have a sense, looking back, that working that out would have been a lot of work. And, there just wasn't the time and resources to do it right. And, so, we were just going to move forward. And, that, obviously, limited the usefulness of what was ultimately produced but it didn't feel like there was any option.

(Campbell, 2008)

Campbell came to accept the fact that the closest that they were going to get to a translator was the neighborhood summary table with its neighborhood statistics and rankings.

Related to the issue of translation, Campbell was also concerned about how he and the other authors, which by the end of the project included Campbell, Sharkova (the schools chapter), Fuglister (health and design as well as the introduction), and Jim Labbe (who was by then on loan from Audubon to specifically work on the parks and greenspaces chapter of the Atlas), were going to deal with the question of causality as it relates to equity. Coming from an economics background, Campbell believed that being able to deal with that question was important and unavoidable. From his perspective, the maps didn't provide any clues related to causality and he was concerned about how he and others might handle such a complicated question:

A related factor that was difficult for me and my perspective - I have some economics training - and I guess a piece of it that really didn't get worked out was the complexity of causality in those [equity] questions, right? We're talking about whatever analytic you look at, 
whether it's income or housing values, poor areas have fewer parks. Well, those parks have been there a lot longer than the poor people.

(Campbell, 2008)

Recognizing the limitations of the data, the tools (the maps and the summery table) at their disposal, and his own limited access to the available data and tools, Campbell resolved to take more than usual care with any causal statements that he, as an author, might make (Campbell, 2008). The issue of causality and the inability of the maps to reveal that story would come up again when the CLF's regional equity solutions workshops were underway.

Campbell's approach to writing about specific issues was always in reference to the neighborhood summary table and other tabular data, not the maps, making sure to consider at least two variables together. While looking at the Atlas, he described the process this way:

So, the transportation chapter, I'm talking about the neighborhoods with the highest poverty rate, how those score relative to all other neighborhoods on transit access. And, so, this was my general approach with most of my chapters, was to look at neighborhoods that scored high or low on this metric that we're looking at and then compare those to the ones that scored high or low on some kind of economic metric. (Campbell, 2008)

This approach allowed Campbell to compare multiple variables, in addition to those included in Sharkova and Radin's access maps, that he thought were important to the equity discussion. His approach to incorporating the maps, that were developed for his chapters, into his writing was to provide the reader with some general reference to location but the data and his understandings of the data came from the tables rendering the maps merely locational markers (Campbell, 2008). 
For Fuglister, who understood better than anyone else involved in the project, the significance of the mapping in terms of CLF's own history, its identity, and its future agenda, the mapping process had been a long, contentious negotiation between the GIS analysts' desire for analytical and cartographic sophistication that they believed was their responsibility to provide and CLF's need to reach a broad audience. Running short of resources, Fuglister found herself an author as well, contributing heavily to the introduction and writing the health and design chapter. As Campbell had done, Fuglister used the neighborhood summary table to make comparisons among the neighborhoods, put the maps in the context of the other variables included in the Atlas, and to associate actual numbers with locations. For these purposes, the maps were simply too hard to work with:

...you kind of need, at least the way the maps were designed, you need the data to go with them because otherwise it's hard to describe them... The neighborhood maps [which were added later] ended up being really small; we couldn't use the labels effectively because you couldn't see them. So, then we took the labels off but then you get this amorphous, meaningless blob on a map... When I was trying to say something specific I had to go to the table... (Fulgister, 2008)

Thus, the neighborhood summary table became the most efficient way for each of the authors to understand the data, make comparisons among the neighborhoods, and make the kind of multi-variable comparisons that Campbell outlined. And, although it was clear given the time and monetary constraints that a "next generation" of maps that "cross-compared" multiple variables would not be possible, at least one neighborhood summary map was created for each chapter (table 8.1) that was meant to provide an understanding of the rasterized surface data at a neighborhood level. 
Table 8.1

\begin{tabular}{|l|l|}
\hline \multicolumn{1}{|c|}{ Chapter } & \multicolumn{1}{c|}{ Map } \\
\hline Housing & $3-1$ a and b: Housing Affordability Index \\
\hline Schools & 4-3: Access to Teacher Training and Experience \\
\hline Transportation & $5-3:$ Average Walking Distance to Transit Stop \\
\hline Health \& Design & 6-3: Access to Grocery or Natural Food Stores \\
\hline Parks \& Nature & $\begin{array}{l}\text { 7-4: Public Parkland Access } \\
7-6: \text { Nature Nearby:Percent Population within } 1 / 4 \text { Mile of Natural } \\
\text { Habitat } \\
7-7: \text { Natural Habitat Acres per Capita }\end{array}$ \\
\hline
\end{tabular}

Although the writing had been made easier by the creation of the summary table, Fuglister's concern about the legibility of the raster maps that would make up a large part of the Atlas, with their incomprehensible legends, continued to plague her.

She was familiar with the methodologies but still found the maps a strain to decipher:

[Referring to the raster maps] It wasn't that you didn't understand them if you sat there and thought and thought and thought and talked it through but that is not what your optimal output should be when you're trying to make things compelling. I can remember saying many times, "we're shooting for $8^{\text {th }}$ graders." Trying to communicate, I know we didn't even get close to that. But in all of the trainings that I've had around public information, that's the bar you're supposed to set.

(Fuglister, 2008)

The Atlas had to work as an advocacy tool and this meant that it had to be consumable for the authors and its audience. During 2006 and part of 2007, when the bulk of the editing occurred, Fuglister continued to press Radin and Sharkova to either simplify the maps or simplify the legends. In the end, compromises were reached on both 
fronts. In general, the question of color that had been troublesome in the diagnostic phase (with the associations between race and color) was resolved by accepting, in most cases, Orfield's blue to red dichromatic protocol - a color scheme that map consumers intuitively interpret as cold to hot, low to high, even good to bad. The cartography related to schools is also reminiscent of Orfield's work, something that Sharkova has commented on herself - a return to Orfield (Sharkova, 2008). The legends that Radin had developed for his early raster maps that referred to people and households in fractional terms were eliminated. And, wherever possible, neighborhood geographies were used instead of census geographies. Additional explanation was sometimes included in the legends as well as in the narrative. And for those who want detailed information related to the mapping methodologies, a comprehensive technical appendix was included in the published atlas.

Sharkova, too, would be drafted into authorship as it was decided that of the available writers, she had the most experience with school district data in her capacity as a demographer at the PRC. This was not a role that she felt comfortable with, however, because the focus was to be on school finance, a topic about which she knew little (Sharkova, 2008). Of all of the chapters, the schools chapter was, from a mapping perspective, the least challenging. There are no "access" maps per se and only one compound variable, "teacher training and experience" displayed by schools and summarized by neighborhood.

Each of these authors, Campbell, Fuglister, and Sharkova would be considered a highly trained professional in their own right. But they did not share a common 
discipline or professional experience. Campbell's experience was probably the closest fit to the topics of his writing assignments. But out of necessity, Fuglister and Sharkova ended up having to write about topics about which they knew relatively little. What holds true for all these authors is the distance they held between an advocacy position and the topics themselves. Even Fuglister, who, in her role at CLF was a professional advocate, distanced herself from her topic, but she was not associated with any particular organization representing food or health advocacy as staff or as a volunteer. Any advocacy was more indirect in the inclusion of the various access variables.

It is notable that although authorship of the specific chapters is identified at the end of the published atlas, there are no bylines for the chapters per se. And while it is true that they reviewed and commented on each other's work, there may have been reasons to essentially disassociate any particular author from particular topics.

Had Harmon continued with the project, there is evidence to suggest that the distance between topic analysis and advocacy would have been less - even if she wasn't employed in that capacity at the time. The writing of the parks and greenspaces chapter that occurred under the guidance of the Portland Audubon Society, in this respect, followed a different but parallel path.

\section{A Parallel Process}

At the outset of the Equity Atlas project, Fuglister and Harmon asked CLF members and its working groups to suggest variables (along with possible sources of data) that they would like to be included in the Atlas. Perhaps more than any other 
CLF member, other than perhaps Harmon, Mike Houck, a CLF founding member and naturalist at the Portland Audubon Society, understood how the integration of socioeconomic data with environmental data in a mapping context could be used for advocacy.

In April, 2003, Houck drafted a "Natural Resource Protection/Parks and Greenspaces Equity Draft Outline” (Houck, 2003b) for consideration by CLF's Parks and Greenspaces work group. In this document, he suggested that the group submit for the Equity Atlas project a document that: (1) makes the argument that natural resource protection and parks and greenspaces are an equity issue that has regional significance; (2) identifies 1-3 year policy or project goals that the Equity Atlas research would support; and (3) outlines indicators that the group wanted to see mapped and the primary questions that should be answered by the Equity Atlas research (Houck, 2003b). In fact, Houck's thesis, articulated in this document, was that there were disparities related to access to "the full range" of park, recreational facilities, and trails in the Portland-Vancouver metropolitan area:

These inequities are evident both at the local and regional levels. So, too, are there inequities with respect to access to water-based recreational opportunities for contact recreation. Access to natural areas is another equity issue in the four-county region. (Houck, 2003)

Although in an earlier draft the language was softer, "[w]e suspect that there are geographic and economic disparities with regard to access ..." (Houck, 2008a) based on the MPAC Parks Subcommittee 2001 Report, and a 2002 PolicyLink report, there was no ambiguity in this document, no struggle with articulating the equity issue, the 
data required for making the argument, or how the resulting maps would be utilized. And so, the question of equity was framed in terms of access to nature, and access to public parks (Labbe, 2008).

Under the leadership of Audubon, particularly Houck, Carley, and Labbe, the parks and greenspaces group had always been the best organized and most active of CLF's work groups (Carley, 2008; Fuglister, 2008; Johnson, 2008). In 2003, Audubon and others were advocating for the adoption of a regional functional plan that would establish levels of service required of local jurisdictions for a full range of park and recreational opportunities, the adoption of regional policies by local jurisdictions to ensure the protection and restoration (if necessary) of natural areas, and the clean-up of local tributaries to the Willamette River to ensure equal access to water-based recreational activities (Houck, 2008). Just as Orfield's maps had mobilized CLF to begin with and influenced Metro's 2040 Regional Concept Plan, Houck saw the opportunity of the Regional Equity Atlas to mobilize and shape regional policy related to parks and greenspaces as one that could not go wasted. As a result, Audubon decided that it would be in its best interest to dedicate some of its own staff time to the Equity Atlas project. Labbe, who had become an Audubon staff member, was the obvious choice as he had a long volunteer history with both CLF and Audubon and was familiar with each organization's issues and cultures.

Initially, the parks and greenspaces mapping was going to be done by one of the professional volunteers, however, as it became clear to Harmon, Radin, and Fuglister that they couldn't depend on the volunteers for any of the mapping, Radin 
agreed to take it on. By the summer of 2004, after more than a year of struggle over mapping strategy, Sharkova and Radin gained approval from Fuglister and Harmon to proceed with the conversion to raster for as many of the census variable maps as possible and obtained an extension of the Equity Atlas deadline, first to October, and then, when it was clear that more time was needed, to February 2005. It was during this period that Labbe began to closely collaborate with Radin to explore possible variables, measures, and mapping techniques that, given the limitations of resources, would best suit the working group's advocacy needs.

In some ways, Labbe's relationship to Radin was similar to Harmon's. Labbe, like Harmon, was an insider with a many-year history with CLF; Labbe, like Harmon, was an advocate with deep knowledge about his own particular issue, and Labbe, like Harmon, had a pretty clear idea of the story he wanted to tell even prior to any mapmaking (Labbe, 2008). However, Harmon was hired to frame and to write about a broader range of topics. And with Harmon's departure, it was clear that Labbe would write the text for the parks and greenspaces chapter.

Furthermore, his familiarity and comfort level with computer technology in general, and GIS in particular, was much greater than Harmon's had been. As a result, more than any other topic in the Atlas, the parks and greenspaces chapter was constructed through a close collaboration and an iterative process between the writer and mapper that Labbe describes this way:

We had a team of people [from the parks and greenspaces working group] who were advising, very early on, what sort of measures to use, that kind of thing. But then, Ken [Radin] and I kind of got into it. I 
mean Ken played a role in suggesting things and putting the different measures into GIS and doing analysis. But we stayed in close communication on that because I was writing the narrative so I had to understand - we kind of went back and forth on a lot of those things.

(Labbe, 2008)

Much more than was the case with the authors of the other topics, it was Labbe who held sway on the variables and the measures to use. The clarity of purpose with which Labbe entered the mapping process was due in large part to the stake that Audubon had in the project as well as the strength of working group he represented:

We [Labbe and Radin] did decide on what maps would be in there [the Atlas], what results we really wanted to show with the maps, what results we wanted to show with tables and charts, the extent to which we wanted to explain the method so people could interpret the results in light of the methods, how much to put in the Appendix. So, I didn't do any mapping myself, I gave feedback on a lot of the maps and discussed with Ken which measures we wanted to try to feature in the maps. (Labbe, 2008)

Although the work group itself explored how to address the question of access to nature, how to pose it, and how to analyze it, that discussion continued once Labbe engaged directly with Radin. Labbe has stressed the iterative nature of the process and the tremendous learning opportunity that it created for his particular interest group. For example, Labbe saw the Equity Atlas mapping project as a way to contribute to the larger conversation around the measurement of access:

For many years, planners have measured access to parks in terms of per capita measures, like acres per thousand residents. It really didn't deal with spatial distribution.... And, then there is a newer effort to really look at walking distances and distribution. We tried to combine these two things. And, we came up with a pretty innovative way of doing that, I think, by developing these little parksheds-service areas that we 
defined. We do per capita measurement within those, and then kind of combine it with the walking measures to rate every location and landscape... (Labbe, 2008)

In essence, this was the access methodology that Radin had developed with Sharkova for the other access variables applied to parks. In retrospect, Labbe would criticize this particular approach seeing that, in fact, the measures could "cancel each other out" or communicate little about the differences in the quality of access, for example, whether it is overcrowded or poorly maintained. But even the "overcrowded" assessment can be misleading:

Ultimately, I think that the per capita measure isn't a good measure because more people can actually be an asset to a park, can make a public space more attractive - depending on the type of park too, you know.... So, I think the problems with the per capita measure, the problems with trying to integrate it with the distribution measure, we made a good run at it. I don't think that ultimately it's the best way to go and I kind of regret that we tried to do that as much in the chapter.

(Labbe, 2008)

However, Labbe was pleased with the usefulness of much of what they decided to do:

But, some of the other measures we developed like the percent of population within a quarter mile is a really good measure. It's a measure we can track over time, and as a result, we got a baseline. In retrospect, I would have elevated that measure more in the narrative. It's just kind of a learning process of doing it. (Labbe, 2008)

Like Campbell, Labbe was concerned about the issue of causality and how it was handled in the Atlas:

I think that one of the tricky things with that [the disparities depicted in the parks access maps] is that it's easy to see those patterns on the landscape but it's hard to understand the forces that create them. That's another thing I've been trying to emphasize in talking about the Atlas, is to talk about the connection of affordable housing and parks. It's not just where we've decided to make investments, it's whether we've 
decided to make investments at certain periods over the last 100 years as interest and enthusiasm for investing in parks ebbed and flowed over time. (Labbe, 2008)

It is this argument, the argument for investing in complete communities that include parks promoted for many years by Audubon and others, that, according to Labbe, the Atlas "bolsters" (Labbe, 2008). It is also notable that he connected affordable housing and parks - one of CLF's early signature achievements. But, the issue of causality was one that Labbe continued to ponder:

So, it's not as simple as our poor, underfunded parks department is not spending enough money in low-income neighborhoods because of the decisions made long ago. Those neighborhoods were probably not poor when they were first built but because they didn't get adequate parks when they were built, that's why they are the low-income communities today. (Labbe, 2008)

Whether the Atlas provides the evidence to support this argument is questionable but what Labbe implies related to the use of the Atlas is the visual cross-comparison between multiple variables in the neighborhood summary table and the maps.

Labbe brought data to the table and as a result, or perhaps because of his close working relationship with Radin, unlike Campbell's case, there were no obstacles to Labbe using and distributing the data on his own (Labbe, 2008). In fact, the ability to use and distribute the data independent of the Atlas has been critical to the full utilization of Audubon's investment of staff time in the project. In part, because of the close working relationship that Labbe and Radin had throughout the analysis and mapping process, Labbe developed a better idea of how the data could be utilized in a spatial context for others with similar concerns: 
I gave the data to the Interstate Urban Renewal folks who were working on developing a park with urban renewal dollars in the Interstate Urban Renewal area. And, I said, "This is the kind of information that you might want to use. Knowing that there are some park deficient areas in that renewal area, this might be a good guide for where you want to make these investments." So, I've been using the data since then for making maps and other things. (Labbe, 2008)

When asked if he used the maps included in the Atlas to communicate

Audubon's issues to the public at large, Labbe responded that the data had been more useful than the maps to his lobbying agenda:

I don't use the maps as much as I use the summary tables by neighborhood. And, I use them in a lot of different contexts. I guess at the broadest level we used it in shaping the 2006 bond measure in creating some equity goals for that in the nature-neighborhoods capital grant program. And subsequently, we've used that to facilitate and target our outreach efforts in encouraging proposals that try to get at those equity goals. So, there's that whole arena where we've been working with CLF, but there's also just regularly things that come up where there's opportunities to raise, to identify relevant equity issues in public policy decisions. (Labbe, 2008)

In spite of the potential of the power of maps to communicate spatial relationships,

Labbe's deep knowledge of the data and the maps, having worked so closely with

Radin to tell Audubon's story, allowed him to effectively utilize the data in a number of different ways in the advocacy arena that the maps could not.

Labbe's access to Radin, from Sharkova's point of view, took a considerable

toll on the rest of the project, however:

... if Ken were able to work on every chapter like [this]... Yes, his [Labbe's] chapter came out sooner than anything else. Yes, it was shown to Metro to pass the bond - all of that is wonderful but it took so much time. (Sharkova, 2008) 
Sharkova estimated that it took six months of Radin's time on a project that was

running way behind its succession of deadlines. Adding to Sharkova's frustration was the fact that in the latter phase of the project, Radin and Sharkova were essentially working as volunteers putting them in an awkward position with the PRC. Moreover, the relationship between Labbe and Radin, from Sharkova's point of view, smacked of the blurred boundaries between expert and client, that she was experiencing elsewhere on the project - Campbell with his demands for the raw data and Fuglister with her insistence that the maps be made simpler - that she felt was inappropriate.

When Sharkova contracted to work with CLF on the Equity Atlas, she thought she understood what the relationship would be: “... at the time, it sounded like we had a client; it was a model I had experienced before working with other kinds of clients" (Sharkova, 2008). She was being hired for her expertise in demography and GIS modeling and in that capacity would oversee, or in reality collaborate with Radin, and advise CLF on the development of methodologies for the mapmaking and map design. What she did not expect was the extent to which the distinctions between expert and client would be diminished and confused.

\section{Experts and Clients Revisited}

When CLF asked Orfield to produce the Portland Metropolitics (1998) report, it was in service of the Coalition's desire to influence Metro's 2040 Concept Plan. The fact that it was a good fit for their agenda is not surprising since it was Orfield's metropolics work that inspired the Coalition in the first place. Orfield was the unquestioned expert and CLF was in its infancy. However, by the time that Orfield 
suggested that the Coalition might want to pay for an updated report, CLF had successfully influenced the 2040 Concept Plan and had developed from an informal coalition into an official 501(c)3 nonprofit with approximately 60 member organizations that was struggling with its sense of identity. While an update (using the 2000 Census) could be desirable given the demographic, economic, and environmental changes that were rapidly occurring in the region, CLF had to consider whether or not Orfield's metropolitics framework was still the best fit for its needs. The answer, the Board determined, was "no." If CLF was going to raise and spend considerable resources on such a project, this time, it would be shaped by the Coalition, not others. CLF determined the question and with Harmon would determine the theoretical frame. CLF member organizations were deeply engaged and knowledgeable about issues relating to affordable housing, urban growth, transportation, jobs, and the environment. As experts in their own fields it seemed appropriate for CLF to turn to its membership, as it always had done, for ideas and sources for potential indicators.

The project that they would develop would inevitably be an offspring of Orfield's work in its use of maps and data - only more so. This was to be an "atlas," not just a report, that would largely rely on maps to tell its story. And as such, CLF hoped that it would have a larger audience than Portland Metropolitics had had. CLF didn't have in-house GIS capability which required it to go elsewhere for that expertise. In part because of the limited budget, in part because of relationships that CLF had with PSU, but also because of the neutrality associated with a university, CLF engaged first with IMS and later with the PRC in a contractual relationship to 
provide the maps for the Atlas. Early on, CLF also assumed that it would be able to limit costs by summoning professional GIS practitioners to volunteer for the project.

The ways in which CLF had done its work for much of its existence had been creative, collaborative, and largely voluntary. Participatory practice was integral to its sense of self. In examining the contested terrain of expertise that the Equity Atlas project, in many respects, came to represent, it is the unspoken expectation of participation by CLF and the lack of clear role delineation relating to the expert/client relationship that plagued the project throughout and especially once the hard work of translating the meaning of the maps to text began in earnest.

Who are the experts and who are the clients? Certainly, clients can be experts and experts, clients, but presumably the client is seeking something not in his or her possession. In hiring Harmon to frame equity and to write about it, CLF was hiring an insider who knew its culture well. There was little question that the Equity Atlas would be an interactive process involving the myriad of players and interests that CLF represented. Because she was an insider she was also fearful of the "eternal optimism" of CLF (Harmon, 2008) that had the potential to crash under the weight of its ambition. She expected to work closely with Radin, as a colleague, to come up with the maps that would tell her story. There would have to be iterations of the work to incorporate feedback from the mapping group, CLF's Board, focus groups, and at CLF's Summit. But there were no formal participatory research protocols put into place; they weren't seen as necessary. 
Sharkova came into the project with very different assumptions. She understood from Radin that there was a degree of disorganization in the project and that he'd been required to make endless iterations of maps during the diagnostic mapping phase. Nevertheless, she agreed to participate as an expert consultant who would strive to provide services at the highest standard possible given the constraints of budget and time. Sharkova's impression was that both Fuglister and Harmon knew what they wanted and that it would be up to her and Radin to provide it (Sharkova, 2003).

The situation started to more seriously unravel once the raster modeling and conversion was seriously underway and Harmon began to push back for a second time as she struggled to translate the meanings of the maps to the written page. Moreover, Campbell's insistence on having access to the raw data for his own analysis independent of the maps, Labbe's intrusion on Radin's time, and Fuglister's unrelenting pressure to simplify the maps, were all instances of challenges to Sharkova's role as trusted expert. The ambiguity of the situation meant that she and Radin were neither trusted experts nor real partners:

... maybe if we were truly partners from the start, maybe if there were some different dynamics. One of the things that kind of irritated me, honestly, it felt like we were told what to do. On the other hand, the requests, frequently, and I don't mean Tasha at this moment, I mean in more generally, we were treated as if we were research assistants. On the other hand, we were left to make decisions that basically, a team of analysts should be doing. And, then, at any moment that decision could be overturned. It doesn't mean that all decisions were overturned but that was kind of the dynamic. I don't think it was good.

(Sharkova, 2008) 
Sharkova had felt for some time that the project, generally, and Fuglister, in particular, were in "survival mode." Fuglister was doing her best given the situation but the lack of clarity in terms of the roles that each of them were supposed to play traditional experts and clients or equal partners - was tremendously frustrating to Sharkova. She often felt marginalized and never understood why her only communication with CLF's Board was through Fuglister:

I don't understand why we were never allowed to talk to the Board or explain the situation, get their input, or in any way participate ... So, basically, there is just Jill there ... [For example,] "We understand that the board is upset." "Okay, let me just explain our situation and what we are doing and what we're not doing." (Sharkova, 2008)

By the close of 2005, the Regional Equity Atlas project, as far as Fuglister and CLF were concerned, was definitely in survival mode. Fuglister was well aware of the fact that Radin had been volunteering for months but she was also frustrated by the resistance that she was encountering from Sharkova and Radin whenever she asked for a change - that resistance only consumed time. She had been promoting the project, both internally to CLF members and to the outside world, for more than two years with little to show for it. 


\section{Chapter 9. Making Maps Work: Building an Equity Agenda}

Power is a measure of work. Which is what maps do: they work. (W

ood, 2010, p. 1)

\section{Designing the Atlas}

The actual design of the Atlas document began long before most of the final maps had been developed or the text had been written. Ryan Sullivan had training in architecture and urban design and in that capacity was familiar with CLF's work. In the spring of 2004, Sullivan formally interviewed with Fuglister for the job of graphic designer for the Atlas. Sullivan seemed a particularly good fit for the project because in addition to his architectural and urban design background he had experience as a graphic designer with a focus on communicating complex information through illustrations, maps, and charts. Sullivan, too, was intrigued by the "atlas component and the idea that maps would play a prominent role in the project" (Sullivan, 2008). Sullivan was subsequently hired by CLF with the expectation that the project would take nine to twelve months to complete (Sullivan, 2008).

Sullivan's ideas about the project changed, however, as his understanding of it grew: "I came to see the Equity Atlas as a hybrid document in which maps and text were integrated in order to tell a more complete and compelling story" (Sullivan, 2008). Fuglister served as the client for the project but the overall layout of the pages, document structure, and the relationship between the maps and the text were established by a larger group that, in addition to Fuglister, included Radin, Sharkova, Harmon, and Shelley Signett who Fuglister enlisted to do copy editing. 
Most of the design work was accomplished during Sullivan's first year of engagement. There was a series of meetings during which he offered three design options that explored different relationships between the text and the maps as well as various publication sizes and orientations (Sullivan, 2008). Providing dummy pages so that content could be arranged and re-arranged, Sullivan encouraged the group to "find ways to organize the content so that it would be easy for readers to navigate the Atlas" (Sullivan, 2008). As the project "dragged on," Sullivan worked on the project sporadically, "stopping and starting because various other project issues slowed us down" (Sullivan, 2008). As the project began to come together in 2006 and 2007, Sullivan worked more closely with Radin and Signett, by phone and by email (Sullivan had moved to Boston by this time) to complete the document.

Given his understanding that CLF hoped to reach a broad audience with the Atlas, and as a graphic designer interested in the challenge of data communication, Sullivan found trying to deal with the legibility of the maps, or what he has called the "map issue," to be "tricky" (2008):

As a graphic designer, I was very interested in their legibility and pursuing strategies to make them more legible, such as using one color and shades per map. Ken and Irina wanted to proceed with their discipline's map-making conventions. I found this reasonable and tried to focus on the maps' typography and legend design in order to make them feel consistent with the document and legible. (Sullivan, 2008)

Sullivan had no training in cartography and was, therefore, willing to defer to Radin and Sharkova's expertise on this matter. Ideally, however, Sullivan would have liked to have had greater control over the cartographic elements: 
If I had to do it again, I would have liked to take on the responsibility of adjusting the colors and line weights of the final maps myself. I don't think that Ken and Irina would have supported that though.

(Sullivan, 2008)

An additional complication in terms of dealing with the aesthetics of the maps was the fact that they were a moving target:

...the maps were constantly being re-designed and re-issued because of various technical and data-related issues (as I understood it). This also made focusing on their aesthetics difficult in terms of process. By the time the maps were finally "finished" in terms of their selection and data collection, we were already a few years behind. (Sullivan, 2008)

The legibility of the maps, Sullivan knew, would also depend on their size in the printed document. Sullivan recalls that the team explored various document sizes and orientations in the early meetings. A landscape orientation was finally chosen because it could best accommodate the integration of the maps (most of which were square in shape) with the text. For budgetary reasons, an $8 \frac{1}{2}$ by 11 inch page size was selected.

As the project progressed and as Fuglister and the other authors began to realize that the equity story they wanted to tell would require more text and more maps than originally anticipated, the page number grew from a target of forty pages to four times that length (Sullivan, 2008). This combined with the budgetary constraints for printing meant that the maps would have to be small. Ultimately, the document would include 63, approximately four 4 inch by 4 inch, mostly regional maps rendering the neighborhoods in urban areas nearly undetectable. Only the Neighborhood Summary Orientation Map was close to a full page in size. 


\section{Crafting an Equity Narrative}

An equitable region is one where: (1) Every person has access to opportunities for meeting their basic needs and advancing their health and well being; (2) The benefits and burdens of growth and change are fairly shared among our communities; (3) All residents and communities are fully involved as equal partners in public decisionmaking. (The Regional Equity Atlas, 2007, p. 2-3)

Kris Smock's experience as a community organizer for the now defunct community development corporation, Housing Our Families, in the 1990s had made her acutely aware of a lack of analysis that took into consideration "all of the different and intersecting factors" (Smock, 2010) that affect the development of neighborhoods. Wanting to delve more deeply into the issues of community organizing, community development, urban politics, and urban development, she decided to pursue a Ph.D. in Sociology at Northwestern University. In anticipation of her return to Portland in 2001, Smock contacted Fuglister to introduce herself as a community engagement expert and analyst as well to convey her interest in CLF generally (Smock, 2010).

As a result, Fuglister consulted with Smock informally several times during the Atlas process. By the time the publication of the Atlas seemed imminent in late 2006, Smock was the obvious choice for both Fuglister and Carley (now a co-executive director of CLF with Fuglister) to assist them in creating and implementing a rollout strategy. They had two goals. One was to introduce CLF members, key activists, and leaders to the Atlas encouraging them to use it to serve their own needs. The other was to utilize the contents of the Atlas to create an equity action agenda for CLF. 
Initially, Smock, Fuglister, and Carley assumed that they would develop a single workshop, to be delivered in locations around the region, that would accomplish both of their objectives. The participants would first be introduced to the Atlas (the maps and findings) and then be prompted to discuss possible solutions and equity agenda items. The problem was that this approach didn't work:

We did a pilot of it, and we invited key allies and people to get feedback. And, the feedback we got at that point was that it was too much to be trying to get people to digest the Atlas and then immediately go to solutions. (Smock, 2010)

There was confusion among the pilot's participants about the goal of the workshop. Was it primarily to introduce the Atlas as a tool for the participants? Or was it to get input for creating an equity action plan? And there was confusion about the meaning of "equity" in the context of the Atlas project. It was suggested that the equity idea should be fleshed out with personal stories to give it life and resonance for audience members (Smock, 2006a).

Additionally, participants stated that they needed more time to "grapple with the maps directly" (Smock, 2006a). Rather than being told what the maps were saying by a facilitator at the outset, participants wanted "to take a map and discuss what they think it means" for themselves (Smock, 2006a). Based on what she'd observed during the pilot, Smock (2006a) thought that one way to help people to relate to the maps would be to have them create a story about their own neighborhoods and "work it back up [to the regional scale] (i.e. start with something people can relate to)." 
Furthermore, the maps were sometimes seen by the participants in the pilot as "misleading:" "the poverty one [change in child poverty map] looks like we've solved inner city poverty and now it's all suburban" (Smock, 2006a). And, because the maps appeared to be misleading, the participants raised lots of questions about the data, a diversion from the task at hand (Smock, 2006a). Moreover, the maps did not provide solutions to the question of equity, the "[a]ccess to nature [map] doesn't show us what we can do strategically together," (Smock, 2006a) as some of the participants expected the maps to be able to do.

Altogether there were too many topics and too many "trends" (the findings of the Atlas) for the workshop participants to digest (Smock, 2006a). The tasks of understanding the maps, learning how to use them, and translating those efforts into policy solutions were so daunting that some of the participants suggested that the process, in order to do it well, would require a multi-step series of sessions rather than a single workshop (Smock, 2010).

Smock, Fuglister, and Carley believed, however, that it simply wasn't realistic to expect enough people to commit to a prolonged series of workshops. And so, they came up with a compromise: a 2-tiered process that would include one introductory session to the Equity Atlas with opportunities to explore the maps and data, and a second session dedicated to identifying equity agenda "items" and policy solutions (Smock, 2010). Participants in the second session would either have to have attended an introductory session or be familiar with the Atlas and its findings. 
It was also clear to Smock, Fuglister, and Carley that the maps needed further revision in order to make them work for their purposes. The feedback had indicated that the map legends were sometimes ambiguous. Participants had difficulty telling which color meant "more" and which meant "less" (Smock, 2006a). Many of the maps had no neighborhood boundaries to orient map users. Someone suggested that a transparent overlay of the neighborhood boundaries could be created for use with the printed maps that were provided for the participants of the workshops (Smock, 2006a). This, however, would have meant that all of the maps would have to be at the same geographic extent, size, and scale and would incur an additional cost that, given the number of people that CLF hoped to engage, would be prohibitive.

It was also noted that, at least with the maps that were shown at the pilot, there wasn't any way for maps users to assess geographic areas, such as neighborhoods, in terms of all of the equity access topics (housing, education, transportation, health and food, and parks and nature) in one, all-encompassing "equity rank" - as, for example, is used in Opportunity Mapping. This, it was suggested, would make it possible for Atlas users to "identify the hotspots of where equity is not up to par in multiple ways" (Smock, 2006a).

In late November 2006, Smock proposed to Fuglister and Carley a number of revisions to the pilot workshop that incorporated much of the feedback. Ideally, CLF hoped to engage approximately 300 people in the introductory sessions. Given the small-group activities that Smock devised for the sessions, she anticipated that CLF would need to hold 30 introductory sessions to accommodate that number. The 
introductory sessions, Smock suggested, should be conducted by leaders and staff of what she called "network organizations," organizations that could bring others with similar interests into CLF's equity agenda process. Affordable Housing Now, the Vision Action Network, the Food Policy Council, the National Resources Working Group, and the Ecumenical Ministries of Oregon were specifically named by Smock in her proposal (2006b). Ideally, the solutions workshops would bring people together "across issues to analyze the underlying dynamics and develop solutions" (Smock, 2006b). For these workshops, CLF would cast a smaller net in terms of numbers but not interests.

Because most of the potential facilitators would be unfamiliar with the details of the Atlas, they would need training - something that Smock would provide. It would be the facilitators' job, according to Smock (2006b), to present an overview of the Atlas, deliver the discussion questions, and oversee a process by which participants would explore the Atlas in some depth.

Smock recommended that the agenda for the introductory sessions begin with an exercise focused on the neighborhood summary table. This was because this summary table, unlike the maps, allowed users to relatively easily find their neighborhoods and make neighborhood-to-neighborhood comparisons among the population/household variables and the access variables included in the Atlas. Participants would be asked to first find their own neighborhood or neighborhood of interest in the summary table, make comparisons with other neighborhoods, and discuss, in small groups, what surprised them (Smock, 2006b). 
The session would then move to a PowerPoint overview of the Equity Atlas that was intended to showcase the maps but would also provide clarity about the purpose of the Atlas, equity's meaning in the context of the Atlas, instructions on how to read the maps, and caveats, specifically, the limitations of the data, the reliance on proxies to measure access, and the limitations of maps in general - "maps only tell part of the story" (Smock, 2006b). This was to prepare the participants for a groundtruthing exercise focused on interpreting the maps.

So as not to overwhelm the audience, as had been the case during the pilot, Smock knew that she would have to be concise about the story she would tell and selective about which maps from the yet-to-be finalized atlas to include, a task that proved to be frustratingly difficult:

...I remember issues where some of the maps that were the most interesting or the most compelling or that most directly spoke to potential policy solutions were intuitively very difficult to understand as a visual. And, so we really debated whether to use them.

(Smock, 2010)

And, to tell CLF's equity story, each map, data point, and image would need to be connected to the operational terms of CLF's equity definition. A review of the presentation reveals the ways in which Smock and CLF assembled their equity narrative.

After an introduction to the Equity Atlas project and definitions, the finalized PowerPoint presentation begins with a demographic overview that includes charted data, not maps, indicating the increase in racial and ethnic diversity in the region between 1990 and 2000, as well as maps of the change in the geographic distribution 
of child poverty and of upper income households during the same period. This demographic profile of the region concludes with a photograph of suburban development with the caption, "Get Ready for the Next Million," that gives the impression of explosive growth but no supporting map is shown.

The final Atlas document would include additional demographic maps but because of the response to the pilot, Smock believed that it was critically important to engage the session's participants in the story that CLF wanted to tell as quickly as possible without endangering the process with potential debates about the data, questions about the maps, or the relevance of proxies. The decision to display the change in the percentage of racial and ethnic minorities in charts instead of the spatial specificity of maps and to introduce the maps by highlighting child poverty and the concentration of wealth, instead of race and ethnicity, and in the context of change (figures 8.1 and 8.2 ) rather than static points in time, served this purpose. By showing the growth of racial and ethnic minorities in the region independent of the spatial dimension, the facilitators would be able to avoid possible contention, at the outset of the session, related to relative minority impacts that could have been exacerbated by the confusion generated when the same color ramps (or symbology) are used for different data ranges. As seen in figures 9.1 and 9.2 (two maps from the Atlas) the identical red could just as easily represent 100 as 3,000 depending on the range of the data for the particular variable. 


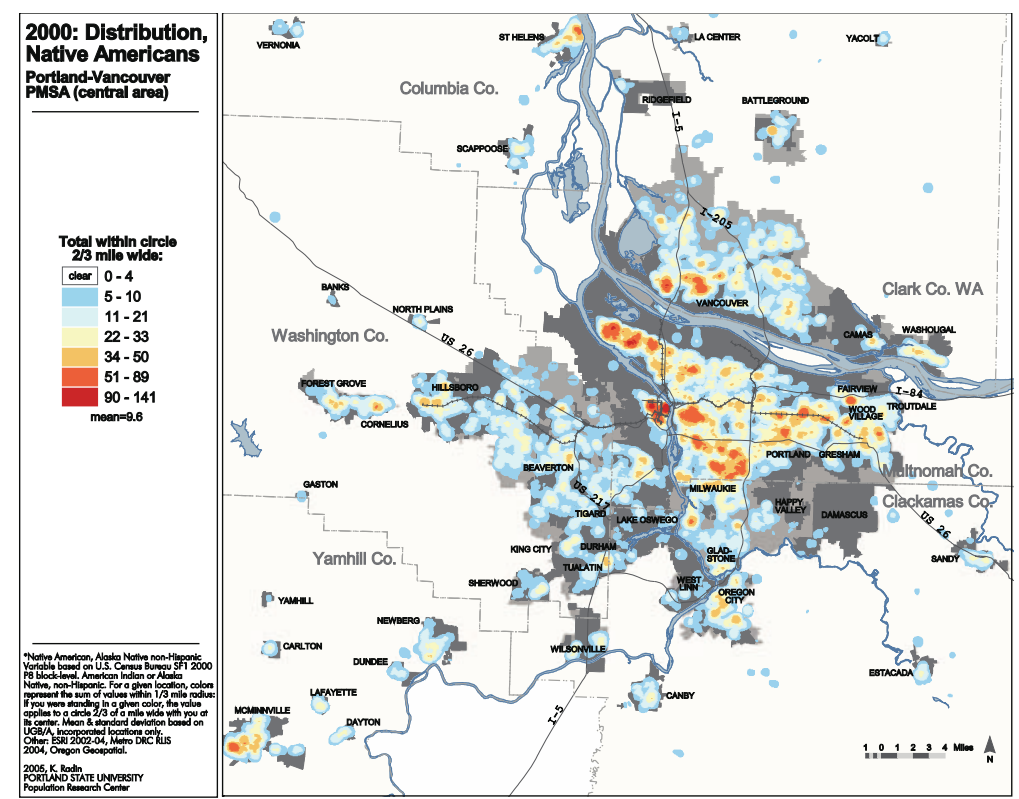

Figure 9.1. 2000: Distribution of Native Americans.

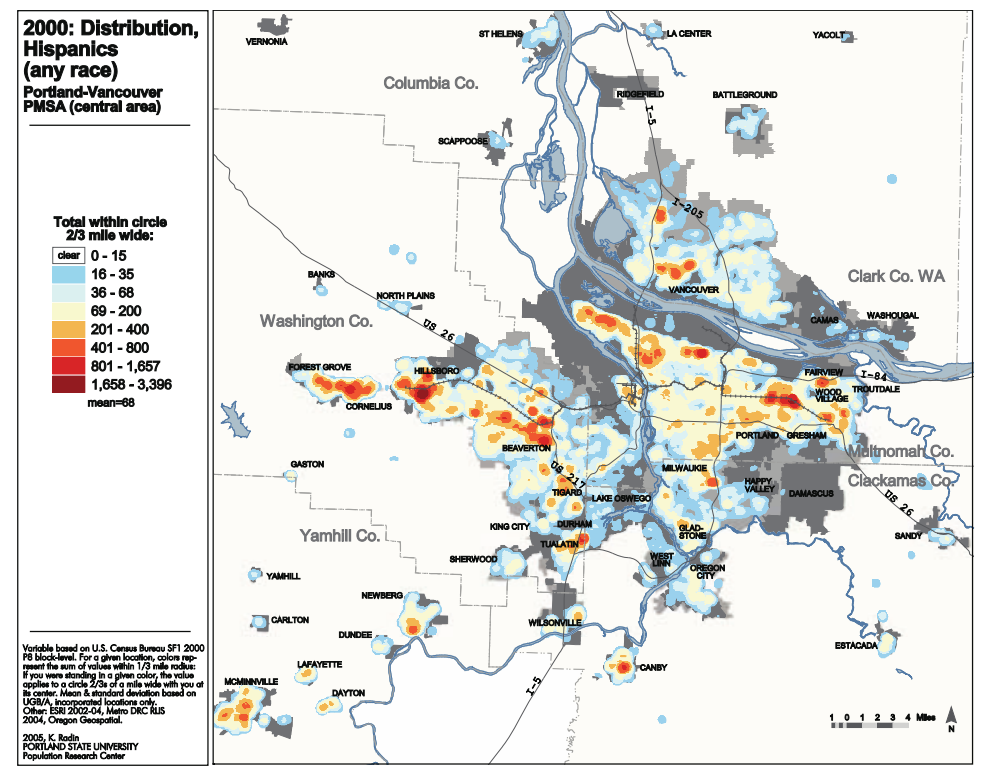

Figure 9.2. 2000: Distribution of Hispanics. Cartography by Ken Radin. Source: Regional Equity Atlas (2007) 
The Change in Children in Poverty and the Change in Upper-Income Household maps (figures 9.3 and 9.4) were not only "safe" choices in terms of topic but they are graphically provocative and convey a sense of movement, urgency, and perhaps the unexpected that would be desirable to hook an audience.

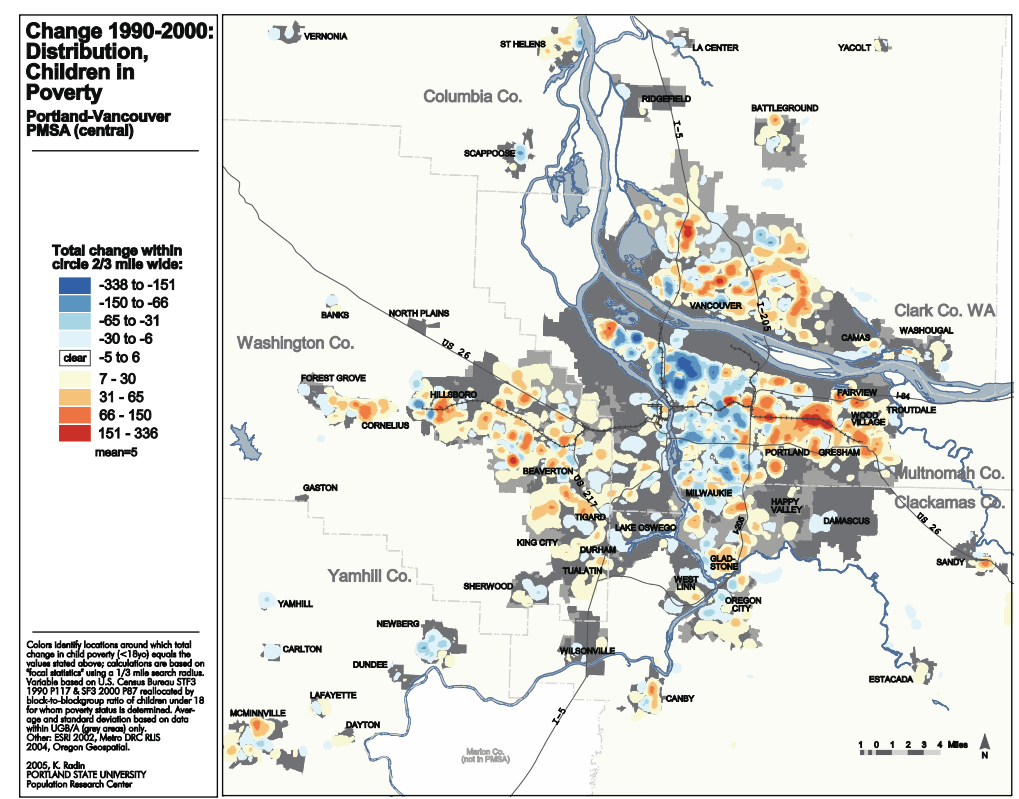

Figures 9.3. Change in Distribution of Children in Poverty, 1990-2000. Cartographer, Ken Radin. Source: Regional Equity Atlas (2007). 


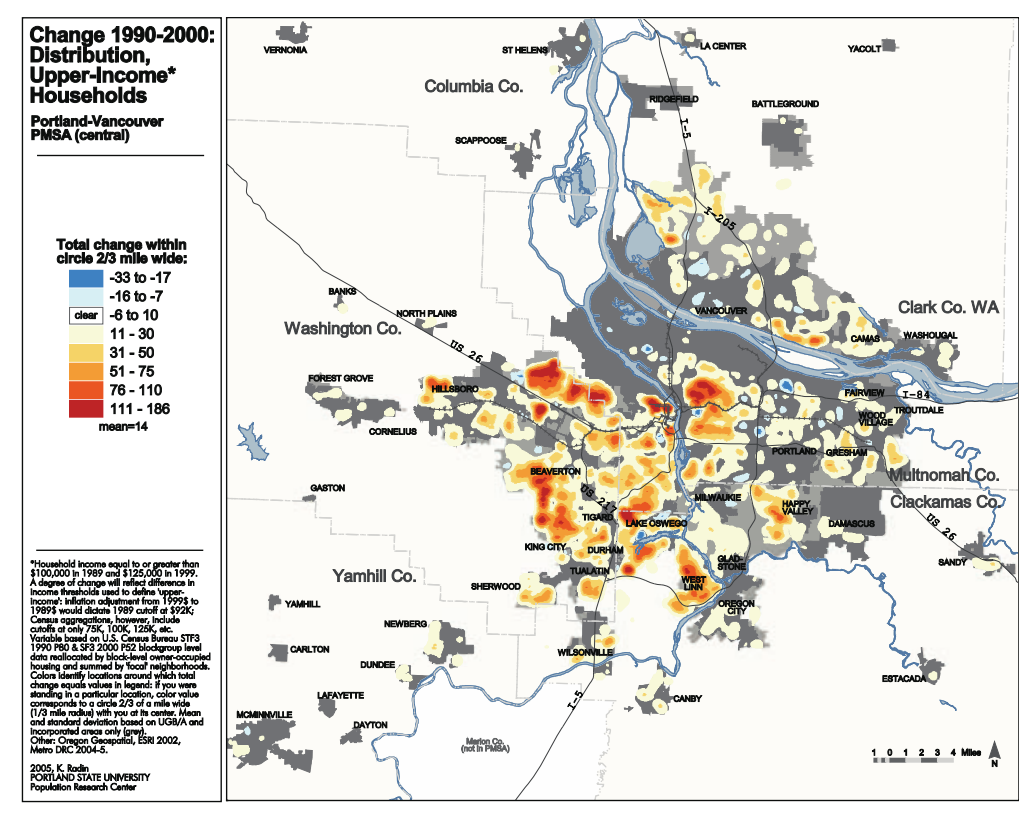

Figure 9.4. Change in Distribution of Upper Income Households, 1990-2000. Source: Regional Equity Atlas (2007)

These maps do not, however, tell the viewer where the concentrations of child poverty or household wealth actually are, only where changes have occurred - a distinction that had confused some participants of the pilot workshop. A map of the distribution of the African American population in 2000 included in the final Atlas document, for example, indicates that the highest concentrations (or red if using the color scheme that the Atlas employs) of that population still existed in the historically African American neighborhoods in northeast and north Portland. These areas also experienced the largest losses (or blue), in terms of numbers, in the change over time map shown later in the presentation (figure 9.5); they give the impression, however, that inner northeast and north Portland are devoid of African Americans. This condition in terms of confusion related to interpretation may, in fact, be the case for 
viewers of the distributions of child poverty or household wealth maps as well. Any of the variables could be represented as red or blue in the maps depending on whether or not the population or change in population was being mapped - something, again, that a sophisticated map user would know to look for but not necessarily a novice. But it was important to be able to demonstrate that the region had, in fact, experienced both growth and geographic shifts, phenomena that could be related to the second component of CLF's equity definition that states that "the benefits and burdens of growth and change are fairly shared among our communities."

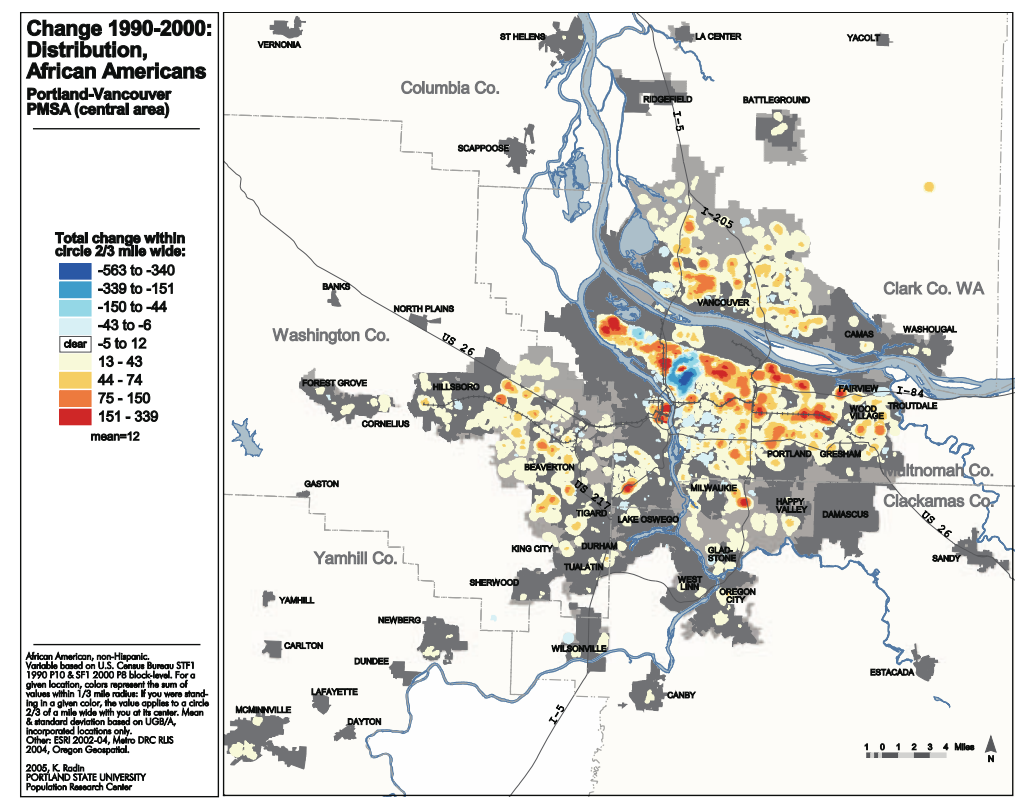

Figure 9.5. Change in Distribution of African Americans, 1990-2000. Cartography by Ken Radin. Source: Regional Equity Atlas (2007)

For the "access to key resources" section of the presentation, Smock integrated some additional demographic maps or locational information derived from them, with 
Radin's physical access maps (that employed Radin and Sharkova's access model) in an exploration of trends in equitable access to housing, quality public education, transportation, parks and greenspaces, and health and food (Smock, 2007a). Although the Atlas authors referenced some of the demographic maps in their access chapters, the entire demographic map-set would be separated into their own "Demographics" chapter in the final Atlas document, away from the access maps. The direct comparisons offered in Smock's presentation, however, between the physical access maps and the demographic maps creates a kind of mental overlay that implies a direct relationship or correlation between "access" and race, ethnicity, and poverty and suggests that equitable access is more complex than the issues of geographic distance, supply, and demand (the components of the Radin/Sharkova assess model) alone.

For example, in exploring access to housing, the "Change in Distribution of African Americans, 1990-2000" map and two maps showing the distribution of Native Americans, one for 1990 and one for 2000, are paired with the "Percentage Change, 1995-2004: Median Sales Price of Single-Family Homes” suggesting a relationship between the cost of housing and race that is approached as a mapped index (minority homeownership gap) in the Atlas document. In examining access to health, graphic circles were derived from the distribution of child poverty map and placed over the "Percentage Sidewalk Coverage around Elementary and Middle Schools" map to identify areas with increasing poverty and poor sidewalk access. Similarly, Radin's map of "Transit Access Summary Score by Neighborhood or City," that is a measure that combines distance to transit stops, population size, and service, is modified to 
include outlines around those neighborhoods with both increased poverty and poor physical access to transit. This illusion of overlay harkens back to Bosworth's early attempt at mapping access that tied poverty to physical access in a simple overlay process.

Because of the feedback from the pilot, Smock was mindful of the importance of connecting the introductory participant experience to the purpose of the solutions workshops. If the introductory sessions were successful, the stories told by the maps and the data would be translated through the participants' own experiences "on the ground" to inform the process of creating CLF's equity action agenda. However, in her examination of the maps as well as the experience of the pilot workshop, Smock had become acutely aware both of the power of the "visuals," the maps, to grab people's attention and to spark ideas but also of the power of maps to confuse and their inability to deal with causality - so crucial to the business of policy-making. In showing maps of socio-economic variables such as poverty, ethnicity, and race with the physical access maps, she was suggesting a possible correlation between the two, something that the authors of the Atlas document tended to confirm, but there was the risk, especially because causality was so important to developing solutions, that these relationships could be misconstrued as causation.

Smock's own experience as a community organizer, researcher and analyst had given her extraordinary insight into the underlying complexity of neighborhood dynamics. And she, herself, struggled with the necessity of simplification from a research perspective on the one hand and the fear of not being comprehensive enough 
on the other - that some key variable would be overlooked negating the validity of whatever explanation might result. So that even though she saw many of the maps as overly dense and sometimes misleading or illegible, and even though she sometimes wished for a greater level of simplicity in the maps for CLF's non-technical audience, she also felt that she could relate to the struggles that Sharkova and Radin, as researchers, must have gone through in trying to come to terms with mapping something as complicated as equity:

I remember being able to completely understand the perspective of the academics or the mappers who were involved with it [the Atlas]. I mean I struggled throughout graduate school with the idea of taking really dense, complex information and how to turn it into a sound bite. I know with my dissertation I remember thinking the thing that actually makes people remember something or allows something to be a contribution to the literature is that it basically has one argument or maybe two. And, my dissertation had maybe hundreds of arguments.

(Smock, 2010)

Smock, like Harmon, both of whom had extensive experience at the community level, was wary of the simplicity of the sound-bite in trying to analyze real-world relationships and develop meaningful solutions. The irony of this is that simplification is exactly what Sharkova and Radin were attempting to do with their access model. Although Sharkova, when she first got involved with the Atlas, touched on the possibility of developing a single equity index (Sharkova, 2004c) and Campbell had indicated that the kind of multiple variable statistical analysis that the development of such an index would entail would greatly strengthen the analytical rigor of the project, by the time these things were seriously considered, it was determined that they would be too time-consuming and costly to the already over- 
budget project. Never mind the fact that several key access variables, such as access to jobs where the large scale geographic data simply weren't accessible or available, were totally missing from the analysis. By eliminating a multitude of known and unknown socio-economic factors that could affect equitable access to opportunities as well as the complication of weighting factors (that could be part of the development of such an index), by focusing only on distance, supply, and demand, Sharkova and Radin created a conceptually simple model of access - one that in spite of its limitations they believed they could stand behind as researchers and academics. These physical access maps and resulting data could be used, after all, by the authors of the Atlas, and as Smock had done, in conjunction with the demographic maps and data from the neighborhood summary table to construct a more complete equity picture. In many ways, what Smock had interpreted as complexity in the maps was complex more in the realm of the software procedures and the dense digital output that their relatively straightforward model produced.

In additional to dealing with the complexity of the maps, in telling the Atlas story to the public, Smock had serious concerns about the limitations of the data that meant that everything had to be a proxy - a notion that many participants in the pilot session found difficult to grasp:

The other thing that we struggled with ... was the whole idea that you were limited to whatever data were available and mappable and that everything is a proxy. From a researcher's standpoint, that's something you deal with all the time especially with quantitative research.... One of the things we were trying to do is ground-truth them [the maps] and see how well they resonated with people's experience. And, of course, 
people's experience is much more nuanced. And, so people were frustrated.... A proxy is a limited thing. (Smock, 2010)

The ground-truthing exercise that Smock designed for the introductory sessions was intended to help the participants to come to terms with what they'd seen of the Atlas (in the PowerPoint presentation and the neighborhood summary table) and to find out whether or not the Atlas analysis reflected "people's on-the-ground experiences" (Smock, 2007b). In small groups, the participants would be asked two questions: (1) does this resonate with your experiences - with what you're seeing in your work and in your own lives (why and why not)?; and, (2) how could this inform or support your work? (Smock, 2007b) This is where the rubber would hit the road. This is where, Smock, Fuglister, and Carley knew, the participants could opt in or out of the process and where the Atlas would prove its worth because if the maps didn't relate to participants' experiences and if participants couldn't see using what they'd seen in their own work, if they didn't see value in it, there would be no solutions workshops or equity action agenda.

Although the solutions workshops, unlike the introductory sessions, were to be focused almost entirely on identifying and prioritizing equity items and cross-issue solutions, facilitators were required to set the stage for the small-group discussions with an abbreviated PowerPoint presentation to remind the participants of the Atlas' findings. An examination of the operative language in the presentation script provides some insight into CLF's understanding of how the Atlas maps worked to make the equity argument. 
Regarding the two key demographic variables that were included in this PowerPoint, child poverty and upper income households, the Atlas "shows" that poverty is no longer a problem restricted primarily to urban Portland and it "shows" that certain areas in the region experienced an increase in upper income households over the past decade (Smock, 2008). The argument relates directly to growth and change and has a spatial dimension that is communicated through the visual inspection of the maps. Similarly, the Atlas "illustrates" the displacement of low-income residents and people of color from one geographic area to another and provides a "visual representation" of this issue (Smock, 2008). Further, the script states, "[w]e can point to several neighborhoods that have both sub-par transit service compared with the regional standard and higher numbers of poor people and seniors" (Smock, 2008) - as in "pointing to" places on the map in the literal sense. These operative words stress the illustrative function of the maps (the Atlas' earliest purpose) rather than the analytical or measurement functions (a later refinement of purpose).

There are places in the script where measurement is stressed over the visual, however. Referring to the findings related to health, the script states, "[w]hat we found in measuring school walkability is that how easy it is to walk to school corresponds most directly to when the surrounding neighborhood was developed" (Smock, 2008). However, although the Radin/Sharkova model involved precise measurement along networks of sidewalks, this finding like the others aforementioned has as much to do with the visual inspection of the sidewalk network around schools 
map combined with the assumption that sidewalk grids are a function of history than historical spatial analysis.

The only place where a direct numeric argument is used by Smock is related to access to parks and greenspaces. The script states, "[f]orty percent of the region's residents live more than a quarter mile from a public greenspace" with the additional claim, "[t]hese residents are disproportionately less affluent and not white" (Smock, 2008). These claims were, in fact, derived by Labbe using the neighborhood summary table's ranks for access to greenspaces, race, and poverty. The 40 percent number was made possible through the data assignment resulting from the Radin/Sharkova GIS access model but not through the maps per se. In a few other instances important claims are made without explicit reference to maps or space: "[t]he Atlas analysis of the region's housing market demonstrates that the single-family home standard of living has moved out of the reach of many homeowners" (Smock, 2008); and, "[t]he Atlas found that there is a large and growing homeownership gap between communities of color and whites" (Smock, 2008). These were Campbell's own findings that were drawn independent of the mapping process.

Thus, according to the presentation script, the presented maps and data made the case that for many residents of the region, particularly those in poverty and racial or ethnic minorities, access to key resources were not equitable and that the prevailing development patterns had negatively affected this vulnerable population's access to transit, health, and greenspaces. The maps did this by "showing," "illustrating," 
"pointing," and to a lesser extent "measuring." Having made the case, the participants of the solutions workshops would be invited to roll up their sleeves and get to work:

As we have just heard, residents in our region don't have equal access to key opportunities and resources.... But there are also areas, like public transit, where a concerted policy commitment to equitable access has made a big difference. The goal of today's workshop is to identify public policy strategies that could address key areas of inequity in our region, in order to develop an action plan for regional equity.

(Smock, 2007b)

There seems to be, throughout the whole explanation of how to read the maps and understand the findings sections of the presentation, a subtext that goes something like this: "This is how the maps really work ... because you won't be able to figure them out on your own;" and, "This is how this what this map really says ... because you may not be able to tell without translation." The experience of sharing some of the draft maps with CLF members and others earlier in the Atlas process had taught CLF that it simply couldn't allow the maps to speak entirely on their own in making its equity argument.

More than four years after the process began and with the acquisition of funds from Kaiser Permanente for the printing, in July, 2007, The Regional Equity Atlas: Metropolitan Portland's Geography of Opportunity went to press and was delivered in time for distribution at most of these events [according to Carley, as of June 2011, 3,390 copies out of 5,000 printed atlases have been distributed]. With the support of Washington Mutual, the IMS, and the PRC, between May and December 2007, CLF staff and its members, with training from Smock, conducted 26 introductory workshops that engaged approximately 750 people in The Regional Equity Atlas. 
Five solutions workshops were held between January $15^{\text {th }}$ and February $1^{\text {st }} 2008$ the results of which were tabulated by CLF to draft its regional equity action plan. The importance of Smock's presentations should not be underestimated since it is probably safe to say that most of the people who contributed to the equity action plan came to know the Atlas through the narrative developed for these workshops rather than the document itself. Ultimately, CLF would engage more than 1,000 people in the development of CLF's regional equity action agenda.

\section{A Different Approach}

At the time Fuglister and Carley approached Smock to work on the process by which the equity action agenda would be created, CLF and IMS, with support from Kaiser Permanente, put together a series of three panel discussions as another way to introduce an invited list of key stakeholders to the soon-to-be-published Regional Equity Atlas. These events, that took place between January and March 2007, unlike the introductory sessions or the Atlas document, paired topics (Transportation and Housing, Housing and Education, and Health and Environment) and brought together panels of experts in each field who had reviewed selected maps to talk about the topics in light of equity and how the Atlas helped them to think about them differently. The venue for each session included a "gallery" of poster-sized maps for attendees to preview before the formal panel discussion began as well as a PowerPoint presentation, developed by Fuglister, of the most relevant maps. The panel discussion was followed by an opportunity for questions and answers as well as informal discussion. 
Merrick (2007) distributed surveys to the attendees for CLF at the second two of the events to help CLF get a general sense of how audience members reacted to the maps prior to the publication of the Atlas. This survey was not conducted for the purposes of this dissertation and the findings are not conclusive, however, they are interesting in light of the fact that this was an approach that focused almost entirely on grappling with the maps rather than a reliance on a predetermined narrative by CLF (with the exception of Labbe who spoke on the Health and Environment panel) or the text of the Atlas document. Both events attracted approximately 60 audience members.

In general, the findings were encouraging. When asked if they thought that the maps helped them to identify geographic patterns of the phenomena, all of the respondents $(\mathrm{n}=14)$ from the Housing and Education session said either "somewhat yes" (64 percent) or "strongly yes" (36 percent). For the Health and Environment session respondents ( $\mathrm{n}=18)$ replied "somewhat yes" (49 percent) or "strongly yes" (39 percent) to this question (Merrick, 2007). When asked whether they thought the maps were persuasive, 43 percent of the respondents from the Housing and Education session replied "somewhat yes," with 43 percent replying "strongly yes," At the Health and Environment session 39 percent of the respondents replied "somewhat yes" while 44 percent replied "strongly yes" (Merrick, 2007). When asked if the maps helped them to ask new or better questions, 58 percent of the respondents from the Housing and Education session said "somewhat yes" with 21 percent saying "strongly yes." And, 61 percent of the respondents from the Health and Environment session 
responded "somewhat yes" with 22 percent responding "strongly yes" (Merrick, 2007).

While it is undoubtedly true that CLF would have liked to have seen a larger percentage of the responses in the "strongly yes" category for all of these questions, the results indicate very little negativity. However, the fact that 64 percent of the respondents from the Housing and Education session and 49 percent of the respondents from the Health and Environment session replied "somewhat yes" rather than "strongly yes" to the question of whether the maps helped them to identify geographic patterns was troublesome in that pattern demarcation is a keystone of thematic mapping. It also confirms Fuglister's sense that the Atlas needed to include an explanation not only of the statistical trends but of the map symbology itself. Nevertheless, the results also indicate, with the relatively high percentage of respondents from both sessions replying "strongly yes" (43 percent and 44 percent respectively) to the map persuasiveness question, that as far as these respondents were concerned, the maps were convincing and could be used to persuade others. 


\section{Chapter 10. The Atlas: An Analysis}

Typically, when people think about an atlas they imagine a document that features maps and where text, graphs, and imagery, if included, are supplemental to the maps. The maps are the primary storytellers. The Regional Equity Atlas is not a traditional atlas. Rather, it developed, over time, into what Sullivan (2008) has called, a hybrid document, something between an atlas and a report. This is largely because of the need for extensive explanatory text related to the maps, CLF's desire to make the equity story as clear as possible, and the atlas team's belief that in order to make that happen, the maps and the text needed to be visually connected.

One could, however, imagine a different approach that would have featured the maps more prominently - presenting them, more like a traditional atlas, in their own separate map section, away from the text. One of CLF's goals was to encourage others to use the contents of the atlas to promote their own agendas. By allowing each map to fill its own page, perhaps as a tear-off, one could envision users of the atlas selecting and ordering the maps to tell their own stories to promote their own agendas. However, separating the maps from the text would have required them to stand on their own without lengthy explanation. CLF's primary goal was, in its attempt to better understand equity conditions in the region, to build an equity action agenda that would shape all of CLF's future activities and influence regional policy based on that agenda. To do this, it had to create a coherent narrative for its findings - something that the maps, in and of themselves, could not do. [After the atlas was published, CLF did make pdfs of each of the maps available for download at its website.] 
There were no precedents for the work at least as far as CLF was concerned; no pre-determined methodology; no pre-existing equity index to apply; and no single map that could identify "equity hotspots" to tell the equity story. Instead, the entire process was exploratory, from the framing to the variables to the mapping, with a result that required each author to tease out of the available maps and data, with help from Radin and Sharkova, their own triangulations and interpretations. The conversations among CLF members related to the indicators and variables started before any equity framework had been adopted by the Coalition. And, when it was, its translation into the mapping environment proved challenging. This was in part because the three components of its equity definition, or dependent variables, represented not only space, but time, and socio-political dimensions that can be conceptualized as depicted in figure 10.1: 


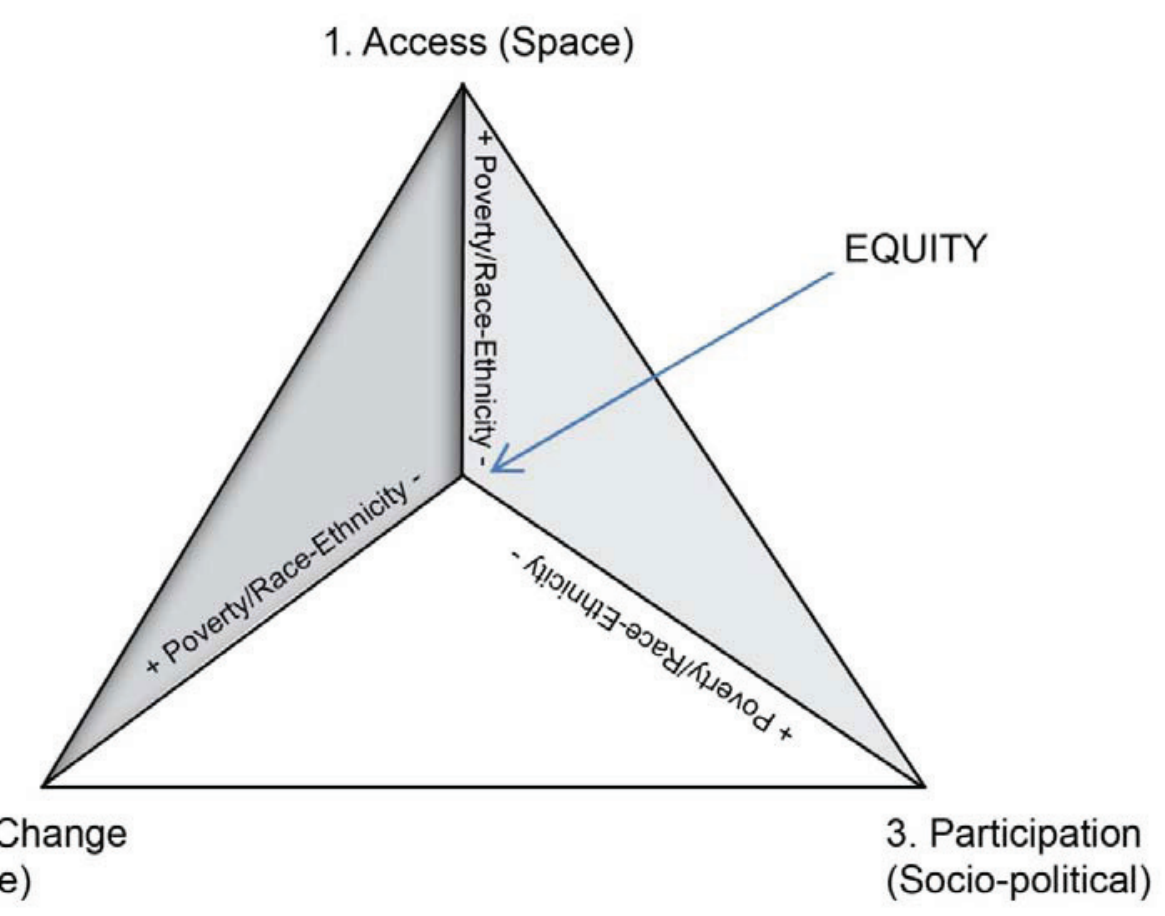

Figure 10.1. Merrick's Conceptual Model of CLF's Equity Framework.

In this model, the extent to which equity is achieved is determined by the extent to which poverty and race/ethnicity affect the three components of CLF's equity framework. The more that poverty and race/ethnicity determine a person's access to key resources, the ways in which they are affected by growth and change, and their ability of fully participate in public decision-making, the less equity there is. Of course, there could be other determinants besides poverty status and race/ethnicity, including some touched on in the Atlas document but not mapped, such as age, that could be added - just as the list of key resources addressed in the Atlas, most notably jobs, is incomplete. But this appears to be, generally, how the authors of the Atlas tried to approach their work. It also helps to explain the enormously challenging task 
of trying to come to terms with not just a socio-spatial dimension of the issue but also a socio-temporal one. The participation component was largely untouched.

Even so, the maps that were selected for inclusion in the document do not represent a pre-determined method or set of methods. Rather, their differing methodological approaches (choropleth and raster, single- and multi-variable, displayed in tracts and block groups, pixels or grid cells, and neighborhoods) represent points along the journey that CLF staff and its members, CLF and Harmon, Harmon and Radin, Radin and Sharkova, Radin and Labbe, and Radin, Sharkova, Campbell, and Fuglister took in their efforts to frame and map equity (figure 10.2). All are represented in the Atlas document: there are four choropleth maps by Census geographies; 29 are rasters; 13 are choropleth maps by neighborhood or city; one is a choropleth map by school districts; and, eight are point maps where the data are map at the XY coordinates for each school location. Only the choropleth maps by neighborhood or city include neighborhood boundaries. 


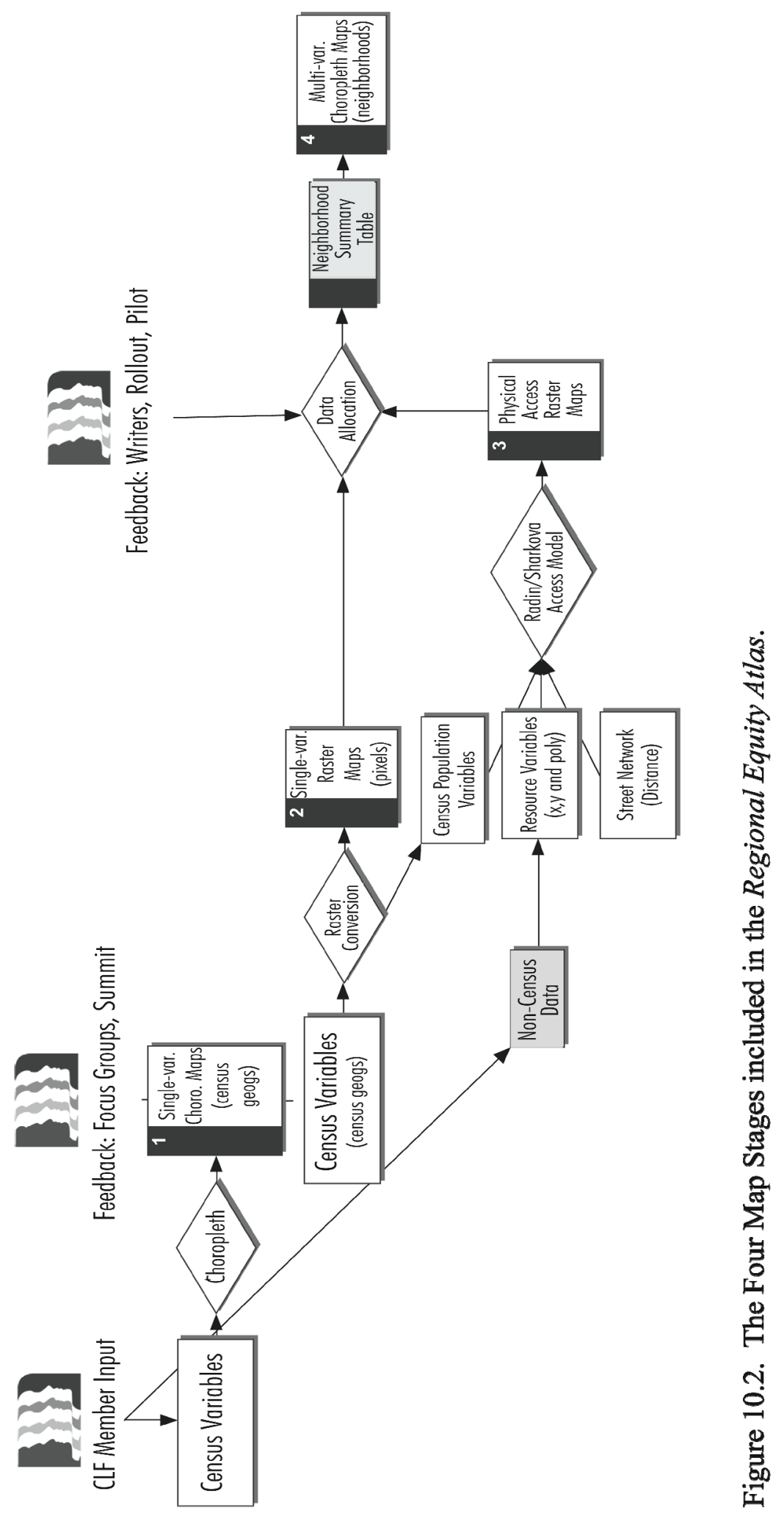


The project began with what Harmon would call the "naive" assumption that the document's story would naturally emerge out of the maps: the maps would "diagnose" equity and solutions would suggest themselves. But this did not happen. Instead, it became the Atlas' authors' task to work the maps into their arguments (generally derived from the neighborhood summary table and other sources) describing each map's meaning as they did so.

The printed Atlas is made up of two parts: "Equity, Who We Are, Where We Live" or a demographic overview that emphasizes change in the region; and the "Access to Resources" section that attempts to address, primarily, the first of CLF's equity criteria but to some degree looks at the impact of change as well. All of the chapters in the Atlas utilize maps to help to tell the equity story with the exception of a section entitled, ironically, "Money Matters - The Landscape of Public Resources," that falls between the transportation chapter and the health and design chapter. This section was written by Campbell and focuses on the importance of public finance, a topic that he believed was important to the equity discussion and one with which he was familiar. It showcases Campbell's approach to analysis that is statistical rather than spatial in the mapping sense. And it adds a dimension, the dynamics behind the availability and distribution of public dollars, that is only really touched on cartographically in the education chapter, and then indirectly, in the "2000, Median Household Income by School District" map. 
It is important to note that the printed atlas also includes two appendices: the Neighborhood Summary Table; and a technical appendix that explains the methodologies used for each map.

\section{Part I: The Demographic Section}

Given the number of population variables available from the Census and the large number that were mapped during the diagnostic phase of the project, those included in the demographics section of the Atlas are relatively few. They include total population, the number of housing units, the four primary race categories (African American, Asian, Native American, and White) plus Hispanic, child poverty, and upper income households all as rasters with legends using a 2/3 mile search radius for the reported data. Their red to blue, dichromatic color schemes, allow for the user to easily see patterns of the distribution of income, race, and ethnicity across geographic space but not actual quantities related to any particular tract, block group, neighborhood, or grid cell, for that matter. No neighborhood boundaries are included as a visual guide, only municipal boundaries.

In addition, there are two choropleth maps included in the chapter: "1990 \& 2000: Neighborhood Child Poverty Rates Relative to Regional Rates” and "1989: Median Household Income, by Census Tract." The restrictions on space that the budget imposed meant that the authors had to select, in addition to the poverty, race, and ethnicity variables necessary to the equity argument, those variables that they believed would draw their audience into the equity story. 
The chapter begins with the statement, "Region Adds 400,000 People in 10 Years" and "shows" and "illustrates" this with maps of the distribution of the population in 2000 and the change of the population between 1990 and 2000 . The remainder of the chapter is prefaced, however, by a map that wasn't created by Radin or Sharkova at all. It is a "Residential Security Map" created in 1938 by the Home Owners' Loan Corporation (HOLC) that effectively redlined several neighborhoods in Portland. This sets the stage for the Atlas' findings by suggesting that a combination of factors including institutional racism exemplified by this map that historically devalued certain neighborhoods and subsequent gentrification contributed to the current geographic distributions of minorities and people in poverty - a nod to causation.

To support these claims, the map narrative moves to three graphically powerful maps: the distribution of African Americans in 2000, (regional scale); the change in the distribution of African Americans between 1990 and 2000, (regional scale); and the change in the distribution of African Americans between 1990 and 2000 zoomed in to inner northeast Portland, an historically redlined area and the historic home to the African American community. Although the text states, and the corresponding map's legend indicates, that the largest number of African Americans still resided, in 2000, in the historical African American communities in northeast Portland, visually the reader's attention is drawn to the neighborhood scale map indicating, in a sea of dark blue (see figure 9.5), the loss in those neighborhoods of that population. Because the gains and losses that were generated by Radin's raster conversion are given in numeric 
terms rather than the percent of the total, the actual impact of these changes are difficult to gage. And because of the nature of the dichromatic color ramp with extreme color intensities at either end of the data range, the impact of the losses and gains appear to be dramatic, but, again because of the way Radin's raster conversion process worked the percents of the total population per grid cell were not generated. This neighborhood scale map is not only the only one at this scale in the chapter, highlighting its importance, but the only one at this scale in the entire atlas. It is clear that this particular demographic shift was a key element of the equity story that the authors were trying to tell.

The narrative moves to a discussion of the demographic changes in the Hispanic population between 1990 and 2000. But here the emphasis is different. Rather than focusing on "change" per se, the authors of the chapter chose to display it using two maps of the total population within a $2 / 3$ mile search radius:

[The maps] illustrate change in the distribution of Latinos by showing 1990 and 2000 distributions side-by-side. Both maps use the same classes, with the exception of the last class (darkest red) added to the 2000 legend, which didn't exist in 1990. Between 1990 and 2000, the Latino population more than doubled as a share of the regional population ... (The Regional Equity Atlas, 2007, p. 17)

Based on the visual inspection of the maps, the narrative goes on to suggest that this population grew along light rail lines, in parts of the region where subsidized housing may be located, and where other Latinos have already settled. This latter claim, however, is difficult to verify with the maps since this population appears in many areas where they were absent in 1990. 
The Asian population and the Native American populations are similarly displayed in side-by-side comparisons of the populations in 1990 and 2000, rather than change, as the text in both cases focuses on the geographic "shifts" and growth of these populations that would be well served by the inclusion of a "change" map in each case. The decision not to include them was undoubtedly related to the budget and the decision to rely on the text to describe these changes. The chapter does include, however, an additional change map by race of the White population but no side-by-side comparison of this population is provided. The White population has always dominated the demography of the region but less so in 2000 . And, what the map illustrates is the growth in number of the White population at the suburban fringe and a decline at the urban core. Again, it is very hard to tell what the impact of these changes are because the data have not been normalized to the total population.

In concluding the race and ethnicity portion of the chapter and before moving to the income-related variables, the text confronts one of the key challenges of working with Census data that CLF saw as particularly relevant to the discussion of equity: the undercount of minorities and the poor, particularly the homeless or those living in transient living arrangements, Latinos who may fear Census enumerators, transient populations in general, and problems specifically associated with counting Native Americans. The geographic specificity of the maps implied a numeric precision that wasn't necessarily the case and given CLF's desire to do justice to these populations, it was important to try to acknowledge the limitations of the data upfront. 
Poverty was always considered by Harmon and CLF to be a key determinant of access and child poverty is the proxy for poverty in the Atlas:

The experience of poor adults and poor children is central to our study of regional equity. With the exception of high adult poverty rates in downtown and very close-in Southeast Portland neighborhoods, distributions of child poverty and change closely mirror those for poverty as a whole. (The Regional Equity Atlas, 2007, p. 21)

But there is little doubt that child poverty provokes a more sympathetic response than poverty in general. The Atlas dedicates four maps to the topic indicating its importance to the Atlas' authors: side-by-side maps of the distribution of child poverty in 1990 and 2000; a change in the distribution of child poverty between 1990 and 2000; and a choropleth map by neighborhood that relates the neighborhood rate to that of the regional whole. While the authors acknowledge that the percentage of the population in the region in poverty and child poverty declined between 1990 and 2000 , they note that there were 31,300 more people living in poverty in 2000 than in 1990 with nearly a third of them being children (The Regional Equity Atlas, 2007, p. 21). And, echoing the findings of the race and ethnicity findings, the authors stress the substantial spatial shifts that occurred for children in poverty during the decade.

The final map of the series, "1990 \& 2000: Neighborhood Child Poverty Rates Relative to Regional Rates," provides an illustration of the legibility issues that resulted from a misguided desire to add explanatory power of the data through the map - thus, requiring convoluted explanatory text:

Rather than focusing on density, [this map] compares 1990 and 2000 neighborhood or city child poverty rates to regional rates. Yellow-red tones mean rates increased over the decade; blue-purple tones mean 
rates decreased. (The two tones don't correspond to degree of change; they only indicate whether an increase or decrease occurred, but not by how much.) In addition, the colors indicate whether the child poverty rate was below or above the regional rate in each year. For example, the darkest purple indicates that the child poverty rate declined between 1990 and 2000 and it was also below the regional rate in both 1990 and 2000 - that is, a "good" place getting "better."

(The Regional Equity Atlas, 2007, p. 23)

The problem created by the inclusion of this map is not only that the symbology is difficult to interpret but so is the explanatory text. The narrative continues:

The middle classes are difficult to interpret using "good" and "bad" terminology. Is it worse to be a neighborhood with a declining child poverty rate, yet above regional rates in both years (light blue), or a neighborhood with an increasing child poverty rate yet below regional rates (light yellow)?

(The Regional Equity Atlas, 2007, p. 24)

One could ask why include this map at all, when other possible maps, such as "change" maps for the Asian and Native American populations were not. This is the first "neighborhood" map in the Atlas. As stated earlier, none of the other maps in the chapter include neighborhood boundaries even as an overlay. Because of the persistent feedback related to the desire to be able to associate the information in the maps directly to neighborhoods of interest, in the concluding months of the Atlas production there was a move to include as many neighborhood summary maps as possible and this was the only one created for the demography section.

The final two maps in this chapter focus on the distribution of wealth in the region. The first is the second choropleth map in the chapter but instead of neighborhoods, the geographic unit is Census block groups. Interestingly, this median household income map includes 1989 (or Census 1990) data (in 1999 dollars) only, 
that is paired with a raster map of the change in upper-income households (or those earning equal to or greater than $\$ 100,000$ in 1989 and those earning equal to or greater than $\$ 125,000$ ) between 1990 and 2000 . With a red-blue symbol-set that is designed to clearly differentiate incomes on either side of the regional mean, the median household income map for 1989 displays a striking spatial divide, that with the exception of downtown Portland, lies on either side of the Willamette River. In general, west of the Willamette are "red" households or those whose incomes are above the median, and east of the Willamette are the "blue" households or those with incomes under the regional median. But, the inclusion of this map is not as much to focus on this spatial divide as it is meant to support the authors' observation that wealth not only grew during the period but "intensified" "near" historically wealthy areas and in parts of northeast Portland with declining populations of color (The Regional Equity Atlas, 2007, p. 25). However, in many respects these maps are not comparable (figures 10.3 and 10.4). 


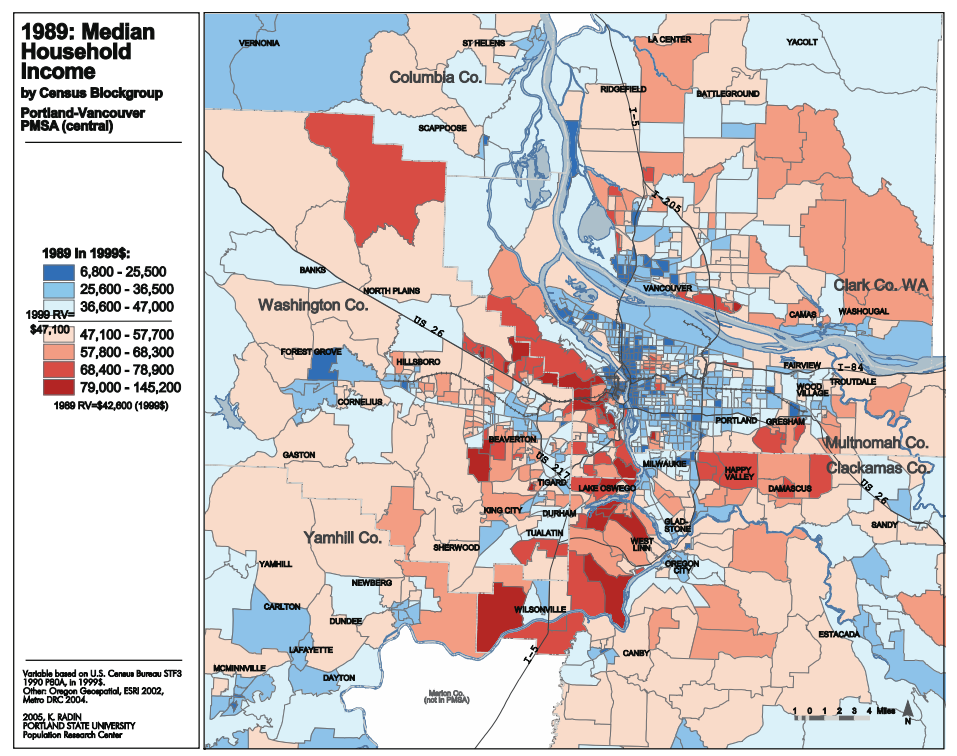

Figure 10. 3. 1989: Median Household Income by Census Block Group. [Legend \$6,800-\$145,200] Source: The Regional Equity Atlas (2007)

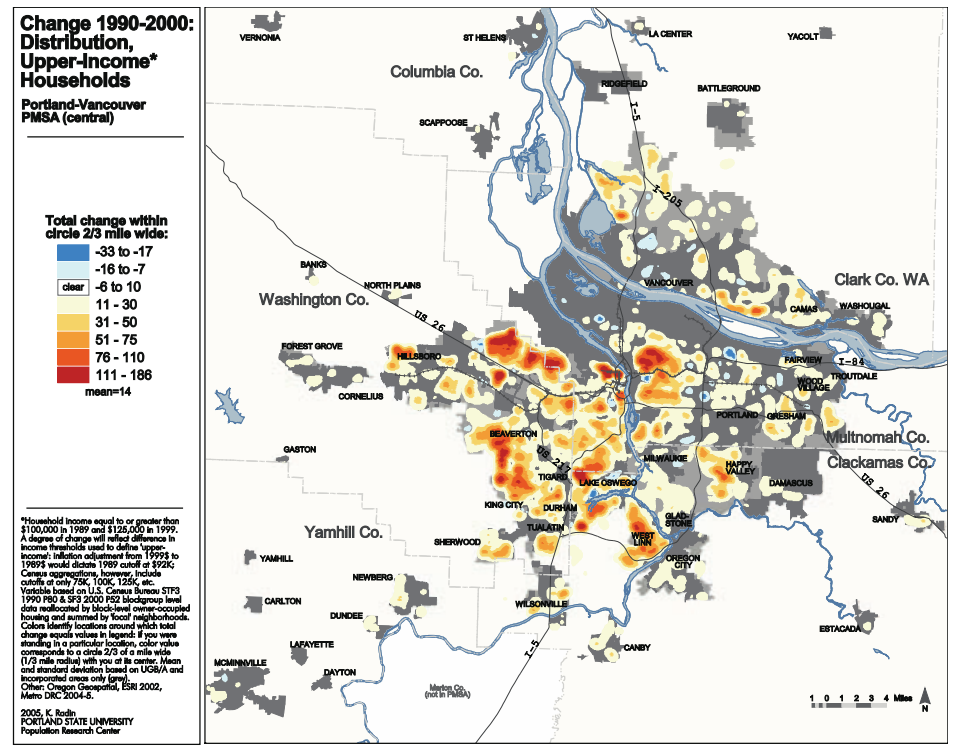

Figure 10.4. Change 1990-2000: Distribution of Upper-Income Households. Defined as equal to or above $\$ 100,000$ in 1990 dollars, or $\$ 125,000$ and above in 2000 dollars. Source: The Regional Equity Atlas (2007) 
As discussed earlier in this study, Census geographies such as the block groups used here, are inconsistent in terms of area and irregular in shape whereas the grid cells used in the raster maps are identical to each other in both size and shape. In addition, Radin's raster conversion process eliminated data outside of urbanized areas but the block group geographies cover the entire geographic extent of the map. The two maps aren't calibrated to each other in another important respect, the one, according to the text, that ties the two maps together: median income. The classification breaks used in the first map (a median household income of $\$ 79,000$ is the threshold for the highest class) do not correspond to the income criterion for "upper-income" households (\$100,000 in 1990 dollars). This may seem like quibbling but the two maps are hard to compare and it is likely that either they would be passed over by the reader in preference of the text or viewed for their individual content only. This is an example of the authors using, as best they could, what was available to them to make their case. And, here, what was important, in terms of storytelling, was further evidence of the displacement of low-income people of color as is evident in the chapter's summation: (1) that children in poverty and communities of color "are becoming proportionally larger in suburban areas," again emphasizing change over actual conditions; and (2) that gentrification and displacement "are taking place in parts of the region" (The Regional Equity Atlas, 2007, p. 25). The narrative suggests that further research is needed to better understand the impact of this movement on both the affected families and their new and former neighborhoods but, interestingly, doesn't explicitly link these findings with CLF's equity criteria. 


\section{Part II: Access to Resources}

While the demographics section of the Atlas focuses on the locations of demographic phenomena with an emphasis on geographic shifts and change, touching on the second element of CLF's equity definition that is concerned with the impacts of growth and change, the access section relates most directly to the first element, physical access to key resources. However, it is important to recognize that the uneven distributions of communities of color and the poor in addition to their locational shifts and changes identified in the demographics section, although not overtly articulated in the Atlas, provide the justification for a spatial analysis of the geographic access to resources of those populations. Given the limitations of the project in terms of time, funding, and the lack of data, and given the complexity of the issue generally and the multi-dimensionality of equity as defined by CLF, it was a question of how to utilize what had already been created in terms of maps (the demographic maps included in the demographics section and the physical access maps using the Radin/Sharkova access model) or could quickly be generated to tell CLF's equity story.

As discussed earlier, concern about the legibility of the maps remained and the request for some reference to neighborhoods in the maps persisted throughout the project. The idea of including a neighborhood boundary transparent overlay was rejected as problematic but by the time the Atlas was published, Radin did create at least one summary variable mapped at the neighborhood level using the choropleth technique for each of the access topics. These are identified in table 10.1. 
Table 10.1. Summary Variables and Components by Neighborhood

\begin{tabular}{|c|c|c|c|c|c|}
\hline $\begin{array}{l}\text { Neighbor- } \\
\text { hood } \\
\text { Summary } \\
\text { Variables }\end{array}$ & Chapter & Components & Distance & Race & Income \\
\hline $\begin{array}{l}\text { Housing } \\
\text { affordability } \\
\text { index }\end{array}$ & Housing & $\begin{array}{l}\text { Tri-county median income over } \\
\text { the median sale price of homes } \\
\text { by neighborhood. }\end{array}$ & & & $X$ \\
\hline $\begin{array}{l}\text { Minority } \\
\text { homeownership } \\
\text { gap }\end{array}$ & Housing & $\begin{array}{l}\text { Minorities as a percentage of } \\
\text { all households minus minority } \\
\text { home-owning households as a } \\
\text { percentage of all home-owning } \\
\text { households. }\end{array}$ & & $X$ & \\
\hline $\begin{array}{l}\text { Teacher training } \\
\text { and experience } \\
\text { index }\end{array}$ & Education & $\begin{array}{l}\text { Teacher training = percentage } \\
\text { of teachers with advanced } \\
\text { degrees. } \\
\text { Teacher experience = average } \\
\text { number of years per school. }\end{array}$ & & & \\
\hline $\begin{array}{l}\text { Average walking } \\
\text { distance to } \\
\text { transit stops }\end{array}$ & $\begin{array}{l}\text { Transport- } \\
\text { ation }\end{array}$ & $\begin{array}{l}\text { Average network-distance to } \\
\text { transit per neighborhood. }\end{array}$ & $x$ & & \\
\hline $\begin{array}{l}\text { Transit access } \\
\text { summary score }\end{array}$ & $\begin{array}{l}\text { Transport- } \\
\text { ation }\end{array}$ & $\begin{array}{l}\text { Network walking distances to } \\
\text { transit stops plus total } \\
\text { population relative to transit } \\
\text { service within a "transit shed" } \\
\text { or small area. }\end{array}$ & $X$ & & \\
\hline $\begin{array}{l}\text { Access to } \\
\text { grocery or } \\
\text { natural food } \\
\text { stores summary } \\
\text { score }\end{array}$ & $\begin{array}{l}\text { Health and } \\
\text { Design }\end{array}$ & $\begin{array}{l}\text { Network distance to closest } \\
\text { store plus population per } \\
\text { store(s) service area. }\end{array}$ & $X$ & & \\
\hline $\begin{array}{l}\text { Public parkland } \\
\text { access } \\
\text { summary score }\end{array}$ & $\begin{array}{l}\text { Parks and } \\
\text { Nature }\end{array}$ & $\begin{array}{l}\text { Network distance to parkland } \\
\text { plus total population relative to } \\
\text { total parkland acres within a } \\
\text { "parkshed" or small area. }\end{array}$ & $X$ & & \\
\hline $\begin{array}{l}\text { Percent } \\
\text { population within } \\
\text { a } 1 / 4 \text { mile of } \\
\text { natural habitat }\end{array}$ & $\begin{array}{l}\text { Parks and } \\
\text { Nature }\end{array}$ & $\begin{array}{l}\text { Population within a } 1 / 4 \text { mile of } \\
\text { natural habitat summed by } \\
\text { neighborhood. }\end{array}$ & $X$ & & \\
\hline $\begin{array}{l}\text { Natural habitat } \\
\text { acres per capita }\end{array}$ & $\begin{array}{l}\text { Parks and } \\
\text { Nature }\end{array}$ & $\begin{array}{l}\text { Sum of habitat acres by } \\
\text { neighborhood divided by the } \\
\text { sum of population by } \\
\text { neighborhood. }\end{array}$ & $X$ & & \\
\hline
\end{tabular}

Generally, these summary access variables were derived through the reallocation of data generated by Radin and Sharkova's access model, but this is not always the case. Household income, which is a major factor in access to housing was incorporated into 
the single-family housing affordability index and the cost-burdened renter-household rate, as is race in the minority home-ownership gap variable mapped in the housing chapter. It is not surprising that these particular measures were included in Campbell's housing chapter since it was he who most strongly advocated for a multi-variable approach that incorporated the social with the physical elements and had pushed for the creation of the neighborhood summary table.

In reviewing the maps that are included in the access chapters of the Atlas, the connection between physical access to key resources and poverty, race, and ethnicity is generally made by other means, such as the neighborhood summary table and other supporting information. One of the exceptions to this is Campbell's housing chapter where the first point of access is income rather than physical distance. What follows is a brief examination of the evidence provided in each chapter as it relates to CLF's access definition and the case that CLF was trying to make.

Housing. As stated earlier, the housing chapter is the only one of the access chapters not to include any maps employing the Radin/Sharkova access model. Instead, Campbell focused on housing costs in terms of homeownership and rents, the availability of rental housing, and minority homeownership as a share of the total. In reviewing the maps and additional evidence that Campbell included (table 10.2), several things stand out. 
Table 10.2. Access to Housing Chapter: Maps, Tables, Graphs

\begin{tabular}{|c|c|c|c|c|c|c|}
\hline Type & Title & Time & Geography & $\begin{array}{l}\text { Incomel } \\
\text { Assets }\end{array}$ & $\begin{array}{l}\text { Racel } \\
\text { Ethnicity }\end{array}$ & $\begin{array}{l}\text { Dist- } \\
\text { ance }\end{array}$ \\
\hline $\begin{array}{l}\text { Map } \\
\text { (spatial) }\end{array}$ & $\begin{array}{l}\text { Single-Family Housing } \\
\text { Affordability Index Maps (2) } \\
\text { (2004 and } 2004 \text { incomes with } \\
1995 \text { prices) }\end{array}$ & $\begin{array}{l}\text { Static (2) } \\
\text { paired } \\
\text { (change) }\end{array}$ & $\begin{array}{l}\text { Neighborhood } \\
\text { or City }\end{array}$ & $x$ & & $x$ \\
\hline $\begin{array}{l}\text { Map } \\
\text { (spatial) }\end{array}$ & $\begin{array}{l}\text { Percent Change1990- } \\
\text { 2000:Median Value Owner } \\
\text { Occupied Single-Family } \\
\text { Housing }\end{array}$ & Change & $\begin{array}{l}\text { Census Block } \\
\text { Group }\end{array}$ & $x$ & & $x$ \\
\hline $\begin{array}{l}\text { Map } \\
\text { (spatial) }\end{array}$ & $\begin{array}{l}\text { Percent Change 1995-2004: } \\
\text { Median Saleprice Single- } \\
\text { Family Homes }\end{array}$ & Change & $\begin{array}{l}\text { Neighborhood } \\
\text { or City }\end{array}$ & $x$ & & $x$ \\
\hline $\begin{array}{l}\text { Map } \\
\text { (spatial) }\end{array}$ & $\begin{array}{l}\text { Change } 1990=2000: \text { Cost } \\
\text { Burdened Renter Household } \\
\text { Rate }\end{array}$ & Change & $\begin{array}{l}\text { Neighborhood } \\
\text { or City }\end{array}$ & $x$ & & $x$ \\
\hline $\begin{array}{l}\text { Map } \\
\text { (spatial) }\end{array}$ & $\begin{array}{l}\text { Change 1990-2000: share of } \\
\text { Single-Family Homes Rented } \\
\text { Rather Than Owned }\end{array}$ & Change & $\begin{array}{l}\text { Neighborhood } \\
\text { or City }\end{array}$ & $x$ & & $x$ \\
\hline $\begin{array}{l}\text { Map } \\
\text { (spatial) }\end{array}$ & $\begin{array}{l}\text { Change 1990-2000: } \\
\text { Distribution, Rented Single- } \\
\text { Family Homes }\end{array}$ & Change & Raster & $x$ & & $x$ \\
\hline $\begin{array}{l}\text { Map } \\
\text { (spatial) }\end{array}$ & $\begin{array}{l}\text { 2000: Minority Home- } \\
\text { Ownership Gap }\end{array}$ & Static & Census Tract & $x$ & $x$ & $x$ \\
\hline Graph & $\begin{array}{l}\text { 1990-2005: Housing Prices } \\
\text { vs. Household Income }\end{array}$ & Change & Region & $x$ & & \\
\hline Table & $\begin{array}{l}\text { Median Household Income, } \\
1989 \text { and } 1999\end{array}$ & Change & County & $x$ & & \\
\hline Table & $\begin{array}{l}\text { Conventional Home Mortgage } \\
\text { Denials by Income Group, } \\
\text { Ptld-Vancouver PMSA, } 2003\end{array}$ & Static & Region & $x$ & $x$ & \\
\hline
\end{tabular}

$\mathbf{X}=$ direct relationship $\mathbf{x}=$ indirect relationship

One is the emphasis on change. Campbell not only describes the current conditions but suggests that the trend in terms of housing affordability and available was getting worse. Throughout his text, he references information visible in the maps provided in the demographic section to support these contentions, such as the "Change 1990-2000: 
Distribution of Upper-Income Households" map that suggests gentrification in northeast Portland, and the "Change 1990-2000: Distribution, Child Poverty" where he states, describing the "Change 1990-2000: Distribution, Rented Single-Family Homes" map, "The general pattern is similar to change in the distribution of child poverty shown on page 23" (The Regional Equity Atlas, 2007, p. 37). The other authors, in tying poverty and race to their equity arguments, do the same. Unfortunately, the textual reference lacks the power of the side-by-side visual display (something that Smock was able to do in her PowerPoint presentation of the Atlas' findings) and lends to a sense that the story is less in the maps than in the text.

The analysis in the table above, indicates that Campbell, in spite of his hesitancy about the maps, may be responsible for the map that may come closest to a single indicator for equity. This is because the "2000: Minority Home-Ownership Gap" index incorporates the distribution of minorities with homeownership (a proxy for wealth) in relationship to the total population and homeownership by Census tract (providing the spatial distribution). This map doesn't not provide the temporal dimension but it could have. By incorporating historical HUD record data and other data sources, Campbell was able to provide some historical context in his text but not with the same spatial resolution that this map provides. No other chapter in the Atlas combines in a single map, data relating to the resource at hand, income, and race/ethnicity.

Finally, it is notable that four out of seven maps are mapped at the neighborhood or city level, two out of the seven use Census geographies, and only one 
is a raster map. This is in part because Campbell believed that it was essential to be able to associate an actual number or rank to a particular geographic unit which was, for all practical purposes, impossible to do with the raster maps. But it was also because access in the case of housing was so clearly defined around income and to a lesser degree race, making the analysis of distance performed in the raster environment less useful.

The chapter ends with two major findings: one that is general to the region and a second that is distinctly spatial. The first is that homeownership, between 1990 and 2000 , moved out of the reach of many of the region's households. The second is that people of color, during the same period, were being displaced because of rising housing costs and were moving to places with lower housing prices.

Schools. The access to education chapter, in the mapping sense, differs from the other access chapters in that it is the only one to map most of the data included in the chapter as XY coordinates, or points - in this case at the locations of public elementary schools. This was one of the last chapters to be developed and in determining how to approach the chapter, Sharkova, turned to Orfield as a reference. This was his general approach to mapping schools data. As with the other chapters, the legends of the maps employ are blue to red color scheme that, in this case, corresponds with "blue" signifying "good" and "red" signifying "bad" for each dataset. Table 10.3 provides an overview of the maps and tables included in the chapter. 
Table 10.3. Access to Schools Chapter: Maps and Tables

\begin{tabular}{|c|c|c|c|c|c|c|}
\hline Type & Title & Time & Geography & $\begin{array}{l}\text { Incomel } \\
\text { Assets }\end{array}$ & $\begin{array}{l}\text { Race/ } \\
\text { Ethnicity }\end{array}$ & $\begin{array}{l}\text { Dist- } \\
\text { ance }\end{array}$ \\
\hline $\begin{array}{l}\text { Map } \\
\text { (spatial) }\end{array}$ & $\begin{array}{l}\text { 2000: Median Household Income by } \\
\text { School District }\end{array}$ & Static & $\begin{array}{l}\text { School } \\
\text { District }\end{array}$ & $x$ & & \\
\hline $\begin{array}{l}\text { Map } \\
\text { (spatial) }\end{array}$ & $\begin{array}{l}\text { AY2002: Teacher Training \& Experience } \\
\text { by Public Elementary School (Oregon } \\
\text { only) }\end{array}$ & Static & $\begin{array}{l}\text { Points } \\
\text { (schools,xy) }\end{array}$ & & & \\
\hline $\begin{array}{l}\text { Map } \\
\text { (spatial) }\end{array}$ & $\begin{array}{l}\text { Access to Teacher Training \& } \\
\text { Experience at Public Elementary } \\
\text { Schools by Neighborhood }\end{array}$ & Static & $\begin{array}{l}\text { Neighborhood } \\
\text { or City }\end{array}$ & & & \\
\hline $\begin{array}{l}\text { Map } \\
\text { (spatial) }\end{array}$ & $\begin{array}{l}\text { AY1999: Percent Students Eligible for } \\
\text { Free/Reduced Price Meals by Public } \\
\text { Elementary School }\end{array}$ & $\begin{array}{l}\text { Static } \\
\text { (change) }\end{array}$ & $\begin{array}{l}\text { Points } \\
\text { (schools, xy) }\end{array}$ & $x$ & & \\
\hline $\begin{array}{l}\text { Map } \\
\text { (spatial) }\end{array}$ & $\begin{array}{l}\text { AY2003: Percent Students Eligible for } \\
\text { Free/Reduced Price Meals by Public } \\
\text { Elementary School }\end{array}$ & $\begin{array}{l}\text { Static } \\
\text { (change) }\end{array}$ & $\begin{array}{l}\text { Points } \\
\text { (schools, xy) }\end{array}$ & $x$ & & \\
\hline $\begin{array}{l}\text { Map } \\
\text { (spatial) }\end{array}$ & $\begin{array}{l}\text { AY1997:Percent White Students by } \\
\text { Public Elementary School }\end{array}$ & $\begin{array}{l}\text { Static } \\
\text { (change) }\end{array}$ & $\begin{array}{l}\text { Points } \\
\text { (schools, xy) }\end{array}$ & & $X$ & \\
\hline $\begin{array}{l}\text { Map } \\
\text { (spatial) }\end{array}$ & $\begin{array}{l}\text { AY2003:Percent White Students by } \\
\text { Public Elementary School }\end{array}$ & $\begin{array}{l}\text { Static } \\
\text { (change) }\end{array}$ & \begin{tabular}{|l} 
Points \\
(schools, xy)
\end{tabular} & & $x$ & \\
\hline $\begin{array}{l}\text { Map } \\
\text { (spatial) }\end{array}$ & $\begin{array}{l}\text { AY1997: Student-Teacher Ratio by } \\
\text { Public Elementary School }\end{array}$ & $\begin{array}{l}\text { Static } \\
\text { (change) }\end{array}$ & $\begin{array}{l}\text { Points } \\
\text { (schools, xy) }\end{array}$ & & & \\
\hline $\begin{array}{l}\text { Map } \\
\text { (spatial) }\end{array}$ & $\begin{array}{l}\text { AY2003: Student-Teacher Ratio by } \\
\text { Public Elementary School }\end{array}$ & $\begin{array}{l}\text { Static } \\
\text { (change) }\end{array}$ & $\begin{array}{l}\text { Points } \\
\text { (schools, xy) }\end{array}$ & & & \\
\hline Table & $\begin{array}{l}\text { Public Schools by Percentage of } \\
\text { Students Eligible for Free/Reduced } \\
\text { Meals, 1999-2003 }\end{array}$ & Change & & $x$ & & \\
\hline Table & $\begin{array}{l}\text { Public Schools by Percentage of White } \\
\text { Students, } 1997-2003\end{array}$ & Change & & & $x$ & \\
\hline Table & $\begin{array}{l}\text { High School Completion and Dropout } \\
\text { Rates by Race and Ethnicity, State of } \\
\text { Oregon, AY2003-04 }\end{array}$ & Static & State & $x$ & $x$ & \\
\hline Table & $\begin{array}{l}\text { Number and Percentage of } \\
\text { Disadvantaged Groups Not Meeting } \\
\text { "Adequate Yearly Progress" by School } \\
\text { District, AY 2005-06 }\end{array}$ & Static & $\begin{array}{l}\text { School } \\
\text { Districts }\end{array}$ & $x$ & $x$ & \\
\hline
\end{tabular}

$\mathbf{X}=$ direct relationship; $\mathrm{x}=$ indirect relationship 
Sharkova had been drafted to write this chapter because she was the most experienced of the Atlas team with school district demographic data but she was not entirely comfortable with this assignment and had to develop an access to education argument that was less about physical access (elementary schools are well distributed throughout the region) than access to educational opportunity and resources within individual school locations. Suggesting that high socio-economic status is associated with more local funding per student in schools, the chapter begins with a map that displays median household income by school district in 2000 . However, the school district scale of the map, as Sharkova states, conceals the disparities within the districts themselves. Given the limitations on the number of maps to be included in the Atlas, it isn't entirely clear why this map was used since the text reiterates its findings. The remainder of the chapter's maps do indeed focus on the particularity of the individual schools, displaying school district data, with the exception of the summary by neighborhood map of the access to teacher training and experience at public elementary schools scores, a proxy for quality teaching, and providing the one neighborhood summary map for the chapter.

The remaining maps in the chapter focus on the availability of quality teachers (based on educational attainment and years of experience teaching), the percentage of students eligible for free or reduce priced meals for each school in 1999 and 2003 (a proxy for poverty), and the percentage of White students per school in 1997 and 2003. Sharkova opted for pairs of side-by-side static maps (at two points in time), rather than "percent change" maps, that allow for easy comparisons between the two time periods. 
And, given the relatively small number of points on the maps (none appear to overlap) they can all be seen. A page layout that allows the viewer to see not only side-by-side comparisons between dates on a single variable but side-by-side comparisons among the four maps that display the free and reduced priced meals with the percent White student populations between the two points in time, once the legends are understood, is effective in conveying the overlap between poverty and race and the impact of change that is not found elsewhere in the access section of the Atlas. Sharkova uses tables to reinforce these findings and to bring in additional data (at too large a geographic scale to be useful, perhaps) indicating dropout rates at the state level and "disadvantaged groups" not meeting "adequate yearly progress" at the school district level.

Although one of the findings of the chapter focuses on the effect of the socioeconomic status of districts in relationship to teacher experience and training, larger shares of White, non-Hispanic students, and fewer disadvantaged students, generalizing to the school district level may not be all that useful. However, based on the specificity of the maps and a comparison to maps in the demographics section, Sharkova was able to show that poverty in absolute and relative terms had grown and that schools that were already poor were getting poorer and that schools that were getting poorer were also becoming less White. Sharkova makes some additional observations that may be based on maps elsewhere in the Atlas or her own knowledge of school district and census data as a demographer but that she does not cite. These 
relate to possible causes and impacts of gentrification on the demographic composition of schools:

Families that have stayed include low-income families in subsidized housing, those concerned about racial prejudice elsewhere (African Americans), or upper-class families sending their children to private schools or who take advantage of the school district's transfer policy. Middle-class newcomers are often childless individuals or couples. Anecdotal evidence suggests that middle-class newcomers with children follow the behavior of upper-class families, and are sending their children to private schools or are transferring them to other schools in the district. (The Regional Equity Atlas, 2007, p. 51)

Clearly, this is an effort to deal with the causality questions that would be important to addressing inequality but the evidence presented in this chapter or elsewhere in the Atlas isn't sufficient.

Transportation. The transportation chapter, written by Campbell, is the first chapter in the Atlas for which distance is the major component of access in the mapping context. Based on the text, it is clear that Campbell understands the importance of poverty and the history of racism as they relate to both physical access to transportation generally (access to an automobile) and to transit in particular. However, in the mapping context, the focus is on the determination of the locations of places where there is an acceptable distance from where people live to a transit stop as well as a more complicated calculus that adds the transit service level to the computation - creating the "transit access score," essentially the Radin/Sharkova access model, used in the Atlas. Table 10.4 provides a list of the maps included in the chapter. No tables or graphs are included. 
Table 10.4. Access to Transportation Chapter: Maps

\begin{tabular}{|c|c|c|c|c|c|c|}
\hline Type & Title & Time & Geography & $\begin{array}{l}\text { Incomel } \\
\text { Assets }\end{array}$ & $\begin{array}{l}\text { Racel } \\
\text { Ethnicity }\end{array}$ & $\begin{array}{l}\text { Dist- } \\
\text { ance }\end{array}$ \\
\hline $\begin{array}{l}\text { Map } \\
\text { (spatial) }\end{array}$ & $\begin{array}{l}\text { Change 1990-2000: Share of Workers } \\
\text { Who Drove to Work }\end{array}$ & Change & $\begin{array}{l}\text { Census Block } \\
\text { Group }\end{array}$ & & & $\mathrm{x}$ \\
\hline $\begin{array}{l}\text { Map } \\
\text { (spatial) }\end{array}$ & $\begin{array}{l}\text { Transit Access: Walking Distance to } \\
\text { Nearest Transit Stop }\end{array}$ & Static & $\begin{array}{l}\text { Raster- } \\
\text { network }\end{array}$ & & & $x$ \\
\hline $\begin{array}{l}\text { Map } \\
\text { (spatial) }\end{array}$ & $\begin{array}{l}\text { Walking Distance to Nearest Transit } \\
\text { Stop: Average by Neighborhood }\end{array}$ & Static & $\begin{array}{l}\text { Neighborhood } \\
\text { or City }\end{array}$ & & & $x$ \\
\hline $\begin{array}{l}\text { Map } \\
\text { (spatial) }\end{array}$ & Transit Access Summary Score * & Static & $\begin{array}{l}\text { Raster- } \\
\text { network }\end{array}$ & & & $x$ \\
\hline $\begin{array}{l}\text { Map } \\
\text { (spatial) }\end{array}$ & $\begin{array}{l}\text { Transit Access Summary Score*: } \\
\text { Average by Neighborhood }\end{array}$ & Static & $\begin{array}{l}\text { Neighborhood } \\
\text { or City }\end{array}$ & & & $x$ \\
\hline $\begin{array}{l}\text { Map } \\
\text { (spatial) }\end{array}$ & $\begin{array}{l}\text { North Portland Transportation Projects } \\
\text { Study Area }\end{array}$ & Static & $\begin{array}{l}\text { CRC Study } \\
\text { Area }\end{array}$ & & & \\
\hline
\end{tabular}

*Radin/Sharkova Access Model. $\mathbf{X}=$ direct relationship; $\mathrm{x}=$ indirect relationship

Although none of the maps include poverty or race variables, Campbell made

extensive use of the neighborhood summary table for his analysis and, therefore,

required the walking distance map and the transit access score map that were both

rasters be translated or reallocated to the neighborhood level for the Atlas users. $\mathrm{He}$

describes his approach to the reader this way:

Summarizing the data by neighborhoods allows us to assess levels of access more directly for poor communities and communities of color. In exploring transit access, we were able to analyze neighborhoods or cities falling within Clackamas, Clark, Multnohmah, and Washington counties served by TriMet or C-Tran. By our measures, we found that the most intensely poor and minority areas of the Portland-Vancouver metropolitan area tend to be well-served by TriMet and C-Tran.

However, there are places where poverty and/or communities of color are concentrated or growing rapidly by regional standards - and where transit access is below regional standards.

(The Regional Equity Atlas, 2007, p. 58-59) 
The neighborhood summary table, which is what Campbell actually used for his analysis, not the maps, not only provided actual populations by neighborhood for each variable but the change in population and percent change in population plus a ranking for each variable. He doesn't refer to the table in his text, however, only the maps. Campbell also mentions two additional populations that are not analyzed in the Atlas, the elderly and people with disabilities, and he makes a case for their inclusion in the future:

...anecdotal information indicates that these services [transit services provided by TriMet and C-Tran specifically catering to these populations], seniors and people with disabilities, in particular, struggle to receive adequate service for meeting basic transportation needs. As the region ages over the decades to come, this issue will become critically important to address.

(The Regional Equity Atlas, 2007, p. 61)

The findings of this chapter derived through the conversion of the rasterized access data to neighborhood boundaries compared with the race and poverty data contained in the neighborhood summary table suggest that "the most intensely poor and minority areas" in the region have good transit access but specifically twelve neighborhoods were identified, mostly in outlying areas that were also poor and where a relatively large percentage of people of color lived. These results are distinctly spatial. Outside of the realm of the maps and data, Campbell's exploration of TriMet's and C-Tran's transit policies indicated increasing efforts to address transit equity particularly focused on the elderly and people with disabilities. 
Health and Design. It fell to Fuglister to write this chapter and as can be seen in table 10.5, it is not as robust as those discussed thus far. In fact, Fuglister begins her chapter with these comments:

The chapter touches briefly on several issues related to health. First, we zero in on schools, examining how easily our children can walk to school and get the exercise they need to be healthy. We then look at access to food - another basic prerequisite for community and individual health. Finally, we provide a brief overview of regional air quality patterns. (The Regional Equity Atlas, 2007, p. 70)

Table 10.5. Health and Design Chapter: Maps

\begin{tabular}{|l|l|l|l|l|l|c|}
\hline Type & Title & Time & Geography & Incomel & Race/ & $\begin{array}{l}\text { Dist- } \\
\text { ance }\end{array}$ \\
\hline $\begin{array}{l}\text { Map } \\
\text { (spatial) }\end{array}$ & Percent Sidewalk Coverage Around Schools & Static & $\begin{array}{l}\text { Points (school } \\
\text { xy locations) }\end{array}$ & & & $\mathrm{X}$ \\
\hline $\begin{array}{l}\text { Map } \\
\text { (spatial) }\end{array}$ & $\begin{array}{l}\text { Access to Grocery or Natural Food Stores: } \\
\text { Summary Score* }\end{array}$ & Static & Raster & & & $\mathrm{X}$ \\
\hline $\begin{array}{l}\text { Map } \\
\text { (spatial) }\end{array}$ & $\begin{array}{l}\text { Access to Grocery or Natural Food Stores } \\
\text { Summary Score*: Average by Neighborhood }\end{array}$ & Static & $\begin{array}{l}\text { Neighborhood } \\
\text { or City }\end{array}$ & & & $\mathrm{X}$ \\
\hline $\begin{array}{l}\text { Map } \\
\text { (spatial) }\end{array}$ & $\begin{array}{l}\text { Diesel Particulates, North and Northeast } \\
\text { Portland, 2005** }\end{array}$ & Static & Isolines & & & $\mathrm{X}$ \\
\hline
\end{tabular}

*Radin/Sharkova Access Model, **DEQ Map

$\mathbf{X}=$ direct relationship; $\mathbf{x}=$ indirect relationship

Access to health had always been considered by CLF to be an important indicator to include in the Atlas but Kaiser Permanente's interest in not only the social determinants of health and the Equity Atlas' possible analytical contribution to the subject made it a requirement that a health chapter be included. While some social determinants such as poverty and age may be available through the Census, health outcome data at the geographic scales required by the Atlas were impossible to obtain. CLF's own history that had been focused on urban planning and design lent itself to the approach that Fuglister would take and that is the connection between the physical 
attributes of place, or urban design, and health. Mapping the sidewalk coverage around schools using the point locations developed for the schools' demographic data, used in the schools chapter, meant that Fuglister could make comparisons between the findings. The grocery and natural food store data were also well suited to the Radin/Sharkova access model that could show detailed areas of good and bad access in a raster surface but also could be allocated to neighborhood boundaries for comparison with the demographic variables of poverty and race/ethnicity in the neighborhood summary table. Here the emphasis is not on change; merely on what "was" when the data were collected.

The chapter also includes a map made by the Oregon Department of Environmental Quality (ODEQ) and was used by permission from that agency. Although the map that is included only shows a portion of Interstate 5 in northeast and north Portland, Fuglister cites locations with poor air quality near to freeways in general, and industrial and commercial zones associated with hazardous emissions areas that have historically been close to poor neighborhoods.

Utilizing the neighborhood summary table as well as the maps created for the schools chapter, Fuglister was able to identify several areas where sidewalk coverage was inadequate, according to the criterion of the Atlas, poor, and racially and ethnically diverse. And by examining both the access maps developed for grocery and natural food stores and the neighborhood summary table, she was able to conclude that poor communities and communities of color have decent access to grocery stores by regional standards. 
Parks and Nature. Labbe worked for an extended period of time directly with Radin to develop the measures and the maps that were included in the Parks and Nature chapter. Like Campbell, Labbe had extensive knowledge about his topic generally, but unlike Campbell who was getting to know the region when he wrote his chapters, Labbe had deep knowledge about his topic locally through his experience at Audubon. Audubon had very specific needs for the results of Labbe's work that focused on the shaping of policy around the issue of greenspace preservation. The chapter opens, as Houck had originally suggested that CLF's greenspaces work group should, in the early days of the Equity Atlas process, with an articulation of why access to nature matters and specifically why an equitable access to parks and nature matters. The language is laced with the thinking that went into CLF's early work on Metro's 2040 Framework Plan and ties that effort to this one:

Equitable access to parks and more broadly to nature underpins our region's growth plan to reduce urban sprawl, foster walkable neighborhoods, provide diverse transportation options and protect highvalue farmland. It is no surprise that a lack of parks and greenspaces along with infill development - has sparked controversy over regional growth management. But equity is implicit to the region's vision of its own future. If the region needs to be compact and efficient it must be green and livable - and it must be green and livable for everyone.

(The Regional Equity Atlas, 2007, p. 82-83)

In introducing his approach to examining access to parks and nature, Labbe suggests that a complete examine four primary factors: (1) walkable distance to the nearest public park; (2) acres of parkland per capita; (3) the diversity of park types; (4) social, economic, or cultural barriers to accessing public parks (Regional Equity Atlas, 2007:84). Because of data limitations related to the third and fourth factors, Labbe 
focused on the first two. Table 10.6 provides an overview of the maps and graphs that are included in the chapter.

Table 10.6. Access to Parks and Nature Chapter: Maps and Graphs

\begin{tabular}{|l|l|l|l|l|l|c|}
\hline Type & Title & Time & Geography & Income/ & Race/ & $\begin{array}{c}\text { Dist- } \\
\text { ance }\end{array}$ \\
\hline Map & $\begin{array}{l}\text { Parkland Access: Walking Distance to } \\
\text { Nearest Public Park or Greenspace }\end{array}$ & Static & Raster & & & $\mathrm{X}$ \\
\hline Map & Public Parkland Access: Summary Score* & Static & Raster & & & $\mathrm{X}$ \\
\hline Map & $\begin{array}{l}\text { Public Parkland Access Summary Score: } \\
\text { Average by Neighborhood }\end{array}$ & Static & $\begin{array}{l}\text { Neighborhood } \\
\text { or City }\end{array}$ & & & $\mathrm{x}$ \\
\hline Map & Proximity to Natural Habitat & Static & Raster & & & $\mathrm{X}$ \\
\hline Map & $\begin{array}{l}\text { Nature Nearby: Percent Population within a } \\
1 / 4 \text { Mile of Natural Habitat by Neighborhood }\end{array}$ & Static & Neighborhood & & & $\mathrm{x}$ \\
\hline Map & $\begin{array}{l}\text { Natural Habitat Acres per Capita by } \\
\text { Neighborhood }\end{array}$ & Static & Neighborhood & & & $\mathrm{x}$ \\
\hline Graph & $\begin{array}{l}\text { Percent of Population Within } 1 / 4 \text { Mile of } \\
\text { Public Parkland }\end{array}$ & Static & $\begin{array}{l}\text { Metro, } \\
\text { County, and } \\
\text { City }\end{array}$ & & & $\mathrm{X}$ \\
\hline Graph & $\begin{array}{l}\text { Public Parkland Access vs. Poverty, People } \\
\text { of Color, and Income }\end{array}$ & Static & Region & $\mathrm{X}$ & $\mathrm{X}$ & $\mathrm{x}$ \\
\hline Graph & $\begin{array}{l}\text { Access to Nature vs. Poverty, People of } \\
\text { Color, and Income }\end{array}$ & Static & Region & $\mathrm{X}$ & $\mathrm{X}$ & $\mathrm{x}$ \\
\hline
\end{tabular}

*Radin/Sharkova Access Model

$\mathbf{X}=$ direct relationship; $\mathrm{x}=$ indirect relationship

Because of Labbe's knowledge of the topic and participation in the mapmaking

process, his chapter provides detailed insights into the process that are less apparent in

the others. For example, in discussing how the assessment for access to nature was

developed, he relates:

For our analysis, we defined "access to nature" as the chance to encounter the region's native fish and wildlife and to explore the natural areas that sustain them. This definition is not without cultural subjectivity... Mapping and evaluating access to nature this way 
presents a challenge. Many natural areas are not in public ownership, yet still support access to the experience of nature in our neighborhoods. Native flora and fauna cannot be defined the way a public park can, but the quantity and quality, and distribution of native vegetation and soils are primary determinates of air and water quality and the abundance and diversity of native wildlife - and the former is much easier to map. (The Regional Equity Atlas, 2007, p. 87-88)

And, while noting that the allocation of the access summary scores to the neighborhood levels (as was done for both of his access measures - public parkland and natural habitat) has the advantage of allowing for comparison to the demographic variables included in the neighborhood summary table, he makes clear the downside of doing so:

By averaging access by neighborhood, [the neighborhood map] hides some of the intra-neighborhood variability. For example, the larger neighborhoods and citizen participation organizations (CPOs) in Clackamas and Washington counties obscure pockets that are particularly rich or poor in access.

(The Regional Equity Atlas, 2007, p. 87-88)

Thus, he makes the case for the inclusion of the raster maps in the Atlas because they tell a different part of the story.

In his discussion about access as it relates to the poor and communities of color, he utilized the neighborhood summary table's ranking system to create two very interesting graphs, one for each variable, access to public parkland and access to nature (figure 10.5). He is the only author to use the Table's ranking system in this way. 

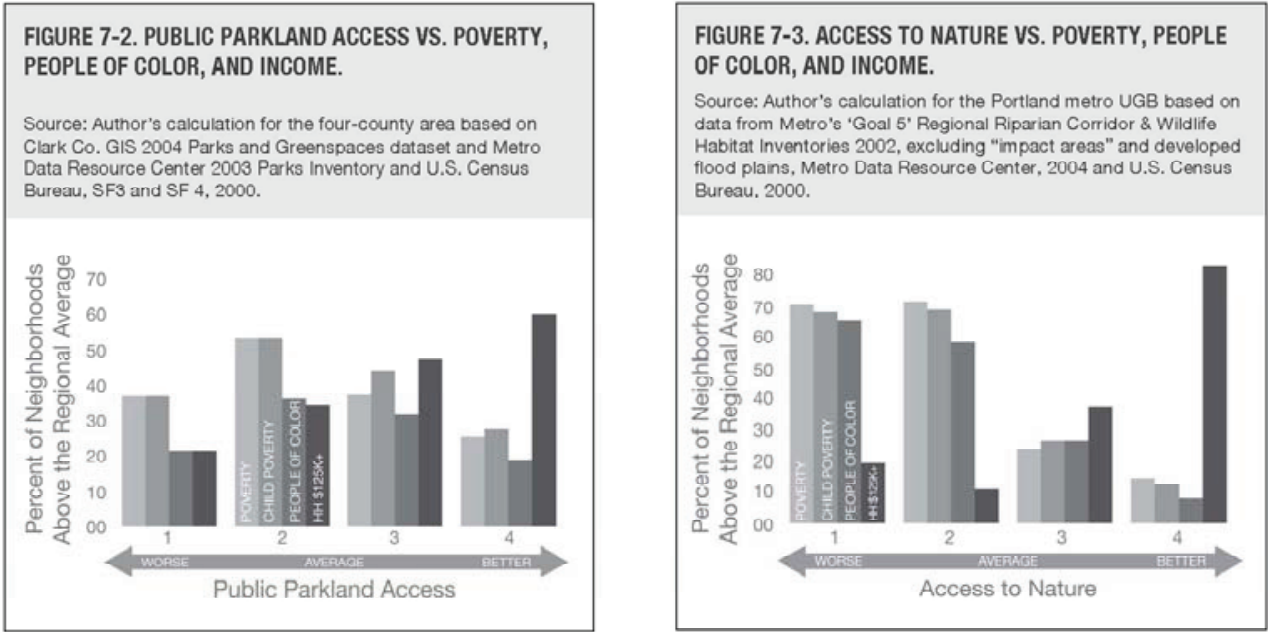

Figure 10. 5. Access to Public Parkland and Nature. Source: Regional Equity Atlas (2007, p. 90).

These graphs do not allow the reader to understand the distribution of access to public parkland or nature as they relate to poverty or race/ethnicity geographically but they do provide a snapshot of the distribution of access, in terms the 1-4 ranking system developed for the neighborhood summary table for the access to public parkland and nature (along the x-axis) and the percent of the neighborhoods in those ranks that are above the regional mean for poverty, child poverty, minority status, and upper-income households (along the y-axis). This presents a startling picture especially with regard to access to nature.

The findings for this chapter come from the combination of factors included in the graphs described above, a combination of physical access with the socio-economic characteristics of poverty, race and ethnicity made possible through the mapping process, and the reallocation of the data to the neighborhood level that reveal the kind 
of detail at the neighborhood level that Audubon could use to demonstrate the inequities in the system.

\section{Observations}

Coming up with an adequate way to analyze the issue of equity as CLF had defined it was a messy process. In the end, it was the neighborhood summary table, made possible by the raster conversion, which provided the link between the variables, that proved to be essential to the equity argument. But the table itself lacked the power of maps to intrigue and to excite an audience and to display the variation, which is the story of the Atlas, across geographic space.

But given the importance of the neighborhood summary table after its development to the analysis and writing phases of the project, it is interesting that no maps were made of the region by neighborhood rank, or "tier," that could have provided an easy comparison between the neighborhoods graphically among the variables. Perhaps there was too much invested in what had already been created and no more resources to add additional pages to an already overly long document. 


\section{Chapter 11. Black Boxes and Traces: Findings, Recommendations, and Future Research}

In initiating the Equity Atlas project, CLF created an actor-world (Callon, 1986) that was seen by the organization as a pioneering effort that could reenergize its membership internally and strengthen its sense of identity. Furthermore, by harnessing the power of maps in the form of an equity atlas, an approach that resonated well with the Coalition's own founding, it hoped to promote its image more broadly, put equity front and center in terms of the regional conversation, and make available to its membership and the region's citizenry a useful tool for advocacy. In many respects, the project accomplished these goals.

However, this actor-world, made up of heterogeneous actor-networks, was also characterized by a breaching of the authority and autonomy generally accorded to experts, particularly technical experts, that contributed to a messiness of interactions and conflict among the actors and lengthened the process to, in the eyes of everyone concerned, an astonishing four years. This breaching came, in part, as a result of the highly participatory culture that was part and parcel of the Coalition's identity. In taking charge of the Equity Atlas initiative, as opposed to handing it off to a consultant, the Coalition assumed a participatory process where the CLF membership would be involved in defining the question to be explored (regional equity) and how it would be examined (mapping), the framework for equity, the identification of equity indicators and data, and the provision of feedback about the maps to be included. It would manage the project and hired a founding member to be the lead author. 
What it didn't have, in-house, was a GIS specialist. Given the limited budget and the desire for the cloak of neutrality with regard to the maps (making the Atlas, in CLF's eyes, credible to policymakers, as Orfield's maps had been, and therefore a more effective advocacy tool), PSU (first, IMS and then, PRC) seemed like the logical place to turn to for much of the mapping. An additional benefit to this arrangement would be the low cost of student labor.

At the outset, CLF sought the assistance of PolicyLink (an Oakland-based organization with similar goals that had begun to analyze regional equity in places across the nation) to learn from its experience. But CLF wanted something different something of its own.

And, as CLF had always done, it solicited volunteers for its work, this time from the professional GIS community, to help with the Atlas framing, brainstorming approaches to the mapping, and the provision of data and the access maps. CLF "owned" the project and it set the tone but there was no expectation on either CLF's or the PSU contractors' parts that it would be a "PGIS" project or that participatory action research (PAR) protocols should be established and formally put into place.

This study indicates that this breaching of authority occurred not only because CLF expected a level of openness and involvement in major aspects of the project, but was made necessary by the disconnect between the abstractions of the maps and the experiences "on the ground" of the project's initial lead author who was responsible for translating and incorporating the maps' meanings into a written narrative, but also 
CLF staff and membership, the other key Atlas authors, and community members who had seen the maps at various venues during the process.

Because of her deep knowledge about particular issues in particular places, rather than merely accepting as truth the maps that didn't resonate with what she knew, Harmon repeatedly challenged their authority by working with the mapmaker to adjust the data categorizations and map symobolization - a process that ultimately led to the change in the GIS data model that was used, from vector to raster. All of these efforts were directed at finding and displaying the "truth" in the data; not influencing that truth.

In a less direct manner, the apparent disconnect between the map abstractions and people's experiences, cited throughout this study, sparked exchanges among the maps, map users, and mapmaker that challenged not just the authority of the maps but that of the analysts (Radin and Sharkova) and mapmaker (Radin) leading to considerable friction throughout the process. It is important to acknowledge that it was this profound breach authority, particularly by Harmon and to a lesser extent by Campbell, Fuglister, and the focus group participants that resulted in the large number of map iterations and written exchanges that permitted the more inclusive understanding of the social interactions of the mapping endeavor that the study provides.

Nevertheless, in spite of these difficulties and what Fuglister (2008) has called, the "murkiness" of the maps, CLF achieved with the Equity Atlas process much of what it set out to do. It did reenergize its membership and strengthen the Coalition's 
sense of identity. It did draw attention not only to the issue of equity regionally and nationally but also to CLF's leadership role in the equity conversation. And it confirmed CLF's belief, when it initiated the project, of the magnetic quality of maps.

There are four interrelated themes that emerge from this study that are summarized here. The first relates to the mapping of equity and what the CLF effort contributes to that conversation. The second relates more specifically to the contributions of the embedded ideologies that are integral to the GIS software that was used and the roles that they played. The third theme is the importance of process in community-based mapping projects and the recognition of that they are social processes in the comprehensive sense that ANT theorists advocate. The fourth theme relates to how maps work, specifically, maps as maps versus the idea of maps.

\section{Mapping Equity: CLF's Contribution}

The history of attempts to map equity outlined in the literature, particularly as it relates to the equitable location of public facilities and environmental justice applications, suggests that there is no consensus about how to do it. There are disagreements about both how to define equity, which populations should be targeted, which indicators to use and how to measure them. Furthermore, there are disagreements about how to measure, within a GIS context, the spatial ramifications of the distributions of public amenities. Specifically, the geographic scale of data aggregation and analysis are mentioned. Talen (1998) has suggested that because of this, the process should be iterative and exploratory where the spatial relationships 
among public facilities and underserved populations are discovered and assessed and data inputs reformulated as the various equity patterns emerge.

Some observers have complained that the these types of mappings are more illustrative than analytical, that very little is revealed about the effects of facilities, positive or negative, on populations living close to them. Moreover, Mantaay (2002) has suggested that the quest for causality that some approaches seek, particularly related to the locations of environmental hazards in relationship to populations, is a fool's errand as these mapping exercises cannot sort out the intentionality of the reality on the ground.

CLF took on the Equity Atlas project because equity was poorly understood but more importantly, CLF, as an advocacy organization well-versed in notions of livability and sustainability (framed in terms of the 3-Es) wanted to be seen as a leader in this issue both internally and externally. It felt through its wide-ranging community-based membership that it could make a unique contribution to the equity discussion because of its members' grassroots knowledge and engagement in the subject. Furthermore, CLF's own founding and early successes relating to its influence on Metro’s 2040 Framework Plan, which were achieved, in part, by Orfield's maps, demonstrated to its leadership the illustrative power, but more importantly, the persuasive quality of maps.

In tapping Harmon to be the lead author of the Atlas, it chose one of its own, someone who had been deeply involved, as an affordable housing expert and advocate, in the notion of equity. Rather than turning to the literature for a definition 
of equity, CLF chose to develop its own. But once the definition had to be operationalized within the constraints of computerized mapping and the available data, Harmon, like others before her, found the task to be extraordinarily difficult. CLF ended up with a three-pronged definition of equity only one of which, the access to key assets for people in poverty and racial and ethnic minorities, was inherently spatial: the geographic proximity of those things to these populations - an approach very much like those mentioned in the public facility siting literature.

Unlike environmental justice mapping, CLF took a generally positive approach in that it did not focus, in its definition or analysis, on facilities that negatively affect populations except in its brief discussion of air quality and its inclusion of a map generated by the DEQ. Rather, the negative was the absence of access not the effects of the facilities themselves.

The second prong of CLF's equity definition that considers the impacts of regional growth on the poor and communities of color, adds a temporal dimension to CLF's equity definition and analysis. This element which is not always included in the spatial analysis of equity was essential to CLF in that the impacts of regional growth had been central to the Coalition's mission from the start. Furthermore, although, as Maantay (2002) points out, causality in equity mapping may be impossible to sort out, the historical dimension that change over time implies has the potential to speak to causality more easily than a single-point-in-time analysis can. But it is important to acknowledge that although change over time has spatial manifestations which can be mapped using a simple arithmetic calculation or through 
a series of overlays, time is not space. And, in the mapping context, as demonstrated in this study, the two can be confused.

The third prong of CLF's definition of equity focuses on access to civic participation opportunities for the poor and racial and ethnic minorities. Given the difficulty that the Equity Atlas team had in obtaining and utilizing appropriate data related to housing, transportation, education, health, and jobs (which it gave up on), as well as a sense that civic participation may not have meaningful spatial characteristics, the decision was made to leave this dimension as an aspiration. What is notable about the inclusion of this prong is that CLF, in determining its definition of equity, wanted to be comprehensive and, if need be, include dimensions that didn't necessarily lend themselves well to mapping.

It is notable that the populations that CLF explicitly included for analysis in the mapping context focused on the poor and racial and ethnic minorities. The literature suggests that this limited description of the target population is a weakness of much equity mapping activity and that factors such as age (particularly the presence of children and the elderly), pregnant women, and health status should also be taken into account when equity is considered. The Atlas uses child poverty as a proxy for poverty generally rather than explicitly including the very young or the elderly in its target population.

Taking an "atlas" approach was also unique to CLF's equity mapping effort and this meant, initially for CLF, not only a map-driven document but one that would be comprehensive in terms of its access variables (reflecting the desires of its 
membership). Rather than focusing on only one type of facility or community asset, such as Talen and Anselin's (1998) exploration of park access, CLF envisioned an atlas that would explore access to all of the types of facilities and assets that its membership deemed most essential to residents' quality of life. In the end, it did what it could with this comprehensive approach given the resources it had and the available data.

Unlike the Kirwan Institute, that developed Opportunity Maps to affect litigation related to the locations and siting of public and affordable housing during the same period that CLF's Equity Atlas initiative was underway, as a community-based nonprofit coalition focused on advocacy, CLF's agenda for equity was not single-issue driven. In fact, one of its goals in rolling out the Atlas to the public was to encourage the kind of cross-issue discussion, collaboration, and policy analysis for which CLF was known.

The Kirwan Institute and CLF differ in another important way that had a direct bearing on the process and products of each mapping effort. Although, interestingly, both organizations have ties to Orfield (john a. powell, before becoming the executive director of Kirwan, founded and directed the Institute on Race and Poverty at the University of Minnesota where Orfield launched his metropoltics work), the Kirwan Institute for the Study of Race and Ethnicity is a university-based think tank with inhouse GIS expertise. As such, it was able to develop its methodology without the interference and challenges from nontechnical outsiders; it controlled the methodological development process; and it did not have to rely on volunteers. To its 
credit, the approach, not having to serve all masters, is relatively simple conceptually and analytically with a result that, because of its clear and focused underlying purpose, is relatively easy to interpret - if, because it is an index, opaque. Like Orfield's metropolitics work, Opportunity Mapping has become something of an industry for Kirwan since, unlike CLF's Equity Atlas endeavor, it uses only one methodology and its application is easy to adapt from place to place. And, although Kirwan shares its method with those who would like to apply it, the expectation is that clients and users already accept the underlying premises. In reflecting on the level of conflict that existed between the university-based consultants and CLF over maps and methods, Sharkova (2008) has commented that if CLF sees maps and mapping to be integral to its work, it should invest in an in-house researcher with GIS expertise where, presumably, the interests and expectations of the GIS expert would be more closely aligned with those of CLF.

Radin has observed that the Equity Atlas document "in a lot of different ways, really captures the complexity of CLF as an organization" (Radin, 2008b). It had to serve the interests of so many masters. It is beyond the scope of this study to look at the impacts of the Equity Atlas after its publication (see Appendix XX), however, it is the only equity mapping exercise that this researcher has been able to identify that could be characterized, to this degree, as a participatory process - especially in the technical sense (intentional or not) - and as such, has the potential to act as a groundtruthing exercise for equity researchers and equity GIS analysts who tend to operate away from the light of day. 


\section{Embedded Ideologies: Actors Exposed}

Most software users, sooner or later, understand that in the power relations between the user and the software, the software usually wins: we learn to work around the parameters and the constraints of the software and not the other way around. With the exception of computer scientists, programmers and geeks, we tend to think of software as monolithic, and definitely black-boxed. We want to get a job done and we let it tell us how to do it. And, while most GIS analysts are far more sophisticated about these things than the average software user, with the operation of GIS software by far the largest number of decisions have already been made for the mapmaker by software designers working around the parameters of computing, graphic display, data models, historical cartographic protocols and practices, and algorithms, not to mention cultural and historical influences. Trained GIS analysts know this but given the inevitable time constraints, the number of decisions that still must be made by the analyst, and the assumption that best practices (in this case, geo-spatial analytical and cartographic practices) are embedded in the software design, it is easy to come to rely on the software defaults to make many of the choices and do much of the work.

This study reveals, through the interactions among the maps and map consumers, and the mapmaker's attempts to work around the requirements of the GIS data models (both vector and raster), and those of the aggregated data, the significant price (in terms of human relations, time and resources, as well as the usefulness of the resulting product) that can be paid when the technical actants aren't recognized and taken into account at the outset. Specific examples include: the affects of aggregated 
population data that isn't spatially uniform and doesn't reflect actual population densities on the ground; the impacts of various data classification techniques used for choropleth mapping, including the ability to create custom classifications, that may or may not be reflective of the underlying data; the reactions to the symbology included with the software, particularly the color models employed, the default color ramps, and the ordering of their accessibility, that when used in various cultural circumstances can be seen as offensive; vector to raster conversion processes and smoothing algorithms that give the map user a false impression of the nature of the continuity of the actual statistical surface (where population densities actually are and how quickly they dissipate); and spatial analytical processes in the raster environment that produce incomprehensible legends. All of these "actions" played significant roles in the stories that the maps told and their credibility.

Additionally, this study indicates the importance of the linkage between map scale and the expectations among map consumers, especially when mapping places that community members know well, for the spatial accuracy of data: the more we are "zoomed in" the greater the detail in the map. This a perfectly logical expectation since in most people's experiences with maps, especially with street maps or those, such as topographic maps that focus on physical features, this tends to be true. But in the case of thematic maps, where political and physical features are commonly added for reference, the addition of aggregated demographic or other data whose spatial resolution is entirely dependent on the scale of the aggregation of the available data, the situation is far more complicated. This is because at larger scales more detail is 
generally available for the political and physical features such as roads or streets but the resolution of the aggregated data remains the same. This study found that when map readers could locate places they knew well on the map, they expected to find recognizable conditions there and had difficulty coming to terms with the generalization of the Census data over space that hid the variations that actually exist. Sophisticated map consumers understand this. Unlike some forms of analysis where spatial detail is less important, the promise of the Equity Atlas for CLF as an advocacy organization focused on a relatively small geographic area, rested in large part in its ability to allow community members to see and recognize their places in relation to others. The decision to convert the data from the vector environment where the data where generalized at the census tract or block group levels to a raster approach was an attempt to provide a greater sense of detailed spatial resolution by creating continuous surfaces made up of much smaller grid cells. But these are modeled surfaces that are in actuality a further step away from the actual spatial resolution of the data.

As the literature suggests, aggregated population data have long been considered by cartographers to be far from ideal; the dasymetric approach that uses additional spatial data such as satellite imagery, land use or zoning GIS layers, or road densities to verify where populations are most likely to be located is one possible approach that has been suggested for overcoming the problem. But the extent to which this issue would affect the Equity Atlas process was unanticipated. How a dasymetric approach could be applied to CLF's notion of equity mapping is beyond the scope of this study. Neither Orfield nor the Kirwan Institute has found it necessary 
to add the additional complication of dasymetric mapping to their approaches but their work is less community driven.

These issues, in turn, relate to the move from a focus on maps to a dependence on text and a summary data table to convey the meanings of the maps. Throughout the process there was a profound tension between the desire of CLF to reach a general audience (as Fuglister (2008) stated, "an $8^{\text {th }}$ grade level") and the analysts' desire for the Atlas to be credible for a sophisticated, scientifically inclined audience. This analysts' desire for sophistication sometimes resulted in incomprehensible map legends that had to be simplified at the insistence of CLF - and, still, the maps and their legends required explanatory text in the Atlas document.

In addition, after the decision was made to move to a raster or surface approach to the mapping to avoid the "big geography/big color" confusion caused by the choropleth mapping technique, the option to create an equity index that could combine the demographic variables of income and race with the other equity variables was dropped. This meant, for example, in order to draw out comparisons or possible correlations between the demographic variables (race/ethnicity and poverty) and the access variables (each mapped separately in separate sections of the Atlas) argumentative text was necessary to make these comparisons rather than simply pointing to the maps. The necessity for all of this explanatory text required that the maps be exceedingly small in the printed document - which, in turn, led to an even greater reliance on text. 


\section{Participatory GIS}

As has been previously stated, CLF, because of the culture that it had developed, owned the project and expected a participatory role throughout. The academic actors, on the other hand, as the level of interactions with CLF around the mapping efforts grew more intense, became confused about their role and to some degree felt violated.

Pielke (2007) has suggested that scientists do, in fact, adopt roles when they engage with society and that is it important to both society and scientists that they recognize that fact. Pielke (2007) identifies four idealized roles that scientists take on: the pure scientist; the science arbiter; the honest broker; and the issue advocate. It is possible to see Pielke's archtypes as a continuum of involvement from isolation from the political sphere (the "pure scientist") to advocacy. The situation was complicated by the fact that Radin began his relationship with the project as a graduate student who while having possession of the skill (GIS expertise) that CLF most needed was, as a student, also at a disadvantage in terms of power. This situation changed, however, once Sharkova got involved and Radin was seen by her as more of a colleague than a scientist-in-training - Radin did, in fact, move during the process, from a work-study student, at IMS, to a paid consultant under the auspices of the PRC. In the context of this study, the academics, rather than adopting a single role for the duration of their relationship with CLF, appeared to have, unconsciously, placed themselves at different times and circumstances at various points along this continuum contributing to a sense 
of confusion and conflict that plagued the process and challenged the notion of partnership that the parties had adopted without articulating what that would mean.

Lessons learned from PAR and CBPR suggest that confusion as to roles, distrust, and conflict can be avoided, if a truly participatory process is desired, by the establishment of operating norms, at the outset of research, that foster listening, openness, democratic leadership, agreement to disagree, identifying and addressing conflicts, negotiation, compromise, and equality (Israel et al., 1998). This formalistic approach to process was antithetical to the ways in which the Coalition typically got things done.

It is probably safe to say that most PGIS practitioners affirm PAR's values and promote the transparency of practice (Aberley and Sieber, 2002). But how these values and protocols actually play out in research partnerships with community groups in a technical realm as complicated as GIS is another matter and suggests this question: If formal PAR practices been requested by CLF, would the university-based GIS analysts (with their own culture, expectations, and discomfort with Pielke's notion of "scientist as issue advocate") have permitted the level of intrusion into the technical aspects of the GIS mapping that Harmon and CLF, once they got into the process, demanded? And, could CLF have imagined desiring inserting itself into mapping process? It is the contention of this author that when participatory research is desired that is centered on mapping, meaningful negotiations, relating to the extent to which the various actors participate in the technical and analytical realms, can only be achieved when the full complement of actors are acknowledged, their capabilities and 
potential actions are recognized, and when the nature of maps are understood by all of the participants from a critical perspective.

\section{The Power of the Idea}

This study demonstrates not only the power of maps to reveal, inspire, persuade (as well as confuse and trigger questions), as CLF's formation and history demonstrate, but the power of the idea of maps, the notion of an equity atlas, to attract attention, to energize and reenergize CLF's own membership, and to bring people to the table around the issue of equity through a mapping project. Like Aberley's observation that "maps hold some primal attraction for the human animal" (1993, p. 1), according to Fuglister (2008) and Carley (2010) people were always enthusiastic about the idea of an equity atlas of maps. Throughout the process including the CLF Summit events, at national conferences where Fuglister presented Equity Atlas maps in development, and the Equity Atlas/Equity Agenda workshops, despite the questions and confusion that the maps sometimes provoked, people were still drawn to the maps and intrigued by them. Fuglister (2008) has observed, "I've done a million presentations with the maps and people do excited about them, with all of their flaws, and questions, and murkiness." This has been a powerful lesson for CLF as it seeks to maintain its momentum as a coalition doing advocacy work focused on livability with an emphasis on equity. And, it is one that has encouraged the Coalition, in spite of the anguish related to its first Equity Atlas effort, to reengage with equity mapping in a Regional Equity Atlas 2.0. 


\section{Recommendations}

GIS is a highly technical endeavor that is generally understood as interactions among hardware, software, data, and people. Critical cartographers remind us, however, that all mapmaking is an exercise of power relations from map patrons, to mapmakers, the technologies employed to make them, and even map consumers who use maps for their own self-interests. ANT studies focused on GIS technology and PGIS practitioners have also suggested that the cultural and historical biases embedded in the software can have significant impacts on the successful implementation of GIS at an institutional level (Walsham and Sahay, 1999), urban planning practice (Lejano, 2008), and the implementation of participatory GIS processes (Fox et al., 2006). Rather than looking at institutional settings for the adoption of GIS or the influence of it on planning practice, this study has looked at GIS and maps in the context of an important community advocacy organization. Here, too, the unseen or unacknowledged technical actors played a significant role. In all of these cases the outcomes are visible but the social interactions that lie beneath them are less so.

It is the belief of this author that, as mapping and maps are more widely valued and used for advocacy, that public education that understands both the process of mapping and maps from a critical perspective is essential. For organizations that either contract with GIS professionals or academic institutions or initiate research partnerships with them, there must be some fundamental acknowledge at the outset that while analysts may strive for objectivity, the mapping effort is a complexity of 
decision-making and choices that are influenced in various ways by who's paying for it, the training and other biases of the mapmaker, the biases of the software, and even those of the users. If a collaborative approach is desired, as Israel et al. (1998) suggest, agreement must be reached among all of the participants at the outset as to operating norms for the project including the extent to which the various participants are engaged with the various actants in the mapmaking process. They must understand and reach an agreement as to the extent of involvement in all aspects of the process and its potential consequences.

But even when there is no desire to actively engage in mapmaking, maps must be understood for what they are - "interested representations" - if they are to be understood and used responsibly. Such understandings should be incorporated at the very least into GIS training programs, urban and regional planning programs, and the increasing number of professional and academic programs that utilize GIS to affect people's lives. Ideally, such education begins in K-12 schools (the National Geography Standards are a good start) but with K-12 funding on the line and geography not seen as math or science by K-12 administrators or funders, it is unlikely that much progress will be made there in the near term. But this is terribly important as maps increasingly insert themselves in our lives because as Wood, who has written so eloquently about the power of maps has said:

Once the map is accepted for the interested representation it is, once its historical contingency is fully acknowledged, it is no longer necessary to mask it. Freed from this burden of ... dissimulation ... the map will be able to assume its truest character, that of instrument for ... data processing, that of instrument of ... persuasive argument. ... Freed 
from the pretense of objectivity ... the map can be restored to the instrumentality of the body as a whole. Freed from being a thing to ... look at, it can become something ... you make. The map will be enabled to work...for you.

(Wood, 1992, p. 182-183)

\section{Further Research}

Since the launch of CLF's first Equity Atlas project, its publication, and rollout efforts equity has become a central concern in the Portland area both at the regional level under various Metro policy initiatives and the Portland-Vancouver Regional Indicators Project, and at the city level in Portland's update of its comprehensive plan. Nevertheless, CLF has decided to update the original atlas with the 2010 Census data and the incorporation of aggregated health record data. And, while the first Equity Atlas was plagued with an extremely limited budget, the budget environment, now, is generally even more challenging. As a result, the Coalition has begun to explore partnership options that will leverage some of the mapping resources (including Internet mapping applications) currently under development by Metro and PSU (at IMS) to achieve its goal for what the Coalition calls version 2.0 of the Atlas. This opens a new chapter and a new array of challenges that relate to the issues of mapping, maps and participatory research that will be interesting to investigate. Given the reality that the mapping will be much less transparent than it was in the first iteration (in that in both cases the Internet-based interactive mapping applications have been developed entirely without public input), education for users relating to the true nature of mapping and maps of whichever interface CLF ultimately chooses will be even more important. The development of educational workshops and training 
materials that specifically address the nature of maps and mapping and their utilization for a wide array of users but particularly for community advocacy organizations is of great interest to me and I believe is important work.

Further, I am interested in investigating the ways in which GIS is incorporated into professional urban planning programs and how both mapping and maps are understood by students to enhance and affect the practice of planning - enhancing or replacing the "habitus of place" (Lejano) in planning practice.

As PSU's University Studies program begins to explore incorporating spatial literacy as a core competency for students, I am very interested in joining that effort, by contributing a critical perspective and the lessons learned from this study to that conversation. 


\section{Epilogue. Regional Equity Atlas 2.0 Considerations}

Can equity be mapped? As is even evident in CLF's own definition of equity that it used for the Equity Atlas project, although social inequity has spatial manifestations that can further exacerbate equity conditions, it is not merely a spatial phenomenon. Social inequity's causes and effects are multi-faceted and highly complex. The spatial depiction of equity, or the lack thereof, can only be partial. Additionally, as the equity mapping literature and the experience of CLF's effort demonstrate, because of differing definitions of equity, the lack of agreement among researchers regarding the identification of target populations, as well as the lack of data in general and the lack of data at appropriate spatial resolutions, even the spatial manifestations of equity (or inequity) that are included in analyses are incomplete. In any effort to map equity, it is important to acknowledge that the spatial manifestations of equity conditions are only one aspect of the social equity story and one that can only provide, in the best of circumstances, a partial understanding of the issue.

Certainly, this was something that the contributors to CLF's Equity Atlas came to believe as the project moved forward. But part of what hampered the project was a fundamental belief, at the outset, that an equity atlas of maps could reveal a more complete picture of equity than was possible for mapping to do. CLF has been, however, able to achieve enough interest in equity conditions and recognition for its Regional Equity Atlas contribution, both regionally and nationally, that it is now poised, with the release of the 2010 Census data, to embark on version 2.0. 
As it moves forward, there are several things that CLF should consider based on the lessons of the first atlas and a changed regional environment that now includes several equity initiatives (some of which include mapping) that have sprung up among governmental agencies in the Portland metropolitan area. In addition, any equity mapping project must consider the challenges that the Census Bureau's American Community Survey (ACS) (a key demographic data source and replacement for the Census Bureau's decennial long form survey) will present to any analytical and mapping endeavor that seeks to explore equity.

\section{Reconsidering the First Equity Atlas}

An acknowledgement that what were being mapped for the Equity Atlas were only the spatial manifestations of equity conditions and that even those would be incomplete could have freed CLF from the overwhelming burden of trying to make the Atlas maps do the impossible: map all of the dimensions of social equity. And, while the promise to users would not have been as groundbreaking as the all-encompassing idea that surrounded CLF's Atlas project, a clear articulation of what the Atlas could and could not do, would have enhanced the understanding of the product among users and mitigated against disappointment when the Atlas didn't meet expectations.

This acknowledgement would have had implications for the mapping itself. Knowing, at the outset, the limitations of the data in terms of availability and spatial resolution, and understanding that not all of the indicators that contribute to equity conditions are available or even identified (by CLF members or the equity literature), 
the silver bullet for equity mapping, a super equity index, becomes impossible - and, its absence explainable.

This is not to say that indices, summary statistics, or rankings (the "tiers" in the Equity Atlas' neighborhood summary table, for example, that offer comparisons among the neighborhoods across several of the demographic and access variables) should not have been used. In fact, it this author's belief that such an approach is highly advantageous but none of these summary measures should pretend to be a comprehensive equity index.

The approach that Radin took in creating the Atlas' neighborhood summary table that uses a 4-tiered system (where " 4 " indicates either the highest percentage of the Atlas' target populations or the least access by neighborhood; a " 1 " indicates the opposite) could have been easily mapped, using the choropleth technique, and would have offered an easy and relatively transparent way to convey meaningful differences among neighborhoods across the region. These tiers (that were made possible through the conversion of all of the data to raster, reallocating them to new, in this case, neighborhood boundaries, and then normalizing them to each other) are well-suited to the simplicity of the choropleth approach. And their four ranks avoid the confusion among map users related to the various approaches to data classification discussed in this study. Moreover, neighborhood boundaries were considered by CLF to be more recognizable to users of the Atlas than Census Bureau geographies such as tracts or block groups. 
Ironically, it is the Equity Atlas' neighborhood summary table (that was created toward the end of CLF's Atlas project) that offers an approach to the cartography that is both elegant and relatively simple - as Radin, after the fact, has acknowledged. Here, the neighborhood summary table would become the basis for all of the maps in the Atlas. In this approach, each primary field in the summary table becomes a cartographic theme that includes not just a map of the theme (say, minority populations) by neighborhood tiers (the summary statistic), but a series of individual maps of the factors (included in the summary table) that help to explain each neighborhood's tier. For example, for each the demographic variables, in addition to a "neighborhood tier map" of a particular population, separate maps would be included of the normalized population (or the percent of the population of interest of the total population) by neighborhood for the decades of interest, and the percent change in the population of interest over the same decade(s).

The methodologies for the access variables in the first atlas vary depending on whether the physical distance (the average number of city blocks per neighborhood, for example) of the population to an asset, such as grocery stores or parks, or some other measure, such as the housing affordability index or proxies for quality education, such as teacher experience or teacher training, were used. Whenever possible the components of these measures that contribute to their "tier," and that can be mapped by neighborhood, should be included.

This approach would, theoretically, provide a more map-centered product (more in the character of an atlas) because it takes advantage of the explanatory power 
of maps to reveal the factors that underlie the summary statistics. Furthermore, an approach that uses the neighborhood summary table as the basis for all of the maps means that the statistics included in the map legends will match those in the table, providing a direct link between the maps and the table, thereby, adding credibility to the maps. This approach could have been used for the first atlas but by the time the neighborhood summary table was developed, so much time and effort had already been invested in the maps that had been developed to that point, that it was considered too late to drop what had already been done for yet another approach.

CLF might explore with its next iteration an additional set of fields for the neighborhood summary table that combine the neighborhood tier scores for the target populations with those each for the access variables. This has the potential, not unlike Kirwan's Opportunity Map methodology, to allow users to see neighborhoods where both physical access to a particular asset is poor and where there is a significant presence of the target population. This should only be done access variable by access variable and not combined into one overall equity measure for the reasons already discussed.

Unfortunately, the Achilles heel of this approach that emphasizes the recognizability of neighborhood boundaries (and that requires data reallocation) is any reliance on the new American Community Survey 5-year population estimates for data (previously available from the Census long-form decennial survey) such as household poverty status. This is because the sample size for the ACS is significantly smaller than that of the decennial long form survey. And, while the ACS is an ongoing survey 
(rather than the decennial approach), in order to have a sample large enough to report at a census tract level, the Census Bureau must use five years of data to create its 5year population estimates. Unfortunately, these estimates at the tract level, for some

of the most important variables for equity mapping (such as household poverty status), have large enough margins of error (MOE) that, unless the differences among the census tracts are large enough (larger than the already large MOEs), it can be impossible to tell if there are, in fact, differences among census tracts or changes over time.

If the reallocation of data from census tracts to some other geographic unit (as was done for the neighborhood summary table) is desired, the MOEs will have to be taken into account and will likely compound the already large MOEs. Some have suggested that proxies for poverty status, such as free and reduced priced school meals data, be used. However, these data ignore households without school-aged children which in some locales can be a major omission. The ACS problem is one that can't be ignored as it affects many of the variables that CLF will be interested in including in whatever Equity Atlas mapping approach it ultimately chooses.

\section{An Interactive Atlas and Equity Mapping Partners}

Since CLF's Equity Atlas introductory sessions and Regional Equity Agenda workshops that, together, engaged approximately 1,000 people region-wide, a number of equity initiatives have sprung up in the Portland metropolitan area, some of which involve mapping. The City of Portland has committed to a major equity initiative; Washington County has completed an Opportunity Mapping exercise; Clackamas 
County is interested in creating an Opportunity Map; and Metro is working on several equity-related initiatives. In addition, Metro's Data Service Center, that maintains the region's tri-county GIS database and performs GIS analyses related to regional planning has, in the last several years, invested in a major new raster-based GIS analytical tool, The Context Tool, for use in-house (but online) that allows users to create "what-if" planning scenarios on the fly. IMS, at Portland State University, is also creating an interactive, online data mapping tool for use in several of its projects.

In thinking about the next iteration of its Regional Equity Atlas, CLF is considering moving toward an online, interactive product. Given the number of equity related efforts underway regionally, and the challenge of raising the significant funds that such an enterprise would require, CLF is currently exploring partnerships that would have the potential to institutionalize the Equity Atlas in an agency that could provide the ongoing technical support and maintenance that would be necessary - in other words, to move the Atlas from a "project" to an ongoing "program" outside of CLF.

There is no doubt that, if CLF moves in this direction, serious consideration will have to be given to translating the opacity of the processing that underlies these mapping technologies and the mappings that result for the users who will want to interact with them. Although, theoretically, CLF will have some input as to the data that should be included in an equity application, it may have very little control over anything else, including the look of the maps and the user interface. While the institutionalization of the Equity Atlas should be seen as a major achievement of the 
Coalition, and the potential for interactivity in the maps, exciting, the ethical use of these tools will require a major education initiative which may well be the most important role that CLF can play in this new environment. 


\section{References}

Abbott, Jo, Robert Chambers, Christine Dunn, Trevor Harris, Emmanuel de Merode, Gina Porter, Janet Townsend, and Daniel Weiner. 1998. "Participatory GIS: opportunity or oxymoron?" PLA Notes 33, October.

Aberley, David. 1993. Boundaries of Home: Mapping for Local Empowerment. Gabriola Island, BC: New Society Publishers.

Aberley, Doug and Sieber Renee. 2002. Public Participation GIS (PPGIS) Guiding Principles First International PPGIS Conference. Held by URISA at Rutgers University. New Brunswick, NJ, 20-22 July. http://www.iapad.org/ppgis_principles.htm

Albert, Stuart and David A. Whetten. 2004. "Organizational Identity." In Organizational Identity: a reader edited by Mary Jo Hatch and Majken Schultz. Oxford: Oxford University Press.

Arnstein, S. R. 1969. "A ladder of citizen participation." Journal of the American Institute of Planners, 35(4): 216-224.

Aronoff, Stan. 1995. Geographic Information Systems: A Management Perspective. Ottawa: WDL Publications.

Berman, O. and E. H. Kaplan. 1990. "Equity mazimizing facility location schemes." Transportation Science, 24(2): 137-144.

Black, Jeremy. 1997. Maps and Politics. Chicago: University of Chicago.

Bowen, Glenn A. 2005. "Preparing a Qualitative Research Dissertation: Lessons Learned." The Qualitative Report, 10(2): 208-222.

Browne, J. J. and A. C. Millington. 1983. "An evaluation of the use of grid squares in computerized choropleth maps.” The Cartographic Journal, 20: 71-75.

Buisseret, David. 1992. "Introduction." In Monarchs, Ministers, and Maps: The Emergence of Cartography as a Tool of Government in Early Modern Europe, David Buisseret, editor. Chicago: University of Chicago Press.

Bureau of the Census. 2010a. Census Then and Now. http://www.census.gov/history/www/census_then_now/ 
. 2010b. "Tracts and Block Numbering Areas."

http://www.census.gov/history/www/programs/geography/how_we_map/tracts _and_block_numbering_areas.html

. 1994. "Chapter 10: Census Tracts and Block Numbering Areas."

In Geographic Areas Reference Manual. November.

http://www.census.gov/geo/www/GARM/Ch10GARM.pdf

Butterfoss, Frances Dunn, Robert M. Goodman and Abraham Wandersman. 1993.

"Community coalitions for prevention and health promotion." Health

Education Research. 8(3):315-330.

Callon, M. 1986. "The Sociology of an Actor-Network: The Case of the Electric Vehicle." Mapping the Dynamics of Science and Technology. Callon, M., Law, J. and Rip, A. (Eds). London:Macmillan Press.

Callon, Michel. 1999. "The Sociology of an Actor-Network: The Case of the Electric Vehicle." In Actor Network Theory and After, John Law and John Hassard, ed. Oxford: Blackwell Publishing.

Callon, Michel and Bruno Latour. 1981. "Unscrewing the Big Leviathan: How Actors Macro-Structure Reality and How Sociologist Help Them To Do So." In Knorr-Cetina, K.; Cicouvel, A.V. (eds.) Advances in Social Theory and Methodology: Towards an Integration of Micro and Macro-Sociology. London: Routledge.

Campbell, Alex. 1997. "Transportation." The Regional Equity Atlas: Metropolitan Portland's Geography of Opportunity. CLF: Portland.

. 2008. Personal Interview. November $3^{\text {rd }}$.

Campbell, D. E. 1990. "Can equity be purchased at the expense of efficiency? An axiomatic inquiry." Journal of Economic Theory, 51: 32-47.

Carley, Ron. 2010. Personal Interview. Jan. $28^{\text {th }}$.

Champernowne, D. C. 1974. "A comparison of measures of inequality of income distribution." The Economic Journal, 84: 787-815.

Chrisman, Nicholas. 1998. Rethinking levels of measurement for cartography." Cartography and Geographic Information Systems 25(4): 231-242. 
Chua, Wai Fong. 1995. "Experts, Networks, and Inscriptions in the Fabrication of Accounting Images: A Story of the Representation of Three Public Hospitals." Accounting, Organizations, and Society, 20(2/3): 111-145.

Cleveland Planning Commission. 1974. Cleveland Policy Plan. http://www.pdx.edu/usp/planpdxorg-cleveland-policy-plan

Coalition for a Livable Future. 2004. Board Minutes. October. . 1998. CLF Self Assessment. From Steve Johnson's private papers. March.

Coulter, P. B. 1980. "Measuring the inequity of urban public services: A methodological discussion with applications." Policy Studies Journal, 8: 683698.

Craib, Raymond B. 2000. "Cartography and Power in the Conquest and Creation of New Spain.” Latin American Research Review, 35(1):7-36.

Crampton, Jeremy W. and John Krygier. 2006. "An Introduction to Critical Cartography." ACME: An International E-Journal for Critical Geographies, $4(1): 11-33$.

Creswell, John W. 1994. Research Design: Qualitative and Quantitative Approaches. Thousand Oaks: Sage Publications.

Del Casino Jr., Vincent J. Del and Stephen P. Hanna. 2006. "Beyond the 'Binaries': A Methodological Intervention for Interrogating Maps as Representational Practices." ACME: An International E-Journal for Critical Geographies, 4(1): 34-56.

Dent, Borden D. 1993. Cartography: Thematic Map Design, 3rd Edition. Dubuque: W. C. Brown Publishers.

Doolin, Bill and Alan Lowe. 2002. "To reveal is to critique: actor-network theory and critical information systems research." Journal of Information Technology, 17: 69-78.

Dorsey, A. H. J., British Columbia Round Table on the Environment and the Economy. 1994. Public involvement in government decision making: choosing the right model, a report of the B.C. Round Table on the environment and the economy. Victoria, B.C.: The Round Table. 
Dunn, Christine. 2007. “Participatory GIS: a people's GIS?" Progress in Human Geography, 31(5): 616-637.

Eicher, Cory L. and Cynthia A. Brewer. 2001. "Dasymetric Mapping and Areal Interpolation: Implementation and Evaluation." Cartography and Geographic Information Science, 28(2): 125-138.

envirojustice.org. "EJ Timeline." http://www.envirojustice.org/aboutus/ejtimeline.html. Accessed Feb. 5, 2011.

ESRI. 2002. "FAQ: How are the algorithms for color ramps different." Article ID, 17221. ESRI White Paper. http://resources.arcgis.com/content/kbase?fa=articleShow \&d=17221

Foster-Fishman, Pennie G., Shelby L. Berkowitz, David W. Lounsbury, Stephanie Jacobson, and Nicole A. Allen. 2001. "Building Collaborative Capacity in Community Coalitions: A Review and Integrative Framework." American Journal of Community Psychology. 29(2):242-261.

Fox, Jefferson, Krishawati Suryanata, Peter Hershock, and Albertus Hadi Pramono. 2006. "Mapping power: ironic effects of spatial information technology." In Participatory Learning and Action: Mapping for change: practice, technologies and communication. Giacomo Rambaldi; Jon Corbett; Mike McCall; Rachel Olson; Julius Muchemi; Peter Kwaku Kyem; Daniel Weiner; with Robert Chambers, editors. http://www.planotes.org/pla_backissues/54.html

Fuglister, Jill. 2004. Email correspondence between Radin, Fuglister, Harmon, and Sharkova. June 9. Radin's papers. . 2005. Memorandum: Contract Addendum between CLF and PRC for Contract Extension, February 1- June 30, 2005. Radin's papers. . 2008. Personal interview. June 30.

Gambhir, Samir. 2007. Introduction to Opportunity Mapping. A powerpoint presentation for an Opportunity Mapping Workshop, Nov. 30. Created by the Kirwan Institute.

Ghose, Rina and Sarah Elwood. 2003. "Public participation GIS and local political context: propositions and research directions." URISA Journal, 15 (APA II):17-24. 
Gibbons, Michael. "Mode 2 society and the emergence of context-sensitive science." Science and Public Policy, 27(3): 159-163.

Glazer, B.G. and A.L. Strauss. 1967. The discovery of grounded theory: Strategies for qualitative research. Thousand Oaks: Sage.

Goodchild, M. F., L. Anselin, U. Deichmann. 1992. "A framework for the areal interpolation of socioeconomic data." Environment and Planning, 25:383-397.

Gopalan, R., K. S. Kolluri, R. Batta and M. H. Karwan. 1990. "Modeling equity in the transportation of hazardous materials." Operations Research, 38: 961-973.

Green, Howard Whipple and Leon E. Truesdell. 1937. Census Tracts in American Cities: A Brief History of the Census Tract Movement, with an Outline of Procedure and Suggested Modifications. U.S. Census Bureau, accessed at: http://www.census.gov/history/pdf/1937_Census_Tract_Manual.pdf

Harley, J. B. 1989. "Deconstructing the Map.” Cartographica, 26:1-20.

. 2001. The New Nature of Maps: Essays in the History of Cartography. Baltimore: Johns Hopkins University Press.

Harmon, Tasha. 2003a. An Introduction to the Regional Equity Atlas Project Draft Framework, March 2003. Ken Radin's papers.

. 2003b. Memorandum: Equity Atlas Outreach: Creating an Aha Process, August 26, 2003. Ken Radin's papers.

. 2003c. Memorandum: Envisioning an Equitable Region, $3^{\text {rd }}$ Draft. December 27, 2003.

. 2004. "summit_presentation_draft."

. 2004. "CLF Equity Atlas Summit Presentation.” April 3, 2004.

Ken Radin's papers.

. 2004. "Focus Group Pres. Notes.” March 8, 2004. Radin's

papers.

. 2004. "Framework for Selection of Areas of Focus for Atlas Case Studies/Vignettes.” May. Radin's papers. 
. 2004. Email correspondence: "Greenspaces Maps." To

Sharkova, Radin, Fuglister; copied to Jim Labbe and Ron Carley.

. 2005. Correspondence with Radin: "Notes on New Maps."

February 24. Radin's papers.

. 2008. Personal interview. June $23^{\text {rd }}$.

Harmon, Tasha and Ken Radin. 2004. "Atlas Brochure Draft" with comments by Radin. August 16, 2004. Radin's papers.

Harris, T. M. and D. Wiener. 1996. GIS and Society: the social implications of how people, space, and environment are represented in GIS. Scientific Report for the Initiative 19 Specialist Meeting, 2-5 March, Koinonia Retreat Center, South Haven, Minnesota.

http://www.ncgia.ucsb.edu/Publications/Tech_Reports/96/96-7.PDF

Haug, Marie R. and Marvin B. Sussman. 1969. "Professional Autonomy and the Revolt of the Client." Social Problems, 17(2): 153-161.

Houck, Mike. 2003a. "Parks, Recreational Trails and Natural Areas Equity Draft Framework." April 1 ${ }^{\text {st }}$. Steve Johnson's papers.

. 2003b. "Natural Resource Protection/Parks and Greenspaces Equity Draft Outline." April $6^{\text {th }}$. Steve Johnson's papers.

Himmelman, Arthur T. 2001. "On Coalitions and the Transformation of Power Relations: Collaborative Betterment and Collaborative Empowerment." American Journal of Community Psychology. 29(2): 277-284.

Institute on Race and Poverty. 2002. Racism and Metropolitan Dynamics: The Civil Rights Challenge of the $21^{\text {st }}$ Century. A briefing paper for the Ford Foundation by the Institute on Race and Poverty.

. 2011. Institute on Race and Poverty: History. Website: http://www.irpumn.org/website/about/index.php?strWebAction=history, accessed, 2/14/11.

Israel, Barbara A., Amy J. Schulz, Edith A. Parker, and Adam B. Becker. 1998. "Review of Community-Based Research: Assessing Partnership Approaches to Improve Public Health." Annual Review of Public Health, 19:173-202. 
Jankowski, P. and T. Nyerges. 2003. "Toward a framework for research on geographic information systems-supported decision making." URISA Journal, 15 (Access and Participatory Approaches (APA) I): 9-17, http://www. urisa.org/Journal/APANo1/jankowski.pdf.

Johnson, Steve. 1998a. "A Preliminary Methodology for Analyzing the Coalition for a Livable Future's "regional dialogue method" for Affecting Growth Policy and Implementation." PSU paper draft. Steve Johnson's private papers.

. 1998b. "CLF as Self Learning Metropolitan Colloborative." Notes. Steve Johnson's private papers.

. 1998c. "The Coalition for a Livable Future a Regional Civic Capacity Building Organization.” PSU paper draft. Steve Johnson’s private papers.

2008. Personal interview. August $19^{\text {th }}$.

Katz, Bruce and Scott Bernstein. 1998. "The New Metropolitan Agenda: Connecting Cities \& Suburbs." The Brookings Review. 16(4):4-7.

Kinman, Edward L. 1999. "Evaluating health service equity at a primary care clinic in Chilimarca, Bolivia." Social Science and Medicine, 49: 663-678.

Kitchin, Rob and Martin Dodge. 2007. "Rethinking Maps." Progress in Human Geography, 31(3):331-344.

Kofman, Fred and Peter Senge. 1994. Communities of Commitment: The Heart of Learning Organizations. Axialent Integral Evolution. Spring. http://www.axialent.com/uploaded/papers_articles/documentos/Communities\% 20of\%20Commitment. $\% 20$ The $\% 20$ Heart $\% 20$ of $\% 20$ Learning $\% 20$ Organization s.pdf

Kolm, S.C. 1976. "Unequal inequalities.” Journal of Economic Theory, 12: 416-442.

Krumholz, Norman. 1975. "The Cleveland Policy Planning Report." Journal of the American Planning Association, 41(3): 298-304.

Krumholz, Norman. 1982. "A Retrospective View of Equity Planning." Journal of the American Planning Association, 48(2): 163-174.

Krumholz, Norman and John Forrester. Making Equity Planning Work: Leadership in the Public Sector. Philadephia: Temple University Press. 
Labbe, Jim. 2008. Personal interview. September $26^{\text {th }}$.

Langford, M. and D.J. Unwin. 1994. "Generating and mapping population density surfaces within a geographic information system." The Cartographic Journal, 31(6): 21-26.

Larson, Magali Sarfatti. 1984. "The Production of Expertise and the Constitution of Expert Power." In Authority of Experts, edited by Thomas L. Haskell. Bloomington: University of Indiana Press.

Latour, Bruno. 1999. Pandora's hope: essays on the reality of science studies. Cambridge: Harvard University Press.

. 2005. Reassembling the Social: An Introduction to ActorNetwork-Theory. New York: Oxford University Press.

Law, John. 1992. "Notes on the Theory of the Actor Network: Ordering, Strategy, and Heterogeneity." Published for the Centre of Science Studies, Lancaster University, Lancaster LA1 4YN, at http://www.comp.lanc.ac.uk/sociology/papers/Law-Notes-on-ANT.pdf. 6): 91-105. 2002. "Objects and Spaces." Theory, Culture, and Society, 19(5-

Lejano, Raul P. 2008. "Technology and Institutions: A Critical Appraisal of GIS in the Planning Domain." Science, Technology, \& Human Values, 33(5): 653678.

Longley, Paul A., Micheal F. Goodchild, David J. Maguire, and David W. Rhind. 2001. Geographic Information Systems and Science. Chichester: Wiley.

Lopata, Helena Z. 1976. "Expertization of Everyone and the Revolt of the Client." The Sociology Quarterly, 17(3): 435-446.

MacEachren, Alan M. 1995. How Maps Work: Representation, Visualization, and Design. Guilford Press: New York.

MacEachren, Alan M. 2004. How Maps Work. New York: Guilford Press.

Maantay, Juliana. 2002. "Mapping Environmental Injustices: Pitfalls and Potential of Geographic Information Systems in Assessing Environmental Health and 
Equity." Environmental Health Perspectives, Vol. 110, Supplement 2, April: 161-171.

Marsh, Michael T and David A. Schilling. 1994. "Equity measurement in facility location analysis: A review and framework." European Journal of Operational Research, 74: 1-17.

Martin, David. 1989. "Mapping population data from zonal centroid locations." Transactions of the Institute of British Geographers, New Series. 14(1): 90-97.

Martin, D. and I. Bracken. 1991. "Techniques for modelling population-related raster databases." Environment and Planning A, 23(7): 1069-1075.

Mayhew, L. D. and G. Leonardi. 1982. "Equity, efficiency, and accessibility in urban and regional health-care systems." Environment and Planning A, 14: 14791507.

McAllister, D. M. 1976. "Equity and efficiency in public facility location." Geographical Analysis, 8: 47-63.

McTaggart. 1991. "Principles for Participatory Action Research." Adult Quarterly, 41(3): 168-187.

Mennis, Jeremy. 2003. "Generating Surface Models of Population Using Dasymetric Mapping.” The Professional Geographer, 55(1): 31-42.

Merrick, Meg. 2003. "Reflections on PPGIS: A View from the Trenches." URISA Journal, 15 (APA II):33-39. . 2007. "Equity Atlas Rollout Analysis." April.

Merrick, Meg and Jon Dorwart. 2002. "GIS as a Vehicle for Community-based Problem Solving: A Training Model.” A paper presented at URISA's 2 Annual PPGIS Conference, Rutgers University. http://www.pdx.edu/media/i/m/ims_PPGIS02.pdf

Morrill, Richard L. and J. Symons. 1977. "Efficiency and equity aspects of optimum location." Geographical Analysis, 9: 216-225.

Myers, Dowell. 1992. Analysis with Local Census Data: Portraits of Change. Boston: Academic Press Inc. 
Nowotny, Helga, Peter Scott and Michael Gibbons. 2001. Re-thinking Science: Knowledge and the Public in an Age of Uncertainty. Cambridge: Polity. . 2003. "'Mode 2' Revisited: The New Production of Knowledge." Minerva 41(3): 179-194.

Openshaw, S. and P. J. Taylor. 1981. "The modifiable areal unit problem." In Wrigley, N. and Bennett, J.J. (eds.) Quantitative geography: a British view. London: Routledge and Kegan Paul.

Orfield, Myron. 1997. "Metropolitics: Coalitions for Regional Reform." The Brookings Review. Winter, 1997:6-9.

. 1998. Portland Metropolitics. Coalition for a Livable Cities, http://clfuture.org/publications/Orfield/ . 2002. American Metropoltics: The New Suburban Reality. Washington, D.C.: Brookings Institution.

Patton, Michael Q. 1980. Qualitative Research \& Evaluation Methods. Beverly Hills: Sage.

Pickles, John. 1995. "Representations in an Electronic Age." Ground Truth: the Social Implications of Geographic Information Systems. New York: Guilford.

Pielke, Jr., Roger A. 2007. The Honest Broker: Making Sense of Science in Policy and Politics. Cambridge: Cambridge University Press.

President's Council on Sustainable Development. 1996. Sustainable America: A New Consensus for the Prosperity, Opportunity and a Healthy Environment for the Future. http://clinton2.nara.gov/PCSD/Publications/TF_Reports/amertop.html

Provo, John. 2004. Email to Ken Radin: Briefing Book article. December 9. Radin's papers.

Quinn, Robert E. and Kim Cameron. 1983. “Organizational Life Cycles and Shifting Critieria of Effectiveness: Some Preliminary Evidence.” Management Science. 29(1): 33-51.

Radin, Ken. 2003. “tasha_batch110903.” Ken Radin’s papers. 
. 2004a. "Cartographical_Comments0304.” Ken Radin's papers.

. 2004b. "Draft Scope of Work for Regional Equity Atlas

Mapping". April $20^{\text {th }}$. Radin's papers.

. 2004c. "Equity Atlas map-list, post diagnostic set, through

September 11, 2004.” Radin's papers.

. 2004d. Powerpoint presentation: "CLF Meeting 11/09/04."

Radin's papers.

. 2005. "A Primer on Reading the Surface Demographic Maps."

March $4^{\text {th }}$. Radin's papers.

. 2003-2007. Complete Equity Atlas Map Files. Ken Radin's

papers.

. 2008a. Personal interview. April 8.

. 2008b. Personal interview. April 9.

. No date. "Food_by_NBO_Notes_(Alex)." Radin's papers.

Radin, Ken and Tasha Harmon. 2004. “Map_Comments0304.” Ken Radin’s papers.

Reece, Jason and Eric Schultheis. 2009. "Poverty's Place: The Use of Geographic Information Systems in Poverty Advocacy." Journal of Poverty Law and Policy, January/February.

Rose, Nikolas. 1993. "Government, authority and expertise in advanced liberalism." Economy and Society, 22(3): 283-299.

Rubin, A. and E. Babbie. 2001. Research methods for social work ( $4^{\text {th }}$ edition). Belmont, CA: Wadsworth/Thomson Learning.

Schlossberg, M. and Shuford, E. 2005. 'Delineating 'Public' and 'Participation' in PPGIS." Journal of the Urban and Regional Information Systems Association, 16: $15-26$.

Seltzer, Ethan. 2008. Personal interview. July $14^{\text {th }}$.

Semke, Zack. 2010. Personal Interview. Feb. $9^{\text {th }}$. 
Sheppard, E. 1995. "GIS and society: towards a research agenda." Cartography and Geographic Information Systems, 22:5-16.

Seiber, Renee. 2004. "Rewiring for a GIS/2." Cartographica, 39: 25-39.

Sharkova, Irina. 2004a. "Exhibit 1. Scope of Work: Regional Equity Atlas Project." Ken Radin's papers.

. 2004b. Email correspondence between Radin, Fuglister, Harmon, and Sharkova. June 9. Radin's papers.

. 2004c. Email correspondence: Sharkova to Radin, Fuglister, and Harmon. July 30. "Irina_indexing073004." Radin's papers.

. 2004d. Email correspondence with Jill Fuglister:

“jill_parks_transit_schools091504.”September 15. Radin's papers.

. 2008. Personal interview. October 11.

Sharkova, Irina and Ken Radin. 2005. "Access Methods General.” A memorandum dated January $17^{\text {th }}$. Radin's papers.

Shiffer, Michael J. 2002. "Spatial Multimedia representations to support community participation." In Community Participation and Geographic Information Systems, William Craig, Trevor M. Harris, and Daniel Weiner, editors. London: Taylor and Francis.

Shoultz, Jan, Mary Frances Oneha, Lois Magnussen, Mya Moe Hla, Zavi BreesSaunders, Marissa Dela Cruz, and Margaret Douglas. 2006. "Finding solutions and challenges faced in community-based participatory research between academic and community organizations." Journal of Interprofessional Care. 20(2): 133-144.

Slocum, Terry A. 1999. Thematic Cartography and Visualization. Upper Saddle River: Prentice Hall.

Smock, Kris. 2006a. "Regional Equity Atlas Pilot Workshop: Key Feedback to Respond to in Revisions." November $14^{\text {th }}$. Kris Smock's papers. 2006b. "Regional Equity Atlas Project: Revisions to Pilot Workshop." November $20^{\text {th }}$. Kris Smock's papers. 
. 2007a. "Putting Equity on the Map! The Regional Equity Atlas: Metropolitan Portland's Geography of Opportunity" A Powerpoint presentation, April $23^{\text {rd }}$. Kris Smock's papers.

. 2007b. "Regional Equity Atlas Introductory Workshops

Facilitator's Manual.” File date, April 20, 2007. Kris Smock's papers.

. 2007c. "Regional Equity Atlas Solutions Workhshops

Facilitator's Manual.” File date, December 27, 2007. Kris Smock's papers.

. 2008. "Putting Equity on the Map! The Regional Equity Atlas:

Metropolitan Portland's Geography of Opportunity" A Powerpoint presentation, file name "SW Presentation Final," January 3rd. Kris Smock's papers.

2010. Personal interview. October $21^{\text {st }}$.

Sparke, Matthew. 1998. "A Map that Roared and an Original Atlas: Canada, Cartography, and the Narration of a Nation." Annals of the Association of American Geographers, 88(3):463-495.

Stich, Stephen P. and Richard E. Nesbitt. 1984. "Expertise, Justification, and the Psychology of Inductive Reasoning." In The Authority of Experts edited by Thomas L. Haskell. Bloomington: University of Indiana Press.

Strauss, A. and J. Corbin. 1990. Basics of qualitative research: Grounded theory procedures and techniques. Newbury Park: Sage.

Sullivan, Ryan. 2008. Email correspondance. November $21^{\text {st }}$.

Talen, E. 1998. "Visualizing Fairness: Equity Maps for Planners." Journal of the American Planning Association, 64(1): 22-38.

. 2000. "Bottom-Up GIS: A New Tool for Individual and Group

Expression in Participatory Planning." Journal of the American Planning Association, 66(3): 279-294.

Talen, E. and L. Anselin. 1998. "Assessing spatial equity: an evaluation of measures of accessibility to public playgrounds." Environment and Planning A, 30: 595613. 
Tsou, Ko-Wan, Yu-Ting Hung and Yao-Lin Chang. 2005. “An accessibility-based integrated measure of relative spatial equity in urban public facilities." Cities, 22(6): 424-435.

Tulloch, David. 2002. "Environmental NGOs and community access to technology as a force for change." In Community Participation and Geographic Information Systems, W.J. Craig, T.M. Harris, and D. Weiner, editors. London: Taylor and Francis.

. 2003. "What PPGIS really needs is..." $2^{\text {nd }}$ Annual Public

Participation GIS Conference, Portland State University, Portland, Oregon, 2022 July. http://deathstar.rutgers.edu/ppgis/Tulloch.PPGIS.2003.htm.

Tulloch, David and Tamara Shapiro. 2003. "The intersection of data access and public participation: Impacting GIS users' success." URISA Journal, 15:5560, http.://www.urisa.org/Journal/APANo2/Tulloch.pdf.

Turner, Stephen. 2001. "What is the Problem with Experts?" Social Studies of Science, 31(1): 123-149.

United Church of Christ. 1987. Toxic Wastes and Race in the United States: A National Report on the Racial and Economic Characteristics of Communities with Hazardous Waste Sites. New York: United Church of Christ.

Van House, Nancy. 1999. “Actor-Network Theory, Knowledge Work, and Digital Libraries." Adapted from a proposal by the UC Committee on Research under Research Bridging Grant Program, 1999-2001. http://people.ischool.berkeley.edu/ vanhouse/bridge.html

Voss, Paul R., David D. Long, and Roger B. Hammer. 1999. "When Census Geography Doesn't Work: Using Ancillary Information to Improve the Spatial Interpolation of Demographic Data." Center for Demography and Ecology Working Paper.

Walljasper, Jay. 1999 [date determined from Board minutes]. Working for a just and sustainable region: An uncommon alliance with a common vision. Portland: Coalition for a Livable Future.

Walsham, Geoff and Sundeep Sahay. 1999. "GIS for District-Level Administration in India: Problems and Opportunities." MIS Quarterly, 23(1): 39-65. 
Weiner, Daniel, Trevor M. Harris, and William J. Craig. 2002. "Community Participation and Geographic Information Systems." In Community Participation and Geographic Information Systems, William J. Craig, Trevor M. Harris, and Daniel Weiner, editors. London: Taylor and Francis.

Wiedemann, P.M. and S. Femers. 1993. "Public participation in waste management decision making: analysis and management of conflicts." Journal of Hazardous Materials, 33(3): 355-368.

Wood, Denis. 1992. The Power of Maps. New York: The Guilford Press.

Wood, Denis and John Fells. 1986. "Designs on Signs: Myth and meaning in maps." Cartographica, 23(3):54-103.

Wood, Denis, John Fells, and John Krygier. 2010. Rethinking the Power of Maps. New York: Guilford.

Worboys, Michael F. 1995. GIS: A Computing Perspective. Oxford: Taylor \& Francis.

Wright, John K. 1936. "A Method of Mapping Densities of Population with Cape Cod as an Example." Geographical Review. 36(1) 103-110. 


\section{Appendix A. Regional Equity Atlas Project Contributors and Tax Filings}

The contributors listed below are those listed in the Regional Equity Atlas document. The dollar amounts (approximate) were provided by Jill Fuglister and confirmed by Ron Carley. Where no dollar amounts are identified, the number could not be confirmed or the contribution was in-kind.

\section{$\underline{\text { Foundation Support }}$}

Bullitt Foundation

Meyer Memorial Trust $(\$ 50,000)$

Rose Tucker $(\$ 24,000)$

\section{"Lead Sponsors"}

Enterprise Community Partners $(\$ 8,000)$

Kaiser Permanente $(\$ 23,000+)$

Portland Development Commission

Washington County Commissioner Dick Schouten (from the Intel Strategic Investment Program Charitable Fund)

"Co-Sponsors and In-Kind Supporters"

Bi-state Regional Housing Managers

City of Beaverton

City of Lake Oswego

City of Portland Bureau of Housing and Community Development $(\$ 5,000)$

Clackamas County $(\$ 5,000)$

Clark County $(\$ 5,000)$

Fair Housing Council of Oregon (in-kind, data)

Fregonese Calthorpe Associates (in-kind, GIS expertise)

Metro (in-kind, GIS expertise and data)

Multnomah County $(\$ 5,000)$

PolicyLink (in-kind, expertise)

Portland Multnomah Food Policy Council (in-kind, data)

TriMet (in-kind, data)

Source: CLF, Regional Equity Atlas (2007) 


\section{Regional Equity Atlas CLF IRS 990 Filings}

The following is information from CLF's 990 tax filings relating to the organization's fiscal health over the duration of the Equity Atlas project and specific mentions of the Regional Equity Atlas Project during this period.

- 2003: The Regional Equity Atlas is not specifically reported in 2003. However, this was the year that CLF received significant grant funding that allowed the Equity Atlas project to move forward. CLF reported a total of $\$ 331,722$ in gifts, grants, contributions in 2003.

- 2004: The first year in which the Regional Equity Atlas project is reported in CLF's IRS 990 filings is 2004. No specific dollar amount or funding sources are reported. CLF reported a total of $\$ 149,314$ in gifts, grants, and contributions in 2004.

- 2005: Detail for CLF's activities are referred to in attachments to the 2005, 990 filing that are not available. CLF reported a total of $\$ 178,022$ in gifts, grants, and contributions in 2005.

- 2006: The Regional Equity Atlas effort is described. Reported expenditure: $\$ 35,100$. CLF reported a total of $\$ 139,988$ in gifts, grants, and contributions in 2006.

- 2007: The unveiling of the Regional Equity Atlas and the Equity Agenda activities are specifically outlined as a significant achievement. Expenditures reported are $\$ 17,202$. CLF reported a total of $\$ 230,068$ in gifts, grants, and contributions in 2007.

Source: http://nccsdataweb.urban.org/orgs/profile/931278845?popup=1\#formsCLF 
Appendix B. Chronology

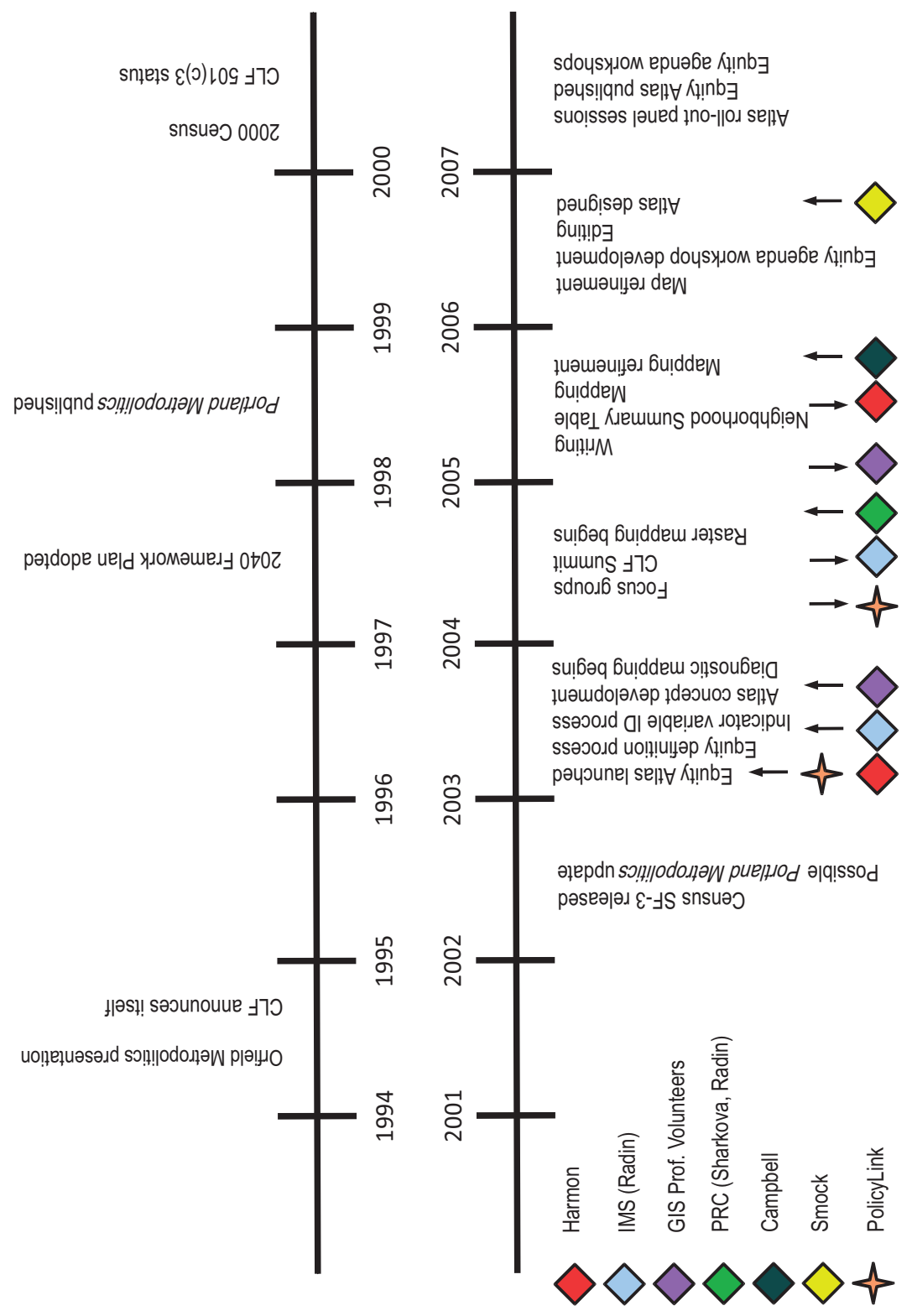


Appendix C. Regional Equity Atlas Distribution

\section{Numbers of Copies}

According to Ron Carley, 3,390 copies of the Regional Equity Atlas (out of the 5,000 that were printed) have been distributed since its publication in 2007. Approximately, 706 copies were purchased; the remaining 2,684 copies were distributed to those who had contributed financially, were in-kind contributors to the Atlas project, or attended the Equity Atlas Introductory Sessions and Equity Agenda Workshops.

\section{Revenue}

The average price of those atlases that were sold, according to Carley, is $\$ 20.00$. This is an average figure because CLF charged differing amounts (up to $\$ 30.00$ per atlas) depending on the number purchased and the type of purchaser (for-profit and nonprofit organizations, or individuals).

Total revenue, to June 2011, was \$14,118. 


\section{Appendix D}

\section{Some Regional EquityAtlas Impacts}

The following is excerpted from The Regional Equity Atlas Story Bank, a publication of the Coalition for a Livable Future, that describes some of the accomplishments of the Regional Equity Atlas project.

The Regional Equity Atlas Story Bank is a collection of stories and short testimonials from services providers, government agencies, planners, and advocates who wish to share the details of how they have used the Regional Equity Atlas research to change their communities.

\section{Washington County Consolidated Plan Opportunity Mapping: A New Approach to Housing Needs Analysis Washington County Office of Community Development}

The Regional Equity Atlas inspired the Washington County Office of Community Development (OCD) to takea whole new approach to looking at where federal community development and affordable housing funds should be invested as part of its Consolidated Plan Update. Required by the federal government, consolidated plans identify housing, homelessness, community, and economic development needs and resources and include a five-year plan to address identified needs.

The new approach taken by OCD focused on analyzing 1) which of these investments occur in places that provide the best opportunities for low income residents to connect with resources that enhance their life chances, such as places with good schools and with connections to transportation, jobs and necessary goods and services; and 2) whether such opportunities could be enhanced in areas where there is already a concentration of affordable housing by providing future public investments. This new focus on location and linkages is one way to ensure that the costs of global warming and peak oil do not fall most heavily on those who can afford it least.

Story courtesy of: Andree Tremoulet, Washington County

\section{Clark County Public Health Education: Educating Decisionmakers and the Public about Health Equity}

The Regional Equity Atlas helped Clark County Public Health to broaden their staff's understanding of how the county fits into the broader regional context in terms of access to resources that impact community health. They used the Atlas as an education tool to communicate the importance of environmental and social justice issues and how they impact community health. Story courtesy of: Dan Rubado and Tricia Mortell 


\section{A Pedestrian Safety Program for Schools City of Milwaukie}

Alex Campbell, City of Milwaukie Resource and Economic Development Specialist, used the Regional Equity Atlas to successfully establish a pedestrian safety program in Milwaukie. Mr. Campbell cited the Atlas's Percent Sidewalk Coverage Around Schools map as being helpful, "because it is a really good representation of sidewalk coverage" allowing him to effectively illustrate the need for the pedestrian safety program to the City Council members.

Story courtesy of: Alex Campbell, City of Milwaukie

\section{Metro Regional Transportation Options Program: Refocusing Resources toward Underserved Communities}

The Regional Equity Atlas led the Staff and Council at Metro to add an equity criterion to the Regional Transportation Options Program grant scoring process. The program works to increase the use of travel options and reduce pollution. As a result of using this new equity lens, the Community Cycling Center received funding for a project to increase awareness and acceptability of bicycling as a transportation option among minority and low-income participants in North and Northeast Portland by creating a culturally specific program to meet their needs.

Story courtesy of: Pam Peck, Metro

\section{Oregon Food Bank: Refocusing Services to Address Growing Needs in New Place}

The Regional Equity Atlas helped better inform Oregon Food Bank where gaps in its services existed across the region in relation to areas of high need. In particular, the map that showed changes in poverty by location over time was especially useful. As a result, Oregon Food Bank shifted its focus to the increasingly high needs areas outside of the inner core of Portland.

Story courtesy of: Eric Sopkin, Oregon Food Bank

\section{Improving Access to Parks in a Low-Income Neighborhood Nadaka Nature Park in Gresham, Oregon}

Trust for Public Land (TPL) works to conserve land for people, from neighborhood parks to wilderness and everything in between. TPL, along with Metro, the City of Gresham, and the East Multnomah Soil and Water Conservation District worked to acquire a two-acre parcel adjacent to the Nadaka Nature Park in Gresham. Their goal was to expand the park and make it more accessible by public transit and to the underserved residents nearby. 
In searching out an appropriate property, and grant monies to acquire it, the partners used the Regional Equity Atlas to understand where pocket parks of nature deficiency were located. In their application to Metro's Nature in Neighborhoods Capital Grant program, these organizations cited the Atlas repeatedly to build a compelling argument in favor of this land acquisition. Their focus was largely on the parks and natural areas chapter but they also relied on the overall demographic information and public transit sections of the atlas. Mr. Wozniak adds, "I am continuing to look for new land conservation projects in the region and will be guided in my efforts by the Regional Equity Atlas."

Story courtesy of: Owen Wozniak, Oregon Field Representative

\section{Food System Assessment Clark County, Washington}

In response to high percentage of overweight, obese, and diabetic Clark County residents, Community Choices convened partners to apply for a grant coordinated by the Centers for Disease Control and Prevention and the U.S. Department of Health and Human Services. Clark County was chosen as one of four Washington communities to receive the five year grant and in 2003 the Steps to a Healthier Clark County Initiative (Steps) began. The aim of the Steps initiative was to reduce rates of obesity, diabetes, and asthma by increasing access to physical activity, healthy foods, and smoke-free environments. In 2007-2008, a food assessment, "Exploring the Clark County Food System" was conducted to investigate the local food supply and nutrition environment trends in Clark County, inform the Clark County Food System Council (CCFSC) and guide future food system assessment areas. Project objectives were to:

1. Inform the CCFSC on Clark County trends in four indicator areas: Personal \& Community Health,

2. Food Access, Farm \& Agriculture Profile, and Resource Management Determine the availability of, and price between, healthier and less-healthy food options in selected Clark County grocery and convenience stores

3. Prepare a case study that identified factors influencing food access in two urban neighborhoods and another case study that explored Community Supported Agriculture (CSA) as a model for farm direct marketing (CSA Survey)

4. Arrange a series of food atlas maps unique to Clark County.

The Access to Healthy Foods team used the Equity Atlas because it was an excellent resource that used ranking and scoring metrics to show where the true gaps in food access were for Clark County residents. It was one of the best resources to support the 
anecdotal stories that CCFSC was hearing from the community on how they experienced access to healthy food in their community. The Atlas was also a great example of how visual mapping, combined with data, can increase community understanding about equity issues and can lead to stronger dialogues and commitment for change.

The Regional Equity Atlas was a useful community engagement and advocacy tool because it allowed Food System council members to better understand inequities in food availability and visualize access issues that existed in the community. It is also helped prioritize primary data collection by identifying neighborhoods most at need, allowing opportunities to dig deeper to uncover food preferences, perceived and real barriers, and potential solutions to improve food security for some of Clark County's at-risk communities.

Not only was the Equity Atlas an important resource for the Food System Council, but the Atlas was shared with others interested and involved in improving the health of the community. The Public Health Advisory Council (PHAC) was one group that engaged in review and discussion about the data. This information, coupled with the release of "Unnatural Causes" led the PHAC and Community Choices to prioritize health equity as their number one priority and to focus on improving health for all residents.

Story courtesy of: Amy Gilroy, Consultant, Clark County Food System Assessment and Tricia Mortell, Clark County Public Health

\section{City of Portland Community Watershed Stewardship Program: Refocusing Resources toward Underserved Communities}

The City of Portland's Community Watershed Stewardship Program (CWSP) is a partnership between Portland Environmental Services, Portland State University, and AmeriCorps. CWSP works to improve the health of Portland's watersheds, promote citizen connection to natural systems and build community capacity. This program offers funding for community projects, helps with project planning, and assists in connecting community groups with resources for their projects.

As the CWSP grant focus has broadened from streamside restoration to include more educational and stormwater management projects throughout Portland, equitable distribution of grants has become a more prominent program objective. In 2009, CWSP staff used the Equity Atlas in conjunction with data produced by PSU graduate students to identify neighborhoods and communities that had not been directly served by previous CWSP grants.

Once identified, these neighborhoods were targeted for additional outreach and support during the grant writing periods in 2009 and 2010. 
CWSP utilized many chapters of the Regional Equity Atlas to achieve their goals of identifying underserved communities in Portland. The Demographics chapter was the most heavily used section of the Equity Atlas, but CWSP also consulted the Housing, Schools, and Parks chapters as well to identify these communities. The CWSP referenced the Regional Equity Atlas because, "CLF is a trusted organization, so rather than reinvent the wheel by mapping resource accessibility and high needs communities on our own, we referenced the Equity Atlas." CWSP believes the Equity Atlas is a fantastic resource for the Portland community and key to addressing equity needs throughout the city.

Story courtesy of: Kate Carone, City of Portland

\section{East Multnomah Soil and Water Conservation District: Siting a New Facility}

Using the Regional Equity Atlas, the East Multnomah Soil and Water Conservation District decided where to locate its new office and environmental education facility so that it could be more easily reached by underserved communities.

The District also secured a grant for installing several educational components at the new site that could be accessed by the surrounding community. This included pervious paving of the parking lot, re-used concrete benches and reinforced slopes, a cistern, several rain gardens, and a nature-scaped landscape.

\section{What They're Saying... Local Leaders agree that the Regional Equity Atlas has had a great impact on communities.}

The Equity Atlas was invaluable to us because it documented the fact that poverty in our community had moved from one neighborhood to a distinctly different area of town. The area into which a very large number of low-income people had moved was not receiving its "fair share" of funding for services. The Equity Atlas was instrumental in changing that.

Jean DeMaster, Executive Director, Human Solutions

The equity atlas is a unique resource, and supports our efforts to give low-income people a voice in the environmental changes affecting their neighborhoods.

Alan Hipolito, Director, Verde

I am particularly interested in working with our community partners to reshape the way we think about urban planning and transportation planning to address issues of equity. The conversation has already benefitted from the engaged leadership of community partners representing the Coalition for a Livable Future, Metro, the PDC, and others. Ideally, we will agree on quantitative measures of equity and publish our 
progress toward reducing them. (As a starting point, we should build upon the Coalition's outstanding Equity Atlas). When it comes to allocating funds, projects that benefit underserved areas and address disparities in our community should be prioritized.

Blue Oregon, guest column by Ted Wheeler, Multnomah County Chair, June 19, 2009

Without this information it would be impossible for people to understand the inequality within the region. This [Atlas] is fundamental to making positive change if it is even thinkable of doing so.

Elders in Action, CLF member

The CLF Equity Atlas gives decision-makers and community organizations the data they need to deliver effective anti-poverty and neighborhood revitalization programs.

ROSE Community Development, staff member

The Portland metropolitan area has had substantial shifts in income, government investments, migration of families and businesses and loss of jobs. The Equity Atlas Project has allowed us to study how the change has impacted the areas livability, learning, health and safety. This resource provides a blueprint to help us learn how we can make certain all citizens have the necessary tools needed to live prosperous lives.

United Way of the Columbia Willamette, staff member 